Tiago Naviskas Lippi

\title{
Restrições de Manufatura aplicadas ao Método de Otimização Topológica
}

\author{
Dissertação apresentada à Escola \\ Politécnica da Universidade de São \\ Paulo para obtenção do Título de \\ Mestre em Engenharia Mecânica.
}


Tiago Naviskas Lippi

\title{
Restrições de Manufatura aplicadas ao Método de Otimização Topológica
}

\author{
Dissertação apresentada à Escola \\ Politécnica da Universidade de São \\ Paulo para obtenção do Título de \\ Mestre em Engenharia Mecânica. \\ Área de concentração: \\ Engenharia de Controle e Automação \\ Mecânica \\ Orientador: \\ Prof. Dr. Emílio Carlos Nelli \\ Silva
}


Este exemplar foi revisado e alterado em relação à versão original, sob responsabilidade única do autor e com a anuência de seu orientador.

São Paulo, 7 de abril de 2008.

Assinatura do autor

Assinatura do orientador

\section{Ficha Catalográfica}

Lippi, Tiago Naviskas

Restrições de Manufatura aplicadas ao Método de Otimização Topológica/ T.N. Lippi - ed. rev. - São Paulo, 2008. 117 p.

Dissertação (Mestrado) — Escola Politécnica da Universidade de São Paulo. Departamento de Engenharia Mecatrônica e de Sistemas Mecânicos.

1. Otimização Topológica. 2. Manufatura. 3. Restrições de Manufatura. 4. $\quad$ Otimização Matemática. 5. Otimização Estrutural I. Universidade de São Paulo. Escola Politécnica. Departamento de Engenharia Mecatrônica e de Sistemas Mecânicos. II. t. 
Dedico este trabalho à meus pais Anibal e Rita, e à meus avós Pedro e Maria. 


\section{Agradecimentos}

Ao meu Orientador Emílio C. N. Silva pela orientação, apoio e motivação para a realização deste trabalho.

A EPUSP por fornecer os recursos necessários para a realização deste trabalho.

A toda minha família pelo apoio incondicional em todos os momentos de minha vida.

A Juliana pelo apoio, e pela paciência nos intermináveis finais de semana dedicados a este trabalho.

Aos amigos da poli Vitor, João Lucas, André, Renato, Luis e Ricardo, pelas discussões acadêmicas, amizade, companheirismo e ótimos momentos de descontração que foram essenciais para obter motivação ao longo do trabalho.

Aos amigos de Santana, Fernanda, Alexandre, Thiago, Bruno Zoca, Bruno Basso, Sidenei, Kamylla, José Rogério e Denis que apesar da falta de tempo sempre estiveram presentes quando necessário.

E por fim a todos aqueles que contribuíram de forma direta ou indireta com a realização deste trabalho. 


\section{Resumo}

O projeto de um componente mecânico, é uma atividade muito complexa, onde muitas vezes se tem restrições de projeto como peso do componente e rigidez máxima, e também restrições de manufatura, associada aos processos de fabricação disponíveis para serem utilizados.

É fato conhecido que a Otimização Topológica (OT), apesar de ser um método extremamente eficiente para a obtenção de soluções ótimas, gera soluções com geometrias complexas que são ou muito caras de se fabricar ou infactíveis.

A técnica de projeção foi escolhida como adequada para implementar as restrições propostas neste trabalho. Esta técnica resolve o problema posto num domínio de variáveis de projeto e projeta essa solução num domínio de pseudodensidades, que são a resposta do problema. A relação entre os dois domínios é determinada pela função de projeção e pelo mapeamento das variáveis definidos de forma diferente para cada restrição.

Neste trabalho foram implementadas restrições de manufatura para OT de modo a restringir a gama possível de soluções no problema de otimização. Como exemplo foi considerado o problema de maximização de rigidez, com restrição de volume. Todas as implementações foram realizadas em linguagem de programação C, e o algoritmo de otimização utilizado é o critério de optimalidade.

Foram implementadas as seguintes restrições de manufatura com a técnica de projeção: membro mínimo, buraco mínimo, simetria, extrusão, revolução, repetição de padrões, fundição, forjamento, e laminação. Estas restrições mostram a grande capacidade da técnica de projeção para controlar a solução do problema de otimização sem implicar num grande aumento do custo computacional.

Os resultados encontrados mostram a potencialidade de utilizar restrições de manufatura na OT, porém estão longe de esgotarem o assunto, nesse tema recente que vem sendo explorado no Método de Otimização Topológica (MOT). 


\section{Abstract}

The design of a mechanical component is a very complex task, which includes constraints such as maximum weight and maximum stiffness, and also manufacturing constraints, associated with the manufacturing processes required at the shop floor.

It is known that Topology Optimization (TO), despite of being a very effective and powerful method to obtain optimal solutions, generates solutions with complex geometries that are too much expensive to be manufactured or just can not be made.

The projection scheme has been chosen as the most appropriate technique for implementing the proposed constraints. This scheme solves the proposed problem in a domain of design variables and then projects these results into a pseudo-density domain to find the solution. The relation between both domains is defined by the projection function and variable mapping defined in a different way for each constraint.

In this work, manufacturing constraints for TO are implemented in a way that the possible solutions of the optimization problem are restricted. As an example, the traditional stiffness maximization problem is considered. All implementations have been done using $\mathrm{C}$ programming language, and the optimization algorithm applied is the optimality criteria.

The following manufacturing constraints have been implemented using the projection scheme: minimal member size, minimal hole size, symmetry, extrusion, revolution, pattern repetition, casting, forging and lamination. These constraints show the large capacity of the projection scheme to control the solution for the optimization without adding a large computational cost.

The results that have been found show the great power of using manufacturing constraints in the TO, however, they are far from exhausting this topic that has been recently explored in the Topology Optimization Method (TOM). 


\section{Sumário}

\section{Lista de Figuras}

\section{Lista de Abreviaturas}

\section{Lista de Símbolos}

1 Introdução 1

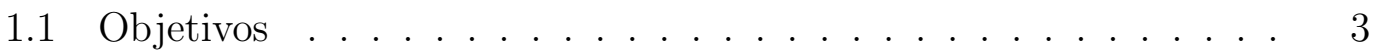

1.2 Motivação e Justificativa . . . . . . . . . . . . . . . . . . . . . . . 3

2 O Método de Otimização Topológica (MOT) 5

2.1 Introdução . . . . . . . . . . . . . . . . . . . . . 5

2.2 Formulação geral do problema de OT . . . . . . . . . . . . . . . . 12

2.3 Modelos de material . . . . . . . . . . . . . . . . 16

2.3.1 Materiais Baseados em Micro-estrutura . . . . . . . . . 16

2.3.2 Modelo de Material Artificial . . . . . . . . . . . . . 17

2.4 Problemas Numéricos do MOT . . . . . . . . . . . . . . . 19

2.4.1 Escala de Cinza . . . . . . . . . . . . . . . . 20

2.4 .2 Dependência da Malha . . . . . . . . . . . . . . . 23

2.4.3 Instabilidade de Tabuleiro . . . . . . . . . . . . . . 25

2.5 Métodos de Otimização Aplicados na Solução do Problema de Otimização Topológica . . . . . . . . . . . . . . . . . . . . . . 27

2.5.1 Critério de Optimalidade . . . . . . . . . . . . . 27

3 Método dos Elementos Finitos 28 
3.1 Formulação do Elemento Isoparamétrico 2D em Estado Plano de Tensão (EPT) de Quatro Nós . . . . . . . . . . . . . . . . . . . 28

3.2 Formulação do Elemento Isoparamétrico 3D de Oito Nós . . . . . 33

4 Filtros, Controles de Gradiente e Técnica de Projeção de Domínios

4.1 Filtros . . . . . . . . . . . . . . . . . 40

4.1.1 Filtragem de Vizinhança Fixa . . . . . . . . . . . . . . . 41

4.1 .2 Filtros Espaciais . . . . . . . . . . . . . . 43

4.2 Controle de gradiente . . . . . . . . . . . . . . . . 45

4.3 Projeção de Domínios . . . . . . . . . . . . . . . . . . . . . . 47

4.3.1 Mapeamento dos domínios . . . . . . . . . . . . . . 48

4.3.2 Cálculo da Sensibilidade . . . . . . . . . . . . . 50

4.3.3 Projetando as variáveis . . . . . . . . . . . . . . . . 50

5 Restrições de Manufatura $\quad 52$

5.1 Fundição . . . . . . . . . . . . . . . . . . . . . . . . 53

5.2 Fresamento . . . . . . . . . . . . . . . . 55

5.3 Torneamento . . . . . . . . . . . . . . 56

5.4 Extrusão . . . . . . . . . . . . . . . . . . 56

5.5 Laminação . . . . . . . . . . . . . . . . . . . . . . 57

5.6 Forjamento . . . . . . . . . . . . . . . . . . 58

6 Implementação Numérica $\quad 60$

6.1 Membro Mínimo . . . . . . . . . . . . . . . . . . 61

6.2 Buraco Mínimo . . . . . . . . . . . . . . . . . . . . 64

6.3 Simetria . . . . . . . . . . . . . . . . 67

6.4 Extrusão . . . . . . . . . . . . . . . . . . . . 68

6.5 Revolução . . . . . . . . . . . . . . . . . . . . . . . 70

6.6 Repetição de Padrões . . . . . . . . . . . . . . . . . . . . . . . 73 
6.7 Fundição . . . . . . . . . . . . . . . . . . . 76

6.8 Forjamento . . . . . . . . . . . . . . . . . . . . . . . . 79

6.9 Laminação . . . . . . . . . . . . . . . . . . . . . . . . . . . . . 81

$\begin{array}{llr}7 & \text { Resultados } & 83\end{array}$

7.1 Restrição de Membro Mínimo . . . . . . . . . . . . . . . . . . 83

7.2 Restrição de Buraco mínimo . . . . . . . . . . . . . . . . . 86

7.3 Restrição de Simetria . . . . . . . . . . . . . . . . . . . . . . 87

7.4 Restrição de Extrusão . . . . . . . . . . . . . . . . . . . . . . . . 92

7.5 Restrição de Revolução . . . . . . . . . . . . . . . . . . . . . . 96

7.6 Restrição de Repetição de Padrões . . . . . . . . . . . . . . . . 99

7.7 Restrição de Fundição . . . . . . . . . . . . . . . . . . . . 103

7.8 Restrição de Forjamento . . . . . . . . . . . . . . . . . . . . 106

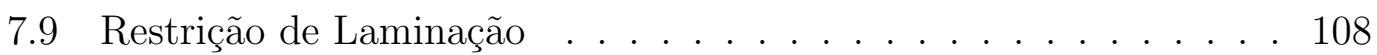

8 Conclusões e Sugestões para Desenvolvimentos Futuros 111

$\begin{array}{lr}\text { Referências } & 113\end{array}$ 


\section{Lista de Figuras}

1.1 Exemplo de problema resolvido com a utilização do MOT. . . . . 1

1.2 Exemplo de solução do MOT com alto grau de complexidade. . . 2

2.1 Otimização paramétrica. . . . . . . . . . . . . . . 6

2.2 Otimização de forma. . . . . . . . . . . . . . . . . 6

2.3 Otimização topológica . . . . . . . . . . . . . . . . . . . 7

2.4 Otimização topológica de uma estrutura discreta. . . . . . . . . . 7

2.5 Estrutura ótima obtida por Michell. . . . . . . . . . . . . . . 8

2.6 Resultado da otimização topológica do mesmo problema solucionado por Michell . . . . . . . . . . . . . . . . . . . . . . . 8

2.7 Domínio Fixo Estendido (DFE) e notação adotada. . . . . . . . . 13

2.8 Representação do modelo de material baseado na micro-estrutura. 17

2.9 Curva limite superior de Hashin-Shtrikman e curvas do modelo SIMP. . . . . . . . . . . . . . . . . 18

2.10 Procedimento típico de OT. . . . . . . . . . . . . . . . . 20

2.11 Representação esquemática da influência da penalização $q$ na função de flexibilidade do problema de OT . . . . . . . . . . . . . 21

2.12 Exemplos resolvidos com volume de solução de 30\%. (a) Solução com a penalização $q=1$. (b) Solução com a penalização $q=2$. (c) Solução com a penalização $q=3$. (d) Solução com continuação da penalização.

2.13 O limite do volume dos problemas apresentados é de 30\%. (a) Malha com 4.000 elementos. (b) Malha com 16.000 elementos. . .

2.14 Exemplo de não-unicidade da solução. Barra sob tração uniaxial para material com coeficiente de Poisson igual a zero e extremidades (regiões hachuradas) rígidas. 
2.15 Problema apresentando os problemas de dependência de malha e instabilidade de tabuleiro. (a) Solução com filtro na malha com 4.000 elementos. (b) Solução sem filtro na malha com 4.000 elementos. (c) Solução com filtro na malha com 16.000 elementos. (d) Solução sem filtro na malha com 16.000 elementos. . . . . . . 25

3.1 Estrutura em EPT e seu respectivo sistema de coordenadas. . . . 29

3.2 Transformação de variáveis locais para as paramétricas. . . . . . . 29

4.1 Super elemento composto por 4 elementos simples, e o efeito do filtro sobre suas pseudo-densidades. . . . . . . . . . . . . . . . . 42

4.2 Elemento em que o filtro está atuando no filtro de vizinhança fixa $3 \times 3$.

4.3 Abrangência do filtro espacial em uma malha irregular. Somente os elementos com o centróide dentro do raio de abrangência do filtro são considerados. . . . . . . . . . . . . . . . . . . . . . . 44

4.4 Representação do espaço de soluções original e restringido. . . . . 48

4.5 Exemplo de relação entre o domínio de $d$ e de $\rho$. (a) Domínio das variáveis de projeto $(d)$. (b) Domínio das pseudo-densidades $(\rho)$. .

4.6 Exemplo de função de projeção entre o domínio de $d$ e de $\rho$. (a) Domínio das variáveis de projeto $(d)$. (b) Domínio das pseudodensidades $(\rho) \ldots \ldots \ldots \ldots$

5.1 Solução ótima conhecida para problemas de torção. . . . . . . . . 52

5.2 Peça com condições que permitem a fundição. . . . . . . . . . . . 54

5.3 (a) Furo aceitável na fundição. (b) e (c) Furos aceitáveis na fundição apenas com cera perdida. . . . . . . . . . . . . . . 54

5.4 Peça com rasgos feitos com um processo de fresamento. . . . . . . 55

5.5 (a) Peça que pode ser fabricada através do torneamento. (b) Peça que não pode ser fabricada por torneamento. . . . . . . . . . . 56

5.6 Peça extrudada e curvada. . . . . . . . . . . . . . . . 57

5.7 (a) Processo simplificado de laminação. (b) Exemplo de geometria obtida com o processo de laminação. . . . . . . . . . . . . . 57 
5.8 (a) Processo simplificado de forjamento. (b) Exemplo de geometria obtida através do processo de forjamento. . . . . . . . . . 58

6.1 Fluxograma da técnica de projeção dentro de uma rotina de MOT. 60

6.2 Esquema de projeção para restrição de membro mínimo. . . . . . 63

6.3 Esquema de projeção para restrição de membro mínimo. . . . . . 63

6.4 (a) Solução representada pelas variáveis de projeto $d$. (b) Solução

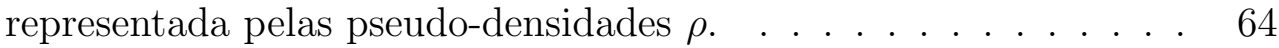

6.5 Representação das possibilidades de membro mínimo em apenas um plano. . . . . . . . . . . . . . . . . 65

6.6 Mapeamento da restrição de buraco mínimo. (a) Domínio das variáveis de projeto. (b) Domínio das pseudo-densidades. . . . . . 65

6.7 Exemplo de solução encontrada para a restrição de buraco mínimo. 66

6.8 Esquema de projeção para restrição de simetria. . . . . . . . . . . 67

6.9 Esquema de projeção para restrição de extrusão. . . . . . . . . . . . 69

6.10 (a) Domínio com formato curvo. (b) Domínio com trechos com fator de escala e com inclinações diferentes. . . . . . . . . . . . . . 70

6.11 (a) Exemplo de perfil utilizado para se realizar uma revolução.(b) Peça obtida através da revolução do perfil. . . . . . . . . . . . . . 71

6.12 Esquema de projeção para restrição de revolução. . . . . . . . . . 72

6.13 Efeito de simetria na direção perpendicular a revolução. . . . . . . 72

6.14 Esquema de projeção para restrição de repetição de padrões num único domínio conexo. . . . . . . . . . . . . . . . . . . . . . . . 74

6.15 Esquema de projeção para restrição de repetição de padrões em domínios não-conexos.

6.16 Esquema de projeção para restrição de fundição com apenas um molde. . . . . . . . . . . . . . . . . 76

6.17 Esquema de projeção para restrição de fundição com dois moldes.

6.18 Esquema de projeção para restrição de fundição com dois moldes e uma linha de encontro pré determinada. 
6.19 Exemplo de camada a ser utilizada para criar os domínios da restrição de forjamento. . . . . . . . . . . . . . . . . . . . . 79

6.20 Esquema de projeção para restrição de forjamento. . . . . . . . . 80

6.21 Intersecção entre os domínios de projeto $d$ da restrição de forjamento. 80

6.22 Restrições agindo em conjunto para garantir a restrição de laminação. 82

7.1 Resultados obtidos com volume restrito a 50\% do domínio. (a) Variáveis de projeto $d$. (b) Pseudo-densidades $\rho \ldots \ldots$. . . . . 84

7.2 (a) Solução para o problema apresentado na figura 7.1 resolvido com raios diferentes de membro mínimo. (a) $R_{\min }=0,3$. (b) $R_{\text {min }}=0,6 \ldots \ldots \ldots \ldots \ldots \ldots$

7.3 Resultados obtidos com volume restrito a 50\% do domínio. (a) Variáveis de projeto $d$. (b) Pseudo-densidades $\rho \ldots \ldots$. . . . 85

7.4 Resultados para o problema posto com: (a) sem restrições; (b) com membro mínimo esférico; (c), (d) e (e) membro mínimo aplicado como discos normais ao vetor indicado. . . . . . . . . . . . . . 86

7.5 Resultados obtidos com volume restrito a 50\% do domínio. (a) Variáveis de projeto $d$. (b) Pseudo-densidades $\rho \ldots \ldots$. . . . . . 87

7.6 Resultados obtidos com a restrição de buraco mínimo, com os seguintes raios mínimos de furo. (a) $R_{\min }=0,6$. (b) $R_{\min }=1,6$. (c) $R_{\text {min }}=2,6 \ldots \ldots \ldots \ldots \ldots$

7.7 Solução encontrada com a restrição de simetria. (a) Campo de variáveis $d$. (b) Projeção da restrição de membro mínimo. (c) Projeção da simetria horizontal. (d) Projeção da simetria vertical.

7.8 (a) Resultados sem restrição de simetria para uma viga em balanço. (b) e (c) Solução com restrição de simetria aplicada apenas a um plano. (d) Restrição de simetria aplicada aos dois planos simultaneamente. . . . . . . . . . . . . . . . .

7.9 Resultados aplicados ao caso de carga da viga MBB, considerando sua simetria de carregamento com as condições de contorno indicadas na figura (a). (a) Resultados sem restrição de simetria. (b) e (c) Solução com restrição de simetria aplicada apenas a um plano. (d) Restrição de simetria aplicada aos dois planos simultaneamente. 90 7.10 Exemplo da existência de regiões cinza devido as restrições aplicadas. 91 
7.11 Soluções encontradas com simetria parcial. (a) Com membro mínimo com $R_{\text {Min }}=1$. (b) Com membro mínimo com $R_{\text {Min }}=2$. $\quad 91$

7.12 Solução com restrições de simetria aplicadas nos planos indicados demonstrando a ocorrência da simetria natural do problema. . . . 92

7.13 (a) Solução para o problema de uma viga com carga, com restrição de extrusão, sua resposta é similar a de um caso bidimensional. (a) Solução para um problema de torção com restrição de extrusão. 93

7.14 Soluções para o problema de barra engastada com carga de flexão resolvido com a restrição de extrusão, com as seguintes razões de aspecto. (a) $1 \times 2$. (b) $1 \times 1$. (c) $2 \times 1$. (d) Extremidade engastada com razão 2 x1 e extremidade com carga com razão 1x2 . . . . . . 94

7.15 (a) Solução sem a restrição de extrusão. (b) variáveis de projeto $d$ da restrição de extrusão. (c) Solução após a projeção do membro mínimo. (d) Solução após a projeção da extrusão. . . . . . . . . . 95

7.16 Resultado sem a restrição de extrusão. (b) Resultado com a restrição de extrusão. . . . . . . . . . . . . . . . . . . . . . 96

7.17 Rotação do domínio de variáveis de projeto de forma a gerar a solução para as pseudo-densidades. . . . . . . . . . . . . . . . 97

7.18 Resultado com a restrição de revolução. (a) variáveis de projeto. (b) Projeção da restrição de revolução. (c) Projeção do membro mínimo. (d) Solução ignorando elementos de pseudo-densidades intermediárias.

7.19 Resultado para a restrição de revolução (a) vista frontal (b) vista traseira. (c) Resultado com restrição de revolução e extrusão. ..

7.20 (a) Viga em balanço com domínio cilíndrico sem restrição de revolução. (a) Viga em balanço com domínio cilíndrico com restrição de revolução.

7.21 (a) Resultado com repetição de padrões. (b) Resultado sem repetição de padrões. . . . . . . . . . . . . . . . . . . . . 100

7.22 (a) Resultado sem repetição de padrões. (b) Resultado com repetição de padrões. . . . . . . . . . . . . . . . . . . . . . . 101

7.23 Viga em balanço. (a) $2 \times 2$ padrões. (b) 4x2 padrões. . . . . . . . . 101 
7.24 Viga em balanço. (a) 20x10 padrões. (b) Região ampliada para mostrar os detalhe do padrão. . . . . . . . . . . . . . . . . . . 102

7.25 (a) Sem repetição de padrão. (b) Repetição com 2 padrões. (c) Repetição com 3 padrões. (d) Repetição com 4 padrões. . . . . . . 103

7.26 (a) variáveis de projeto. (b) projeção do membro mínimo (c) projeção da repetição de padrões . . . . . . . . . . . . . . . . . 104

7.27 Restrição de extrusão em conjunto com a repetição de padrões. (a) Variáveis de projeto. (b) projeção da restrição de membro mínimo. (c) Projeção da restrição de extrusão. (d) Projeção da restrição de repetição de padrões. . . . . . . . . . . . . . . . . . . . . . 105

7.28 Solução do problema da roda com repetição de padrões com 5 repetições. (a) Com membro mínimo. (b) Com buraco mínimo. . 106

7.29 Solução para um problema com a restrição de fundição com o molde em apenas uma direção. . . . . . . . . . . . . . . . . . 106

7.30 Exemplo de fundição feita com dois moldes, sem um plano definido de encontro entre os dois moldes. . . . . . . . . . . . . 107

7.31 Exemplo da restrição de fundição aplicada a uma peça sob torção.

(a) Vista em perspectiva. (b) Vista lateral. . . . . . . . . . . . . . 107

7.32 Resultado para a restrição de forjamento em um exemplo em três dimensões de uma viga engastada com carga de torção. . . . . . . 108

7.33 Resultado para a restrição de forjamento em um exemplo em três dimensões de uma viga em balanço. . . . . . . . . . . . . . . . . . 109

7.34 Muitas restrições forçam o surgimento de áreas cinza quando não existe massa o suficiente para a solução. (a) Restrição de volume a $50 \%$ com região cinza. (b) Restrição de volume a $70 \%$ sem cinza. (c) Restrição de volume a 70\% sem cinza. . . . . . . . . . . . . . . 110

7.35 Resultado para a restrição de laminação em um exemplo em três dimensões. . . . . . . . . . . . . . . . . . . . . . 110 


\section{Lista de Abreviaturas}

CAD "Computer-Aided Design"

CO Critério de Optimalidade

DFE Domínio Fixo Estendido

EPD Estado Plano de Deformação

EPT Estado Plano de Tensão

MEF Método de Elementos Finitos

MLA Método do Lagrangeano Aumentado

MMA "Method of Moving Asymptotes"

MOT Método de Otimização Topológica

OT Otimização Topológica

PLS Programação Linear Seqüencial

SIMP "Simple Isotropic Material with Penalization"

TO Topology Optimization

TOM Topology Optimization Method 


\section{Lista de Símbolos}

\begin{tabular}{|c|c|}
\hline$\Omega$ & DFE \\
\hline$\partial \Omega$ & Contorno do domínio $\Omega$ \\
\hline $\bar{d}$ & Vetor de deslocamentos nodais \\
\hline$f$ & Vetor de carregamento nodal \\
\hline $\boldsymbol{K}$ & Matriz de rigidez global \\
\hline$C^{H}$ & Tensor constitutivo efetivo de uma material \\
\hline$C_{0}$ & Tensor constitutivo do material base \\
\hline$\rho$ & Pseudo-densidade do material \\
\hline$d_{i}$ & Variáveis de projeto da técnica de projeção \\
\hline$\Omega_{i}$ & Domínios mapeados da técnica de projeção \\
\hline$i, j$ & Índices utilizados nas formulas de somatória \\
\hline$E$ & Módulo de Young \\
\hline$\nu$ & Coeficiente de Poisson \\
\hline$f(\rho, d)$ & Função objetivo \\
\hline$\epsilon$ & Campo de deformações \\
\hline
\end{tabular}




\section{Introdução}

O Método de Otimização Topológica (MOT) é um método computacional capaz de sintetizar estruturas mecânicas através da distribuição de material em uma região determinada do espaço com condições de contorno definidas, como está exemplificado na figura 1.1.

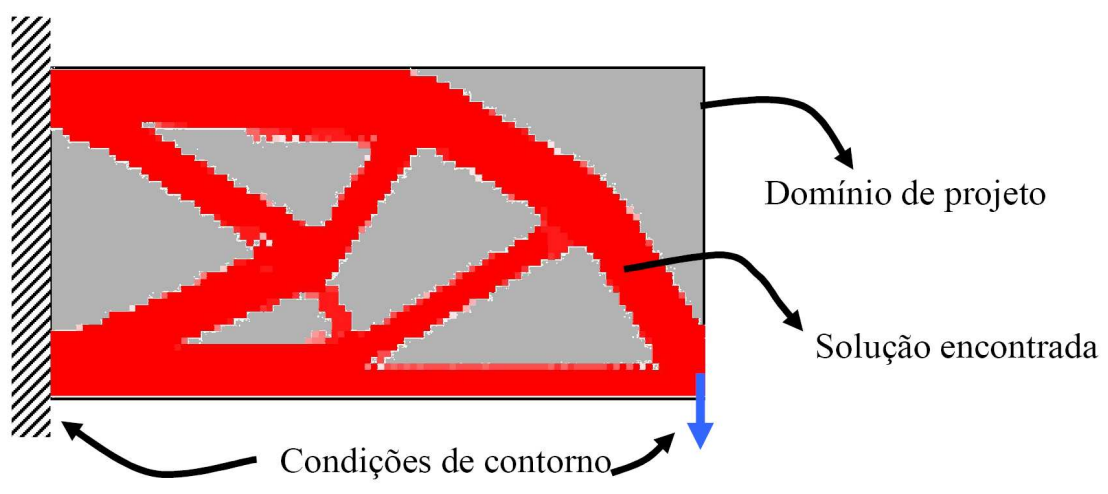

Figura 1.1: Exemplo de problema resolvido com a utilização do MOT.

Apesar de se apresentar extremamente poderoso para obter soluções ótimas do ponto de vista de projeto, muitos dos resultados obtidos através da OT, precisam ser interpretados devido a soluções demasiadamente complexas e muitas vezes infactíveis, com seções muito complexas, como pode ser observado na figura 1.2.

Por esse motivo o procedimento de execução do MOT envolve diversas etapas até que seja obtida uma solução que atenda tanto a restrições de projeto, quanto restrições de fabricação.

Nesse trabalho serão propostas formas de se restringir as soluções possíveis através de restrições de manufatura, de maneira a buscar uma solução mais prática do ponto de vista de Engenharia para os problemas resolvidos através do MOT.

As restrições de manufatura são uma solução prática para o problema de complexidade de leiaute obtido através do MOT, proporcionando soluções com características pré-estabelecidas e conseqüentemente mais próximo do leiaute desejado. 


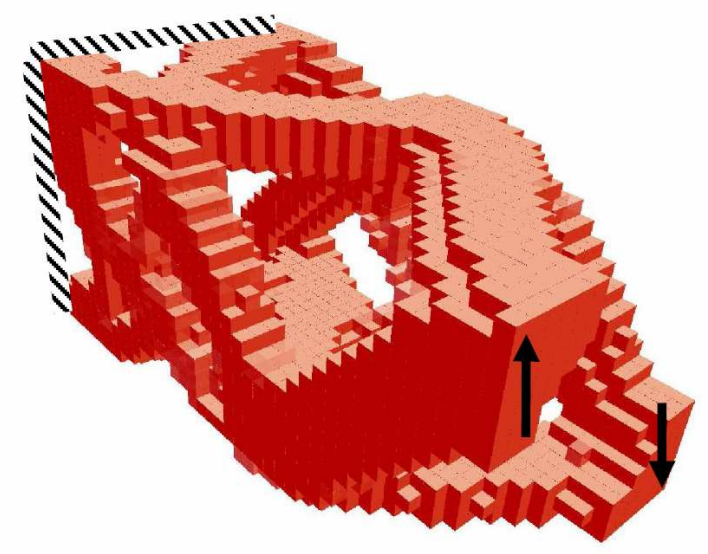

Figura 1.2: Exemplo de solução do MOT com alto grau de complexidade.

A aplicação das restrições de manufatura a leiautes obtidos através do MOT ainda é recente, e existem poucos trabalhos desenvolvidos na área. A maior fonte de trabalhos nesse caso vem de aplicações comerciais como o software "OptiStruct", que vislumbram nelas uma maior aplicabilidade do MOT nas indústrias.

Na literatura existem técnicas para se garantir restrições nas soluções de OT, como filtros, controles de gradiente, técnica de projeção e a inclusão de restrições extras no problema. Porém técnicas como o controle de gradiente e a inclusão de restrições extras no problema de otimização são muito custosas computacionalmente, ou com escopo de utilização restrito como os filtros baseados em filtros de imagens (CARDOSO, 2000).

Neste trabalho, será utilizada a técnica de projeção de domínios (LE, 2006). Esta técnica foi desenvolvida com o intuito de resolver problemas numéricos associados ao MOT, como a instabilidade de tabuleiro e a escala de cinza (BENDSøE, 1995), no entanto pode ser utilizada para resolver problemas com restrições de manufatura, de forma a diminuir a complexidade geométrica das soluções, como será mostrado neste trabalho.

Como podemos ver pelos trabalho já realizados por Guest, Prevost e Belytschko (2004), Zuo et al. (2006), Harzheim e Graf (2006, 2005), Zhou, Shyy e Thomas (2001) e Ishii e Aomra (2004), este novo desafio de se garantir soluções que sejam controladas de forma a simplificar sua fabricação vem ganhando cada vez mais espaço no meio acadêmico. 


\subsection{Objetivos}

O objetivo deste trabalho é estudar e implementar restrições no problema de otimização de forma a simplificar a geometria das estruturas obtidas através da técnica de OT de maneira a aumentar sua viabilidade de fabricação, reduzindo e controlando sua complexidade. Assim, são obtidas soluções que podem ser fabricadas com a utilização técnicas de manufatura disponíveis atualmente, sem que grandes alterações tenham que ser feitas na etapa de pós-processamento dos resultados.

Essas simplificações serão obtidas levando em conta aspectos geométricos da estrutura, como a simetria, repetição de padrões, e aspectos de manufatura propriamente ditos, com restrições que visam permitir a manufatura por algum processo de fabricação específico como fundição ou extrusão, por exemplo.

Através da utilização destas restrições pretende-se obter resultados simplificados, de forma a encurtar o tempo de projeto utilizando a técnica de OT já que a etapa de pós-processamento de resultados tende a se tornar mais simples, porém ainda necessária. Hoje em dia este processo de pós-processamento é demorado, impondo uma séria restrição à utilização da OT de forma mais ampla.

\subsection{Motivação e Justificativa}

A motivação desse trabalho é ultrapassar uma barreira para maior utilização do MOT nas indústrias como um todo, já que os resultados obtidos são mais próximos das necessidades das indústrias com relação à manufatura.

Com a redução do tempo de pós-processamento e também da complexidade das formas, o custo da utilização da OT como ferramenta de projeto é reduzido.

Ao final do processo de OT os leiautes obtidos terão contornos mais controlados e mais condizentes com os resultados esperados pelo projetista. Assim a otimização visa conseguir reduzir não somente o peso das peças, mas também o seu custo como um todo através do controle da solução, encontrando assim soluções mais apropriadas para se fabricar.

Outra motivação é o fato de até existirem leiautes otimizados que podem ser relativamente simples de serem fabricados, porém o processo de fabricação que claramente seria o melhor para fabricá-lo não está disponível nos recursos da fábrica ou oficina. Como por exemplo a solução apresentada na figura 1.1, 
caso utilize uma chapa estampada, é simples de ser fabricada, já se tiver que ser usinada, poderá ter restrições devido a tamanhos mínimos de ferramentas de fresa. Com isso uma restrição em relação à fabricação pode restringir essa forma ótima, que não é aceitável para o problema estudado, conduzindo a otimização para um leiaute diferente do obtido sem a restrição e que seria difícil de ser encontrado pelo mero pós-processamento dos resultados obtidos na otimização livre de restrições.

Há vários anos a comunidade científica vem sendo atraída pela abordagem racional de otimização estrutural como pode ser acompanhada em trabalhos de revisão como Eschenauer e Olhof (2001) e cada vez mais sua utilização vem sendo trazida para o lado prático.

Assim, este trabalho visa contribuir com a comunidade científica no desenvolvimento do tópico, buscando encurtar a distância existente entre indústria e meio acadêmico. 


\section{O Método de Otimização Topológica (MOT)}

\subsection{Introdução}

Ao longo dos tempos o projeto de estruturas vem ocupando grande parte dos esforços dos engenheiros. Mesmo sendo uma atividade antiga, as fases do processo não se alteraram muito ao longo do tempo. Inicialmente definem-se as formas básicas, a geometria das peças, e a partir dessa se verifica a aceitação da estrutura confrontando os resultados com os requisitos de projeto solicitados. Porém, muito mais do que verificar se uma estrutura suporta as condições de carga a ela aplicadas, o trabalho do engenheiro visa melhorar o desempenho desta estrutura, fazendo-a com melhor relação custo benefício possível, como disse o piloto e escritor francês Antoine de Saint-Exupéry

"A designer knows that he has achieved perfection not when there is nothing left to add, but when there is nothing left to take away."

ou em uma tradução livre:

"Um projetista sabe que atingiu a perfeição não quando não existe nada mais a ser adicionado, mas sim quando não há mais nada para ser removido."

Visando fazer com o que o processo de melhoria das estruturas fosse mais facilmente aplicado foram se desenvolvendo ao longo do tempo diversos métodos de otimização, como a otimização paramétrica, de forma e topológica. Para ilustrar esses tipos de otimização e diferenciá-los será utilizado um problema clássico de otimização onde a viga é engastada e uma carga é aplicada no centro de sua extremidade oposta.

A otimização paramétrica, utiliza parâmetros de projeto como variáveis. No caso da viga engastada, como ilustrada na figura 2.1, as variáveis são $h, b$ e $t$, respectivamente, a distância entre as abas, a largura das abas e a espessura das paredes. O processo de otimização da estrutura se dá através da variação 
desses parâmetros até a obtenção de uma solução ótima. Este método é mais simples e funcional, porém altamente restritivo já que as formas básicas da figura não podem ser alteradas, apenas as proporções entre elas. O projetista tem que definir uma forma básica para o projeto, o que nem sempre é simples quando a estrutura e/ou a situação de carregamento é complicada. Esse método também é conhecido na literatura por "size optimization".

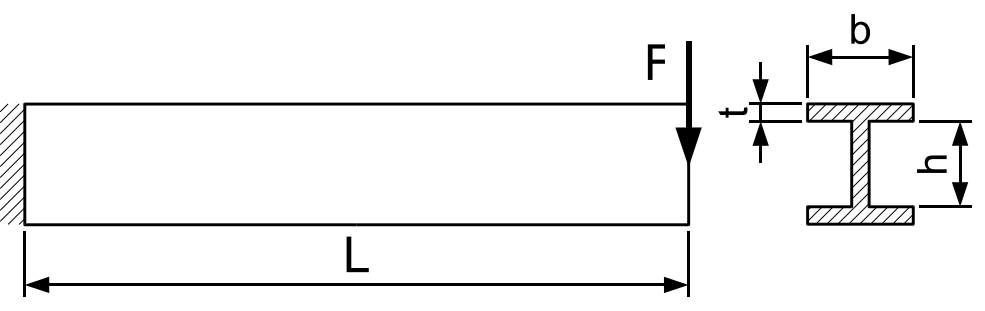

Figura 2.1: Otimização paramétrica.

Na otimização de forma, são utilizadas como variáveis os parâmetros de curvas "splines" que definem os contornos internos e externos da estrutura. Através da modificação desses parâmetros, ou seja, da forma dos contornos, é realizada a otimização. Apesar de mais abrangente que a otimização paramétrica esse método ainda não apresenta a possibilidade de se criar novos furos em sua estrutura, e também necessita de valores iniciais para o processo, ficando por isso limitado ao conhecimento do projetista sobre uma forma aproximada da solução ótima para que possa ser bem utilizado. Podemos ver um exemplo na figura 2.2. $\mathrm{Na}$ literatura internacional esse método é conhecido como "shape optimization".

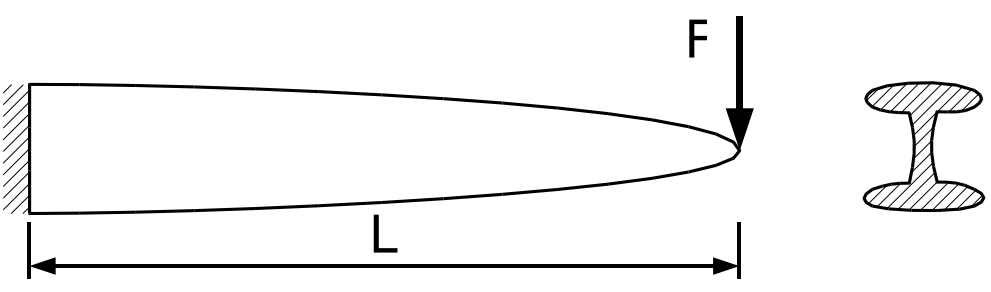

Figura 2.2: Otimização de forma.

Neste trabalho o método utilizado será o Método de Otimização Topológica (MOT) ou também denominado na literatura Otimização de Leiaute ou Otimização de Forma Generalizada. Este método propõe um método genérico capaz de auxiliar o engenheiro a definir a topologia da estrutura de maneira direta e sistemática. Pedaços da estrutura podem ser realocados, ou até mesmo removidos de maneira a se obter a estrutura ótima desejada.

Como se percebe pelos exemplos a grande vantagem proposta pelo MOT em relação a outros métodos de otimização, como a Otimização de Forma e 

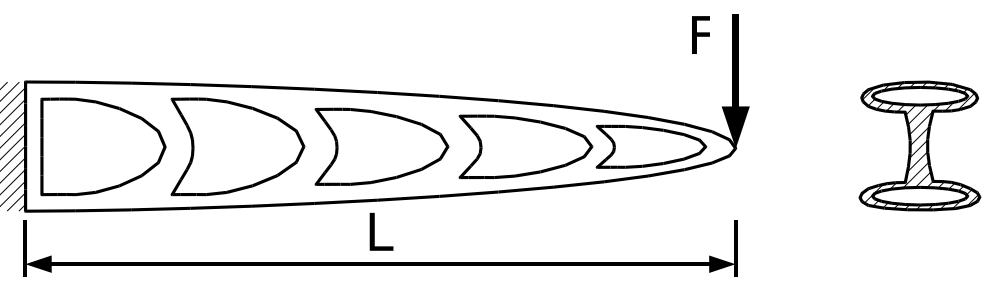

Figura 2.3: Otimização topológica

a Otimização Paramétrica, é o fato desses não serem capazes de sintetizar o leiaute de uma estrutura, sem uma solução conceitual inicial, o que na otimização topológica é possível, já que apenas com as informações do domínio ocupado, uma restrição de volume e as condições de contorno é possível se chegar a uma solução conceitual inicial.

A Otimização Topológica (OT) de estruturas pode ser dividida em duas categorias distintas: a OT de um meio discreto e a OT de um meio contínuo.

A OT a partir de um meio discreto considera o domínio da estrutura discretizado por barras rígidas ou treliças, como mostrado na figura 2.4. Esta categoria é subdividida em outras duas: OT de estruturas de malha contínua e OT de estruturas discretas. A OT de estruturas de malha contínua ("gridlike contínua") trabalha com um infinito número de barras rígidas separadas por um espaço infinitesimal, cuja solução ótima é obtida analiticamente.

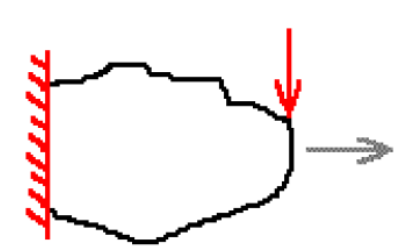

a)

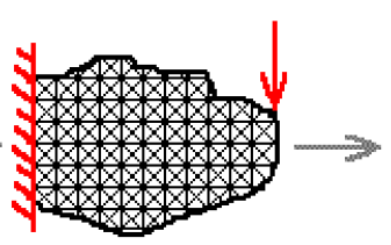

b)

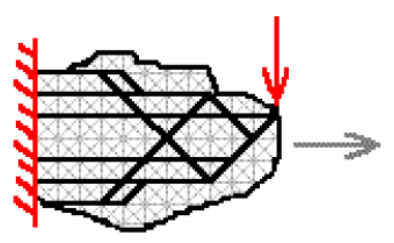

c)

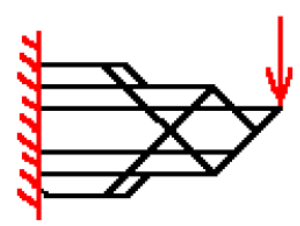

d)

Figura 2.4: Otimização topológica de uma estrutura discreta.

Este conceito de otimização não é recente, em 1904 Michell foi o pioneiro a oferecer uma abordagem teórica para a solução analítica de problemas de otimização em estruturas de malha contínua com mínimo volume de material. A figura 2.5 mostra um exemplo da configuração otimizada de uma alavanca encontrada por Michell onde as linhas de isotensão principais, determinadas através da teoria da elasticidade, podem ser compostas por uma série de barras. Os trabalhos realizados por Michell foram considerados muito acadêmicos e sem aplicação prática para a época. Anos depois, na década de 80, com o advento dos com- 
putadores e o desenvolvimento dos métodos numéricos como a OT, os trabalhos de Michell foram retomados e surgiram várias extensões desses trabalhos (PRAGER, 1974; CHENG; OLHOFF, 1981; TAYLOR; BENDSØE, 1984; BENDSøE; KIKUCHI, 1988). Outros exemplos e detalhes sobre a metodologia de Michell podem ser visto em Michell (1904) apud Rozvany, Bendsoe e Kirsch (1995).

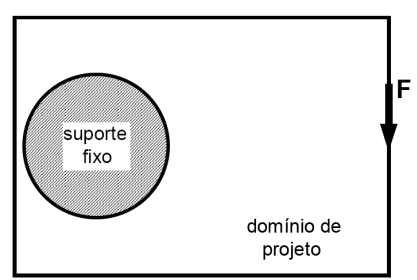

a)

Problema de otimização estrutural

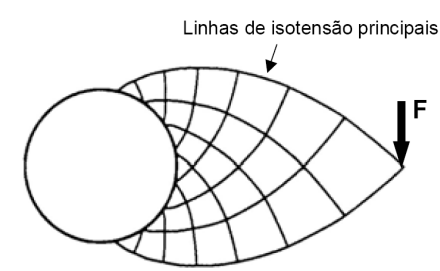

b)

Resultado analítico obtido por Michell em 1904

Figura 2.5: Estrutura ótima obtida por Michell.

A outra categoria de OT considera uma estrutura contínua. Tomando-se uma região do espaço onde a estrutura possa existir, e determinadas condições de contorno do problema, uma disposição do material dentro desse domínio é encontrada, obtendo dessa forma os furos e contornos do leiaute ótimo para o problema. Trabalhos como Bendsøe e Kikuchi (1988) estabeleceram o MOT como um método eficiente para a otimização estrutural, e Suzuki e Kikuchi (1991) comprovou o resultado da solução analítica obtida por Michell apresentado na figura 2.5 reproduzindo-o através do MOT como pode ser visto na figura 2.6.

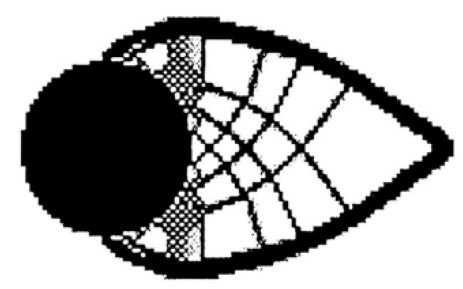

Figura 2.6: Resultado da otimização topológica do mesmo problema solucionado por Michell

Dentro da abordagem contínua ainda podemos dividir o problema de duas outras formas como definido por Eschenauer e Olhof (2001): a abordagem micro, ou baseada no material, e a abordagem macro, ou baseada na geometria.

A abordagem micro, a primeira a ser desenvolvida, é baseada na existência de uma micro-estrutura porosa que define as relações constitutivas do material em função da geometria e da pseudo-densidade volumétrica de uma célula unitária representativa do material. Por sua vez, a pseudo-densidade é representada por 
variáveis contínuas continuamente distribuídas no espaço do domínio. Nesta abordagem o domínio é discretizado por uma malha de elementos finitos que não se altera ao longo da otimização e permite calcular as respostas mecânicas (ex. campo de tensões e deformações). A otimização consiste em determinar quais pontos da estrutura devem possuir ou não material; assim sendo, a distribuição de pseudo-densidades é parametrizada de modo que cada ponto do domínio possa variar entre um (1) (material sólido) e zero (0) (ausência de material ou presença de um material mole). Assim, durante o processo de otimização as variáveis tendem aos seus valores limites indicando regiões com presença de material e regiões com buracos, o que define o leiaute da estrutura.

A otimização de leiaute que utiliza essa abordagem já possui uma vasta literatura introdutória encontrada em livros, como Bendsøe e Sigmund (2002), com um enfoque mais voltado à aplicação, ou em Allaire (2002), no qual a formulação matemática é apresentada e discutida junto com uma implementação numérica. Um desenvolvimento teórico matemático mais aprofundado pode ser encontrado no livro de Cherkaev (2000).

Apesar da comunidade científica não aceitar completamente o uso do termo Otimização Topológica (OT) para designar a abordagem micro, nesse trabalho será utilizada esta associação, de acordo com Bendsøe e Sigmund (2002) e os trabalhos de Silva (2003), Silva, Nishiwaki e Kikuchi (2000) e também em Stump (2006).

Dentre a abordagem macro, ou baseada na geometria, podem-se agrupar três principais vertentes: o "bubble method" ${ }^{1}$, a otimização de leiaute, baseada no método de "level set"2, e os métodos evolucionários.

O "bubble method" consiste em alterar o leiaute da estrutura através do crescimento e degeneração de furos no interior da mesma, baseando-se no conceito de derivada topológica. Essa abordagem é descrita em (ESCHENAUER; OLHOF, 2001).

O método de otimização de leiaute baseado no método de "level set" estudado em Allaire, Jouve e Toader (2004) é baseado na representação do leiaute da estrutura através da curva de nível zero de uma função de alta ordem. Por exemplo, no caso bi-dimensional a fronteira da estrutura é definida pelo conjunto

\footnotetext{
${ }^{1} \mathrm{O}$ termo "bubble method" poderia ser traduzido para a língua portuguesa como método das bolhas porém essa nomenclatura é pouco comum de forma que se optou por manter o termo em inglês ao longo do texto.

${ }^{2} \mathrm{O}$ termo "level set" poderia ser traduzido para a língua portuguesa como curva de nível, porém, essa nomenclatura é pouco comum de forma que se optou por manter o termo em inglês ao longo do texto.
} 
de pontos de valor zero de uma função escalar em termos das coordenadas x e y do plano. Dessa forma, a fronteira da estrutura, definida pela curva de nível zero, é movimentada de modo a minimizar uma dada função objetivo. Burger, Hackl e Ring (2004) combinaram essa abordagem com a análise de sensibilidade da função objetivo.

A principal vantagem do método de "level set" é a definição precisa dos contornos da estrutura. Esta vantagem é importante para tratar problemas que a carga da estrutura depende de sua geometria (por exemplo: carga devido a pressão (ALLAIRE; JOUVE; TOADER, 2004)) ou em problemas onde os fenômenos ocorrem na superfície, como por exemplo o projeto de uma aleta ou trocador de calor.

Ainda sobre o método de "level set", Burger e Osher (2005) apresentam uma revisão sobre o seu desenvolvimento, suas áreas de aplicação e desafios futuros.

Recentemente, o trabalho de (BURGER; HACKL; RING, 2004) aponta para uma convergência da otimização de leiaute baseada no método de "level set" com o "bubble method".

Os métodos evolucionários baseiam-se no conceito de uma estrutura base, em geral uma malha de elementos finitos de onde serão inseridos e/ou retirados elementos. A modificação da estrutura base é feita através de critérios heurísticos. Uma descrição mais detalhada desse método pode ser encontrada nos artigos de Chu et al. (1997, 1996), Liu, Parks e Clarkson (2005), Liu, Korvink e Huang (2005)

Nesse trabalho será tratada apenas a otimização de meios contínuos baseada na abordagem micro: Método de Otimização Topológica (MOT), ou simplesmente Otimização Topológica (OT).

O MOT foi proposto por Bendsøe e Kikuchi (1988) e se baseia fortemente, segundo o próprio autor, na contribuição de diversos pesquisadores. Nesse trabalho Bendsøe apresenta uma aproximação da OT por um problema de distribuição de dois materiais, sendo um deles material vazio (buracos). Para isso o autor se baseia na parametrização das propriedades do material através do conceito de micro-estruturas.

A utilização de micro-estruturas no problema de projeto ótimo de estruturas já havia sido proposta nos trabalhos de Cheng e Olhoff (1981) e Cheng e Olhoff (1982). Como conseqüência da utilização de micro-estruturas para parametrização do problema, o método de homogeneização, também desenvolvido 
previamente por Bensoussan, Lions e Papanicolaou (1978) e por Sanches-Palencia (1980), passou a ser aplicado no cálculo das propriedades efetivas dos materiais obtidos.

A formulação matemática para a relaxação do problema de otimização estrutural e sua relação com o método de homogeneização também já havia sido demonstrada no trabalho de Kohn e Strang (KOHN; STRANG, 1986a, 1986b, 1986c).

A partir do trabalho de Bendsøe e Kikuchi (1988), se seguiu uma série de trabalhos dedicados a aprimorar o método e ampliar o espectro de aplicação do MOT. Um grande marco no desenvolvimento do MOT foi a utilização de modelos de material artificiais por Bendsøe (1989) e Rozvany, Zhou e Birker (1992), que substituiu a necessidade de utilizar os métodos de homogeneização para a sua implementação numérica, facilitando, assim, a difusão do MOT.

Dentre as publicações precursoras do método devem se citar também os trabalhos de Suzuki e Kikuchi (1991) e Olhoff, Bendsøe e Rasmussen (1991) que, apesar de posteriores, auxiliaram sua consolidação; o primeiro faz uma verificação numérica da eficiência do método através de diversos exemplos, além de comparar as soluções obtidas com as soluções de Michell (MICHELL, 1904); o segundo apresenta a aplicação do MOT associada à otimização de forma e utiliza essa metodologia em alguns problemas reais, entre eles a tradicional viga MBB ( "Messerschmidt-Bölkow-Blohm").

Após a consolidação do MOT surgiram várias linhas de desenvolvimento e aplicação desse. Parte da comunidade científica despendeu um grande esforço para a compreensão e o tratamento de alguns problemas inerentes à sua formulação. Dentre as contribuições para o desenvolvimento do método, os principais tópicos desenvolvidos foram: o controle da instabilidade de tabuleiro, o tratamento da dependência da malha e o controle das escalas de cinza descritos na seção 2.4. Estes três tópicos estão intrinsecamente relacionados, pois os métodos que tratam cada um deles, em geral, influenciam os demais. As principais contribuições nesta área foram dadas por: Jog e Haber (1996), Haber, Bendsøe e Jog (1996), Sigmund (1997), Sigmund e Petersson (1998), Petersson e Sigmund (1998), Cardoso (2000), Zhou, Shyy e Thomas (2001), Stolpe e Svanberg (2001), Bourdin (2001), Poulsen (2003, 2002), Rahmatalla e Swan (2003, 2004), Zhang e Duysinx (2003), Matsui e Terada (2004). 


\subsection{Formulação geral do problema de OT}

A formulação matemática do MOT será apresentada para o problema clássico de maximização da rigidez com restrição do volume, além de ser um problema de fácil explanação ela é praticamente a mesma utilizada nesse trabalho, a menos da imposição das restrições de simplificação de geometria.

O problema de maximização de rigidez de uma estrutura linear elástica sob a ação de um único caso de carga é equivalente ao problema de minimização da flexibilidade, definida como o trabalho realizado pelas forças externas. Por sua vez minimizar a flexibilidade equivale a minimizar a energia de deformação elástica total na estrutura.

Isso pode ser observado através da equação do trabalho das cargas externas:

$$
W(\boldsymbol{u}(\boldsymbol{x}))=\int_{\Omega} \boldsymbol{f}(\boldsymbol{x})^{\boldsymbol{T}} \boldsymbol{u}(\boldsymbol{x}) d \Omega+\int_{\partial \Omega} \boldsymbol{p}(\boldsymbol{x})^{\boldsymbol{T}} \boldsymbol{u}(\boldsymbol{x}) d \partial \Omega
$$

sendo $\boldsymbol{x}$ representa as coordenadas espaciais de cada ponto da estrutura, $\boldsymbol{u}(\boldsymbol{x})$ representa o campo de deslocamentos nas condições de equilíbrio, $\boldsymbol{f}(\boldsymbol{x})$ são as forças de campo aplicadas a estrutura e $\boldsymbol{p}(\boldsymbol{x})$ são as cargas aplicadas na superfície da estrutura.

Dessa forma, o problema de maximização da rigidez com restrição de volume é definido como um problema de minimização da energia de deformação elástica da estrutura. Pelo princípio dos deslocamentos virtuais, de forma a atender às condições de equilíbrio dadas e à função discreta $\chi(\boldsymbol{x})$, define-se uma estrutura de volume menor ou igual ao volume de referência solicitado. O problema posto desta maneira tem a característica de possuir como variável uma função de parâmetros discretos continuamente distribuídos ao longo do espaço, e pode ser escrito conforme o problema: 


$$
\begin{aligned}
& \underset{\chi(x)}{\operatorname{minimizar}} \int_{\Omega} \boldsymbol{f}(\boldsymbol{x})^{\boldsymbol{T}} \boldsymbol{u}(\boldsymbol{x}) d \Omega+\int_{\partial \Omega} \boldsymbol{p}(\boldsymbol{x})^{\boldsymbol{T}} \boldsymbol{u}(\boldsymbol{x}) d \partial \Omega \\
& \text { tal que }\left\{\begin{array}{l}
\int_{\Omega} \tilde{\boldsymbol{\epsilon}}(\boldsymbol{x})^{\boldsymbol{T}} \boldsymbol{C}(\boldsymbol{x}) \boldsymbol{\epsilon}(\boldsymbol{x}) d \Omega-\int_{\Omega} \boldsymbol{f}(\boldsymbol{x})^{\boldsymbol{T}} \tilde{\boldsymbol{u}}(\boldsymbol{x}) d \Omega- \\
\int_{\partial \Omega} \boldsymbol{p}(\boldsymbol{x})^{\boldsymbol{T}} \tilde{\boldsymbol{u}}(\boldsymbol{x}) d \partial \Omega=0 \\
\int_{\Omega} \chi(\boldsymbol{x}) d \Omega \leq \Omega_{r e f}
\end{array}\right.
\end{aligned}
$$

em que a função discreta $\chi(\boldsymbol{x})$ é a variável de projeto que define que pontos do Domínio Fixo Estendido (DFE) possuem material:

$$
\chi(\boldsymbol{x})= \begin{cases}1 & \text { se } \boldsymbol{x} \in \Omega_{m} \\ 0 & \text { se } \boldsymbol{x} \in \Omega \backslash \Omega_{m}\end{cases}
$$

Assim, o tensor constitutivo do material ao longo do domínio $\Omega$ é dado por 2.4

$$
\boldsymbol{C}=\chi(\boldsymbol{x}) \boldsymbol{C}_{\boldsymbol{o}}
$$

Ainda no problema $2.2, \tilde{\boldsymbol{\epsilon}}(\boldsymbol{x})$ representa o campo de deformação virtual, que é obtido através do campo de deslocamentos virtuais $\tilde{\boldsymbol{u}}(\boldsymbol{x})$.

A notação utilizada nesse problema está representada na figura 2.7, em que:

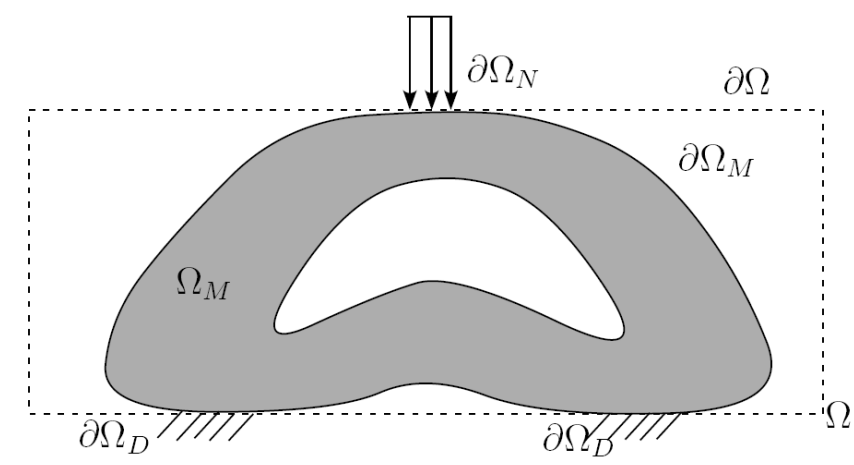

Figura 2.7: Domínio Fixo Estendido (DFE) e notação adotada.

\section{$\Omega$ representa o DFE}

$\partial \Omega$ representa o contorno do DFE

$\partial \Omega_{N}$ representa o contorno do DFE sujeito às condições de contorno de Neumann: 
pressão aplicada conhecida

$\partial \Omega_{D}$ representa o contorno do DFE sujeito às condições de contorno de Dirichlet: deslocamento conhecido

$\Omega_{M}$ representa a região do DFE que apresenta material

$\partial \Omega_{M}$ representa o contorno de $\Omega_{M}$

Para se calcular numericamente a função objetivo $W[\boldsymbol{u}(\boldsymbol{x})]$, é necessário obter primeiramente o campo de deslocamentos da estrutura. A forma tradicional de se resolver esse problema é através da aplicação do Método de Elementos Finitos (MEF). Esse será descrito aqui de forma sucinta, apenas para facilitar o entendimento do MOT (BENDSøE, 1995; ESCHENAUER; OLHOF, 2001). A formulação de MEF utilizada nesse trabalho será apresentada no capítulo 3.

Partindo da equação da energia potencial total (2.5):

$$
\begin{aligned}
\Pi=U-W= & \frac{1}{2} \int_{\Omega} \boldsymbol{\epsilon}(\boldsymbol{x})^{\boldsymbol{T}} \boldsymbol{C}(\boldsymbol{x}) \boldsymbol{\epsilon}(\boldsymbol{x}) d \Omega- \\
& \int_{\Omega} \boldsymbol{f}(\boldsymbol{x})^{\boldsymbol{T}} \boldsymbol{u}(\boldsymbol{x}) d \Omega-\int_{\partial \Omega} \boldsymbol{p}(\boldsymbol{x})^{\boldsymbol{T}} \boldsymbol{u}(\boldsymbol{x}) d \partial \Omega
\end{aligned}
$$

e então, aplica-se o procedimento típico de discretização da estrutura $M \mathrm{em}$ elementos finitos, ou seja, divide-se o domínio inicial em pequenos sub-domínios de maneira a obter problemas menores e mais simples de se resolver. Podemos então interpolar o campo de deslocamentos através de variáveis nodais. Obtemos então a equação (2.5) na sua forma matricial:

$$
\Pi=U-W=\frac{\overline{\boldsymbol{d}}^{T} \boldsymbol{K} \overline{\boldsymbol{d}}}{2}-\boldsymbol{f}^{t} \overline{\boldsymbol{d}}
$$

sendo $\overline{\boldsymbol{d}}, \boldsymbol{K}$ e $\boldsymbol{f}$ são respectivamente o vetor de deslocamentos, a matriz de rigidez e o vetor de cargas. Seguindo o procedimento do MEF, a condição de equilíbrio é obtida pelo princípio da mínima energia potencial, que requer a condição de estacionarídade de $\Pi$ em relação à $\overline{\boldsymbol{d}}$ :

$$
\frac{\partial \Pi}{\partial \overline{\boldsymbol{d}}}=0
$$

o que nos leva ao conhecido sistema linear

$$
K \bar{d}=f
$$


que permite obter os deslocamentos da estrutura analisada para um dado caso de carregamento. Assim, podemos definir a formulação do problema em função de parâmetros discretos, discretamente distribuídos no espaço:

$$
\begin{aligned}
\underset{\chi \in B}{\operatorname{minimizar}} & W(\overline{\boldsymbol{d}}) \\
\text { tal que } & \boldsymbol{K} \overline{\boldsymbol{d}}=\boldsymbol{f}
\end{aligned}
$$

sendo $B$ é dado por $(2.10)$

$$
B=\left\{\chi \mid \int_{\Omega} \chi d \Omega=V_{\text {ref }}\right\}
$$

Analisando as formulações apresentadas, observamos que esse problema é de otimização de parâmetros discretos, também chamado de problema $(0-1)$. É sabido que, de maneira geral, esse problema não tem solução (SIGMUND; PETERSSON, 1998), pois eventualmente pode gerar seqüências de funções $\chi(\boldsymbol{x})$ que fornecem sempre um valor menor da função objetivo.

Apesar de aparentemente estranho o fato de uma função sempre poder ser minimizada, podemos compreender esse fenômeno se considerarmos que, em alguns problemas, a inclusão de furos em certas partes do DFE melhora a função objetivo. O que pode implicar que a solução ótima somente é atingida no limite, quando as dimensões dos furos tendem à zero.

Matematicamente, isso significa que o espaço de soluções possíveis admissíveis, definido pela função $\chi(\boldsymbol{x})$ que atende à restrição de volume dada por (2.10), é não compacto, ou seja, não é limitado e fechado. Assim, para que o problema (2.2) apresente sempre solução é necessário alterar o espaço de solução, de modo que esse se torne compacto e contenha a solução ótima $\chi^{*}(\boldsymbol{x})$.

Isso pode ser feito através da adoção de restrições extras ao problema, como limitar o perímetro da função $\chi(\boldsymbol{x})$, abordagem que foi utilizada na implementação numérica proposta por Haber, Bendsøe e Jog (1996). Outra forma de tornar o espaço de solução compacto é através da relaxação matemática do problema. A idéia de relaxação consiste em aumentar o espaço de soluções admissíveis de forma a garantir a existência de solução. Nesse caso o aumento do espaço de soluções é feito modificando-se a função $\chi(\boldsymbol{x})$ que ao invés de ser discreta passa a ser contínua entre 0 e 1 . 


\subsection{Modelos de material}

Nessa seção serão apresentados os principais modelos de material utilizados na relaxação do problema de OT.

Conforme a formulação apresentada na seção anterior $2.2, \chi$ deve ser substituída por uma função contínua $\chi_{c}$ que parametrize o tensor constitutivo do material para as pseudo-densidades volumétricas $\rho$, variando de 0 (vazio) a 1 (sólido), passando pelas pseudo-densidades intermediárias, que por sua vez, representam materiais porosos. Dessa forma, o espaço das soluções admissíveis é aumentado, relaxando o problema. As principais classes de modelo de material são:

- Material baseado na existência de uma micro-estrutura que é representada por uma célula unitária com geometria parametrizável. As propriedades dos materiais compostos são, em geral, calculadas utilizando o método de homogeneização, o que levou a literatura a nomear essa classe de modelo de material como "Método da Homogeneização". Porém como pode ser visto em Eschenauer e Olhof (2001) existem outros métodos para cálculo das propriedades efetivas de materiais compostos.

- Modelos de material artificial. Esses modelos não são baseados na existência de uma micro-estrutura, eles apenas fornecem uma relação contínua que parametriza o tensor constitutivo do material com pseudo-densidade $\rho$, que varia entre 0 e 1. A formulação mais conhecida desse modelo, e que será utilizada nesse trabalho é chamada na literatura de "Simple Isotropic Material with Penalization" (SIMP).

\subsubsection{Materiais Baseados em Micro-estrutura}

Os modelos de material baseados em uma Micro-estrutura consistem na definição de uma função $\chi_{c}(\boldsymbol{x})$, a partir da escolha de uma micro-estrutura composta por células unitárias de dimensões infinitesimais que se repetem indefinidamente ao longo da estrutura. Esse material é então interpretado como um material composto, uma vez que sua célula unitária é composta por dois materiais. A figura 2.8 representa esta situação.

A partir da definição da célula unitária e de sua parametrização, como por exemplo a direção e as dimensões da laminação ou as dimensões e a rotação de um 
Exemplo de microestrutura perfurada

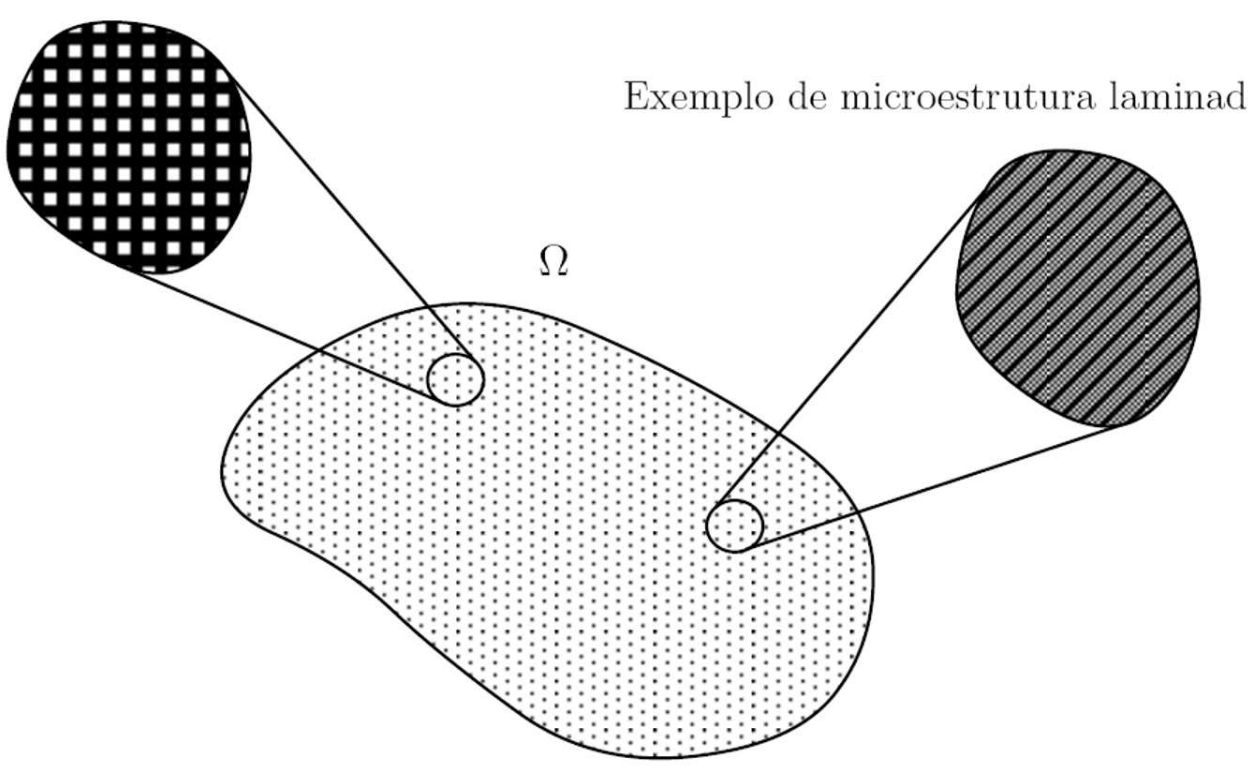

Figura 2.8: Representação do modelo de material baseado na micro-estrutura.

furo retangular dentro de uma célula unitária, é possível, através do método da homogeneização, obter as propriedades mecânicas efetivas do material, também chamadas de propriedades homogeneizadas. Mais informações sobre o método de homogeneização e sobre esse modelo de material podem ser encontrados em Suzuki e Kikuchi (1991), Sanchez-Palencia e Zaoui (1985), Swan C. e Kosaka (1997), Bendsøe e Sigmund (1999), Allaire et al. (2004), Bendsøe e Sigmund (2002)

\subsubsection{Modelo de Material Artificial}

Os modelos de material artificial são baseados na idéia de uma micro-estrutura desconhecida, porém que possui tensor constitutivo conhecido. Essa abordagem foi proposta por Bendsøe (1989) e consiste em parametrizar o tensor constitutivo por uma função contínua, aqui denominada $f_{S I M P}(\rho)$. Assim temos que $\chi_{c}$ é dada por:

$$
\chi_{c}(\boldsymbol{x})=f_{\text {simp }}(\rho(\boldsymbol{x}))
$$

Logo, assim como na equação 2.4, podemos definir o tensor constitutivo da estrutura, que pode ser dado por 2.12, e localmente pode ser dado por 2.13:

$$
\boldsymbol{C}^{\boldsymbol{H}}=\chi_{c}(\boldsymbol{x}) \boldsymbol{C}_{\mathbf{0}}
$$




$$
\boldsymbol{C}^{\boldsymbol{H}}=f_{\text {simp }}(\rho) \boldsymbol{C}_{\mathbf{0}}
$$

em que $\boldsymbol{C}_{\mathbf{0}}$ é o tensor constitutivo do material original a ser distribuído, e $\boldsymbol{C}^{\boldsymbol{H}}$ o tensor efetivo que será utilizado no cálculo da resposta mecânica da estrutura. A função $f_{S I M P}(\rho)$ pode ser uma função contínua que tenha imagem entre zero e um. Porém na literatura se consagrou a utilização de uma função exponencial em relação à $\rho$.

$$
f_{\text {simp }}=\rho^{q}
$$

onde $q$ é o fator de penalização que tem por objetivo reduzir as pseudo-densidades intermediárias no resultado final. O tensor $\boldsymbol{C}_{\mathbf{0}}$ é isotrópico e depende do módulo de elasticidade do material base $\left(E_{0}\right)$ e da razão de Poisson $(\nu)$. No SIMP o módulo de elasticidade do material em cada ponto do DFE varia com a pseudodensidade $\rho$, enquanto que $\nu$ não depende de $\rho$.

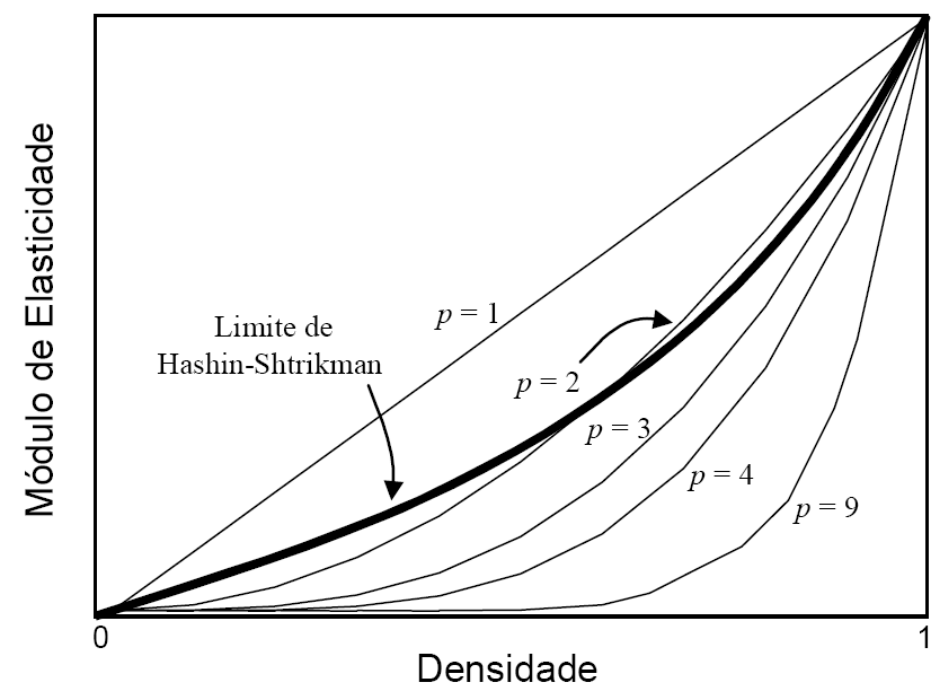

Figura 2.9: Curva limite superior de Hashin-Shtrikman e curvas do modelo SIMP.

O fator $q$ pode e deve ser ajustado para evitar o aparecimento de regiões intermediárias. Uma discussão sobre o ajuste desse fator é feita em (BENDSøE; SIGMUND, 1999), onde é demonstrado a existência de um modelo SIMP formado a partir da mistura de um material base e vazio (buraco) sendo $E_{0} \gg E_{\text {vazio }}$, no estado plano de tensão, as seguintes relações devem ser satisfeitas: 


$$
\begin{aligned}
\rho^{q} E_{0} & \leq \frac{\rho E_{0}}{3-2 \rho} \quad \text { para } 0 \leq \rho \leq 1 \\
q & \geq \max \left\{\frac{2}{1-\nu}, \frac{4}{1+\nu}\right\}
\end{aligned}
$$

As equações (2.15) e (2.16) são baseadas nos limites de Hashin-Shtrikman (BENDSØE; SIGMUND, 2002), os quais definem uma região, onde as propriedades de micro-estruturas formadas a partir da mistura de dois materiais são fisicamente possíveis de serem obtidas. Podemos concluir que se $q \geq 3$ as equações (2.15) e (2.16) são satisfeitas Podemos ver graficamente esse limite na figura 2.9.

O modelo de material SIMP é um modelo de material mais simples de ser implementado numericamente quando comparado ao método de homogeneização, por isso é muito popular na literatura.

\subsection{Problemas Numéricos do MOT}

A utilização dos modelos de materiais baseados em modelos artificiais por Bendsøe (1989) ou em micro-estruturas por Bendsøe e Kikuchi (1988), permitiu que se obtivessem soluções numéricas para os problemas de otimização de variáveis contínuas e parâmetros distribuídos. Através do modelo de material o problema 2.2 pode ser escrito conforme 2.17 , utilizando variáveis contínuas discretamente distribuídas no espaço.

$$
\begin{array}{ll}
\underset{t_{1}, \ldots, t_{n}}{\operatorname{minimizar}} & W(\boldsymbol{d}) \\
\text { tal que } & \left\{\begin{array}{l}
\boldsymbol{K} \boldsymbol{d}=\boldsymbol{f} \\
\int_{\Omega} \rho(\boldsymbol{x}) d \Omega \leq \Omega_{\text {ref }}
\end{array}\right.
\end{array}
$$

em que $t_{1}, \ldots, t_{n}$ representam, de maneira genérica, os parâmetros do modelo de material adotado e $\rho$ a fração volumétrica de material em cada ponto do DFE. No caso do modelo de material SIMP, teríamos apenas um vetor de variáveis $t_{1}$, representando as pseudo-densidades volumétricas $p$ dos elementos.

O processo típico pelo qual se resolve numericamente um problema de OT pode ser visualizado na figura 2.10. Na seqüência temos as seguintes etapas: determinação do DFE; discretização do mesmo em elementos finitos; otimização 
dos elementos através de algumas das técnicas de otimização; pós-processamento do resultado suavizando-se os contornos quadrados; análise da solução encontrada para verificação; e então, a fabricação.

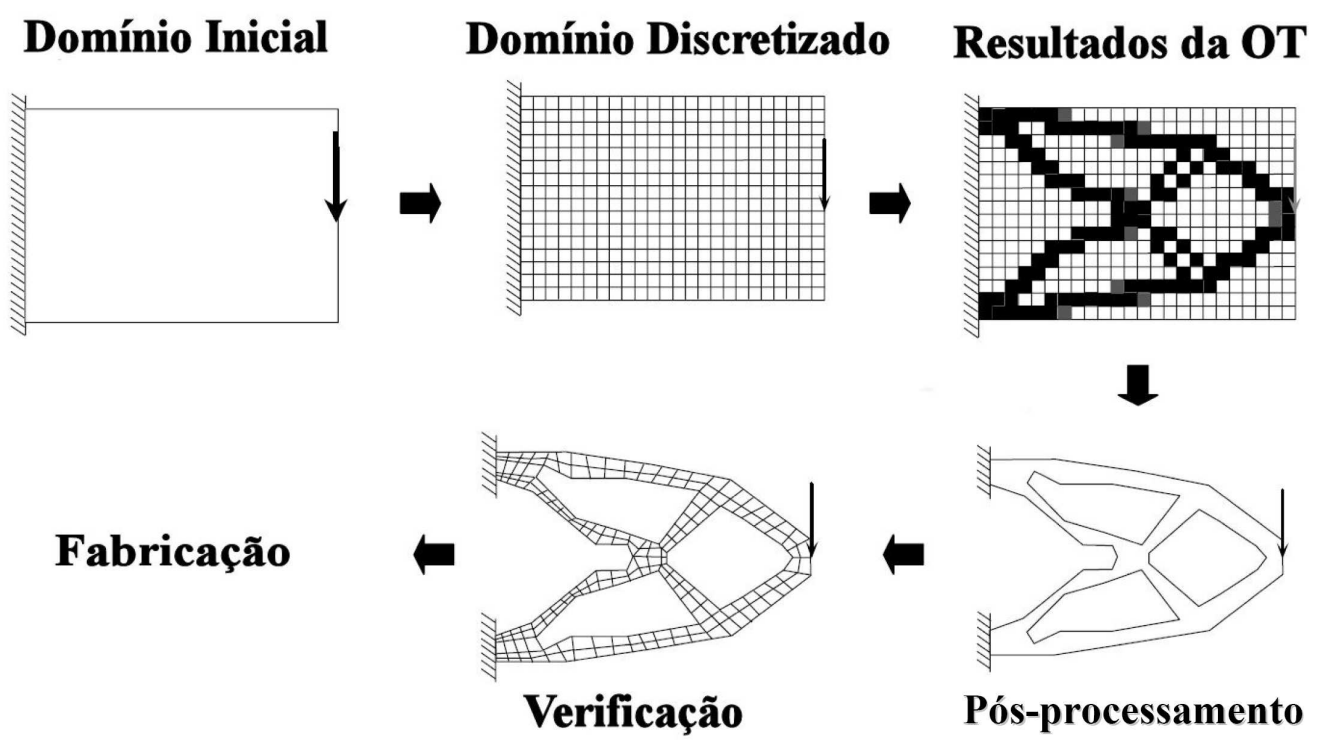

Figura 2.10: Procedimento típico de OT.

Do ponto de vista matemático, o problema que tinha sido inicialmente proposto em (2.2) (função de parâmetros discretos continuamente distribuídos) é resolvido utilizando uma micro-estrutura ótima, garantindo assim a obtenção da solução ótima relaxada. Porém do ponto de vista de Engenharia, a solução ótima do problema relaxado não faz sentido para a maior parte das aplicações, já que esta, como era de se esperar possui um grande quantidade de regiões cinza. Algumas ferramentas ou alterações na formulação foram desenvolvidas de forma a obter soluções mais úteis do ponto de vista da Engenharia, embora não sejam as soluções ótimas matemáticas.

A seguir serão apresentados problemas típicos que surgem em problemas de otimização topológica: são eles, a escala de cinza, a dependência de malha e a instabilidade de tabuleiro. As características e possíveis soluções de cada um dos problemas serão brevemente apresentadas.

\subsubsection{Escala de Cinza}

Em problemas tradicionais em que se deseja encontrar uma solução apenas com respostas discretas, não é interessante, apesar de ser necessário algumas vezes, relaxar o problema, pois a resposta final incluirá uma grande parte de escala de cinza. 
Uma alternativa possível para se definir um problema bem-posto e sem a presença de escala de cinza, é através da solução do problema na sua forma discreta, associado à restrição do espaço de solução.

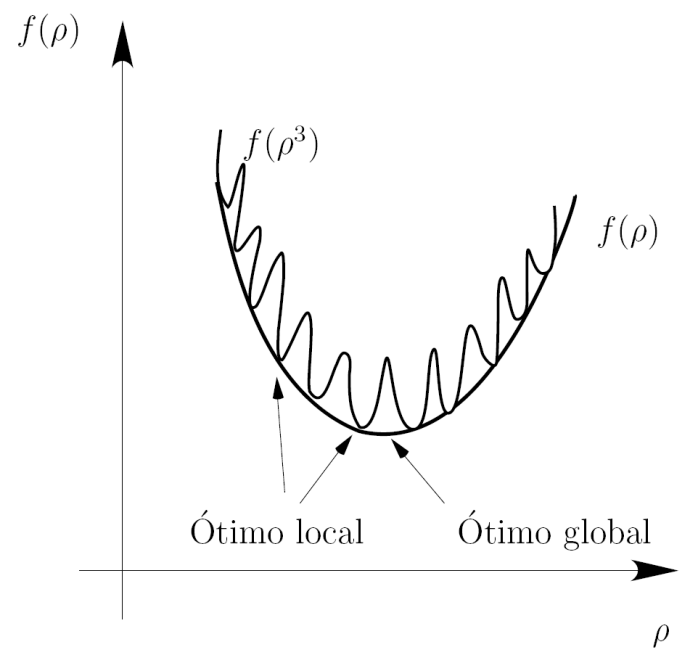

Figura 2.11: Representação esquemática da influência da penalização $q$ na função de flexibilidade do problema de OT

Se for restrito o perímetro da estrutura ótima de maneira a torná-la compacta, o problema se torna bem-posto, ou seja, existe uma solução única para o problema. Essa idéia foi proposta inicialmente por Ambrosio e Buttazzo (1993), e na mesma linha de Haber, Bendsøe e Jog (1996) são propostas restrições que garantem um perímetro máximo do contorno sólido da estrutura. Essas restrições garantem dessa forma que a massa será distribuída de uma forma compacta. Apesar do problema analisado em Haber, Bendsøe e Jog (1996) ter sido implementado de maneira contínua, para se utilizar de meios tradicionais de otimização, as variáveis são altamente penalizadas para impedir o surgimento de pseudodensidades intermediárias.

No caso do modelo SIMP, podemos penalizar o modelo através do seu parâmetro q. Para isso deve ser utilizado algum meio de continuação, ou seja, a penalização inicia-se sempre com um expoente 1 e quando se dá a convergência, esse é adicionado de 1 para que novamente possa se iniciar o processo de convergência. esse processo é repetido até que a penalização desejada seja atingida, na literatura são utilizados como referência índices de penalização $q=3$ ou $q=4$ (BENDSøE; SIGMUND, 2002).

A penalização não deve ser imposta desde o início do problema, pois pode fazer a solução ficar travada em um mínimo local devido à restrição imposta. Como pode ser visto na figura 2.11 a função penalizada é uma função muito irregular facilitando o aparecimento de mínimos locais. 
Na figura 2.12 apresentadas alguns leiautes que exemplificam a diferença encontrada quando são utilizados índices de penalização diferentes.
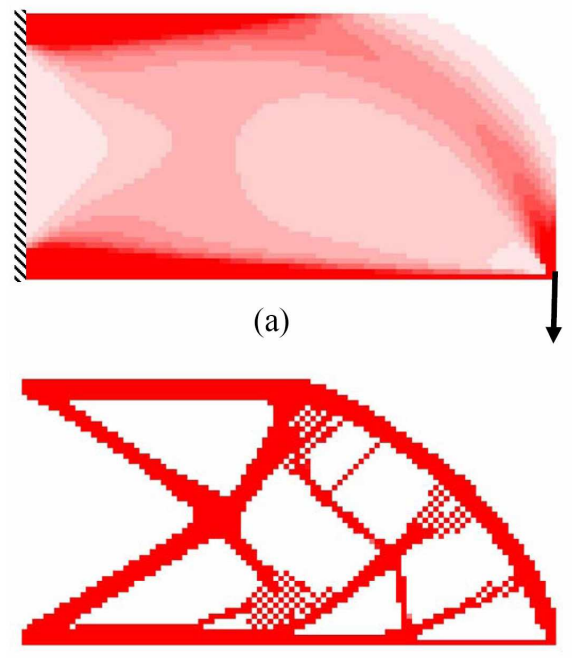

(c)

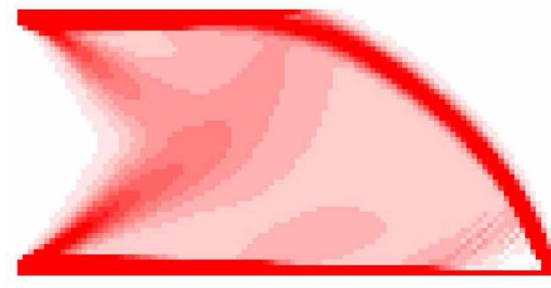

(b)

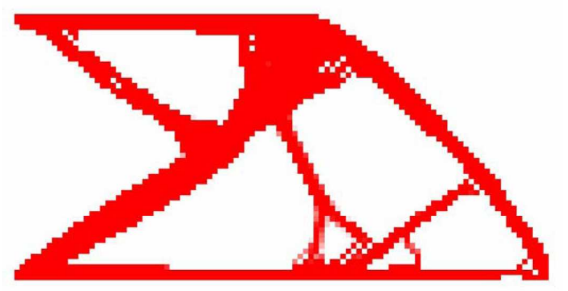

(d)

Figura 2.12: Exemplos resolvidos com volume de solução de 30\%. (a) Solução com a penalização $q=1$. (b) Solução com a penalização $q=2$. (c) Solução com a penalização $q=3$. (d) Solução com continuação da penalização.

Podemos perceber que na figura (2.12-a) onde $q=1$, ou seja, não existe penalização temos praticamente o centro inteiro da figura tomado por uma escala de cinza e nem mesmo as bordas são bem definidas.

Na figura (2.12-b) onde $q=2$ já é possível de se ver um contorno definido e já existe como distinguir algumas regiões mais importantes dentro do sólido, porém ainda temos muita escala de cinza.

Quando adotamos $q=3$ na figura (2.12-c) podemos perceber que a escala de cinza desaparece, porém abre espaço para um outro problema típico da OT a instabilidade de tabuleiro, que será discutida na seção 2.4 .3 em maiores detalhes.

Quando realizamos uma continuação da penalização como a apresentada na (2.12-d) temos uma solução com pouca escala de cinza, com o mesmo problema da solução com a penalização $q=3$, porém a função objetivo é $15 \%$ menor do que a solução anterior, ou seja, a solução está mais próxima do mínimo global. Como a solução da penalização $q=1$ é a mais próxima do mínimo global, ela é utilizada como ponto de partida para uma segunda solução e esta então, para a terceira, e assim sucessivamente. 


\subsubsection{Dependência da Malha}

Outro típico problema do MOT, é a dependência de malha. Podemos observar nas figuras 2.13 (a) e (b), que possuem discretização diferente, 4.000 e 16.000 elementos respectivamente, que a solução encontrada para o problema proposto é diferente. Isso ocorre devido a formação de membros menores na estrutura, diferenciando as soluções e não apenas melhorando seus contornos como era de se esperar com o refinamento da malha.

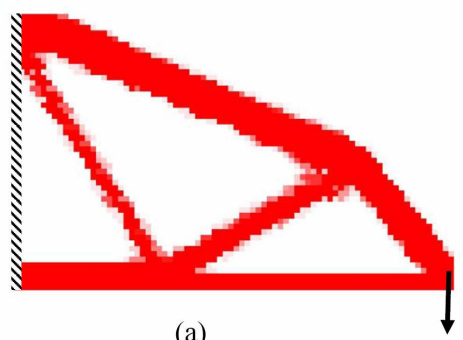

(a)

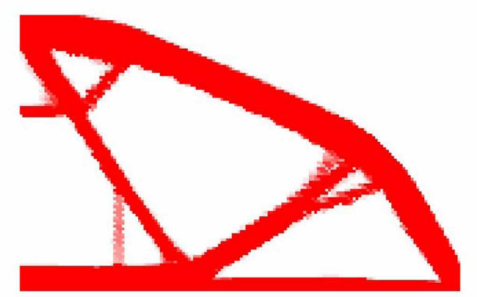

(b)

Figura 2.13: O limite do volume dos problemas apresentados é de 30\%. (a) Malha com 4.000 elementos. (b) Malha com 16.000 elementos.

Esse tipo de problema pode ser dividido em duas categorias de origens distintas. A primeira delas foi apresentada anteriormente, que ocorre devido a um maior refinamento na malha, resultando em estruturas com ramificações cada vez menores. Existe também o caso em que o problema realmente não tem unicidade de solução como o problema proposto na figura 2.14, em que uma região é sujeita a tração com suportes infinitamente rígidos nos extremos. Independentemente de como se distribua a massa, com uma única barra ou com diversas barras paralelas teremos uma solução equivalente (PETERSSON; SIGMUND, 1998).

O problema da dependência de malha ocorre como uma manifestação do fato do problema ter sido relaxado e então penalizado. Essa penalização tem como conseqüência o retorno ao problema discreto. Para resolver esse problema da maneira mais simples seria necessário relaxar o problema, chegando novamente a uma solução com escala de cinza.

A restrição de perímetro apresentada na seção 2.4.1, é uma solução aceitável para o problema de dependência de malha, já que a quantidade de membros que surgem na solução fica restringido à área que eles definem.

Para soluções que podem ser encontradas seguindo-se a abordagem da restrição do espaço de solução, Petersson e Sigmund (1998) propõe uma restrição sobre o gradiente espacial da pseudo-densidade volumétrica. Utilizando o modelo de material SIMP, é possível, para o caso bi-dimensional, inserir uma restrição 
local na forma:

$$
\left|\frac{\partial \rho}{\partial x_{i}}\right| \leq G(i=1,2)
$$

que impede o surgimento de oscilações muito bruscas no campo de pseudodensidades, característica das funções $\chi(\boldsymbol{x})$ minimizantes do problema original (mal-posto). O inconveniente desta abordagem é o grande número de restrições locais impostas ao problema de otimização, que em geral é difícil de ser tratado. Outra solução seria considerar uma restrição global do gradiente, que pode ser escrita da seguinte forma:

$$
\int_{\Omega}(\nabla \rho)^{T}(\nabla \rho) d \Omega \leq C
$$

Essa abordagem é discutida em Bendsøe e Sigmund (2002). A restrição de gradiente na sua forma global se relaciona com a restrição de perímetro, pois a equação 2.19 pode ser interpretada como um índice representativo do perímetro.

No caso da utilização de uma das restrições propostas, de perímetro ou de gradiente, é necessário em geral realizar uma continuação no valor da restrição utilizando um valor alto nas primeiras iterações e diminuindo no decorrer do processo iterativo. Ou seja inicia-se o problema com uma restrição desrespeitada e aumenta-se gradualmente o seu cumprimento, de modo a conduzir a solução a um ponto no qual o valor desejado da restrição seja atendido.

O problema de dependência de malha também pode ser resolvido pela implementação de filtros, que são menos custosos computacionalmente. Os filtros comumente utilizados na literatura são tratados no capítulo 4.
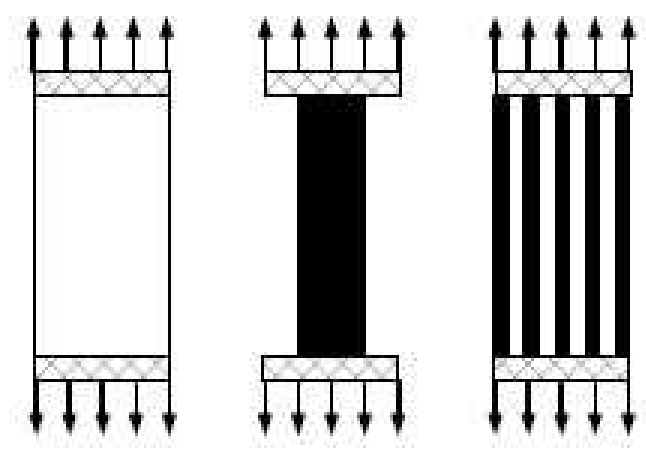

Figura 2.14: Exemplo de não-unicidade da solução. Barra sob tração uniaxial para material com coeficiente de Poisson igual a zero e extremidades (regiões hachuradas) rígidas. 


\subsubsection{Instabilidade de Tabuleiro}

A instabilidade de Tabuleiro é também conhecida na literatura como "checkerboard" devido ao seu padrão de formação de regiões quadriculadas com a alternância de elementos com material e sem material, como podemos ver na figura $(2.15-b)$.

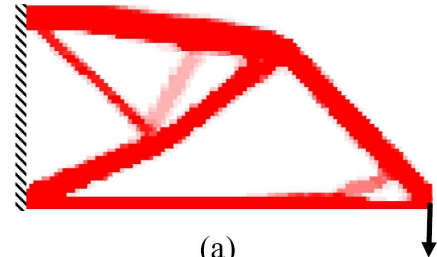

(a)

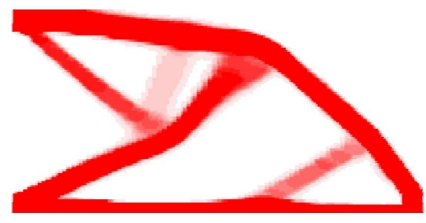

(c)

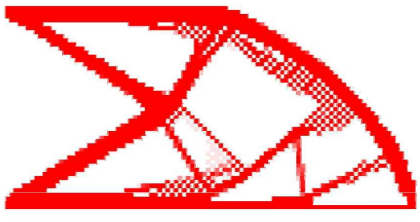

(b)

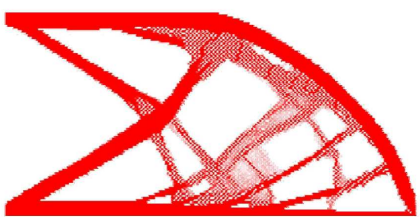

(d)

Figura 2.15: Problema apresentando os problemas de dependência de malha e instabilidade de tabuleiro. (a) Solução com filtro na malha com 4.000 elementos. (b) Solução sem filtro na malha com 4.000 elementos. (c) Solução com filtro na malha com 16.000 elementos. (d) Solução sem filtro na malha com 16.000 elementos.

Esse problema surgiu desde o princípio do desenvolvimento do MOT, e não havia sido previsto por trabalhos anteriores que desenvolveram a base matemática para o trabalho de Bendsøe e Kikuchi (1988), diferentemente de outros problemas como a não-unicidade de solução, que já era esperada.

A origem do problema de instabilidade de tabuleiro é inerente a implementação numérica e não à formulação do MOT. Sua causa é uma conseqüência de que regiões como as que são caracterizadas por essa instabilidade possuem artificialmente uma rigidez mais alta do que uma região homogênea, sendo portanto solução matemática ótima para o problema proposto porém, ela não é aceitável do ponto de vista físico. Essa situação é agravada pela presença de cargas que provocam cisalhamento Bendsøe e Sigmund (2002).

Essa rigidez mais alta do padrão da instabilidade de tabuleiro está associada a utilização de elementos bilineares na solução do MEF como os elementos quadriláteros de quatro nós ou triangulares de três nós.

Uma das possíveis soluções como foi proposta em Jog e Haber (1996) é a utilização de elementos de ordem mais alta como elementos quadriláteros de oito 
ou nove nós, representando dessa forma o campo de deslocamentos com elementos de alta ordem, diferenciando assim a ordem de representação entre os campos de deslocamento e de pseudo-densidades. Porém essa abordagem não é muito conveniente já que a resolução do problema se tornaria demasiadamente mais custosa computacionalmente, então formas mais econômicas são preferidas para a solução desse problema.

Pelo fato da instabilidade de tabuleiro possuir a mesma característica de mudanças bruscas no campo de pseudo-densidades como a solução do problema ótimo discreto, pode ser resolvido pelo mesmo método utilizado para o problema de dependência de malha, através de filtros, que possuem um custo computacional muito inferior a utilização de elementos de ordem mais elevada. Se resolvermos o mesmo problema apresentado na figura 2.15, com um filtro espacial como nos casos (a) e (c), que será detalhado posteriormente no capítulo 4.1.2, podemos obter a solução sem os problemas numéricos de instabilidade de tabuleiro e dependência de malha.

O método de restrição de perímetro, também é um método eficiente no controle da instabilidade de tabuleiro, porém como já foi dito anteriormente, é um método difícil de ser implementado de forma eficiente. Uma abordagem foi proposta por Rahmatalla e Swan (2003) onde a um custo computacional muito baixo reduz-se o padrão de formação da instabilidade e permite que apareçam membros menores. Neste trabalho é proposta uma formulação Q4/Q4, ou seja, com a representação do campo de deslocamentos feita com quatro nós e a representação do campo de pseudo-densidades também feita sobre esses nós, consegue-se com isso minimizar o efeito da instabilidade de tabuleiro. Porém num trabalho posterior os mesmos autores, Rahmatalla e Swan (2004), mostram que essa implementação apresenta efeitos similares à instabilidade de tabuleiro, as quais eles denominam de layering e island e que podem ser traduzidas por formação de camadas e ilhas. A representaçao dos campos de deslocamento e pseudo-densidades feita com o mesmo local e número de nós remete a problemas muito semelhantes, aos que o método buscou resolver, deixando então de ser uma solução eficiênte para a instabilidade de tabuleiro. 


\subsection{Métodos de Otimização Aplicados na Solução do Problema de Otimização Topológica}

Como já referenciado no capítulo 2, o MOT foi proposto por Bendsøe e Kikuchi (1988) e nesse trabalho os autores utilizaram um otimizador baseado Critério de Optimalidade $(\mathrm{CO})$, que será utilizado também no presente trabalho.

Outros métodos utilizados são Programação Linear Seqüencial (PLS) (BEndsøE; Sigmund, 2002), o Método do Lagrangeano Aumentado (MLA) (STUMP, 2006), e o "Method of Moving Asymptotes" (MMA) (SVANBERG, 1987).

\subsubsection{Critério de Optimalidade}

Os métodos baseados no CO, são algoritmos semi-empíricos de atualização das variáveis de projeto que se apóiam na condição de estacionaridade da função Lagrangeana do problema (BENDSøE; SIGMUND, 2002). Esses métodos, também conhecidos simplesmente por CO, são bastante populares no MOT.

Sua principal vantagem é sua grande eficiência, porém é um método muito específico, uma vez que a regra de atualização das variáveis deve ser deduzida para cada tipo de problema. Isso dificulta a aplicação do CO em problemas genéricos, em especial naquelas onde existam muitas restrições.

No caso o critério de atualização que foi implementado é o seguinte:

$$
\rho_{k+1}=\left\{\begin{array}{lc}
\max \left\{(1-\zeta) \rho_{k}, \rho_{\min }\right\} & \text { se } \rho_{k} B_{k}^{\eta} \leq \max \left\{(1-\zeta) \rho_{k}, \rho_{\min }\right\} \\
\min \left\{(1+\zeta) \rho_{k}, 1\right\} & \text { se } \min \left\{(1+\zeta) \rho_{k}, 1\right\} \leq \rho_{k} B_{k}^{\eta} \\
\rho_{k} B_{k}^{\eta} & \text { nos outros casos. }
\end{array}\right.
$$

onde $\rho_{k}$ é o valor das pseudo-densidades para a iteração $k$, e $B_{k}$ é dado por:

$$
B_{k}=\Lambda_{k}^{-1} p \rho(x)^{(p-1)} E_{0} \varepsilon\left(\boldsymbol{u}_{\boldsymbol{k}}\right)^{\boldsymbol{T}} \boldsymbol{\varepsilon}\left(\boldsymbol{u}_{\boldsymbol{k}}\right)
$$

O parâmetro $\eta$ é um valor de ajuste para garantir a convergência e $\zeta$ são os limites móveis utilizados, que limitam as variações que ocorrem em cada iteração. Para mais detalhes ver Bendsøe (1995). 


\section{Método dos Elementos Finitos}

Nessa seção serão apresentadas as formulações dos elementos utilizados na resolução do problema de OT nesse trabalho. Essa apresentação será feita de forma simples não visando prover uma explanação completa sobre o método, e sim apenas uma elucidação das formulações utilizadas. Um detalhamento do método pode ser encontrado em Bathe (1995).

Foram utilizados duas formulações distintas de elementos que serão apresentadas nos ítens seguintes. A primeira se refere a representação do elemento utilizado nas malhas em duas dimensões em elementos quadriláteros isoparamétricos com quatro nós em Estado Plano de Tensão (EPT). A segunda diz respeito a formulação utilizada para a maioria dos problemas apresentados nesse trabalho, que é a formulação do elemento em três dimensões hexaédrico isoparamétrico de oito nós.

\subsection{Formulação do Elemento Isoparamétrico 2D em EPT de Quatro Nós}

Os elementos finitos em duas dimensões são utilizados para resolver 3 tipos de problemas: Estado Plano de Tensão (EPT), Estado Plano de Deformação (EPD) e casos axissimétricos.

No EPT, o elemento de quatro nós diz respeito a domínios bidimensionais onde a terceira dimensão é finita e definida, com carregamentos apenas no plano da própria estrutura, sendo que toda e qualquer força fora do plano é insignificante perto das forças no plano. Um esquema exemplificando o caso é apresentado na figura 3.1. O EPT é o caso utilizado nos exemplos que serão apresentados. 


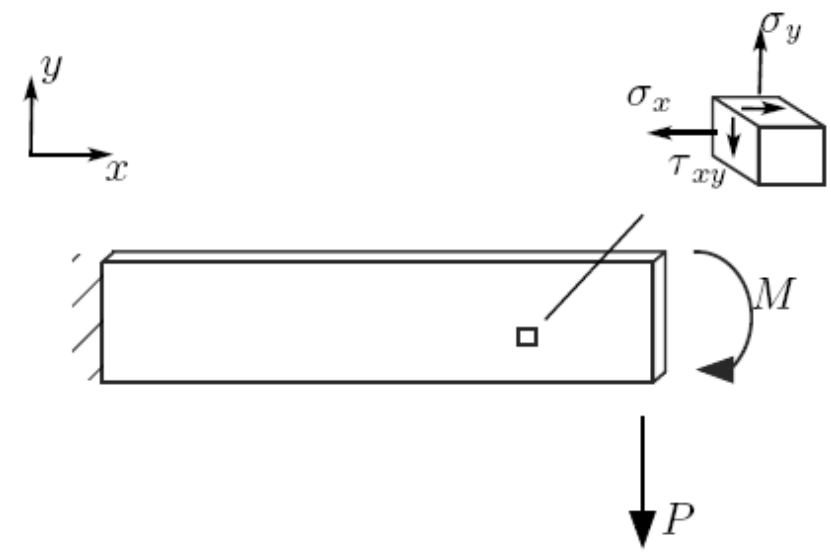

Figura 3.1: Estrutura em EPT e seu respectivo sistema de coordenadas.

$$
\boldsymbol{\sigma}=\left\{\begin{array}{c}
\sigma_{x} \\
\sigma_{y} \\
\sigma_{x y}
\end{array}\right\}
$$

Considerando $\boldsymbol{\sigma}$ o vetor dos componentes do tensor tensão e $\boldsymbol{x}$ o vetor de deslocamentos nodais, podemos escrever que:

$$
x=\left\{\begin{array}{llll}
1 & \xi & \eta & \xi \eta
\end{array}\right\}\left\{\begin{array}{l}
c_{1} \\
c_{2} \\
c_{3} \\
c_{4}
\end{array}\right\}
$$

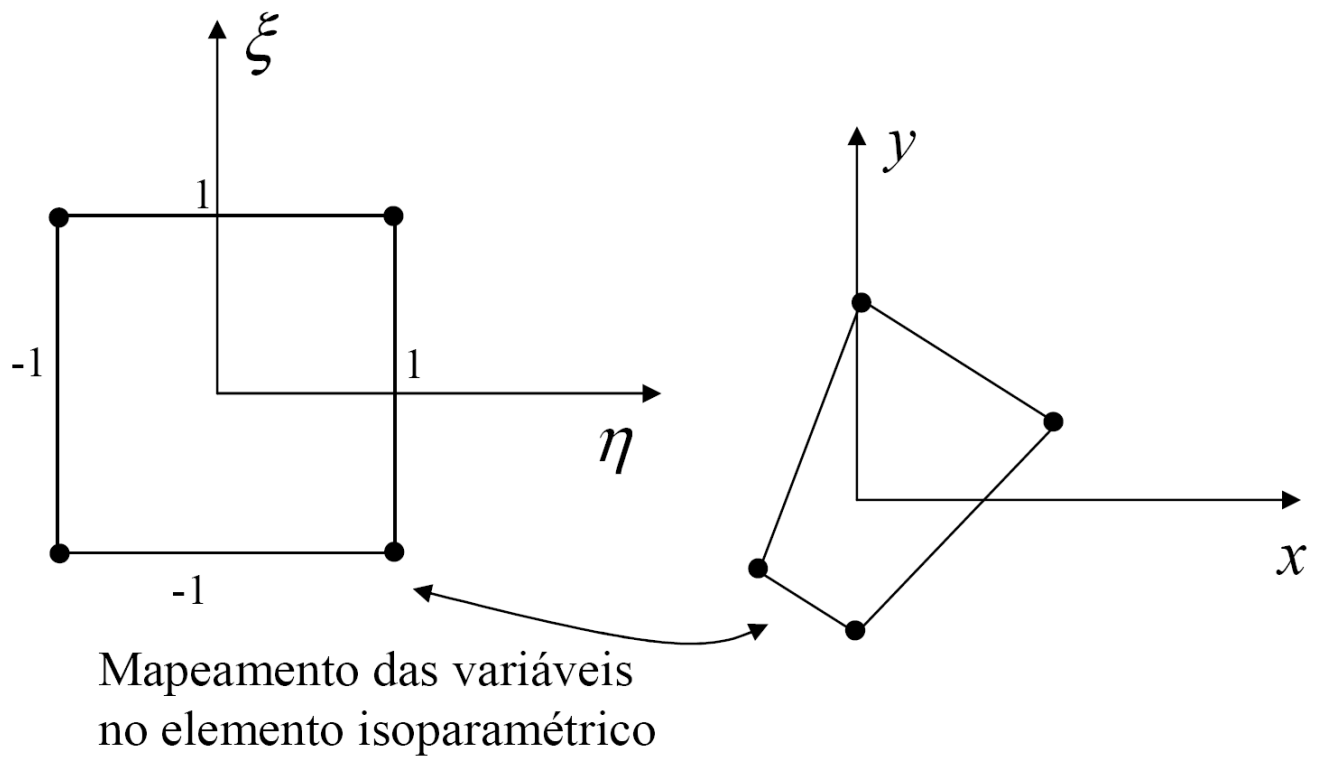

Figura 3.2: Transformação de variáveis locais para as paramétricas. 
sendo $\xi$ e $\eta$ as coordenadas do elemento no sistema de coordenadas paramétricas. Com isso o elemento é considerado isoparamétrico, ou seja, neste elemento as funções de transformação de coordenadas genéricas para o sistema de coordenadas global e as funções de forma do elemento são de mesmo grau. Utilizando as coordenadas dos nós do elemento nas coordenadas paramétricas como representado na figura 3.2 temos:

$$
\left\{\begin{array}{l}
x_{1} \\
x_{2} \\
x_{3} \\
x_{4}
\end{array}\right\}=\left[\begin{array}{cccc}
1 & -1 & -1 & 1 \\
1 & 1 & -1 & -1 \\
1 & 1 & 1 & 1 \\
1 & -1 & 1 & -1
\end{array}\right]\left\{\begin{array}{l}
c_{1} \\
c_{2} \\
c_{3} \\
c_{4}
\end{array}\right\}
$$

Obtemos então as seguintes funções de interpolação:

$$
\begin{aligned}
& N_{1}(\xi, \eta)=\frac{1}{4}(1-r-s+s t)=\frac{1}{4}(1-s)(1-r) \\
& N_{2}(\xi, \eta)=\frac{1}{4}(1+r-s-s t)=\frac{1}{4}(1+s)(1-r) \\
& N_{3}(\xi, \eta)=\frac{1}{4}(1+r+s+s t)=\frac{1}{4}(1+s)(1+r) \\
& N_{4}(\xi, \eta)=\frac{1}{4}(1-r+s-s t)=\frac{1}{4}(1-s)(1+r)
\end{aligned}
$$

em que $N_{i}$ são as funções de interpolação que relacionam o sistema de coordenadas local com o sistema de coordenadas. De forma similar temos para a coordenada y:

$$
y=\left\{\begin{array}{llll}
N_{1}(\xi, \eta) & N_{2}(\xi, \eta) & N_{3}(\xi, \eta) & N_{4}(\xi, \eta)
\end{array}\right\}\left\{\begin{array}{c}
x_{1} \\
x_{2} \\
x_{3} \\
x_{4}
\end{array}\right\}
$$

Podemos então escrever a transformação entre o espaço das coordenadas $(\xi, \eta)$ e o sistema local de coordenadas $(u, v)$, obtendo assim os deslocamentos nodais no sistemas de coordenadas globais.

Sendo $\overline{\boldsymbol{d}}_{\boldsymbol{e}}$ o vetor que representa o deslocamento nos quatro nós do elemento, e $\overline{\boldsymbol{d}}$ o vetor genérico de deslocamento para qualquer ponto dentro do elemento. 


$$
\overline{\boldsymbol{d}}=\left\{\begin{array}{l}
\boldsymbol{u} \\
\boldsymbol{v}
\end{array}\right\}=\left[\begin{array}{cccccccc}
N_{1} & 0 & N_{2} & 0 & N_{3} & 0 & N_{3} & 0 \\
0 & N_{1} & 0 & N_{2} & 0 & N_{3} & 0 & N_{4}
\end{array}\right]\left\{\begin{array}{l}
u_{1} \\
v_{1} \\
u_{2} \\
v_{2} \\
u_{3} \\
v_{3} \\
u_{4} \\
v_{4}
\end{array}\right\}=\boldsymbol{N} \boldsymbol{d}_{\boldsymbol{e}}
$$

Com isso temos que a deformação pode ser escrita como:

$$
\epsilon=B \bar{d}_{e}
$$

sendo,

$$
\boldsymbol{\epsilon}=\left\{\begin{array}{c}
\epsilon_{x} \\
\epsilon_{y} \\
\epsilon_{x y}
\end{array}\right\}=\left\{\begin{array}{c}
\frac{\partial u}{\partial x} \\
\frac{\partial v}{\partial y} \\
\frac{\partial u}{\partial y}+\frac{\partial v}{\partial x}
\end{array}\right\}\left[\begin{array}{cc}
\frac{\partial}{\partial x} & 0 \\
0 & \frac{\partial}{\partial y} \\
\frac{\partial}{\partial x} & \frac{\partial}{\partial y}
\end{array}\right]\left\{\begin{array}{l}
u \\
v
\end{array}\right\}
$$

e que

$$
\boldsymbol{B}=\left[\begin{array}{cc}
\frac{\partial}{\partial x} & 0 \\
0 & \frac{\partial}{\partial y} \\
\frac{\partial}{\partial x} & \frac{\partial}{\partial y}
\end{array}\right]\left[\begin{array}{cccccccc}
N_{1} & 0 & N_{2} & 0 & N_{3} & 0 & N_{3} & 0 \\
0 & N_{1} & 0 & N_{2} & 0 & N_{3} & 0 & N_{4}
\end{array}\right]
$$

obtemos então que

$$
\boldsymbol{B}=\left[\begin{array}{cccccccc}
\frac{\partial N_{1}}{\partial x} & 0 & \frac{\partial N_{2}}{\partial x} & 0 & \frac{\partial N_{3}}{\partial x} & 0 & \frac{\partial N_{4}}{\partial x} & 0 \\
0 & \frac{\partial N_{1}}{\partial y} & 0 & \frac{\partial N_{2}}{\partial y} & 0 & \frac{\partial N_{3}}{\partial y} & 0 & \frac{\partial N_{4}}{\partial y} \\
\frac{\partial N_{1}}{\partial y} & \frac{\partial N_{1}}{\partial x} & \frac{\partial N_{2}}{\partial y} & \frac{\partial N_{2}}{\partial x} & \frac{\partial N_{3}}{\partial y} & \frac{\partial N_{3}}{\partial x} & \frac{\partial N_{4}}{\partial y} & \frac{\partial N_{4}}{\partial x}
\end{array}\right]
$$

Como as funções de forma estão escritas em função das coordenadas locais $\eta$ e $\xi$, para poder relacionar as derivadas é necessário utilizar a matriz Jacobiana

$$
\left[\begin{array}{c}
\frac{\partial N_{i}}{\partial x} \\
\frac{\partial N_{i}}{\partial y}
\end{array}\right]=\boldsymbol{J}^{-1}\left[\begin{array}{c}
\frac{\partial N_{i}}{\partial \eta} \\
\frac{\partial N_{i}}{\partial \xi}
\end{array}\right]
$$

sendo: 


$$
\boldsymbol{J}=\left[\begin{array}{ll}
\frac{\partial x}{\partial \eta} & \frac{\partial y}{\partial \eta} \\
\frac{\partial x}{\partial \xi} & \frac{\partial y}{\partial \xi}
\end{array}\right]
$$

Considerando $\boldsymbol{C}^{\boldsymbol{H}}$ o tensor constitutivo do material utilizado podemos escrever adotando EPT:

$$
\boldsymbol{C}^{\boldsymbol{H}}=\frac{E}{1-\nu^{2}}\left[\begin{array}{ccc}
1 & \nu & 0 \\
\nu & 1 & 0 \\
0 & 0 & \frac{1-\nu}{2}
\end{array}\right]
$$

Calcula-se a energia total de deformação de um elemento quadrilátero de quatro nós da seguinte forma:

$$
\begin{aligned}
U_{e} & =\frac{1}{2} \int_{A_{e}} \boldsymbol{\epsilon}^{\boldsymbol{T}} \boldsymbol{C}^{\boldsymbol{H}} \boldsymbol{\epsilon} d A \\
& =\frac{1}{2} \int_{A_{e}}\left\{\epsilon_{x} \quad \epsilon_{y} \epsilon_{x y}\right\}\left[\begin{array}{lll}
D_{11} & D_{21} & D_{31} \\
D_{12} & D_{22} & D_{32} \\
D_{13} & D_{23} & D_{33}
\end{array}\right]\left\{\begin{array}{c}
\epsilon_{x} \\
\epsilon_{y} \\
\epsilon_{x y}
\end{array}\right\} h d A \\
& =\frac{1}{2} \int_{A_{e}}\left(\boldsymbol{B} \overline{\boldsymbol{d}}_{\boldsymbol{e}}\right)^{\boldsymbol{T}} \boldsymbol{C}^{\boldsymbol{H}}\left(\boldsymbol{B} \overline{\boldsymbol{d}}_{\boldsymbol{e}}\right) h d A \\
& =\frac{1}{2} \overline{\boldsymbol{d}}_{\boldsymbol{e}}^{\boldsymbol{T}} \int_{A_{e}} \boldsymbol{B}^{\boldsymbol{T}} \boldsymbol{C}^{\boldsymbol{H}} \boldsymbol{B} h d A \overline{\boldsymbol{d}}_{\boldsymbol{e}} \\
& =\frac{1}{2} \overline{\boldsymbol{d}}_{\boldsymbol{e}}^{\boldsymbol{T}} \boldsymbol{K}_{\boldsymbol{e}} \overline{\boldsymbol{d}}_{\boldsymbol{e}}
\end{aligned}
$$

na qual a matriz de rigidez é definida como:

$$
\boldsymbol{K}_{\boldsymbol{e}}=\int_{A_{e}} \boldsymbol{B}^{\boldsymbol{T}} \boldsymbol{C}^{\boldsymbol{H}} \boldsymbol{B} h d A=\int_{-1}^{1} \int_{-1}^{1} \boldsymbol{B}^{\boldsymbol{T}} \boldsymbol{C}^{\boldsymbol{H}} \boldsymbol{B} h \operatorname{det} \boldsymbol{J} d \xi d \eta
$$

Para calcular a expressão 3.15 da matriz de rigidez definida, utiliza-se um método de integração numérica, uma vez que a integral não pode ser calculada analiticamente, a menos que o elemento seja um retângulo. Para essa integração é utilizada o método da quadratura Gaussiana que pode ser descrito da seguinte forma:

$$
\int_{-1}^{1} f(\xi) d \xi \approx \sum_{i=1}^{n} w_{i} f\left(\xi_{i}\right)
$$


sendo $w_{i}$ os pesos e $\xi_{i}$ os pontos nos quais se calcula a função, na qual $n$ é o número desses pontos utilizados no cálculo. Numa integração pelo método da Quadratura Gaussiana em que são utilizados $n$ pontos, uma função de $(2 n-1)$ graus pode ser interpolada de forma exata. Como a integral da matriz de rigidez pode ser considerada quadrática em $\xi$ e $\eta$, precisamos utilizar dois pontos em cada direção, isto é, quatro pontos de integração para que o problema plano seja integrado de forma exata.

Calculada a matriz de rigidez local, esta é então inserida na matriz de rigidez global $\boldsymbol{K}$, através da conectividade de cada elemento, que associa os elementos aos graus de liberdade globais. Dessa forma é possível escrever o sistema linear (3.17) que descreve o problema como um todo.

$$
K \bar{d}=f
$$

\subsection{Formulação do Elemento Isoparamétrico 3D de Oito Nós}

No caso da formulação do MEF em três dimensões, os modelos são representados com elementos hexaédricos com oito nós. Apenas carregamentos com forças são utilizados nesse tipo de modelagem, e momentos são representados através de binários aplicados na estrutura.

A representação em três dimensões dos problemas aumenta o número de nós utilizados para a solução dos problemas, o que os torna mais custosos computacionalmente, porém em contrapartida permite uma representação de formas que não seriam possíveis de se representar apenas nos casos em duas dimensões.

Sendo o $\boldsymbol{\sigma}$ o vetor das componentes da tensão em um elemento, podemos definí-lo da seguinte forma:

$$
\boldsymbol{\sigma}=\left\{\begin{array}{c}
\sigma_{x} \\
\sigma_{y} \\
\sigma_{z} \\
\tau_{y z} \\
\tau_{z x} \\
\tau_{x y}
\end{array}\right\}=\boldsymbol{D}\left\{\begin{array}{c}
\epsilon_{x} \\
\epsilon_{y} \\
\epsilon_{z} \\
\gamma_{y z} \\
\gamma_{z x} \\
\gamma_{x y}
\end{array}\right\}=\boldsymbol{D} \boldsymbol{\epsilon}
$$

sendo 


$$
\boldsymbol{D}=\frac{E}{(1-2 \nu)(1+\nu)}\left[\begin{array}{cccccc}
1-\nu & \nu & \nu & 0 & 0 & 0 \\
\nu & 1-\nu & \nu & 0 & 0 & 0 \\
\nu & \nu & 1-\nu & 0 & 0 & 0 \\
0 & 0 & 0 & \frac{1-2 \nu}{2} & 0 & 0 \\
0 & 0 & 0 & 0 & \frac{1-2 \nu}{2} & 0 \\
0 & 0 & 0 & 0 & 0 & \frac{1-2 \nu}{2}
\end{array}\right]
$$

em que $\boldsymbol{D}$ é a matriz inversa da matriz de flexibilidade $\boldsymbol{C}^{\boldsymbol{H}}$.

$$
\left\{\begin{array}{c}
\epsilon_{x} \\
\epsilon_{y} \\
\epsilon_{z} \\
\gamma_{y z} \\
\gamma_{z x} \\
\gamma_{x y}
\end{array}\right\}=\boldsymbol{C}^{\boldsymbol{H}}\left\{\begin{array}{c}
\sigma_{x} \\
\sigma_{y} \\
\sigma_{z} \\
\tau_{y z} \\
\tau_{z x} \\
\tau_{x y}
\end{array}\right\}=\boldsymbol{C} \boldsymbol{\sigma}
$$

Temos as seguintes funções de forma para o elemento em questão:

$$
\begin{aligned}
& N_{1}=\frac{(-1+r)(-1+s)(1-t)}{8} \\
& N_{2}=\frac{(1+r)(-1+s)(-1+t)}{8} \\
& N_{3}=\frac{(1+r)(1+s)(1-t)}{8} \\
& N_{4}=\frac{(-1+r)(1+s)(-1+t)}{8} \\
& N_{5}=\frac{(-1+r)(-1+s)(1+t)}{8} \\
& N_{6}=\frac{(1+r)(1-s)(1+t)}{8} \\
& N_{7}=\frac{(1+r)(1+s)(1+t)}{8} \\
& N_{8}=\frac{(1-r)(1+s)(1+t)}{8}
\end{aligned}
$$

O vetor deslocamento é dado por:

$$
\overline{\boldsymbol{d}}=\left\{\begin{array}{lll}
u_{x} & u_{y} & u_{z}
\end{array}\right\}
$$

e pode ser aproximado por 


$$
\bar{d}=N \bar{d}_{e}
$$

sendo,

$$
\begin{aligned}
\overline{\boldsymbol{d}}_{\boldsymbol{t}}^{\boldsymbol{T}} & =\left\{\begin{array}{llllllllll}
u_{x 1} & u_{y 1} & u_{z 1} & u_{x 2} & u_{y 2} & u_{z 2} & \cdots & u_{x 8} & u_{y 8} & u_{z 8}
\end{array}\right\} \\
& =\left\{\begin{array}{llllllllll}
u_{1} & v_{1} & w_{1} & u_{2} & v_{2} & w_{2} & \cdots & u_{8} & v_{8} & w_{8}
\end{array}\right\}
\end{aligned}
$$

usando essa aproximação, o vetor de deformação $\epsilon$ é aproximado por:

$$
\boldsymbol{\epsilon}=\left\{\begin{array}{c}
\epsilon_{x} \\
\epsilon_{y} \\
\epsilon_{z} \\
\gamma_{y z} \\
\gamma_{z x} \\
\gamma_{x y}
\end{array}\right\}=\left[\begin{array}{ccc}
\frac{\partial}{\partial x} & 0 & 0 \\
0 & \frac{\partial}{\partial y} & 0 \\
0 & 0 & \frac{\partial}{\partial z} \\
0 & \frac{\partial}{\partial z} & \frac{\partial}{\partial y} \\
\frac{\partial}{\partial z} & 0 & \frac{\partial}{\partial x} \\
\frac{\partial}{\partial y} & \frac{\partial}{\partial x} & 0
\end{array}\right]\left\{\begin{array}{c}
u \\
v \\
w
\end{array}\right\}=\boldsymbol{\partial} \overline{\boldsymbol{d}} \cong \boldsymbol{\partial} \boldsymbol{N} \overline{\boldsymbol{d}}_{\boldsymbol{e}}=\boldsymbol{B} \overline{\boldsymbol{d}}_{\boldsymbol{e}}
$$

em que $\boldsymbol{B}$ é uma matriz 6 por 24 definida por

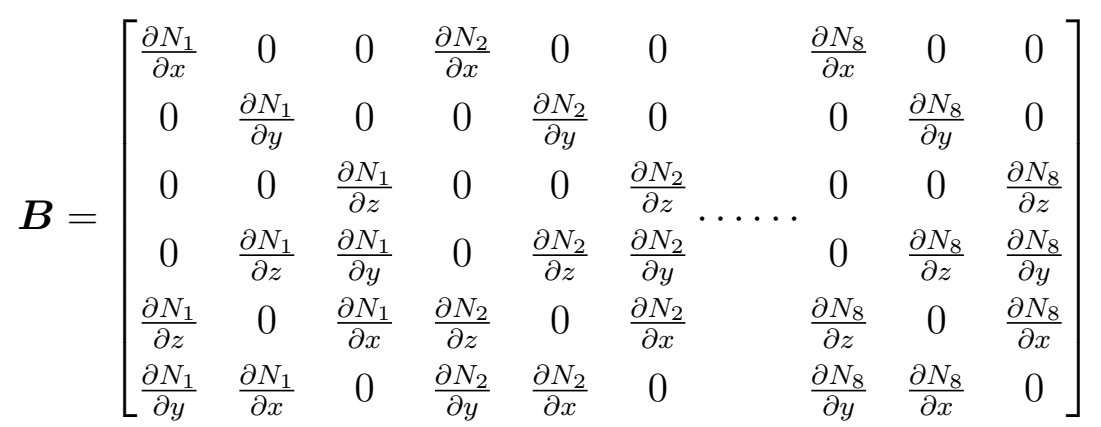

Como temos o Jacobiano $\boldsymbol{J}$ dado por:

$$
\boldsymbol{J}=\left[\begin{array}{lll}
\frac{\partial x}{\partial \eta} & \frac{\partial y}{\partial \eta} & \frac{\partial z}{\partial \eta} \\
\frac{\partial x}{\partial \xi} & \frac{\partial y}{\partial \xi} & \frac{\partial z}{\partial \xi} \\
\frac{\partial x}{\partial \zeta} & \frac{\partial y}{\partial \zeta} & \frac{\partial z}{\partial \zeta}
\end{array}\right]
$$

podemos escrever então a integral para a energia interna: 


$$
\begin{aligned}
U_{e} & =\frac{1}{2} \int_{V_{e}} \boldsymbol{\epsilon}^{\boldsymbol{T}} \boldsymbol{D} \boldsymbol{\epsilon} d V \\
& =\frac{1}{2} \int_{V_{e}}\left(\boldsymbol{B} \overline{\boldsymbol{d}}_{\boldsymbol{e}}\right)^{T} \boldsymbol{D} \boldsymbol{B} \overline{\boldsymbol{d}}_{\boldsymbol{e}} d V \\
& =\frac{1}{2} \overline{\boldsymbol{d}}_{\boldsymbol{e}}^{\boldsymbol{T}} \int_{V_{e}} \boldsymbol{B}^{\boldsymbol{T}} \boldsymbol{D} \boldsymbol{B} d V \overline{\boldsymbol{d}}_{\boldsymbol{e}} \\
& =\frac{1}{2} \overline{\boldsymbol{d}}_{\boldsymbol{e}}^{\boldsymbol{T}} \int_{-1}^{1} \int_{-1}^{1} \int_{-1}^{1} \boldsymbol{B}^{\boldsymbol{T}} \boldsymbol{D} \boldsymbol{B} \operatorname{det} \boldsymbol{J} d \xi d \eta d \zeta \overline{\boldsymbol{d}}_{\boldsymbol{e}} \\
& =\frac{1}{2} \overline{\boldsymbol{d}}_{\boldsymbol{e}}^{\boldsymbol{T}} \boldsymbol{K}_{\boldsymbol{e}} \overline{\boldsymbol{d}}_{\boldsymbol{e}}
\end{aligned}
$$

na qual temos então que:

$$
\boldsymbol{K}_{\boldsymbol{e}}=\int_{-1}^{1} \int_{-1}^{1} \int_{-1}^{1} \boldsymbol{B}^{\boldsymbol{T}} \boldsymbol{D} \boldsymbol{B} \operatorname{det} \boldsymbol{J} d \xi d \eta d \zeta
$$

Fazendo a integração Gaussiana:

$$
\begin{aligned}
\boldsymbol{K}_{\boldsymbol{e}} & =\int_{-1}^{1} \int_{-1}^{1} \int_{-1}^{1} \boldsymbol{B}^{\boldsymbol{T}} \boldsymbol{D} \boldsymbol{B} \operatorname{det} \boldsymbol{J} d \xi d \eta d \zeta \\
& \left.\approx \sum_{i=1}^{2} \sum_{i=1}^{2} \sum_{i=1}^{2}\left(\boldsymbol{B}^{\boldsymbol{T}} \boldsymbol{D} \boldsymbol{B} \operatorname{det} \boldsymbol{J}\right)\right|_{(\xi, \eta, \zeta)=\left(a_{i}, a_{i}, a_{i}\right)}
\end{aligned}
$$

Podemos encontrar a matriz de rigidez de cada elemento e assim compor a matriz de rigidez global do problema. Para evitar um problema conhecido deste tipo de formulação de elemento relacionado com a rigidez ao cisalhamento, será utilizado o método de integração reduzida (COOK et al., 1995). Nesse caso a matriz de elasticidade é decomposta em suas componentes: hidrostática, volumétrica, e cada uma das três componentes de cisalhamento, e então cada uma tem sua integração numérica feita separadamente, como podemos ver na equação (3.31). 


$$
\begin{aligned}
& \boldsymbol{K}_{\boldsymbol{e}}=\int_{-1}^{1} \int_{-1}^{1} \int_{-1}^{1} \boldsymbol{B}^{\boldsymbol{T}} \boldsymbol{D} \boldsymbol{B} \operatorname{det} \boldsymbol{J} d \xi d \eta d \zeta \\
& =\int_{-1}^{1} \int_{-1}^{1} \int_{-1}^{1} \boldsymbol{B}^{\boldsymbol{T}} \boldsymbol{D}_{\boldsymbol{D}} \boldsymbol{B} \operatorname{det} \boldsymbol{J} d \xi d \eta d \zeta+\int_{-1}^{1} \int_{-1}^{1} \int_{-1}^{1} \boldsymbol{B}^{\boldsymbol{T}} \boldsymbol{D}_{\boldsymbol{V}} \boldsymbol{B} \operatorname{det} \boldsymbol{J} d \xi d \eta d \zeta \\
& +\int_{-1}^{1} \int_{-1}^{1} \int_{-1}^{1} \boldsymbol{B}^{\boldsymbol{T}} \boldsymbol{D}_{\boldsymbol{y} \boldsymbol{z}} \boldsymbol{B} \operatorname{det} \boldsymbol{J} d \xi d \eta d \zeta+\int_{-1}^{1} \int_{-1}^{1} \int_{-1}^{1} \boldsymbol{B}^{\boldsymbol{T}} \boldsymbol{D}_{\boldsymbol{z} \boldsymbol{x}} \boldsymbol{B} \operatorname{det} \boldsymbol{J} d \xi d \eta d \zeta \\
& +\int_{-1}^{1} \int_{-1}^{1} \int_{-1}^{1} \boldsymbol{B}^{\boldsymbol{T}} \boldsymbol{D}_{\boldsymbol{x} \boldsymbol{y}} \boldsymbol{B} \operatorname{det} \boldsymbol{J} d \xi d \eta d \zeta \\
& \left.\approx \sum_{i=1}^{2} \sum_{j=1}^{2} \sum_{k=1}^{2}\left(\boldsymbol{B}^{\boldsymbol{T}} \boldsymbol{D}_{\boldsymbol{D}} \boldsymbol{B} \operatorname{det} \boldsymbol{J}\right)\right|_{(\xi, \eta, \zeta)=\left(a_{i}, a_{j}, a_{k}\right)} \\
& +\left.\sum_{i=1}^{2} \sum_{j=1}^{2} \sum_{k=1}^{2}\left(\boldsymbol{B}^{\boldsymbol{T}} \boldsymbol{D}_{\boldsymbol{V}} \boldsymbol{B} \operatorname{det} \boldsymbol{J}\right)\right|_{(\xi, \eta, \zeta)=\left(a_{i}, a_{j}, a_{k}\right)} \\
& +\left.\sum_{i=1}^{2} 4 \boldsymbol{B}^{\boldsymbol{T}} \boldsymbol{D}_{\boldsymbol{y} \boldsymbol{z}}(\boldsymbol{B} \operatorname{det} \boldsymbol{J})\right|_{(\xi, \eta, \zeta)=\left(a_{i}, 0,0\right)} \\
& +\left.\sum_{j=1}^{2} 4 \boldsymbol{B}^{\boldsymbol{T}} \boldsymbol{D}_{\boldsymbol{z} \boldsymbol{x}}(\boldsymbol{B} \operatorname{det} \boldsymbol{J})\right|_{(\xi, \eta, \zeta)=\left(0, a_{j}, 0\right)} \\
& +\left.\sum_{k=1}^{2} 4\left(\boldsymbol{B}^{\boldsymbol{T}} \boldsymbol{D}_{\boldsymbol{x} \boldsymbol{y}} \boldsymbol{B} \operatorname{det} \boldsymbol{J}\right)\right|_{(\xi, \eta, \zeta)=\left(0,0, a_{k}\right)}
\end{aligned}
$$

em que a matriz $\boldsymbol{D}$ foi decomposta como apresentado abaixo.

$$
\begin{gathered}
\boldsymbol{D}=\boldsymbol{D}_{\boldsymbol{D}}+\boldsymbol{D}_{\boldsymbol{V}}+\boldsymbol{D}_{\boldsymbol{y z}}+\boldsymbol{D}_{\boldsymbol{z} \boldsymbol{x}}+\boldsymbol{D}_{\boldsymbol{x} \boldsymbol{y}} \\
\boldsymbol{D}_{\boldsymbol{D}}=\frac{E}{3(1-2 \nu)(1+\nu)}\left[\begin{array}{cccccc}
2-4 \nu & -1+2 \nu & -1+2 \nu & 0 & 0 & 0 \\
-1+2 \nu & 2-4 \nu & -1+2 \nu & 0 & 0 & 0 \\
-1+2 \nu & -1+2 \nu & 2-4 \nu & 0 & 0 & 0 \\
0 & 0 & 0 & 0 & 0 & 0 \\
0 & 0 & 0 & 0 & 0 & 0 \\
0 & 0 & 0 & 0 & 0 & 0
\end{array}\right]
\end{gathered}
$$




$$
\begin{gathered}
\boldsymbol{D}_{\boldsymbol{V}}=\frac{E}{3(1-2 \nu)}\left[\begin{array}{llllll}
1 & 1 & 1 & 0 & 0 & 0 \\
1 & 1 & 1 & 0 & 0 & 0 \\
1 & 1 & 1 & 0 & 0 & 0 \\
0 & 0 & 0 & 0 & 0 & 0 \\
0 & 0 & 0 & 0 & 0 & 0 \\
0 & 0 & 0 & 0 & 0 & 0
\end{array}\right] \\
\boldsymbol{D}_{\boldsymbol{y} \boldsymbol{z}}=\frac{E}{2(1+\nu)}\left[\begin{array}{llllll}
0 & 0 & 0 & 0 & 0 & 0 \\
0 & 0 & 0 & 0 & 0 & 0 \\
0 & 0 & 0 & 0 & 0 & 0 \\
0 & 0 & 0 & 1 & 0 & 0 \\
0 & 0 & 0 & 0 & 0 & 0 \\
0 & 0 & 0 & 0 & 0 & 0
\end{array}\right] \\
\boldsymbol{D}_{\boldsymbol{z} \boldsymbol{x}}=\frac{E}{2(1+\nu)}\left[\begin{array}{llllll}
0 & 0 & 0 & 0 & 0 & 0 \\
0 & 0 & 0 & 0 & 0 & 0 \\
0 & 0 & 0 & 0 & 0 & 0 \\
0 & 0 & 0 & 0 & 0 & 0 \\
0 & 0 & 0 & 0 & 1 & 0 \\
0 & 0 & 0 & 0 & 0 & 0
\end{array}\right] \\
\left.0 \begin{array}{llllll}
0 & 0 & 0 & 0 & 0 & 0 \\
0 & 0 & 0 & 0 & 0 & 0 \\
0 & 0 & 0 & 0 & 0 & 0 \\
0 & 0 & 0 & 0 & 0 & 0 \\
0 & 0 & 0 & 0 & 0 & 0 \\
0 & 0 & 0 & 0 & 0 & 1
\end{array}\right]
\end{gathered}
$$




\section{Filtros, Controles de Gradiente e Técnica de Projeção de Domínios}

Para se obter as restrições de manufatura desejadas, existem dois caminhos utilizados. O primeiro é restringir o problema de otimização através da inclusão de restrições que imponham as condições desejadas no problema de otimização, o que aumentaria a complexidade do problema, e fazendo com que o mesmo se torne mais custoso computacionalmente. A outra opção que será a adotada neste trabalho e diz respeito à restrição através de técnicas de controle das soluções como filtros, controles de gradiente e projeção de domínios. Estas restrições permitem obter os resultados esperados ocasionando um aumento no custo computacional menor do que a alteração da formulação do problema.

Os métodos de filtragem de OT, são na maior parte dos casos baseados em métodos de filtragem de imagens e utilizam os mesmos princípios destes, o que os leva a serem métodos menos custosos computacionalmente e conseqüentemente mais rápidos, embora não consigam garantir um controle efetivo das variáveis de projeto.

Os filtros são mais utilizados do que os métodos de controle de gradiente na literatura hoje em dia (BENDSøE; SIGMUND, 2002), isto ocorre devido a sua facilidade de implementação e velocidade de execução de soluções. Sua formulação consiste em aplicar uma função transformação ao valor da variável de projeto de cada elemento, alterando assim o seu valor.

Controles de gradiente são utilizados para obter uma variação espacial do campo de pseudo-densidades com uma distribuição mais condizente, que caminha para soluções mais aceitáveis, ou seja, sem problemas como a instabilidade de tabuleiro, regiões cinza e falta de unicidade da solução. Apesar de serem utilizados controles de gradiente também em filtros, chamaremos de controles de gradientes neste trabalho apenas a utilização destes controles como restrições diretas na 
formulação do problema de otimização.

Como analisado em Cardoso (2000) e em Cardoso e Fonseca (1999) o controle de gradiente altera a definição do problema, e é uma solução mais correta do ponto de vista matemático. Porém é extremamente dispendiosa computacionalmente, já que sua implementação aumenta substancialmente o número de variáveis.

Já o método de projeção de gradientes aplicado por Guest, Prevost e Belytschko (2004) e Le (2006) utiliza a transformação do campo de pseudodensidades em um campo de variáveis através de um mapeamento definido de forma a garantir que o espaço das variáveis de projeto não possuam soluções indesejadas, ou seja, com um mapeamento das variáveis feito de forma correta é possível garantir restrições com um alto grau de complexidade.

\subsection{Filtros}

Para que o campo de pseudo-densidades volumétricas tenha uma distribuição mais suave ao longo do domínio, aplica-se um operador matemático que impeça variações bruscas, como por exemplo a variável recebe a média dos valores das variáveis dos elementos vizinhos. Esse tipo de abordagem é utilizado em diversas aplicações como em filtros de imagens, filtros elétricos passa alta, passa baixa e passa banda. A transformação causada pelo filtro pode ser representada da seguinte forma

$$
g(x, y)=f(x, y) \otimes h(x, y)
$$

em que $f(x, y)$ é o domínio original da variável analisada. Se o domínio for uma imagem o valor filtrado é a cor do pixel por exemplo, $g(x, y)$ é o domínio alterado e $h(x, y)$ é o operador transformação que realiza a filtragem. A operação de convolução, representada pelo símbolo $\otimes$ corresponde a aplicação do operador sobre o campo de variáveis original. Um tutorial sobre os conceitos de tratamento de imagem pode ser encontrado em http://www.ph.tn.tudelft.nl/Courses/ FIP/ noframes/ fip.html. Esses conceitos são muito semelhantes aos filtros aqui apresentados.

Para a OT classificam-se os métodos de filtragem pela forma com a qual um elemento de referência afeta e é afetado pelos seus vizinhos. Os filtros de vizinhança fixa, são aqueles em que somente os vizinhos de nó e/ou aresta são relevantes para a determinação da pseudo-densidade do elemento de referência, e 
os filtros espaciais são aqueles em que todos os elementos dentro de um intervalo pré-determinado em torno do elemento central são considerados.

Os métodos de filtragem do campo de pseudo-densidades são implementados para controlar a complexidade do leiaute obtido e também eliminar os problemas numéricos descritos anteriormente no capítulo 2 como a instabilidade de tabuleiro. Quanto maior for a área de atuação do filtro em torno de seu elemento de referência, mais simples será o leiaute obtido pois ficará restrito o surgimento de ramificações mais estreitas, assim como o problema da instabilidade de tabuleiros. Neste trabalho, que possui como foco simplificar o leiaute obtido ao final do processo de maneira a garantir a fabricação de forma simples da solução encontrada, os diversos tipos de métodos de filtragem, juntamente com outras técnicas aqui descritas serão explorados, para que com isso se consiga atingir soluções com condições pré-estabelecidas.

A seguir serão detalhados os métodos de filtragem mais comuns na literatura sobre o MOT.

\subsubsection{Filtragem de Vizinhança Fixa}

São os filtros mais simples de serem implementados, pois utilizam apenas os elementos que são vizinhos diretos, ou seja, aqueles que dividem nós e/ou arestas com os elementos de referência. Tem uma relação direta com os filtros de imagens, e como conseqüência tem efetividade apenas em malhas estruturadas e uniformes como as imagens, que são formadas por pixels. Apesar de sua simplicidade de implementação, sua aplicabilidade se restringe muito à casos em que a malha é estruturada e uniforme. A transformação aplicada por esse tipo de filtro em geral consiste em se obter uma média ponderada da pseudo-densidade, levando em consideração a pseudo-densidade dos elementos vizinhos. Os pesos de ponderação e a quantidade de vizinhos considerados são variáveis de cada tipo de implementação. Uma de suas principais desvantagens é o fato de não conseguir gerar soluções que sejam independentes do tamanho da malha, já que este filtro sempre considera a mesma quantidade de elementos em torno do elemento de referência, não sendo relevante o tamanho deste.

Historicamente, o primeiro filtro de imagem utilizado na OT foi implementado por Bendsøe (1995) e foi baseado em um superelemento, formado por quatro elementos quadrangulares de baixa ordem (apenas 4 nós por elemento). Esse filtro, previamente utilizado para solucionar o problema de instabilidade de tabuleiro 
em problemas de Stokes, simplesmente pondera as pseudo-densidades dos quatro elementos formadores do superelemento e considera essa pseudo-densidade ponderada como a pseudo-densidade dos quatro elementos em questão. Como este filtro é aplicado diretamente sobre a distribuição do campo de pseudo-densidades e não sobre seu gradiente, ele impõe uma alteração artificial da distribuição da variável de projeto (SWAN; KOSAKA, 1997).

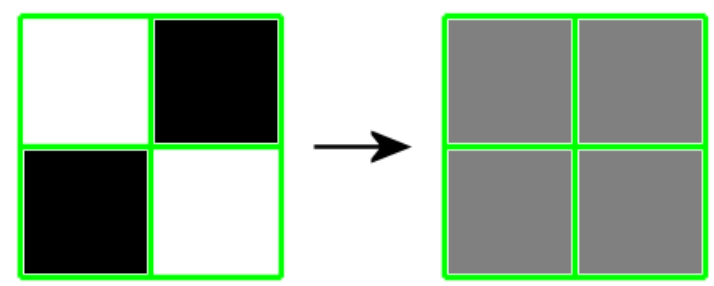

Figura 4.1: Super elemento composto por 4 elementos simples, e o efeito do filtro sobre suas pseudo-densidades.

No mesmo estilo do filtro descrito anteriormente existe o filtro $3 \times 3$ (CARDOSO, 2000) que também é bastante utilizado. Ele possui as mesmas desvantagens descritas para o filtro anterior. Seu operador é dado pela equação 4.2

$$
\boldsymbol{H}=\frac{1}{(b+2)^{2}}\left[\begin{array}{ccc}
1 & b & 1 \\
b & b^{2} & b \\
1 & b & 1
\end{array}\right]
$$

em que $b \in[1, \infty]$, sendo que quanto maior o valor de $b$, menor é o peso dado para os vizinhos. A expressão para este filtro é:

$$
G(i, j)=\sum_{n=1}^{3} \sum_{n=1}^{3} F(m, n) H(m+i-C, n+j-C)
$$

Utiliza-se o valor $C=2$ dado pela expressão 4.4. $G(i, j)$ é o valor filtrado do campo de pseudo-densidades $F(i, j)$ e $(i, j)$ é o centro do elemento no qual o filtro está sendo aplicado, como indicado na figura 4.2 .

$$
C=\frac{c+1}{2}
$$

onde um valor $c=3$ (tamanho do filtro) é utilizado para o filtro $3 \times 3$. Se o valor do parâmetro $b$ tende a infinito, $G(i, j)$ tende a $F(i, j)$. Esse filtro é usualmente aplicado na distribuição das variáveis de projeto ou na distribuição dos gradientes 


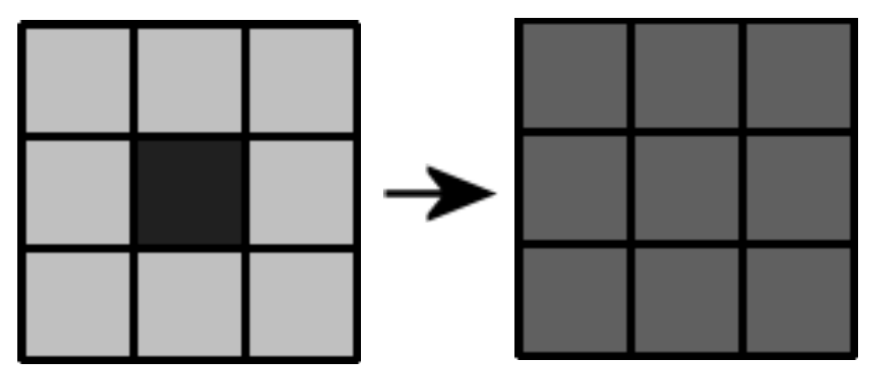

Figura 4.2: Elemento em que o filtro está atuando no filtro de vizinhança fixa $3 \times 3$.

da função objetivo.

Já o filtro de vizinhança fixa proposto por Fonseca e Kikuchi (1998), permite um controle da complexidade da topologia,sendo baseado no número de elementos necessários para ocorrer uma inversão completa $(0-1)$ da variável de projeto. Esse filtro, apesar de se restringir a malhas retangulares e regulares, introduziu o conceito de controle do valor do gradiente ao invés do controle da variável, o que deu origem aos controles de gradiente descritos nesse texto na seção 4.2.

\subsubsection{Filtros Espaciais}

Os filtros espaciais diferem dos filtros de vizinhança fixa principalmente porque eles tem uma área de varredura em torno do elemento central. Essa característica faz com que os formatos dos elementos sejam abstraídos, e como conseqüência fornece uma independência da malha. Basta imaginar um filtro espacial circular de raio fixo utilizado com sucessivos refinos de malha, conforme discutido por Swan C. e Kosaka (1997), Cardoso e Fonseca (1999) e Sigmund (2007). Outra vantagem dos filtros espaciais, é permitir um relativo controle da complexidade da estrutura, já que a restrição do filtro faz com que se crie um tamanho mínimo de massa agrupada, ou seja, quanto maior a área de varredura, maior a área de massa concentrada sem furos internos e menor a complexidade da estrutura.

O filtro espacial mais simples é o filtro espacial linear, onde são considerados os elementos vizinhos que se encontram dentro de um raio $R_{\max }$, em torno do elemento central. Este valor é conhecido como raio de abrangência do filtro. Os pesos da média ponderada são calculados por uma relação linear, inversamente proporcional com a distância,

$$
W_{i}=R_{\max }-R_{i j},\left\{i \in n v \mid R_{i j} \leq R_{\max }\right\}, j=1, \ldots, n v
$$


onde $R_{i j}$, é a distância entre centróides do elemento central $(i)$ e do elemento vizinho $(j)$. Somente elementos com o centróide dentro do raio de abrangência do filtro são considerados, ver figura 4.3.

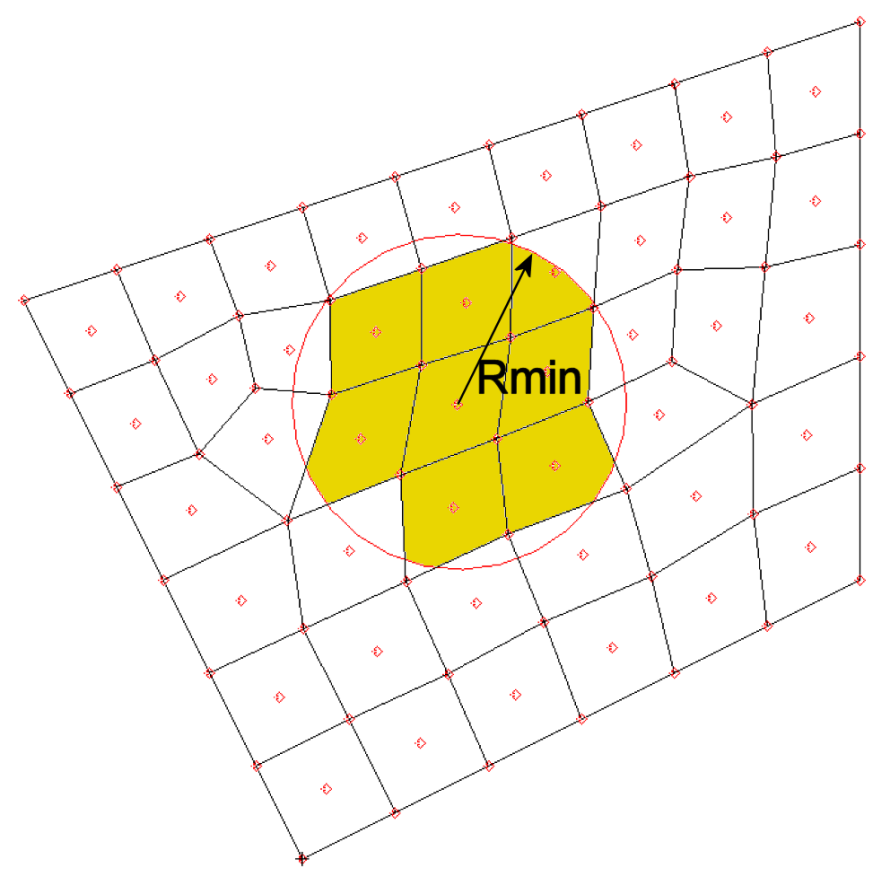

Figura 4.3: Abrangência do filtro espacial em uma malha irregular. Somente os elementos com o centróide dentro do raio de abrangência do filtro são considerados.

O valor filtrado da variável de projeto do elemento central será:

$$
\widehat{a}=\frac{\sum W_{i} a_{i}}{\sum W_{i}}
$$

Experiências com pesos não-lineares não demonstraram convergência para os mesmos valores obtidos com filtros lineares, indicando que o resultado é altamente dependente do processo de filtragem utilizado o que é natural de se imaginar já que o peso de influência de cada um dos elementos vizinhos será diferente, porém continuará atendendo ao controle necessário para uma solução livre dos problemas numéricos já citados. Diferentes métodos de filtragem irão resultar em diferentes topologias.

Sigmund (1997) aplica o processo de filtragem na distribuição dos gradientes da função objetivo. Os pesos calculados por (4.7) e o filtro são aplicados sobre a distribuição de pseudo-densidades, 


$$
\widehat{\rho_{k}}=\frac{1}{\sum_{j=1}^{n v} W_{j}} \sum_{i=1}^{n v} W_{i} \rho_{i}
$$

e sobre as derivadas da função objetivo

$$
\frac{\widehat{\partial f}}{\partial \rho_{k}}=\frac{1}{\rho_{k} \sum_{j=1}^{n v} W_{j}} \sum_{i=1}^{n v} W_{i} \rho_{i} \frac{\partial f}{\partial \rho_{i}}
$$

\subsection{Controle de gradiente}

Enquanto os métodos de filtragem abordados anteriormente permitem reduzir a variação da variável de projeto no domínio, evitando o aparecimento de instabilidades, os mesmos não permitem um controle efetivo do valor do seu gradiente. Por esse motivo, métodos de controle de gradientes tem sido estudados. Embora possamos considerar os métodos de filtragem como métodos de controle de gradiente, apenas métodos que consideram a restrição de gradiente como restrições na formulação serão denominados "métodos de controle de gradiente".

A origem do controle de gradientes remonta do trabalho de Niordson (1983), que demonstrou que a restrição na variação da espessura no domínio permite resolver o problema de não-existência da solução na otimização de placas de Kirchhoff. O conceito foi desenvolvido por Bendsøe (1995) e utilizado por Petersson e Sigmund (1998) e Cardoso e Fonseca (1999). A idéia básica é impedir variações bruscas da variável de projeto no domínio, garantindo o fechamento do espaço de solução. Assim, formulações que contenham penalizações, tanto constitutiva quanto na função objetivo, possuirão um espaço de solução fechado, desde que um valor apropriado do gradiente limite seja selecionado.

Petersson e Sigmund (1998) propõe um controle de gradiente de vizinhança fixa, baseado na imposição de restrições de gradiente diretamente na formulação de otimização, em problemas de minimização de trabalho externo com restrição de volume. O método de Petersson e Sigmund utiliza penalizações no modelo de material de forma crescente, indo até o valor de $p=5$. No entanto, esse método de restrição de gradiente não contempla a relação altamente não-linear entre o valor do módulo de elasticidade e a pseudo-densidade, já que os valores da pseudo-densidade são praticamente discretos $0-1$. Como o objetivo é restringir a variação espacial do material no domínio e a formulação utiliza a pseudo-densidade, relações altamente não-lineares entre as propriedades do ma- 
terial e a pseudo-densidade não irão permitir um controle efetivo da distribuição do material no domínio. Ainda, os resultados do trabalho são apresentados pela distribuição de pseudo-densidades, o que não permite avaliar a real distribuição de material no domínio. Conforme discutido por Cardoso e Fonseca (1999), a verificação da distribuição de energia de deformação específica na topologia final obtida permite verificar a validade dos resultados obtidos. O controle de gradiente proposto por Petersson e Sigmund é aplicado somente para malhas regulares, formadas por elementos retangulares.

Swan e Kosaka (1997), propuseram um controle espacial de gradiente para o problema de minimização de volume com restrição de gradiente e trabalho externo. A restrição de gradiente é adicionada à formulação de minimização de uma função do volume, de forma que o problema se torna:

$$
\begin{aligned}
& \text { Minimizar } \\
& \text { Sujeito à }\left\{\begin{array}{l}
f_{k}^{t} u_{k} \leq F_{l i m_{k}} \\
|\nabla \rho| \leq \nabla \rho_{\text {lim }} \\
k=1 \ldots n c
\end{array}\right.
\end{aligned}
$$

em que nc é o número de casos de carregamento. Essa formulação permite o controle efetivo da complexidade da topologia, que está diretamente associada ao gradiente da variável de projeto.

O gradiente da variável de projeto é aproximado por

$$
\nabla \rho_{i j}=\frac{\rho_{i}-\rho_{j}}{R_{i j}}
$$

sendo $i$ o elemento central e $j$ é um vizinho $(i \neq j)$. $R_{i j}$ é a distância entre os centróides dos elementos $i$ e $j$. Os vizinhos podem ser obtidos por uma varredura em torno do elemento central, ou selecionados por vizinhança fixa, pois não existe um cálculo de pesos que variam com a distância. O gradiente da variável de projeto é restringido de acordo com a 4.11 .

$$
\left|\nabla \rho_{i}\right| \leq \nabla \rho_{\text {lim }}
$$

no qual o gradiente da variável de projeto entre os elementos $i$ e $j$, é definido na Eq. 4.10 e $\nabla \rho_{l i m}$ é o valor limite do gradiente. Reescrevendo as restrições 4.11 na forma utilizada no problema de programação matemática, obtém-se 


$$
\rho_{i}-\rho_{j} \leq \nabla \rho_{l i m} R_{i j}
$$

no qual os sinais dependem do sinal do gradiente, de modo a manter a desigualdade sempre no mesmo sentido. O número de restrições de gradientes por elemento é igual ao número de vizinhos definidos. Em malhas regulares, condições de simetria podem ser utilizadas, diminuindo o número de restrições. Este controle tem um custo computacional muito elevado devido ao grande aumento na quantidade de restrições. Para melhorar a sua aplicabilidade devem ser escolhidos raios pequenos de varredura ou até mesmo elementos vizinhos apenas. Com esse método é possível obter a mesma topologia com o refino da malha, mesmo para vizinhança fixa pelo fato de se controlar efetivamente, o valor do gradiente da variável de projeto, desde que um número mínimo de vizinhos tenha sido selecionado.

\subsection{Projeção de Domínios}

A técnica de projeção de domínios consiste em se projetar um domínio de variáveis sobre um domínio de pseudo-densidades de forma a excluir das possíveis soluções para o problema, geometrias com características indesejadas.

Essa técnica foi utilizada por Guest, Prevost e Belytschko (2004) e Le (2006) para que fosse possível se garantir um tamanho mínimo de membro e com isso eliminou os problemas de dependência de malha, de escala de cinza e de instabilidade de tabuleiro.

Por outro lado, a técnica de projeção pode ser utilizada também para garantir que apareçam características desejadas na solução do problema, restringindo o problema de uma forma simples, sem ter que recorrer a uma formulação com maior quantidade de restrições, o que acarretaria em maior complexidade do problema e conseqüentemente em maior tempo computacional.

Neste trabalho, esta técnica é utilizada para garantir restrições, de forma que se encontre soluções com características que sejam possíveis de ser manufaturadas por processos de fabricação tradicionalmente encontrados nos ambientes fabris, como por exemplo: extrusão, fundição, simetria, simetria radial, etc. Na seção 5 serão detalhadas exatamente como essas restrições podem ser obtidas com a técnica de projeção de domínios e diversos tipos de mapeamento de variáveis.

Algumas das vantagens obtidas através da técnica de projeção são a exclusão 
de padrões indesejados como a instabilidade de tabuleiro e a dependência de malha. Como podemos ver na figura 4.4, o efeito da projeção é uma diminuição do campo possível de soluções através da utilização de outro espaço de variáveis.

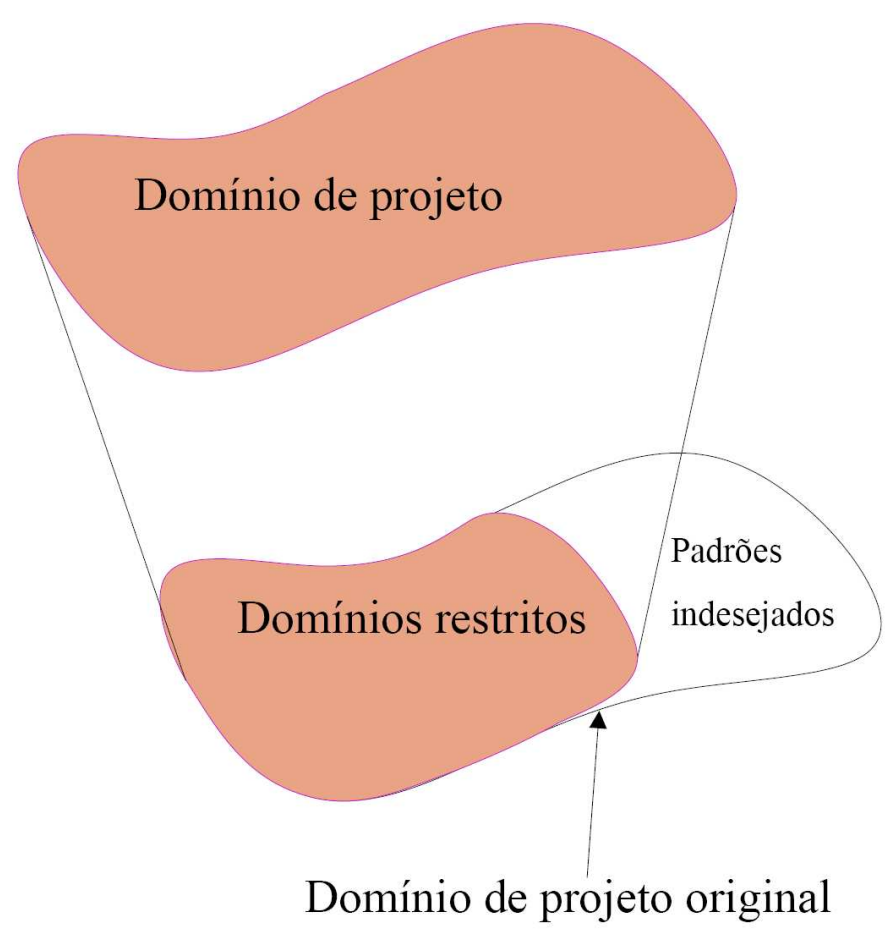

Figura 4.4: Representação do espaço de soluções original e restringido.

Podemos dividir a técnica de projeção em três principais fases: o mapeamento da relação entre o domínio de variáveis $d$ e o domínio de pseudo-densidades $\rho$, a utilização desta relação para o cálculo da sensibilidade das variáveis $d$ através das sensibilidades das pseudo-densidades, e finalmente a projeção do domínio das variáveis $d$ sobre o domínio das pseudo-densidades $\rho$ de forma a encontrar a solução do problema. Essas três fases principais serão detalhadas a seguir.

\subsubsection{Mapeamento dos domínios}

O mapeamento da relação entre os dois domínios, como o mostrado na figura 4.5 , precisa ser encontrado para que se possa facilmente saber quais elementos do domínio das pseudo-densidades influem em cada uma das variáveis $d$, esse mapeamento deve obedecer uma regra estabelecida pela formulação do problema.

No caso da figura 4.5 temos uma regra que tem o formato de uma letra "L", em que todos os elementos do campo de pseudo-densidades que estejam contidos dentro do espaço do "L" (região $\Omega_{1}$ na figura), influenciam a variável $d_{1}$ do domínio 


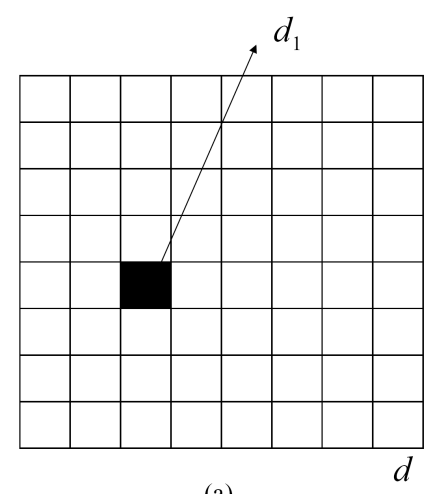

(a)

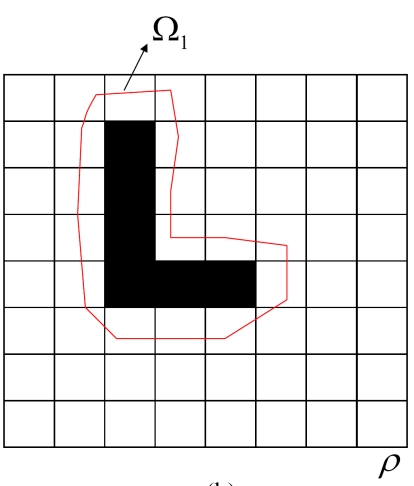

(b)

Figura 4.5: Exemplo de relação entre o domínio de $d$ e de $\rho$. (a) Domínio das variáveis de projeto $(d)$. (b) Domínio das pseudo-densidades $(\rho)$.

das variáveis.

Assim como no caso da influência das pseudo-densidades nas variáveis de projeto, o mapeamento também é utilizado, porém no sentido inverso, na hora de se projetar a solução encontrada nas variáveis sobre o domínio das pseudodensidades. Como podemos ver na figura 4.6 mais de uma variável pode ser projetada sobre uma mesma pseudo-densidade, de forma que é necessário ter uma regra para saber qual será utilizada, isto será discutido na seção 4.3.3.

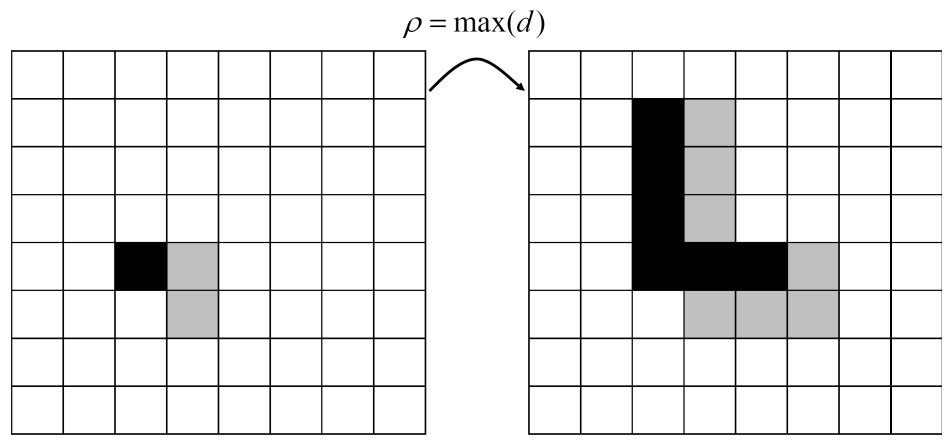

(a)

(b)

Figura 4.6: Exemplo de função de projeção entre o domínio de $d$ e de $\rho$. (a) Domínio das variáveis de projeto $(d)$. (b) Domínio das pseudo-densidades $(\rho)$.

Esta fase do mapeamento é muito custosa computacionalmente, e tende a se agravar quando existe uma projeção feita sobre a outra. Como as regras de projeção utilizadas dentro do escopo deste trabalho não se alteram ao longo da resolução do problema, a fase de mapeamento é realizada apenas uma vez, no início do problema. Com isso é possível se garantir um custo computacional muito semelhante ao problema sem a projeção durante as iterações do problema. 


\subsubsection{Cálculo da Sensibilidade}

As sensibilidades devem ser calculadas para as variáveis de projeto $d$, porém a análise pelo MEF, nos fornece apenas as derivadas com relação às pseudodensidades $\rho$. Portanto, como indicado em Le (2006) para variáveis em elementos e pseudo-densidades em nós em Guest, Prevost e Belytschko (2004), podemos considerar que as variáveis de projeto $d$ estão em função das pseudo-densidades $\rho$.

Ou seja, dada uma função $f$ objetivo, temos que $f \equiv f(\rho(d))$, portanto, podemos escrever as sensibilidades das variáveis de projeto em função das sensibilidades das pseudo-densidades.

As sensibilidades das variáveis de projeto $d_{i}$ estão em função das variáveis que compõe o seu domínio de influência $\Omega_{i}$. Como será descrito na fase de projeção das variáveis, uma alteração na variável de projeto $d_{i}$ causa uma alteração nas pseudo-densidades contidas no domínio $\Omega_{i}$, então temos que:

$$
\delta \rho_{j}\left(d_{i}, \delta d_{i}\right)=\left\{\begin{array}{l}
\delta d_{i} \text { para } j \in \Omega_{i} \\
0 \text { em qualquer outra situação }
\end{array}\right.
$$

A variação da função $f$, é então calculada por:

$$
\partial f\left(\rho\left(d_{i}\right), \partial \rho_{i}\left(d_{i}, \partial d_{i}\right)\right)=\sum_{k \in \Omega} \frac{\partial f}{\partial \rho_{i}} \delta \rho_{k}=\sum_{j \in \Omega_{i}} \frac{\partial f}{\partial \rho_{j}} \delta d_{i}=\left(\sum_{j \in \Omega_{i}} \frac{\partial f}{\partial \rho_{j}}\right) \delta d_{i}
$$

Com isso temos que a sensibilidade da função $f$ com relação à variável de projeto $d_{i}$ tem a seguinte expressão:

$$
\frac{\partial f}{\partial d_{i}}=\sum_{j \in \Omega_{i}} \frac{\partial f}{\partial \rho_{i}} \text { na qual } \rho_{i}=\rho_{i}\left(d_{j}, j \in \Omega_{i}\right)
$$

na qual $\partial f / \partial d_{i}$ é a sensibilidade da função com relação a variável de projeto $d$ do elemento $i$ em questão.

\subsubsection{Projetando as variáveis}

Com as sensibilidades calculadas pode-se então iniciar a iteração do processo de otimização, onde as variáveis $d$ serão calculadas, porém, para que a restrição 
de volume seja obedecida, deve-se a cada iteração do critério de optimalidade, realizar a transformação das variáveis de projeto, para o domínio das pseudodensidades.

Nesse caso exemplificado na figura 4.6, estamos utilizando a projeção com uma função máximo, ou seja, a variável $\rho$ recebe a variável $d$ de maior valor que se projeta sobre ela.

$$
\rho_{i}=\max \left(d_{j}\right) \text { para } j \in \Omega_{i}
$$

No caso exemplificado na figura 4.6 existe uma sobreposição dos conjuntos de variáveis $\Omega_{i}$, o que faz com que sejam mantidas sempre as pseudo-densidades com o valor mais alto o possível, essa sobreposição ajuda a reduzir as regiões cinza da solução.

Essa etapa do processo de projeção de variáveis, é a que tem o maior consumo de recursos computacionais, pois como os métodos de otimização são um processo iterativo, a cada iteração do método, as variáveis $d$ são convertidas para as pseudodensidades $\rho$, estas tem sua somatória analisada de forma a verificar a restrição de volume, e então com essa informação o processo iterativo volta a atuar sobre as variáveis $d$ de forma a otimizá-las. Através desse processo, é possível de se garantir que a restrição de volume será mantida, independente da forma dos domínios de projeção de cada variável. 


\section{Restrições de Manufatura}

Como é sabido as estruturas sintetizadas pelo MOT tem tradicionalmente formas complexas e na maioria das vezes são ou muito caras de serem produzidas ou até mesmo inexequíveis do ponto de vista de Engenharia como pode ser visto na figura 1.2.

Uma das soluções normalmente aplicadas após o processo de OT é o do pós-processamento dos resultados obtidos através de funções de interpolação e suavização de curvas (BENDSØE, 1995). Mas algumas vezes os resultados para serem fabricáveis, devem ser alterados de forma drástica o que os faz perder a característica de solução ótima, muitas vezes levando a uma estrutura que em nada se parece com a solução encontrada pelo MOT como podemos ver na figura 5.1 que se diferencia em muito da 1.2.

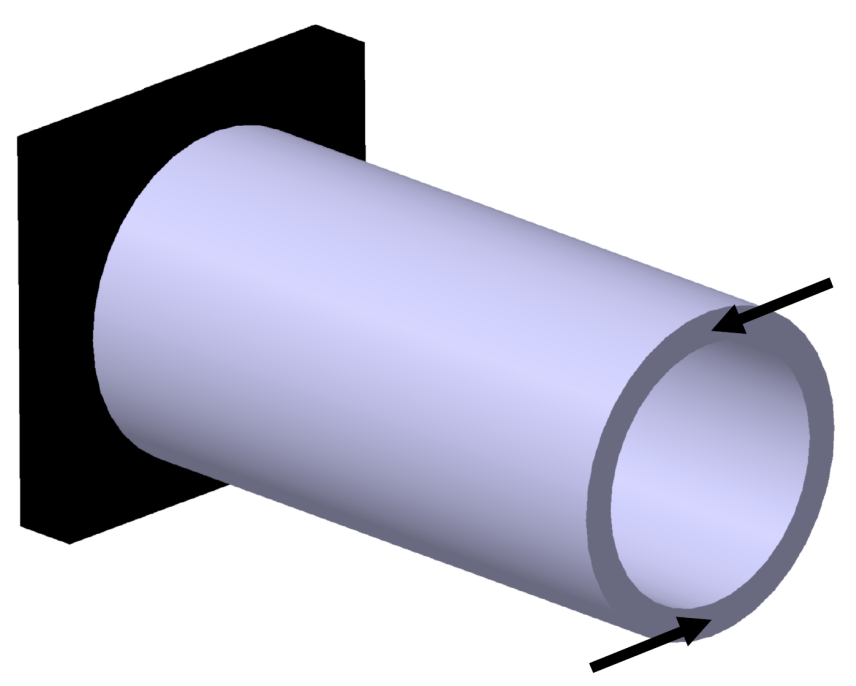

Figura 5.1: Solução ótima conhecida para problemas de torção.

Porém, recentemente uma nova abordagem vem surgindo que é a definição de restrições no problema de otimização ou a formulação de filtros que atendam às exigências dos processos de fabricação que visam pelo menos simplificar os re- 
sultados obtidos. Alguns trabalhos nesse sentido foram desenvolvidos por Guest, Prevost e Belytschko (2004), Zuo et al. (2006), Harzheim e Graf (2006, 2005), Zhou, Shyy e Thomas (2001) e Ishii e Aomra (2004).

Através dessas restrições obtém-se formas que podem ser fabricadas por processos de manufatura bem conhecidos e controlados. Assim garante-se que as soluções encontradas são o mais próximas possíveis da solução ótima do ponto de vista matemático, porém estando também dentro do domínio de viabilidade de produção de Engenharia, sendo mais barata de se fabricar devido a definição de um processo de manufatura principal que dará a forma básica para essa estrutura.

Existem diversos processos para a fabricação de peças e componentes de máquinas. Cada processo possui características e peculiaridades específicas. Entre os processos mais comumente encontrados temos: fundição, forjamento, torneamento, elétro-erosão, corte a laser, conformação, extrusão, fresamento, etc.

Muitas peças são mais complexas e são necessárias mais de uma restrição ao mesmo tempo, o que restringe ainda mais a solução. As restrições de manufatura implementados nesse trabalho serão apresentadas a seguir.

\subsection{Fundição}

A fundição é um dos processos de fabricação mais antigos mas mesmo assim um dos mais utilizados, sendo empregado na manufatura de peças de todos os tamanhos e formas. O seu processo se dá preenchendo um molde oco com metal fundido, e quando este resfria, a peça adquire o formato de seu molde, obtendo-se assim a peça desejada.

São diversas as variações entre os métodos existentes de fundição (DUBBEL, 1979). Estes diferem como o molde é feito e do que ele é feito e também como o metal é inserido nesse molde. Quanto aos moldes, estes podem ser de areia, de argila ou até mesmo de outros metais. Em relação a como o metal fundido preenche o molde, podemos ter um preenchimento devido a gravidade, com o metal apenas escorrendo para dentro do molde, podemos ter sistemas pressurizados no qual o metal é injetado com pressão dentro do molde, e também sistemas centrífugos no qual o metal preenche o molde enquanto este é rotacionado tendo o seu preenchimento ocorrendo de forma radial (DUBBEL, 1979). Como por exemplo a figura 5.2 .

Para que uma peça possa ser fundida de maneira simples, devem existir furos 


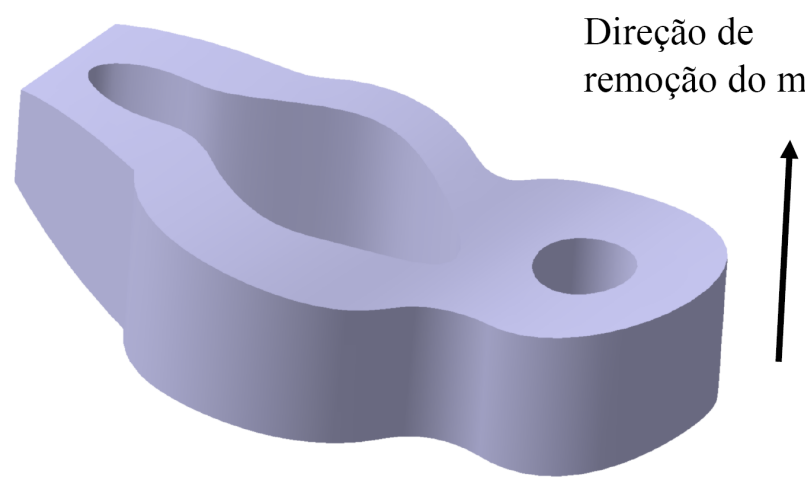

Figura 5.2: Peça com condições que permitem a fundição.

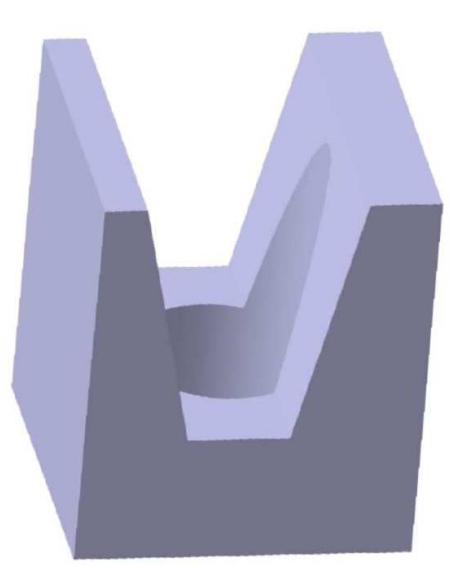

(a)

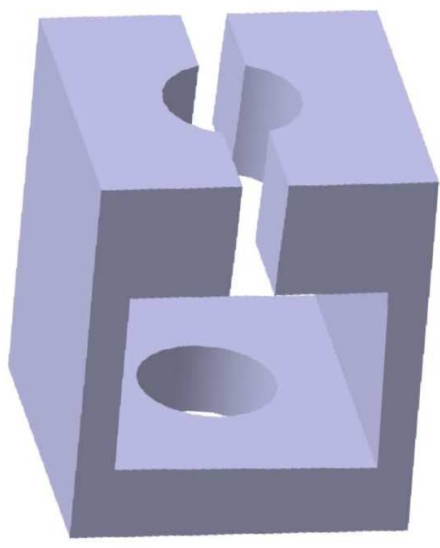

(b)

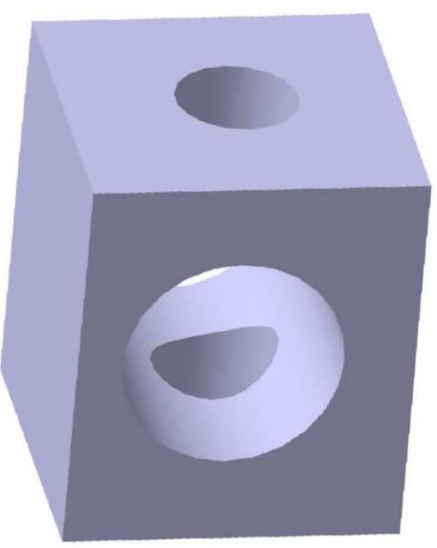

(c)

Figura 5.3: (a) Furo aceitável na fundição. (b) e (c) Furos aceitáveis na fundição apenas com cera perdida.

apenas em uma direção, que é a mesma direção de remoção do molde. Os furos em outras direções devem obedecer aos critérios mostrados na figura (5.3-a). Nas condições apresentadas na figura (5.3-b) e (5.3-c), uma fundição simples não seria capaz de realizar, sendo necessário a utilização de fundição por cera perdida, na qual um molde interno feito de cera é utilizado e depois destruído para que ele saia de dentro da peça. Mesmo utilizando a fundição com cera perdida não é possível fabricar uma peça que possua um buraco isolado em seu interior, assim como em nenhum outro processo de fabricação usual, a menos da utilização de técnicas de prototipagem rápida, como deposição de resina. Como esta última não é um processo de fabricação utilizado em escala, iremos evitar furos internos 
em todos os problemas.

Outra condição que deve ser satisfeita na fundição é o tamanho mínimo de membro, pois os moldes que possuem regiões estreitas demais podem apresentar problemas no seu preenchimento.

\subsection{Fresamento}

O fresamento é a remoção de material da peça com a utilização de uma ferramenta rotativa, enquanto o corpo a ser usinado permanece fixo em uma mesa. Permite a remoção de material por diversas direções dependendo da ferramenta, que costuma ter perfil cilíndrico. Pode ser utilizado para recortar peças até o raio da própria ferramenta, podendo assim criar rasgos ao longo de uma direção para a peça.

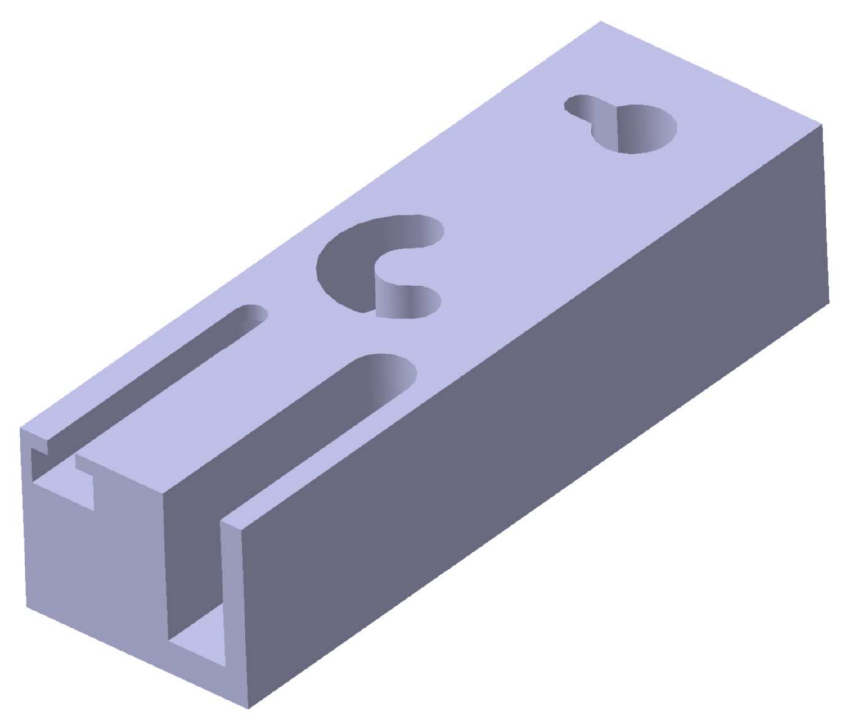

Figura 5.4: Peça com rasgos feitos com um processo de fresamento.

No fresamento as características que devem ser obedecidas são furos com o tamanho mínimo correspondente ao tamanho da fresa com a qual se pretende usinar a peça, como os furos na peça da figura 5.4.

Em uma peça fresada, pode haver rasgos em diferentes formatos, desde que exista sempre um acesso ao longo de seu comprimento, sendo inviáveis rasgos profundos sem espaço de acesso para a ferramenta, e rasgos inclusos no seu interior, sem acesso externo. 


\subsection{Torneamento}

No torneamento a peça é revolucionada enquanto uma ferramenta é levada de encontro a peça removendo material de maneira axissimétrica. Muito utilizado para a usinagem de peças como eixos, tubos, tirantes, enfim, qualquer peça que seja predominantemente axissimétrica.

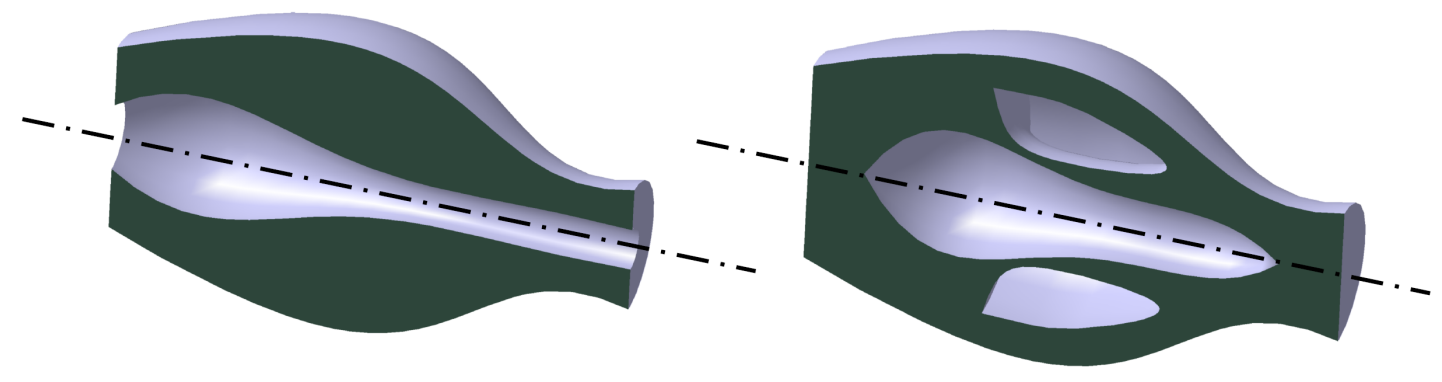

(a)

(b)

Figura 5.5: (a) Peça que pode ser fabricada através do torneamento. (b) Peça que não pode ser fabricada por torneamento.

Para que uma peça possa ser fabricada através de um processo de torneamento, todas as partes dela devem obedecer uma simetria radial. Podem existir furos, desde que esses, bem como qualquer parte da peça sejam distribuídos de forma radial em torno de um centro de revolução, como podemos ver na figura (5.5-a), porém, furos internos como o apresentado na figura (5.5-b), não podem ocorrer.

\subsection{Extrusão}

O processo de extrusão é aquele em qual uma barra de metal é injetada quente através de uma abertura com um formato definido gerando assim uma forma alongada com seção constante. A extrusão é utilizada em geral para geração de perfis de vigas estruturais e de trilhos. Uma barra extrudada pode ser dobrada formando corpos curvilíneos porém com a mesma seção transversal ao longo do seu comprimento, como mostra a figura 5.6.

Para que uma peça possa ser obtida através de um processo de extrusão, todas as suas seções devem possuir exatamente a mesma forma, sem alterações 


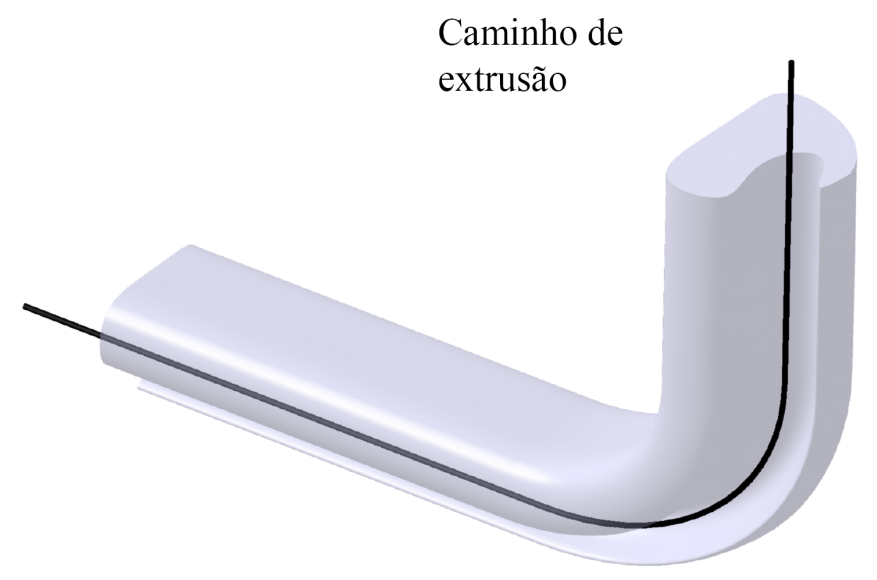

Figura 5.6: Peça extrudada e curvada.

ao longo da direção definida de extrusão.

\subsection{Laminação}

No processo de laminação, uma chapa ou barra é passada através de cilindros que comprimem a estrutura, alterando sua espessura, como podemos ver no esquema simplificado da figura 5.7-a.

Através da laminação obtemos estruturas simétricas, devido a natureza do seu processo de fabricação através da compressão, que aplica a mesma carga sobre os dois lados da estrutura. Com raios de curvatura suaves devido ao próprio raio do cilindro, e uma única seção longitudinal é obtida ao longo do processo.

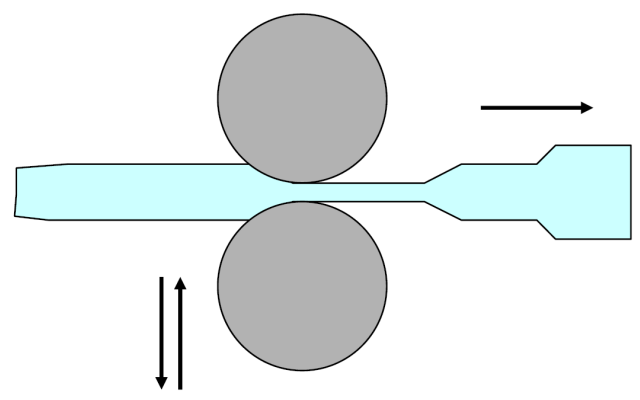

(a)

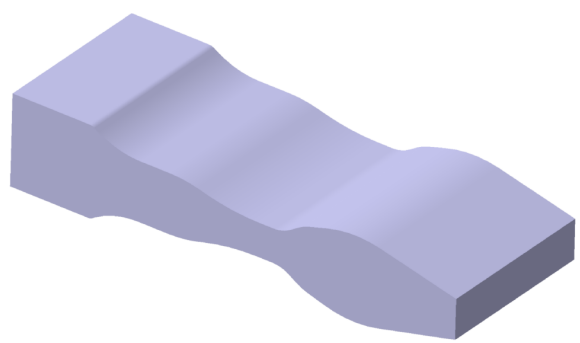

(b)

Figura 5.7: (a) Processo simplificado de laminação. (b) Exemplo de geometria obtida com o processo de laminação. 
O processo de laminação pode ocorrer a quente ou a frio, sendo o resultado de ambos os processos geometricamente similar, ficando as diferenças restritas a características do material, e a tensões residuais existentes na peça final.

Com todas as características indicadas sabemos que para que uma peça possa ser fabricada através de laminação precisaremos impor restrições que atendam a condições de simetria de uma única seção transversal e raios suaves, como a forma que está exemplificada na figura 5.7-b.

\subsection{Forjamento}

Através do processo de forjamento, obtém-se formas simples, que não tem um grande detalhamento e possuem apenas um único membro.

O forjamento ocorre através da conformação mecânica do material bruto através de batidas seqüenciais, ou até mesmo dependendo do caso através de uma única batida. Como está esquematizado na figura 5.8-a, a peça é colocada em uma prensa de alta capacidade e é então conformada até que se atinja a forma desejada.

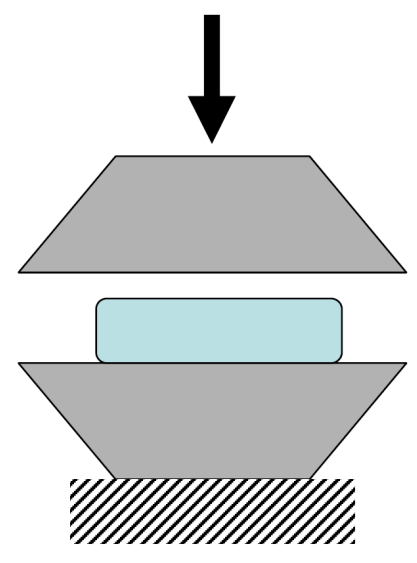

(a)

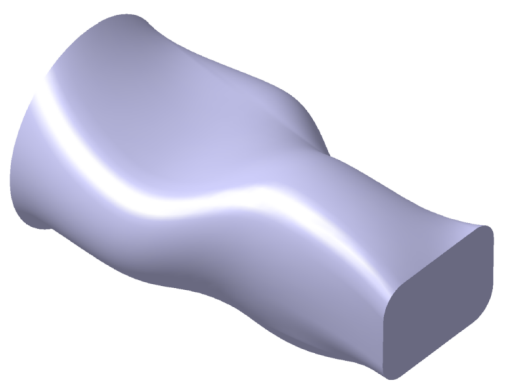

(b)

Figura 5.8: (a) Processo simplificado de forjamento. (b) Exemplo de geometria obtida através do processo de forjamento.

Existem aplicações simples de forjamento onde uma peça do tamanho desejado é conformada com ferramentas planas, nesse caso existe apenas o espalhamento do material, e muitas vezes visa buscar apenas melhores características do material, e não obter a forma final de utilização da peça. Em outros casos 
uma conjunto de ferramentas é colocado de forma a conduzir o escoamento do material de uma forma a atingir um esboço muito próximo da peça final.

Este processo pode ser realizado a quente ou a frio, e ser feito com batidas únicas ou com impactos repetidos seqüenciais, porém as peças obtidas por essas opções possuem todas as mesmas características, que é: a não existência de raios de curvatura muito bruscos, um único membro, e nenhum furo, em nenhuma direção, como a forma ilustrada na figura 5.8-b

O processo de forjamento muitas vezes não é a última etapa do processo de fabricação, sendo seu resultado trabalhado com outros processos para obter melhores precisões em regiões da peça. Porém, a natureza da forma obtida no processo de forjamento não costuma sofrer grades alterações. Por esse motivo é importante conseguir resolver problemas com soluções que atendam as suas restrições. 


\section{Implementação Numérica}

Neste capítulo serão detalhadas as restrições de manufatura implementadas através da técnica de projeção e mapeamentos, assim como restrições e problemas encontrados durante suas implementações.

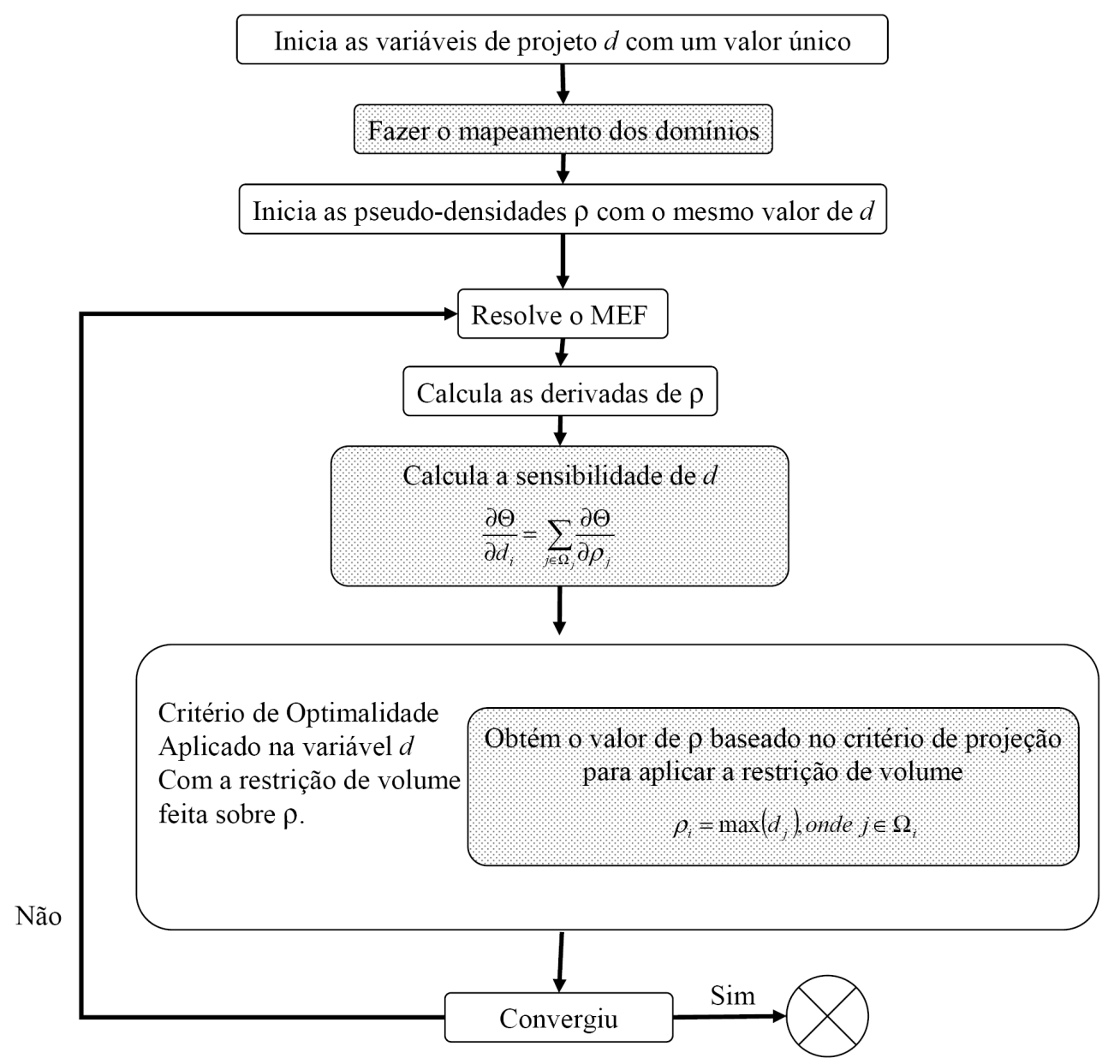

Figura 6.1: Fluxograma da técnica de projeção dentro de uma rotina de MOT.

Um algoritmo de OT é sempre um processo iterativo, que se repete até a convergência do problema, ou pela estabilização no valor da função objetivo, ou pela estabilização dos valores das variáveis de projeto. Na figura 6.1, podemos ver um fluxograma simplificado da implementação de um software de OT com a técnica de projeção. As três fases da técnica de projeção, mapeamento de 
variáveis, cálculo das sensibilidades e projeção das variáveis, estão destacadas no fluxograma. Se forem retiradas estas etapas o software continuará funcionando, porém será um software tradicional de OT.

Com a utilização da técnica de projeção e de mapeamento foram implementadas as seguintes restrições:

- Membro mínimo - garante um tamanho mínimo para membros dentro da estrutura;

- Buraco mínimo - restringe a existência de furos apenas a partir de um tamanho mínimo definido;

- Simetria - Impõe a existência de simetria na solução encontrada, mesmo no caso de cargas não simétricas;

- Extrusão - Garante a existência de uma única seção transversal na solução, e furos apenas no sentido de extrusão;

- Revolução - Garante a existência de um perfil que se rotacionado em torno de um eixo definido encontrará uma solução para o problema posto, e a não existência de furos que não sejam possíveis de serem fabricados em sólidos de revolução;

- Repetição de padrões - impõe que a solução seja composta de blocos idênticos ao longo do domínio;

- Fundição - Restringe o aparecimento de furos, de forma que eles existam apenas em um sentido, e apenas de fora para dentro.

- Forjamento - garante que a solução encontrada não possuirá furos em nenhum sentido, e com o auxílio da restrição de membro mínimo, garante também que os raios de curvatura serão suaves na solução encontrada;

- Laminação - Utiliza outras restrições em conjunto de forma a garantir uma peça simétrica, sem furos e com seção longitudinal única.

A seguir serão detalhadas estas restrições, e como foi feita sua implementação.

\subsection{Membro Mínimo}

A restrição de membro mínimo é uma das restrições mais conhecidas, e foi implementada de diversas formas possíveis. Isso se dá devido a sua característica 
de impedir problemas numéricos como escala de cinza, instabilidade de tabuleiro e não unicidade da solução, como já descrito na seção 2.4. Com a utilização da técnica de projeção, a restrição de membro mínimo foi implementada por Guest, Prevost e Belytschko (2004) e por Le (2006). Como foi visto na seção 4.3, a técnica de projeção está dividida em três fases principais: mapeamento dos sub-domínios $\Omega_{i}$, cálculo das sensibilidades das variáveis $d$ em função das sensibilidades obtidas através da resolução do MEF com a utilização das pseudo-densidades $\rho$, e finalmente projeção das variáveis $d_{i}$ sobre os domínios $\Omega_{i}$ de pseudo-densidades por esta representado.

A restrição do membro mínimo é caracterizada por impor uma área circular sobre cada um dos elementos com o valor máximo da pseudo-densidade contida nessa área circular. Como podemos ver na figura 6.3, as pseudo-densidades são mapeadas de forma que cada variável $d_{i}$ represente sua posição equivalente no domínio das pseudo-densidades, bem como uma área circular de raio $R$ definido, em torno deste elemento.

Com isso, cada um dos elementos que está representado nesse sub-domínio $\Omega_{i}$ tem influência na sensibilidade de $d_{i}$, porém quando o mapeamento de retorno ocorre, apenas o valor mais alto de $d$ que se projetar sobre cada uma das pseudo-densidades será utilizado, já que a função de projeção que é utilizada nesta restrição é a função máximo, sendo possível a utilização de outras funções, como a função mínimo utilizada na restrição de buraco mínimo, e também de outras funções que trabalhem de forma gradual, fazendo um cone de influência em torno do elemento. Desta forma, os elementos com pseudo-densidade próximas de 1 possuem uma área circular de pseudo-densidades 1 ao seu redor, sobrepondo assim a área intermediária que costuma existir entre elementos de pseudo-densidade 1 e 0.

Através da utilização da função máximo o esquema de projeção garante que não será retirada massa por conta dessa projeção, tanto que, os resultados obtidos para as variáveis de projeto e para as pseudo-densidade são diferenciados pelo fato da solução das variáveis de projeto possuir membros mais esbeltos, porém com a mesma quantidade de membros e posições, como podemos ver no exemplo apresentado na figura 6.4.

No caso tridimensional, o membro mínimo em vez de representar uma área circular de raio $R$, representa um volume esférico de raio $R$, sendo as demais características desse membro mínimo exatamente as mesmas do caso plano em $2 \mathrm{D}$. 


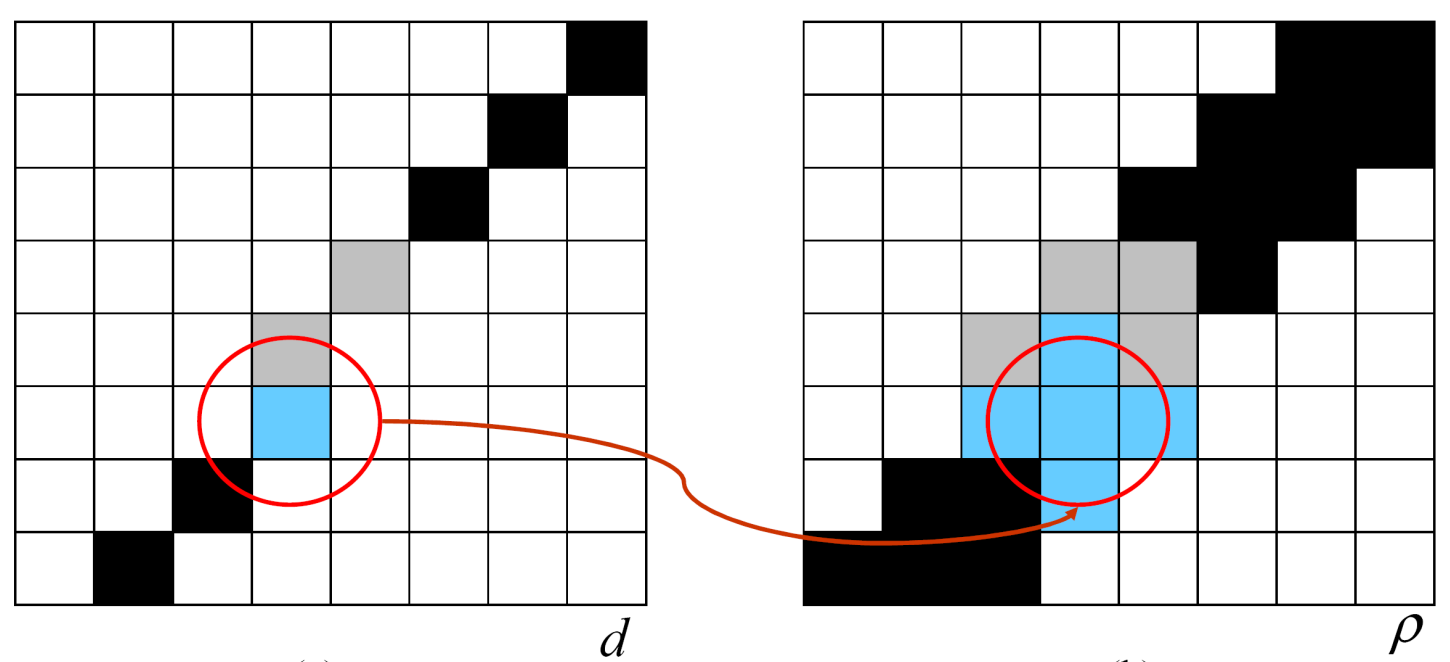

(a)

(b)

Figura 6.2: Esquema de projeção para restrição de membro mínimo.

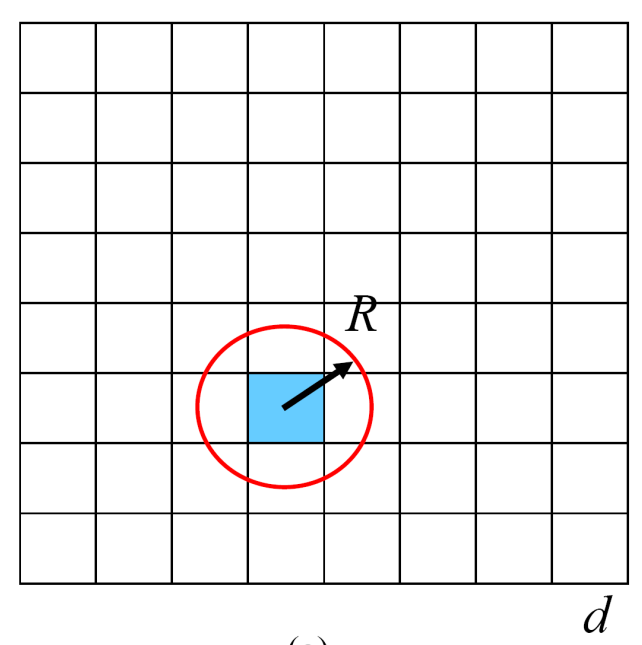

(a)

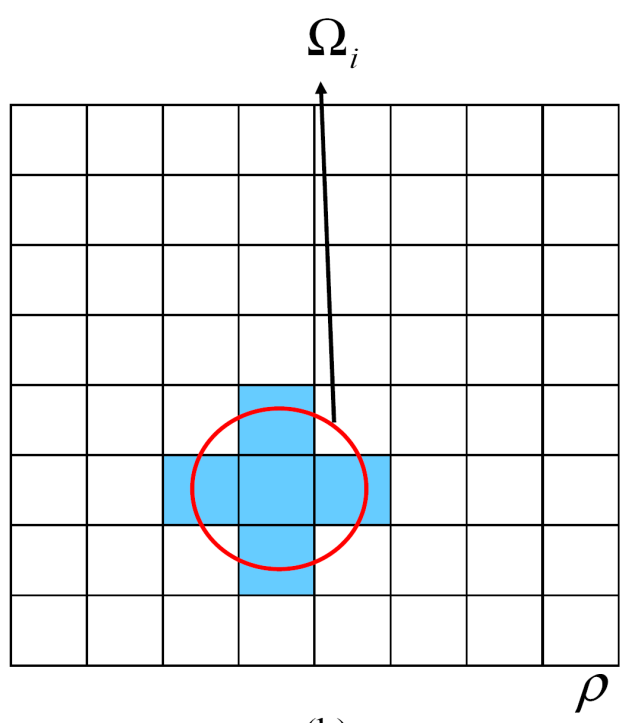

(b)

Figura 6.3: Esquema de projeção para restrição de membro mínimo.

A criação do vetor de mapeamento nos dois casos ocorre antes do início da execução do processo de otimização. O vetor de mapeamento é montado tomando-se elemento a elemento e considerando a área circular ou o volume esférico em torno de seu centro. Todos os elementos que tiverem seu centro contido dentro destas regiões são colocados dentro do vetor que representa o domínio $\Omega_{i}$ da variável de projeto associada aquela posição.

Um único caso implementado de membro mínimo difere destes apresentados em uma pequena consideração durante a formação de seu vetor. A restrição de membro mínimo em disco, é uma representação plana da área circular projetada 


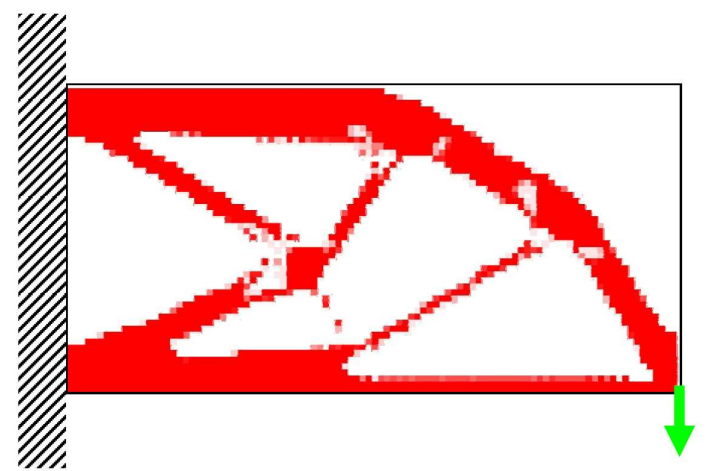

(a)

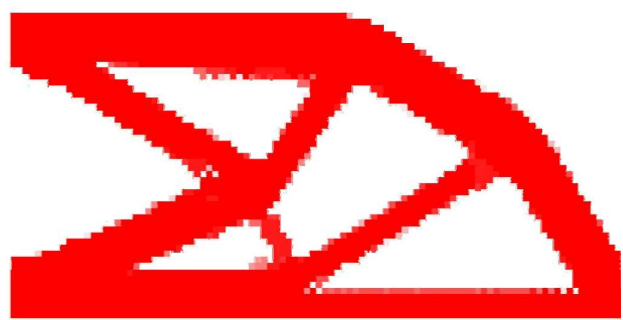

(b)

Figura 6.4: (a) Solução representada pelas variáveis de projeto $d$. (b) Solução representada pelas pseudo-densidades $\rho$.

em torno do centro de cada elemento com referência a um plano dado, isto é, planos $X Y, X Z$ ou $Y Z$. Com isso o membro mínimo mesmo nos casos tridimensionais, é representado por um conjunto de elementos hexaédricos, dispostos em torno do centro do elemento de referência de forma circular, como na figura 6.5. Essa restrição visa atender a situações onde o membro mínimo se difere entre as direções da peça, apesar de não poder ser utilizado um tamanho de membro mínimo para cada direção nesta implementação, uma futura implementação pode vir a apresentar essa característica.

Todas as restrições de membro mínimo apresentadas, podem ser utilizadas em conjunto com todas as restrições implementadas nesse trabalho, salvo a utilização de buraco mínimo que seria contraditória a ela, criando problemas para a convergência do problema e a falta da existência das duas condições na solução final encontrada.

\subsection{Buraco Mínimo}

Apesar da restrição de membro mínimo descrita anteriormente resolver os problemas numéricos intrínsecos do MOT, ainda podem ser gerados como solução regiões que atendem aos membros mínimos, porém apresentem uma distância entre os membros muito reduzida, tornando muito caro, ou muito difícil obter dois membros separados, como é mostrado na figura 7.28. Quando isto ocorre uma solução recorrente é o tratamento de dois ou mais membros como apenas um, o que distancia a solução adotada da solução encontrada pelo MOT.

Com essa motivação, podemos ver a necessidade da implementação de uma restrição de buraco mínimo, onde os membros não são controlados, porém o espaço 


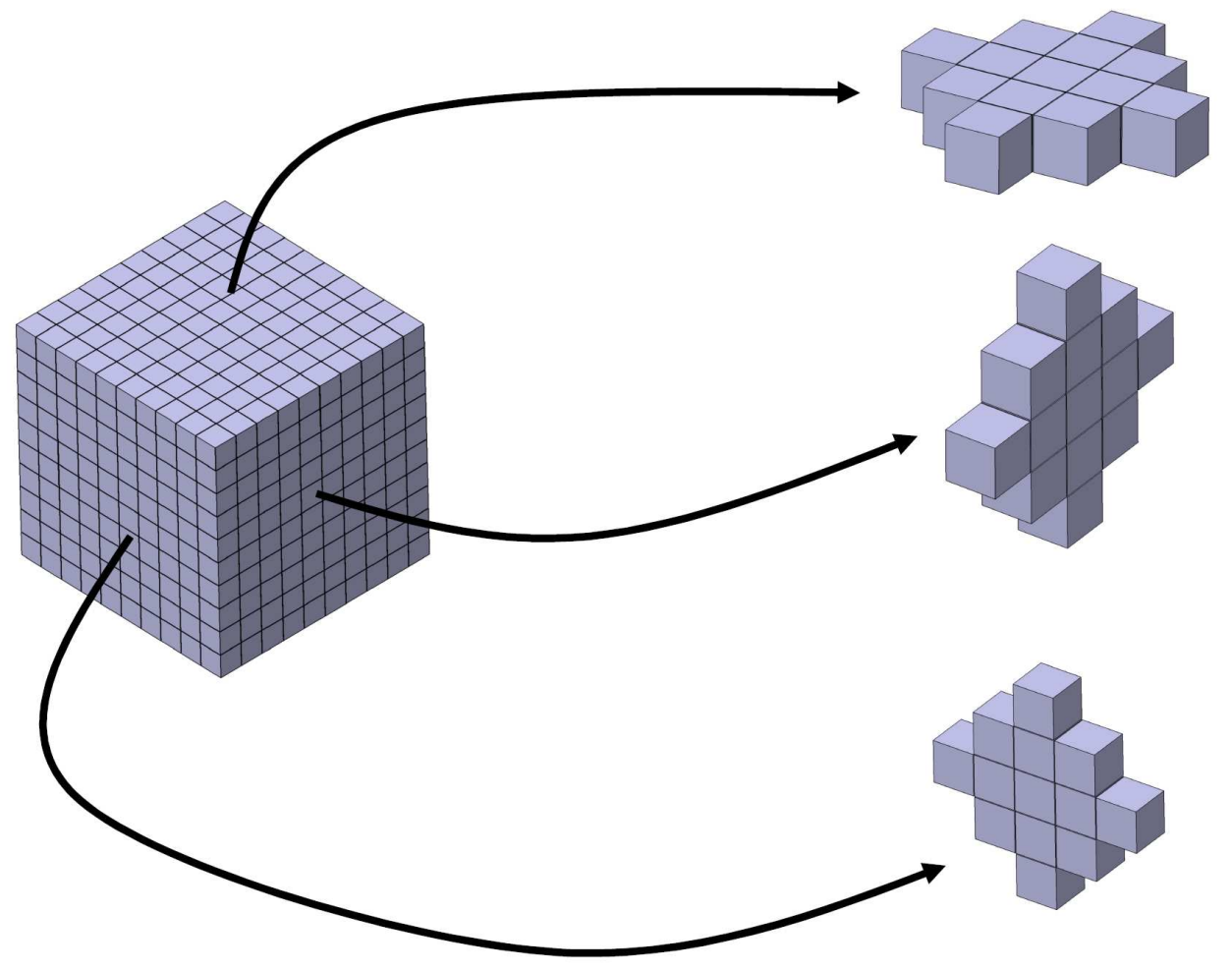

Figura 6.5: Representação das possibilidades de membro mínimo em apenas um plano.

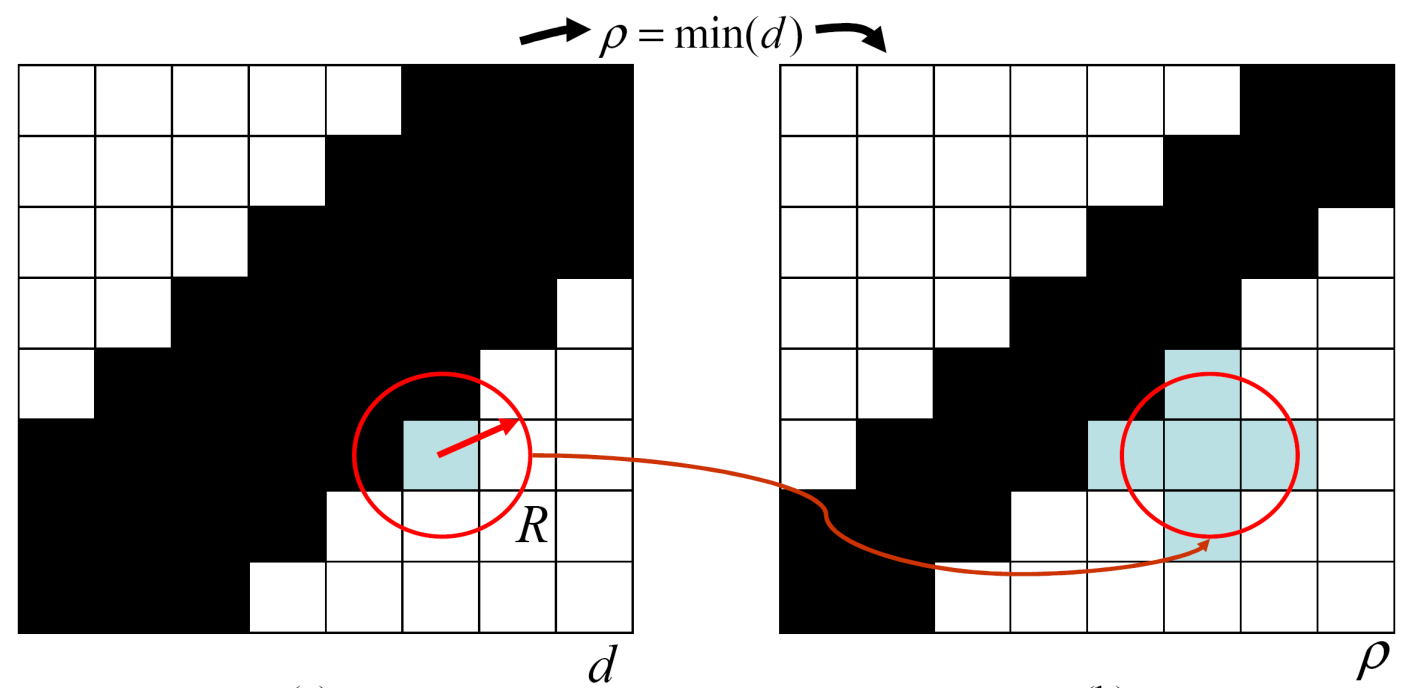

(a)

(b)

Figura 6.6: Mapeamento da restrição de buraco mínimo. (a) Domínio das variáveis de projeto. (b) Domínio das pseudo-densidades.

entre eles são, garantindo espaço necessário para a entrada de uma ferramenta por exemplo.

De forma muito semelhante à implementação utilizada para a restrição de 
membro mínimo, podemos realizar a restrição de buraco mínimo. O mapeamento é realizado da mesma forma que no membro mínimo, porém a projeção feita das variáveis de projeto para as pseudo-densidades utiliza a função mínimo ao invés da função máximo, como podemos observar na figura 6.6.

Com essa inversão da função projeção, de máximo para mínimo, o efeito que se provoca sobre a solução acaba funcionando como uma minimização de membros, de acordo com o tamanho mínimo para buracos existentes na solução. Dentro deste trabalho esta é a única restrição implementada que se utiliza da função mínimo.

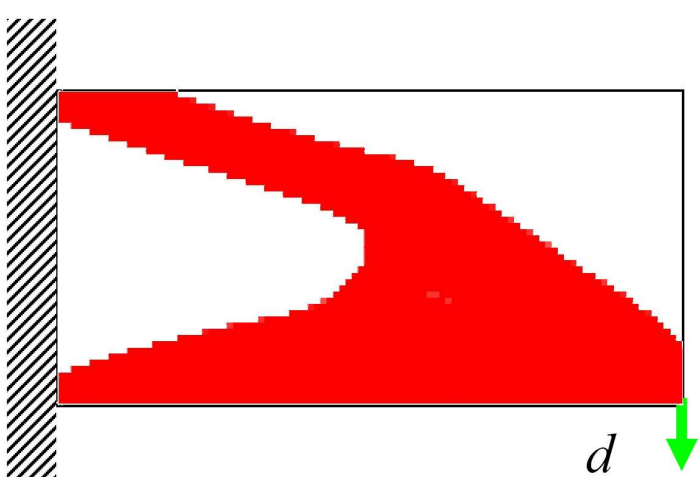

(a)

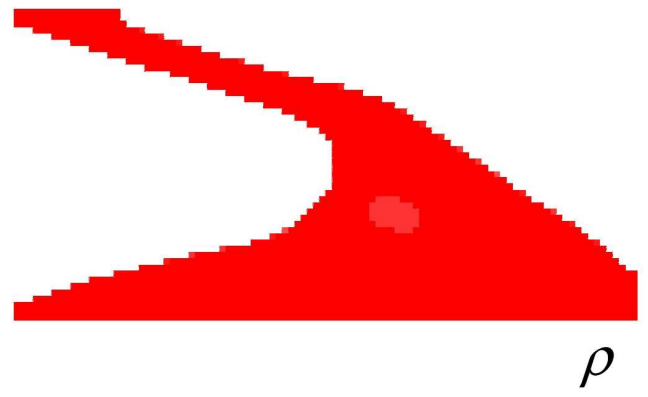

(b)

Figura 6.7: Exemplo de solução encontrada para a restrição de buraco mínimo.

O efeito causado pela restrição de buraco mínimo na solução final, pode ser visto na figura 6.7. Como pode ser observado, o domínio das variáveis $d$, possui uma solução com membros mais grossos que a solução encontrada para as pseudodensidades, porém assim como no membro mínimo, as posições dos membros não têm alteração, nem a quantidade de membros.

A solução de buraco mínimo é essencial para a obtenção de soluções que se adequem ao processo de fresamento, pois as ferramentas disponíveis possuem raios pré determinados e não conseguem executar rasgos menores do que o seu diâmetro.

Por impor uma restrição contraditória ao membro mínimo, a restrição de buraco mínimo não pode ser utilizada em conjunto com este. Este é um problema que não foi resolvido por este trabalho, mas que pode ser muito útil se implementado de forma eficiente. 


\subsection{Simetria}

Na restrição de simetria, foram implementadas as simetrias com relação aos três planos principais, $X Y, X Z$ e $Y Z$. Podendo estas restrições serem utilizadas simultaneamente inclusive. Como podemos ver na figura 6.8, que representa uma restrição de simetria no plano $X Z$, os domínios da restrição de simetria são criados com referência ao centro do modelo, que é calculado considerando-se sempre a maior e a menor coordenada existente para os centros em cada uma das direções.

Com o centro calculado, a restrição de simetria pode então montar o conjunto de vetores considerando sempre apenas um plano de referência. Para tanto são considerados elementos contidos no domínio $\Omega_{i}$ que possuem os centros geométricos com as mesmas coordenadas nas direções não contempladas pela simetria, ou seja, se a simetria se der em torno do plano $X Z$, as coordenadas em relação aos eixos $\mathrm{X}$ e $\mathrm{Z}$ deverão ser iguais e as coordenadas em relação ao eixo Y deverão possuir distâncias iguais porém com sentidos opostos em relação ao plano de simetria. Essas distâncias comparadas sempre com uma tolerância de $1 \%$ da dimensão do maior elemento existente no modelo na direção considerada.

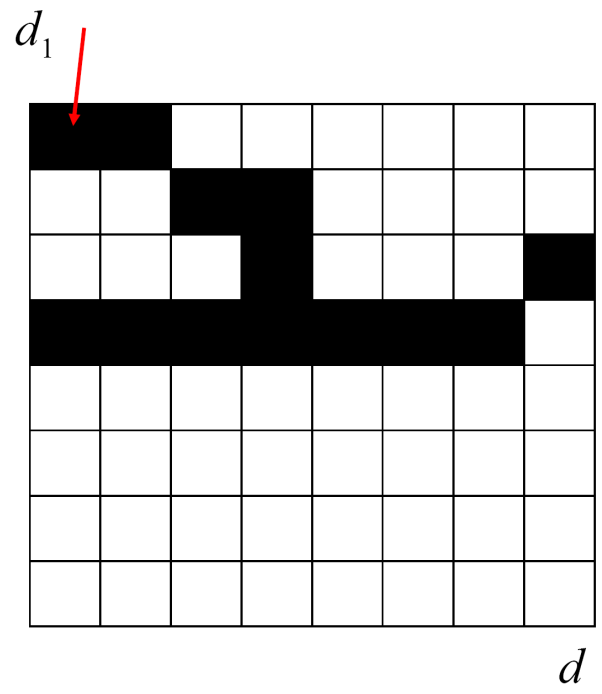

(a)

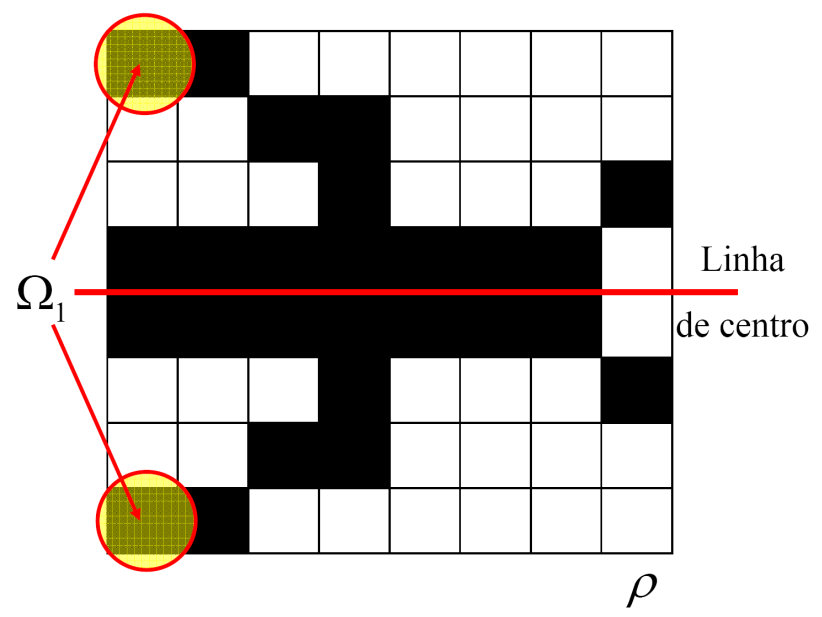

(b)

Figura 6.8: Esquema de projeção para restrição de simetria.

Quando são considerados mais de um plano de simetria, são montados os vetores para cada um dos três planos independentemente e depois são aplicados seqüencialmente sobre o modelo, cada um fazendo o espelhamento de uma parte do modelo até reconstruir a área total do domínio.

Uma condição que não está contemplada dentro das restrições de simetria, é a 
chamada simetria radial, que neste trabalho foi considerada como uma repetição de padrões, que será descrita na seção 6.6.

As restrições de simetria, podem ser utilizadas em conjunto com as seguintes restrições: membros mínimo, buraco mínimo, a restrição de extrusão, a menos da direção em que o modelo esta sendo extrudado, a restrição de fundição com exceção da direção de fundição propriamente dita que causaria problemas por contradição entre as restrições, a restrição de repetição de padrões desde que elas não sejam contraditórias em algum dos padrões. Neste caso vale salientar que a simetria é aplicada sobre o modelo inteiro e não apenas sobre a área de referência do padrão. Uma restrição que contempla a simetria do padrão a ser repetido não foi implementada, mas que pode ser implementada com as mesmas características da simetria aqui apresentada, porém levando em consideração apenas os elementos que representam as variáveis de projeto $d$ da repetição de padrões.

\subsection{Extrusão}

A extrusão assim como o processo de fabricação visa obter uma única seção transversal seja repetida ao longo do domínio inteiro. Com isso podemos definir como variáveis de projeto uma área igual a da seção transversal do modelo, como podemos ver na figura 6.9. Estas variáveis de projeto $d$ estão representando toda a coluna de elementos que se encontra na direção de extrusão. Como mostrado na figura 6.9 , os domínios $\Omega_{i}$ são formados a partir de um elemento de referência contido no plano de coordenadas com menores valores na direção de extrusão, existente no modelo. Com isso todos os elementos contidos naquela direção são incluídos no domínio. Como a malha é estruturada, a quantidade de elementos em cada domínio $\Omega_{i}$ é sempre constante, o que mostra que todos as seções possuem o mesmo número de elementos.

Assim como na restrição de membro mínimo, a sensibilidade é calculada para a restrição de extrusão através da soma da sensibilidade dos elementos contidos dentro de cada um dos domínios $\Omega_{i}$. A única diferença neste caso é o fato de que a sensibilidade de cada uma das pseudo-densidades, tem influência, apenas sobre uma variável de projeto, e não sobre todas as variáveis de projeto situadas em seu entorno, como no caso do membro mínimo.

A restrição de extrusão, utiliza a projeção para transformar as variáveis de projeto $d$ nas pseudo-densidades equivalentes. Porém, diferentemente do caso da restrição de membro mínimo ou de buraco mínimo, onde diferentes domínios 


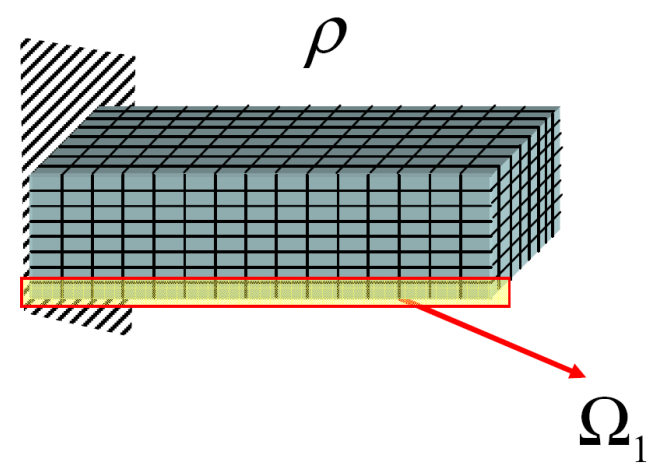

(a)

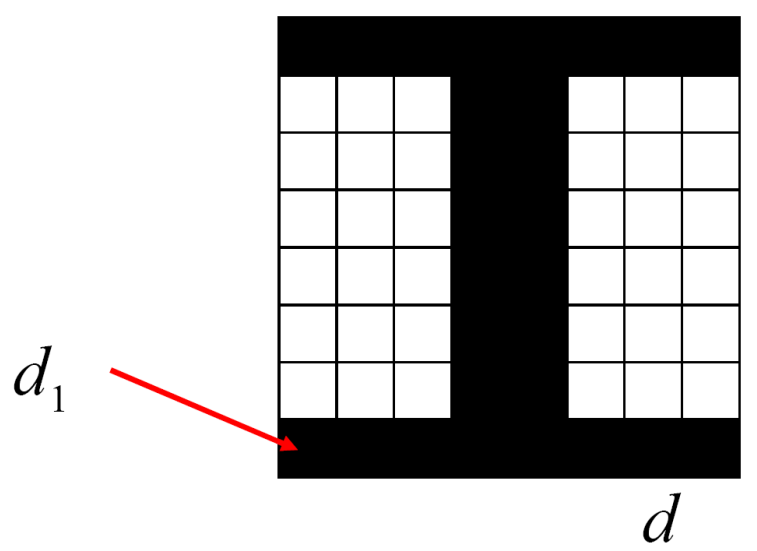

(b)

Figura 6.9: Esquema de projeção para restrição de extrusão.

$\Omega_{i}$ continham uma mesma pseudo-densidade, e por isto existe a necessidade de se utilizar a função máximo ou mínimo, como definido na seção 4.3.3. No caso da restrição de extrusão, por se ter apenas um valor projetado sobre as pseudodensidades de cada domínio, realiza-se apenas uma igualdade, ou seja, o mapeamento é utilizado apenas para fazer a igualdade das pseudo-densidades dos elementos contidas no domínio $\Omega_{i}$ com a sua variável de projeto $d_{i}$ correspondente.

Uma consideração sobre a implementação numérica realizada neste trabalho é que ela trabalha com a posição existente entre os elementos, utilizando para isso os nós que estes compartilham. Como efeito positivo disto, se um domínio for construído de forma a parecer uma barra dobrada, independentemente de quantas dobras, mantendo-se a malha estruturada, o domínio de extrusão fará as curvas acompanhando o perfil existente no domínio. Isso ocorre também se o domínio possuir alguma relação de escala entre suas extremidades, desde que se mantenha a malha estruturada. Na figura 6.10 estão exemplificados domínios com essas características.

Porém, esta forma de implementação faz com que domínios que não possuam uma forma regular não possam ser resolvidos com essa restrição. Para tornar isto possível deveria ser feito um mapeamento geométrico do domínio, e então, baseando-se nas coordenadas dos centros dos elementos realizar o mapeamento das variáveis, que não mais resultaria em vetores de mesmo tamanho para cada uma das relações entre variáveis e pseudo-densidade.

Assim como outras restrições que serão detalhadas ao longo deste capítulo, a restrição de extrusão, muitas vezes possui domínios com muitos elementos re- 


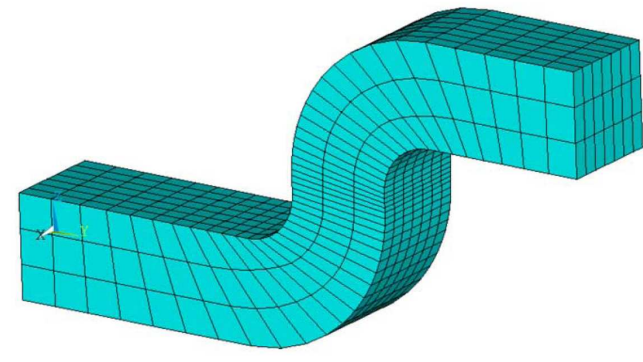

(a)

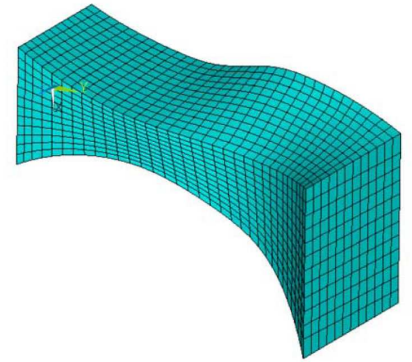

(b)

Figura 6.10: (a) Domínio com formato curvo. (b) Domínio com trechos com fator de escala e com inclinações diferentes.

presentados apenas por uma pequena quantidade de variáveis de projeto, o que faz com que a massa seja movimentada em grandes quantidades, e obrigando muitas regiões que não deveriam possuir massa, a receber uma pseudo-densidade próxima de 1. Desta forma em algumas soluções podem existir grandes áreas de cinza. Duas formas de resolver este problema são: refinando mais a malha de forma que quantidade menores de massa sejam representadas por cada variável de projeto, ou aumentando a restrição de massa, de forma a deixar a região cinza se tornar uma região de pseudo-densidade 1 .

A restrição de extrusão pode ser utilizada em conjunto com todas as outras restrições, desde que sua direção de extrusão não entre em conflito com a direção da outra restrição, como no caso da fundição, ou do forjamento.

\subsection{Revolução}

A restrição de revolução mapeia o domínio de projeto em torno de um eixo central com relação ao plano normal definido pelo usuário para conter as coroas circulares como podemos ver na figura 6.11. As coroas circulares são subdivididas em passos de $d R$ definidos pelo usuário. No caso de uma malha regular com elementos com lados iguais nas direções contidas no plano de referência é aconselhável utilizar a dimensão do lado do elemento. Para a distância entre as camadas na direção perpendicular ao plano de referência o usuário deve especificar o tamanho do elemento nesta direção.

Com isso temos os domínios compostos por coroas circulares, como mostrado na figura 6.12 , onde temos os domínios $\Omega_{i}$ representados cada um por uma cor 


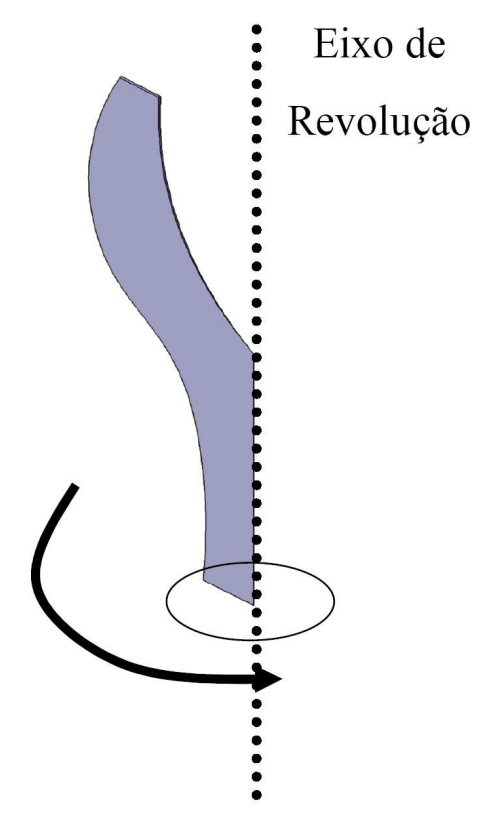

(a)

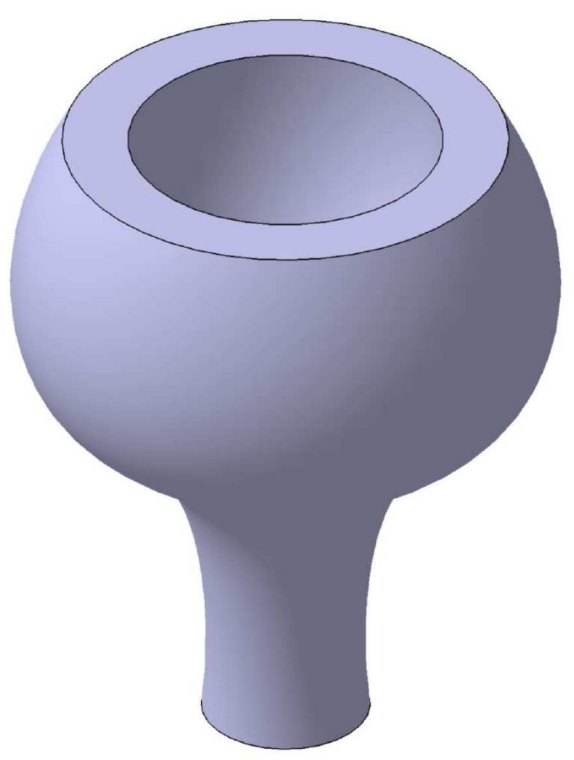

(b)

Figura 6.11: (a) Exemplo de perfil utilizado para se realizar uma revolução.(b) Peça obtida através da revolução do perfil.

diferente. Cada um desses domínios é representado por apenas uma variável de projeto $d$, assim como na restrição de extrusão. Estas variáveis de projeto, não estão contidas sempre em um plano único, já que em um problema discreto não se pode garantir a existência de elementos em todas as coroas circulares para uma dada posição, como podemos ver na figura 6.12. Apesar disto, apenas uma variável de cada coroa é considerada, e quando é feita sua projeção o resultado encontrado no campo das pseudo-densidades as coroas são formadas de forma correta.

Dois efeitos chamam atenção na restrição de revolução, a primeira dela é a ocorrência de formas não-circulares, porém que obedecem aos critérios da restrição, como podemos ver na figura 6.12 , onde a camada mais externa de elementos é representada por apenas 4 elementos, dispostos com simetria em relação ao centro da circunferência, mas que pode causar na solução um efeito visual que foge do esperado para a revolução. Este efeito somente pode ser evitado com a utilização de um modelo com um formato realmente circular ou cilíndrico, já que é apenas um problema de representação.

Outro efeito interessante pode ser visto na figura 6.13, em que a solução possui uma simetria na direção em que não existe esta restrição, o que seria natural 


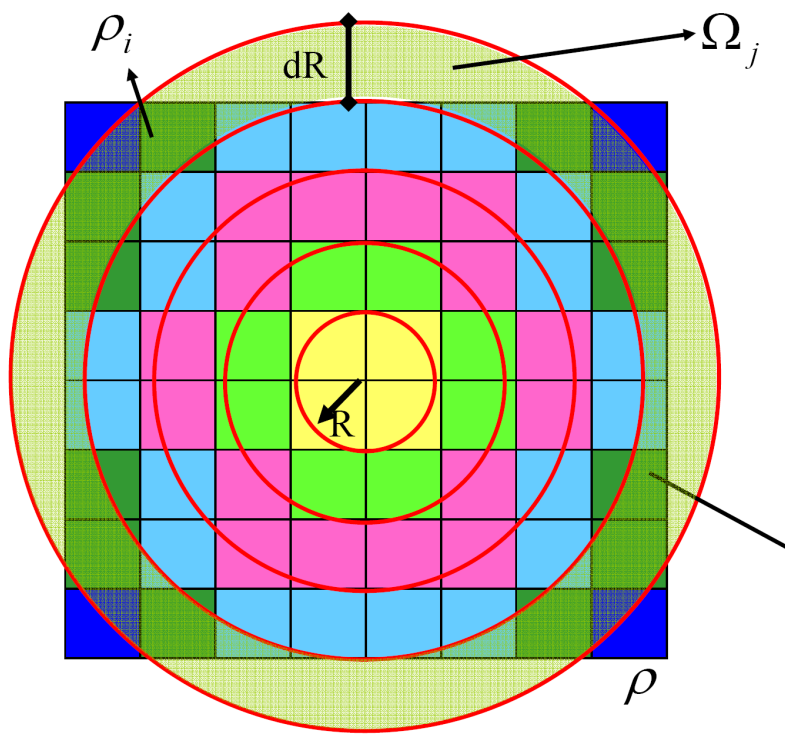

(a)

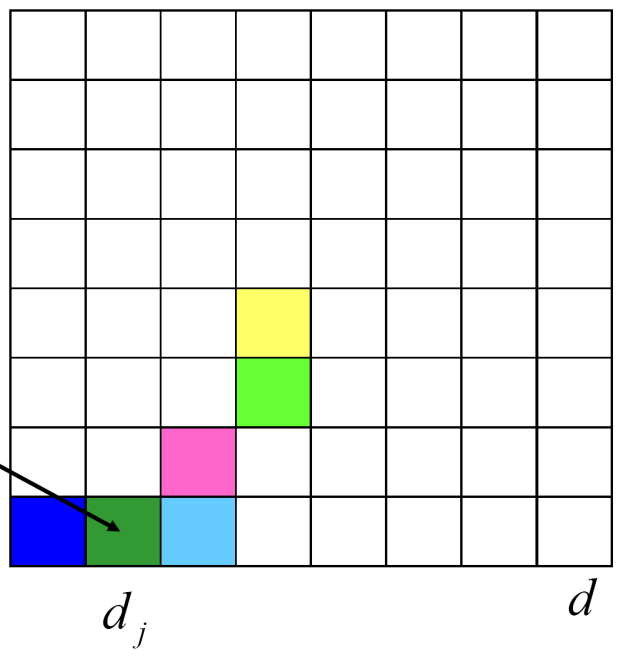

(b)

Figura 6.12: Esquema de projeção para restrição de revolução.

de se esperar já que as condições de carga são simétricas. Porém é conhecido o fato de que as soluções não apresentam simetria nestas condições devido a diferenças numéricas que aparecem nos métodos de resolução de sistemas lineares. Na solução da figura 6.13 devemos sua simetria indicada ao fato de alguns elementos acumularem a influência da sensibilidade de muitos elementos faz com que as diferenças de arredondamentos ocorridas dentro das rotinas sejam minimizadas, encontrando assim a solução com esta simetria.

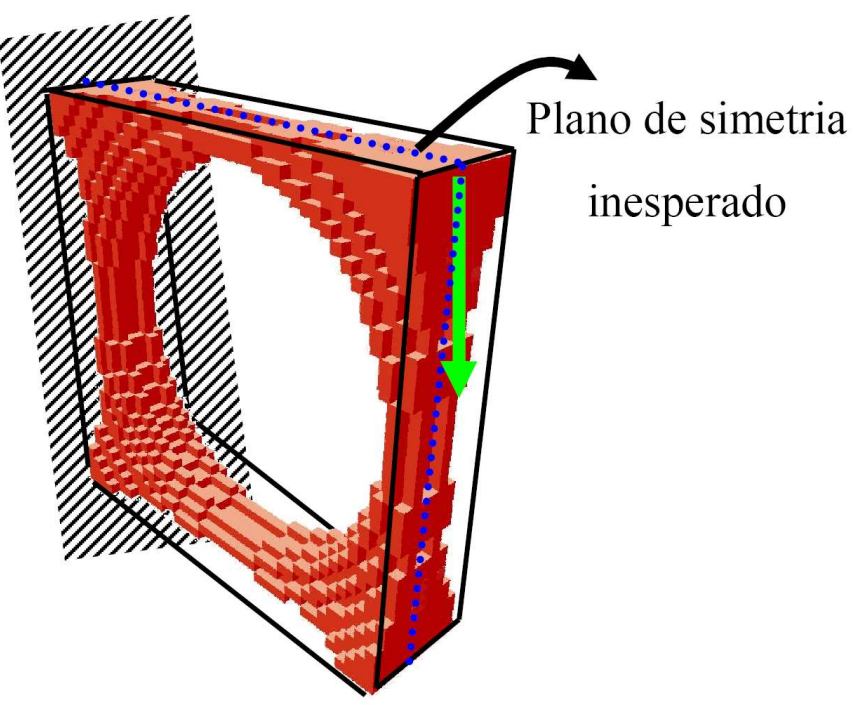

Figura 6.13: Efeito de simetria na direção perpendicular a revolução. 
Este mesmo exemplo possui uma característica interessante, a obrigatoriedade de uma revolução fez com que aparecesse um grande furo concentrado, o que pode ser utilizado com um efeito desejado em casos onde o tamanho de furos deve ser controlado, ou onde se deseja apenas furos centralizados. Os passos entre os raios podem ser definidos de maneira a garantir estas condições de tamanho e posicionamento de furos.

A condição de revolução não precisa ser aplicada em torno do centro geométrico, existindo portanto soluções com o centro deslocado em relação ao elemento. Porém na atual implementação, o mapeamento das coroas será finalizado quando ele encontrar uma coroa que não possui nenhum elemento. Por isso o centro não deverá ser deslocado o bastante para que a primeira coroa não possua nenhum elemento, já que nessa condição o mapeamento seria finalizado antes de encontrar alguma coroa.

Para se obter soluções manufaturáveis através de torneamento, devemos aplicar esta restrição, o que já delimitaria a sua forma principal. Porém para impedir o surgimento de furos internos devemos utilizar a restrição de membro mínimo ou a restrição de buraco mínimo, verificando-se sempre se a solução obtida se encontra dentro do esperado, ou se um ajuste deve ser feito no raio da restrição de membro ou buraco mínimo.

Esta restrição pode ser utilizada com as restrições de membro mínimo e buraco mínimo, fundição e extrusão desde que seus eixos principais não coincidam para não causar uma contradição de restrições. Ela pode ser utilizada em conjunto com a restrição de repetição de padrões , porém com repetições apenas no sentido perpendicular as coroas circulares.

\subsection{Repetição de Padrões}

A restrição de repetição de padrões pode ser utilizada de duas maneiras: induzir uma repetição de formas dentro de um domínio contínuo, com todos os padrões igualmente direcionados, como se fosse a representação da micro-estrutura de um material; garantir que regiões que não possuam mesma direção ou sentido exibam a mesma forma em torno de um sistema de coordenadas local.

Sendo assim a restrição de repetição de padrões, foi implementada de forma dupla, que funcionam de forma similar, porém tem o seu mapeamento feito de forma diferente. Quando considerado apenas um domínio contínuo como na figura 
6.14 e formas repetidas em relação ao mesmo sistema de coordenadas, as variáveis são mapeadas tomando-se como referência o domínio como um todo e dividindo a estrutura nas três direções como solicitado pelo usuário (sendo necessário que o usuário tome o cuidado de entrar números pelos quais a quantidade de regiões em cada direção seja divisível de forma exata). Com isso é possível identificar o número de variáveis de projeto que são necessárias para representar um bloco padrão, incluindo qual o número de elementos desse bloco em cada uma das três direções. Com o os números de elementos encontrados para cada direção podemos definir um elemento de referência dentro de cada bloco, e todos os outros elementos desse bloco são incluídos no domínio $\Omega_{i}$ representado por $d_{i}$, sendo considerada a sua posição em relação ao elemento de referência.

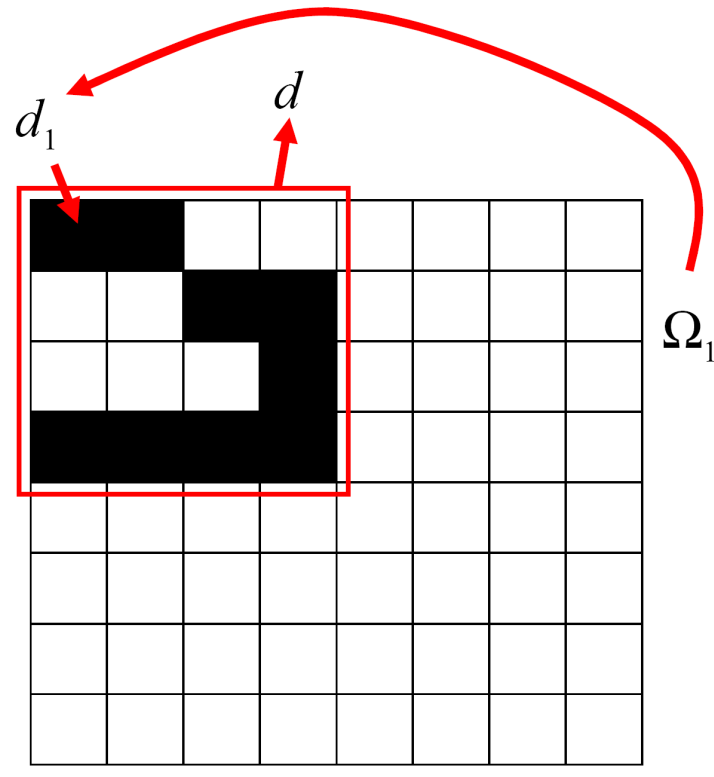

(a)

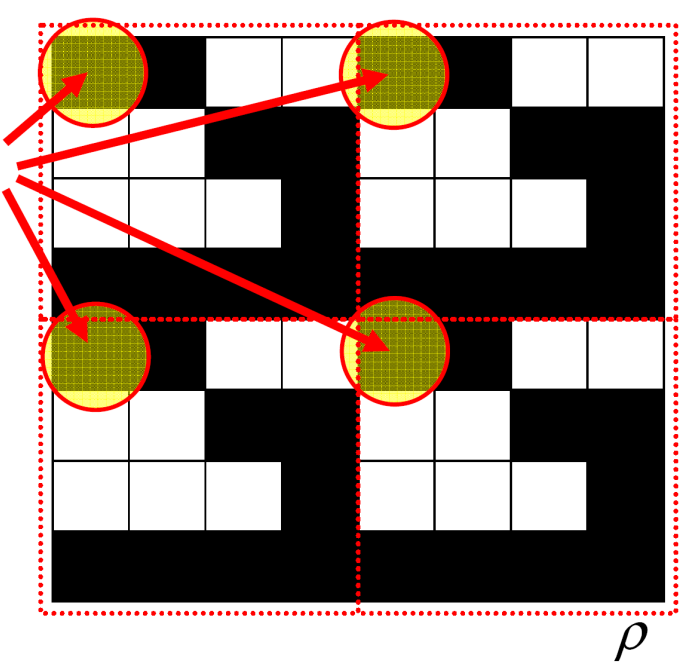

(b)

Figura 6.14: Esquema de projeção para restrição de repetição de padrões num único domínio conexo.

Quando são considerados domínios não-contínuos e não-alinhados como o mostrado na figura 6.15, o usuário deverá montar o modelo identificando para a rotina qual é a área definida para um bloco, e também quais são as origens de todos os demais blocos existentes, bem como as direções dos sistemas de coordenadas locais utilizadas para mapear aquele bloco. Com isso os padrões podem ser repetidos até mesmo de forma a obter uma simetria.

Como no caso da extrusão, as variáveis de projeto $d$ não precisam utilizar a função máximo, pois não existe sobreposição de domínios. Então a projeção é 


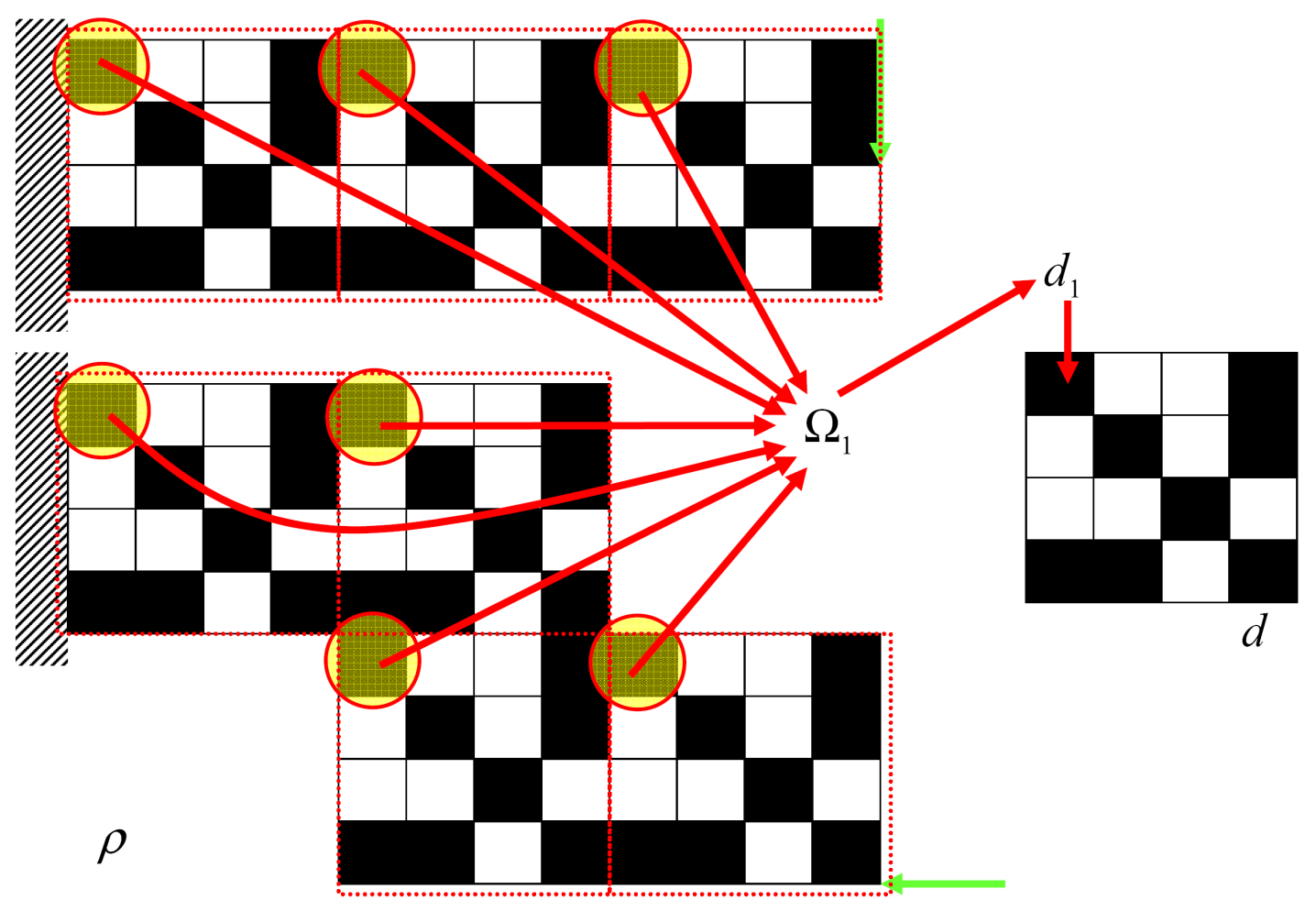

Figura 6.15: Esquema de projeção para restrição de repetição de padrões em domínios não-conexos.

realizada por uma igualdade feita entre os elementos mapeados passando valores das variáveis de projeto para as pseudo-densidades por ela representadas.

De forma semelhante também à restrição de extrusão, esta restrição utiliza a posição relativa entre os elementos para fazer seu mapeamento, não sendo importante o tamanho do elemento, e sim que a malha seja estruturada e os padrões repitam as quantidades de elementos, sendo válidas as condições de domínios com escala diferente e com formas curvas definidas com malhas estruturadas. Assim as vantagens do mapeamento realizado dessa forma é a desvinculação com a escala entre padrões ou até mesmo as extremidades do padrão, porém no caso que se queira garantir padrões iguais em malhas de tamanhos diferentes seria necessário a implementação de um mapeamento geométrico para essa restrição.

Esta restrição pode ser utilizada com todas as demais restrições, desde que a repetição de padrões não implique em uma contradição na direção principal da outra restrição. 


\subsection{Fundição}

A restrição de fundição visa garantir que a solução encontrada possua furos apenas em uma direção, sendo assim, temos a definição do conjunto de variáveis de projeto $d$, como mostrado na figura 6.16. A quantidade de variáveis de projeto neste caso, se iguala ao número de elementos, sendo que cada variável representa a pseudo-densidade de mesma posição relativa no domínio das variáveis $\rho$, e também todas as outras pseudo-densidades de elementos situados abaixo do elemento de referência. Para isso precisa-se definir sempre um sentido e uma direção para que a restrição de fundição possa se referenciar. Assim como na restrição do membro mínimo, algumas pseudo-densidades aparecem em mais de um domínio $\Omega_{i}$, valendo nesse caso a função de projeção máximo, para que ela somente assuma o valor mais alto existente sobre ela.

Desta forma, o mapeamento permite que a técnica de projeção garanta que sempre existirá elementos com no mínimo a mesma pseudo-densidade sob o elemento de referência. Um dos problemas de se fazer isto, é que sempre existirá uma face plana na solução encontrada, que é o lado definido como de baixo. Com isso temos uma solução que se parece com uma fundição onde um dos lados do molde é uma superfície plana, podendo até mesmo ser furada, porém nunca com desníveis.

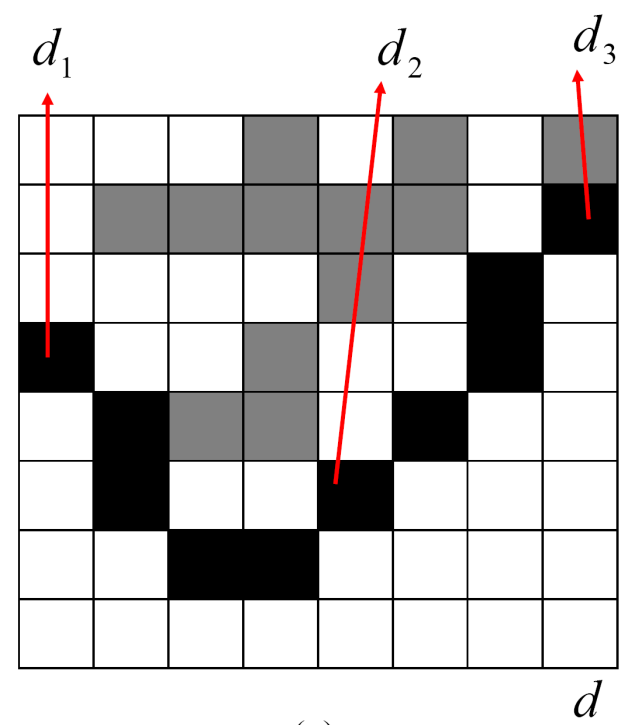

(a)

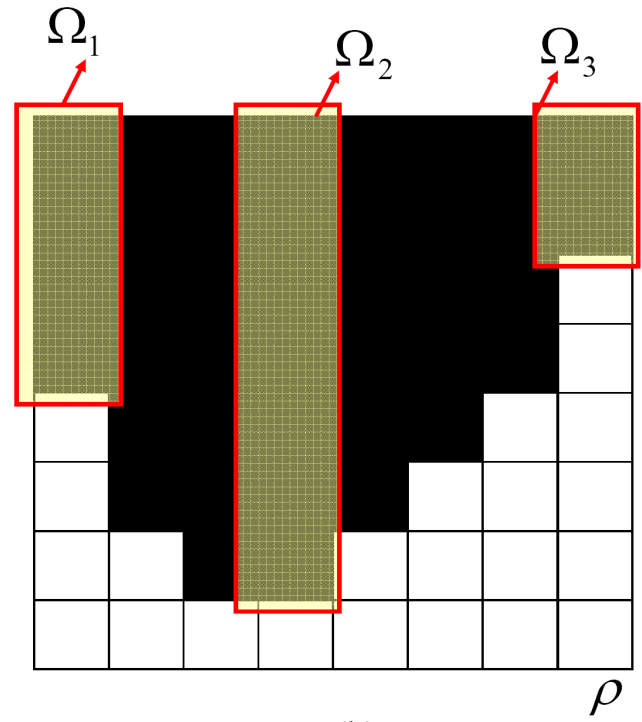

(b)

Figura 6.16: Esquema de projeção para restrição de fundição com apenas um molde.

De forma a resolver o problema da existência de uma superfície plana no extremo definido com lado inferior da solução, foi implementado um segundo 
conjunto de variáveis de projeto, que tem seu mapeamento feito da mesma forma, porém se trocando a face de referência do lado inferior, pela sua face oposta, ou seja o lado superior. Desta forma ficamos com dois mapeamentos opostos.

Ao resolvermos cada iteração da otimização dos dois problemas mapeados de forma oposta, temos duas soluções, cada qual com um lado plano. A solução que desejamos encontrar é uma solução que garanta que sempre haverá massa no seu centro, porém que possa ter dois moldes não planos, para permitir uma maior possibilidade de soluções.

Uma forma encontrada para resolver este problema foi através da intersecção das duas soluções mapeadas de forma oposta, ou seja, depois de se projetar as variáveis de projeto $d$ dos dois domínios sobre o seu respectivo campo de pseudo-densidades, realizamos a intersecção desses campos de pseudo-densidades para encontrar uma solução única, que atenderá aos critérios desejados. Como o problema em questão é um problema resolvido com variáveis contínuas, com infinitos valores possíveis para cada variável, foi utilizada a função mínimo de forma a garantir a intersecção entre as duas soluções encontradas. Dessa forma a pseudo-densidade final, receberá sempre a pseudo-densidade menor existente para a sua posição encontrada nas duas soluções com mapeamento opostos.

Este processo se repete a cada iteração, sendo sempre utilizado para o cálculo das sensibilidades, a solução final das pseudo-densidades.

Uma outra solução implementada para a restrição de fundição é a utilização de um plano de referência situado na parte interna do domínio e não nos seus extremos, com isso pode ser escolhida a altura na qual será definido um plano de onde crescerá a estrutura. Podendo esse plano ser definido no centro e com isso permitir que a restrição de simetria seja utilizada, ou podendo ser a qualquer altura definida pelo usuário. Podemos ver uma representação esquemática da divisão do plano na figura 6.18.

No caso da utilização desta condição, não existe a sobreposição de domínios como no caso de se utilizar dois mapeamentos opostos, aqui existem as mesmas quantidades de variáveis de projeto $d$ e de pseudo-densidades $\rho$, não sendo necessário fazer a operação de intersecção com a função mínimo.

As restrições de fundição podem ser utilizadas com todas as demais restrições, menos com a de forjamento. No entanto deve apenas ser observado se não existe alguma contradição no problema posto.

Um problema que pode surgir no caso da restrição de fundição, é o fato 


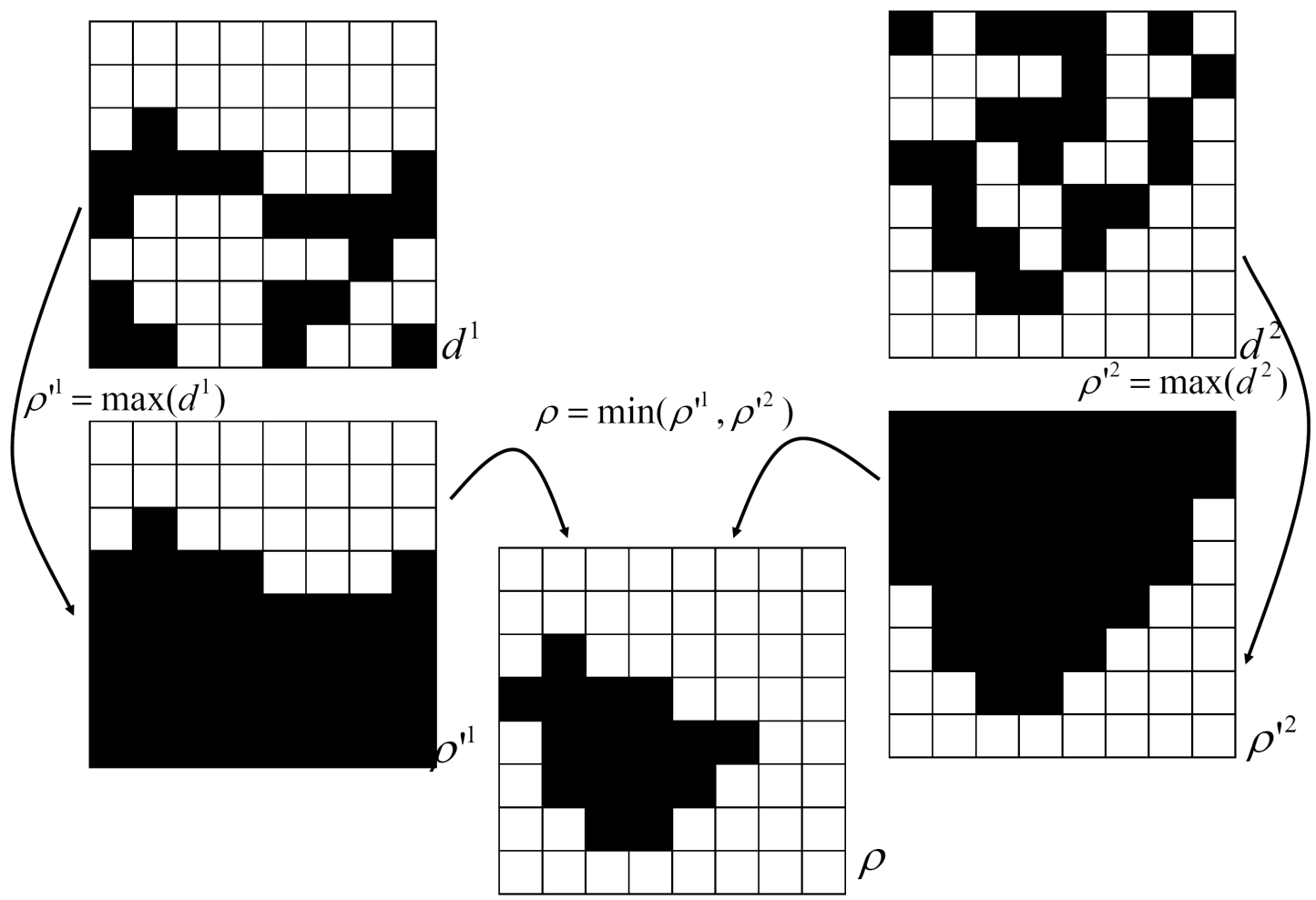

Figura 6.17: Esquema de projeção para restrição de fundição com dois moldes.

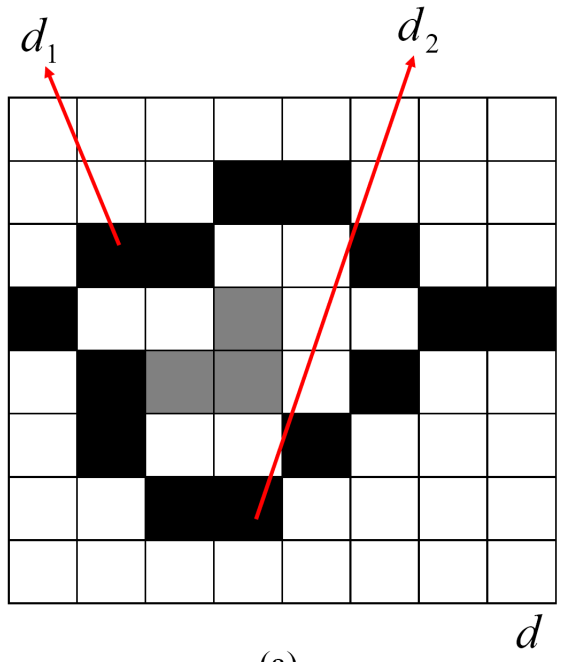

(a)

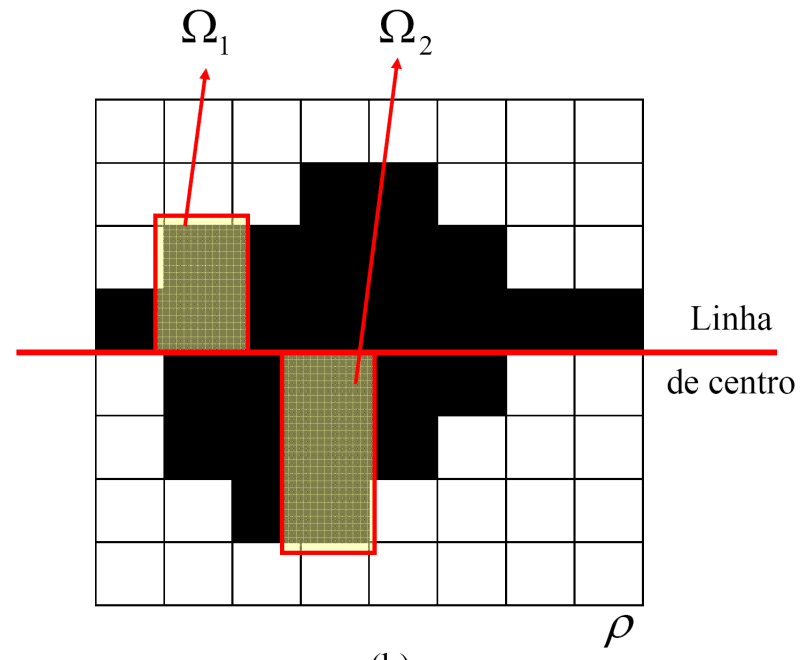

(b)

Figura 6.18: Esquema de projeção para restrição de fundição com dois moldes e uma linha de encontro pré determinada.

de termos muitas pseudo-densidades representadas por uma mesma variável de projeto, aqui de forma muito mais drástica do que no caso da extrusão. Com isso, o problema muitas vezes fica oscilando antes de ter uma convergência rápida, devido ao grande deslocamento de massa realizado de uma vez. Graças a esse problema também pode ocorrer uma grande presença de cinza na solução final, devido a necessidade de se obrigar a existir massa em regiões de pouca importância 
devido a restrição, e até mesmo pela natureza da restrição que dependendo da carga pode obrigar uma boa parte do domínio a ter que ser preenchido por alguma massa para satisfazer a condição. O aumento da penalização não resolve este problema, sendo necessário regular o valor da restrição de massa para um valor superior de forma a deixar o problema um pouco mais solto e encontrar uma solução mais adequada.

\subsection{Forjamento}

Em cima do mesmo princípio utilizado para a criação da restrição de fundição com dois moldes, a restrição de forjamento se utiliza de mais de um conjunto de variáveis de projeto $d$, utilizando ao todo quatro domínios. Inicialmente se define um plano de referência o qual será utilizado para gerar os domínios. Com este plano definido, segue-se paralelamente à ele, como na restrição de revolução, formando os domínios de cada camada de elementos, como está exemplificado na figura 6.19.

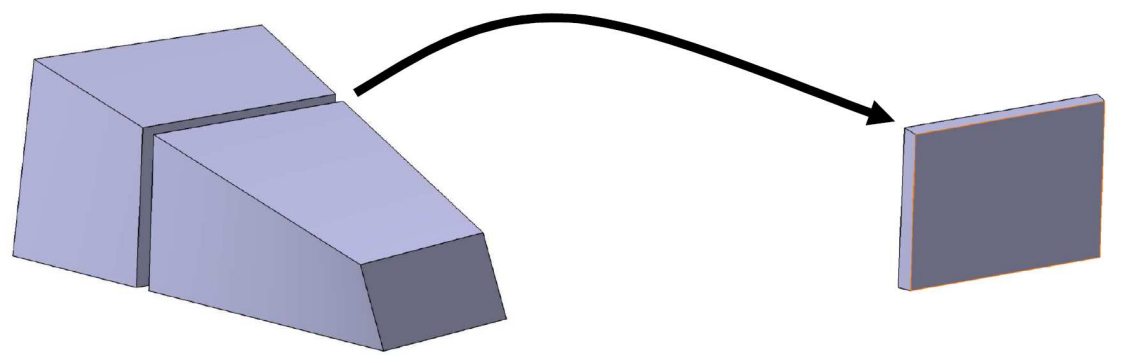

Figura 6.19: Exemplo de camada a ser utilizada para criar os domínios da restrição de forjamento.

O mapeamento do domínio das pseudo-densidades faz com que cada variável de projeto $d$ represente todas as pseudo-densidades localizadas da posição de referência idêntica a variável $d$ e todas as demais situadas em um sentido do eixo $x$ e em um sentido do eixo $y$, formando assim um retângulo que começa no elemento de referência e se estende até o final do modelo, como podemos observar na figura 6.20 .

Desta forma, são realizados os quatro mapeamentos, cada um considerando um quadrante a partir do elemento de referência. Ao se resolver o problema, cada um dos domínios tem a sua sensibilidade calculada de forma independente, a solução encontrada para a pseudo-densidade de cada um dos domínios projetada 


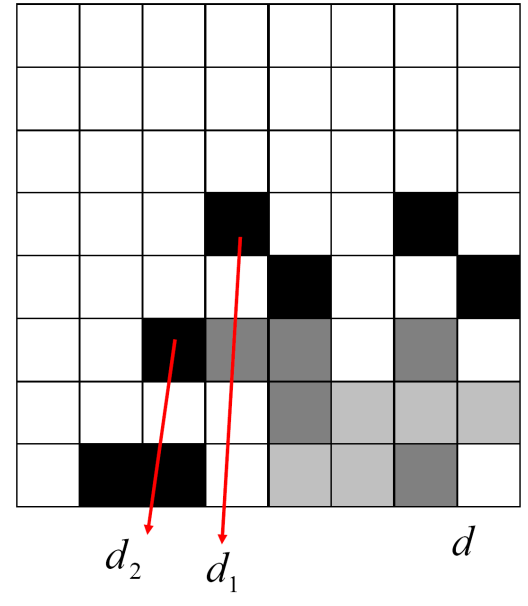

(a)

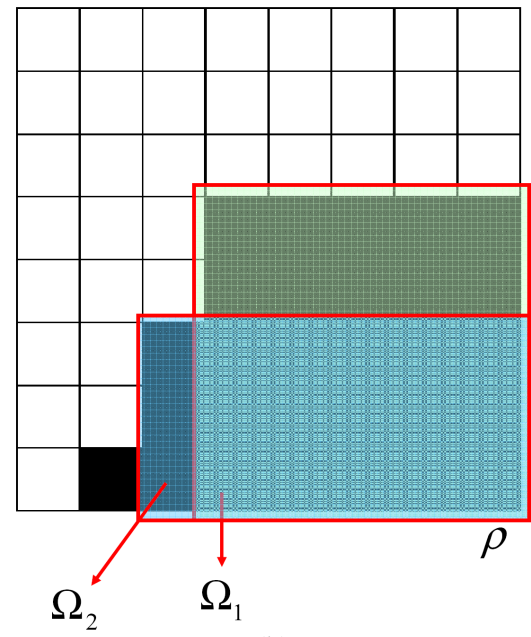

(b)

Figura 6.20: Esquema de projeção para restrição de forjamento.

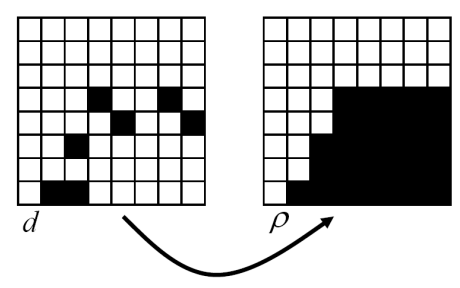

$\rho=\max (d)$
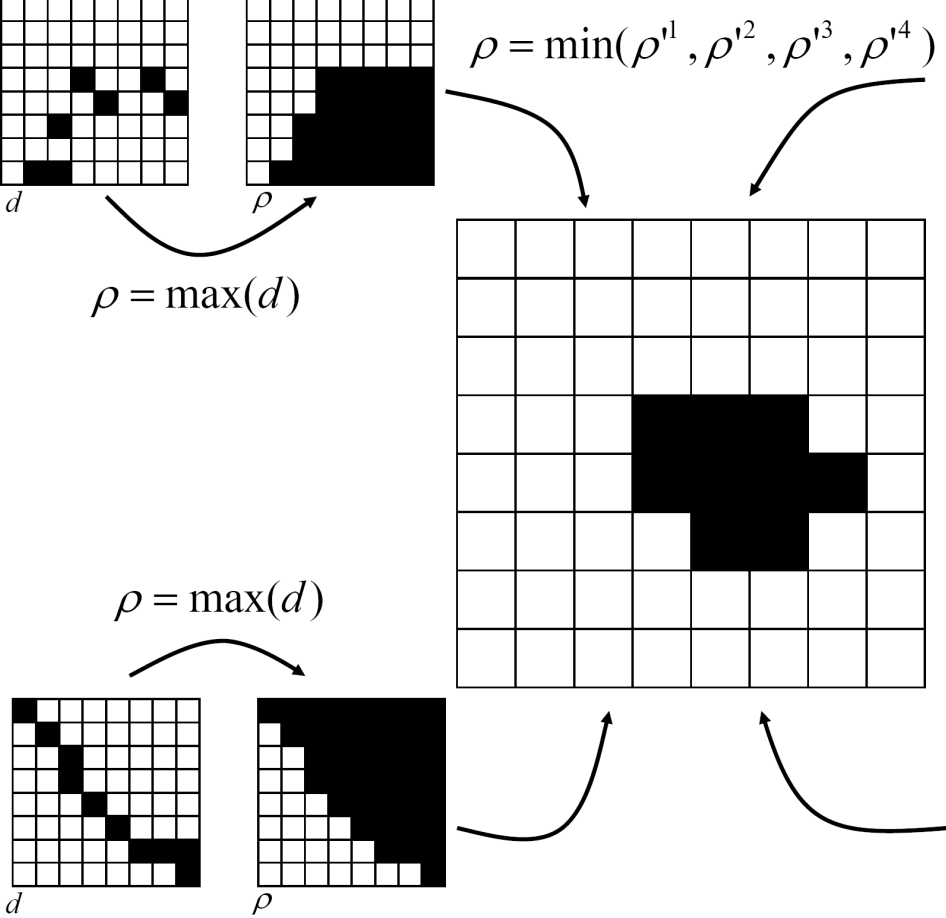
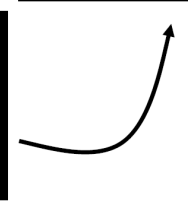

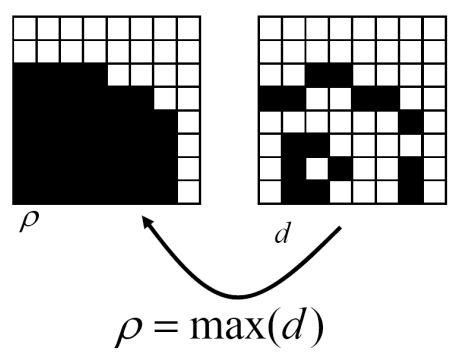

$$
\rho=\max (d)
$$

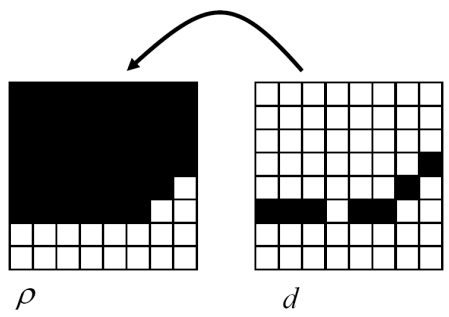

Figura 6.21: Intersecção entre os domínios de projeto $d$ da restrição de forjamento.

a partir do valor da variável de projeto respectiva. Então como no caso da restrição de fundição, é utilizada a função mínimo para realizar a intersecção das quatro soluções, encontrando assim a solução final daquela iteração, sendo estes resultados utilizados para o cálculo das sensibilidades da próxima iteração. $\mathrm{Na}$ figura 6.21 podemos ver o processo de projeção das variáveis de projeto $d$ para as pseudo-densidades de cada domínio, e destes com a intersecção para a solução 
final.

Esta restrição, apesar de poder ser utilizada em problemas de duas dimensões, em geral encontra problemas para convergir, devido ao fato das condições de contorno em geral encontrarem-se nos extremos do domínio de projeto, a restrição acaba chegando a uma solução praticamente toda preenchida por pseudodensidades intermediárias.

A restrição de forjamento, pode ser utilizada com todas as demais restrições, menos com a de fundição. Com as demais deve-se tomar cuidado com presença de contradições, que no caso da restrição de forjamento, ocorrem em muitos casos, devido ao fato de ser uma restrição bem drástica do campo de soluções, chegando sempre a resultados sólidos, sem furos internos.

\subsection{Laminação}

Para se obter restrição de laminação, podemos nos valer apenas da utilização de restrições já implementadas. A restrição de fundição com um plano de referência situado em seu centro como indicado na figura 6.22, a restrição de simetria utilizando este mesmo plano, garantindo desta forma que as duas metades encontradas pela restrição de fundição sejam idênticas. A restrição de extrusão em relação à face vermelha da figura 6.22 que é perpendicular ao plano de referência da restrição de fundição, fazendo com que o formato da fundição seja repetido ao longo da direção de extrusão. Finalmente com o controle de um membro mínimo, ou buraco mínimo de forma a garantir bordas com curvaturas suaves o bastante para que o processo de fabricação se torne viável.

Como pode ser observado, nenhuma restrição extra foi implementada neste caso para se obter a restrição desejada, apenas a sobreposição das restrições já implementadas consegue obter os resultados desejados. Porém poderia ter sido implementada uma restrição que realizasse todo o processo de uma vez, obtendo provavelmente um pequeno ganho computacional.

Com a sobreposição das restrições existentes, ou com uma restrição nova implementada, um problema aparece, que é a grande quantidade de regiões intermediárias quando não existe massa o suficiente para preencher o domínio com uma solução adequada. Neste caso, assim como no caso do forjamento, o problema se agrava devido a grande quantidade de pseudo-densidades representadas por uma única variável de projeto. 


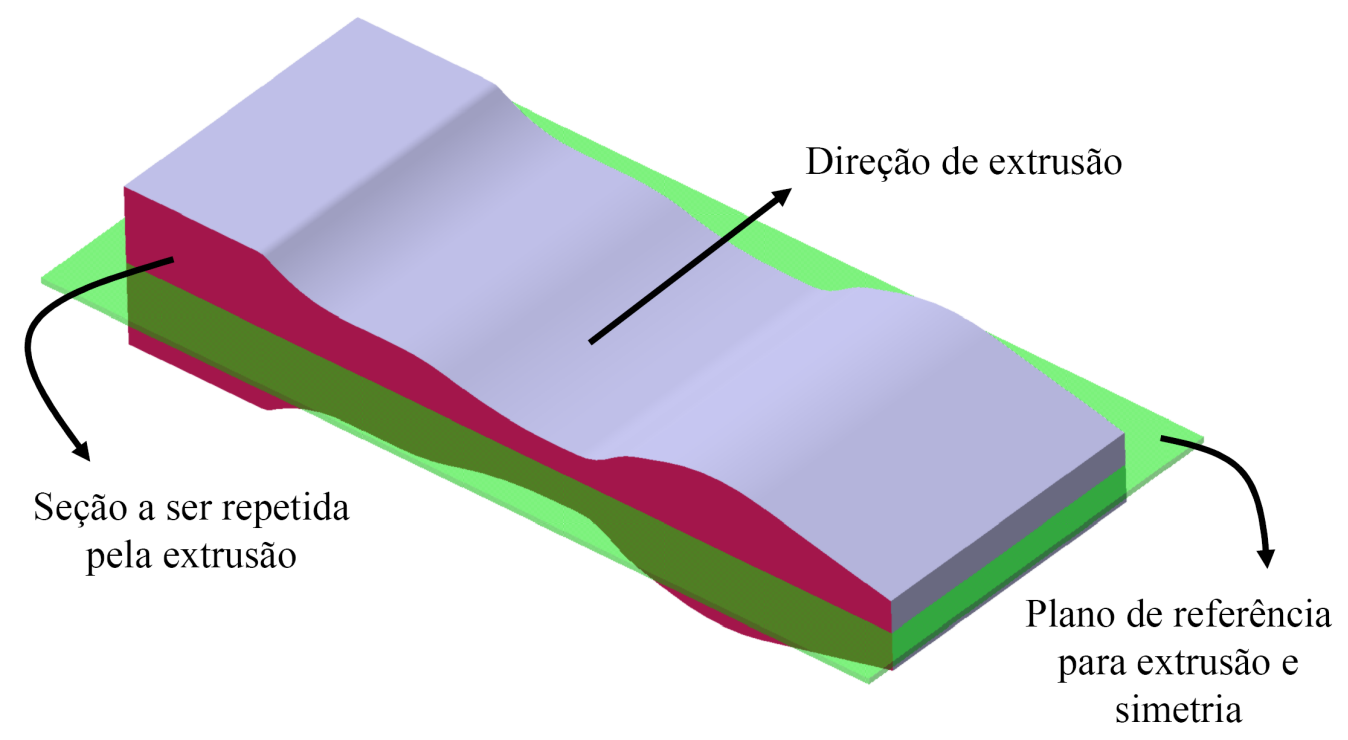

Figura 6.22: Restrições agindo em conjunto para garantir a restrição de laminação. 


\section{$7 \quad$ Resultados}

Diversos resultados podem ser obtidos através das condições de restrições implementadas no problemas de máxima rigidez com restrição de volume apresentado na equação 7.1 .

$$
\begin{aligned}
\underset{d}{\operatorname{minimizar}} & f(\rho(d)) \\
\text { tal que } & \left\{\begin{array}{l}
\boldsymbol{K}(\rho(d)) \overline{\boldsymbol{d}}(\rho(d))=\boldsymbol{f} \\
\sum_{i=1}^{n_{\text {elementos }}} \rho_{i} v_{i} \leq V \\
\rho_{i}=f(d)
\end{array}\right.
\end{aligned}
$$

Serão apresentados a seguir resultados obtidos para simulações com as restrições de manufatura implementadas. Os modelos utilizados em todos os problemas apresentam os seguintes parâmetros: módulo de elasticidade $E_{0}=100$, coeficiente de Poisson $\nu=0,3$ e cada um dos vetores forças que aparece nas figuras tem o valor de carga igual à 100 .

Como nenhum processo de fabricação aceita a presença de furos internos, ou seja, não passantes, quando a restrição aplicada sozinha não conseguir garantir esta condição é utilizado também a restrição de membro mínimo, ou de furo mínimo, de forma a garantir que estes furos não apareçam. Em todos os exemplos, quando não indicado um raio específico para a restrição de membro mínimo, considerar um raio de 1,5 vezes do tamanho do elemento no modelo.

\subsection{Restrição de Membro Mínimo}

O tamanho mínimo de membro indica que deve haver uma seção mínima na solução encontrada. Na figura 7.1 podemos perceber a relação entre as variáveis de projeto $d$ apresentadas em (a) e a solução final encontrada para as pseudovariáveis $\rho$ ilustradas em (b). A relação entre os dois domínios mostra claramente 
que a restrição de membro mínimo não cria novos membros na solução, apenas garante que qualquer membro que apareça possua uma espessura mínima definida para o problema.

Número de elementos: 5000

Restrição de volume: $50 \%$

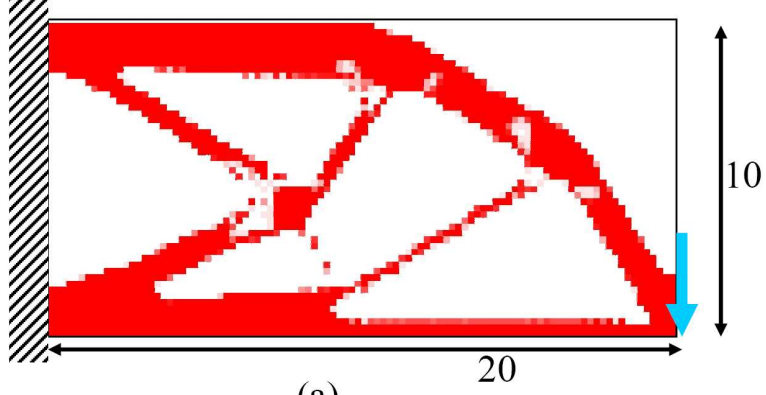

(a)

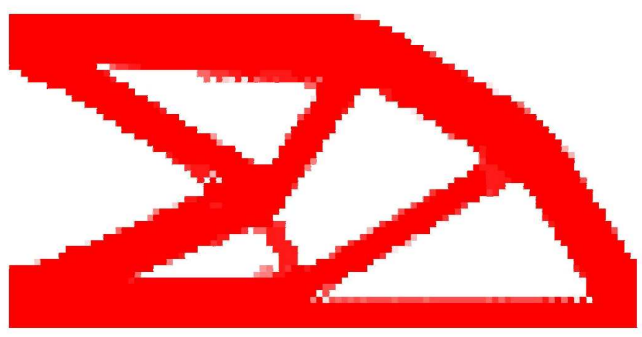

(b)

Figura 7.1: Resultados obtidos com volume restrito a 50\% do domínio. (a) Variáveis de projeto $d$. (b) Pseudo-densidades $\rho$.

A restrição de membro mínimo, além de resolver os problemas numéricos apresentados na seção 2.4, consegue através do controle do membro mínimo, controlar a quantidade de membros existentes na solução. Na figura 7.2, podemos ver duas soluções para o mesmo problema, porém com raios de membro mínimo distintos. Esta diferença de raios, leva o problema a soluções diferentes. Porém, este controle do número de membros, é feito na base da tentativa e erro, ou seja, se testa diversos raios até se encontrar uma solução que atenda a quantidade de membros mínimos, e mesmo desta forma a restrição de membro mínimo não consegue garantir que tal solução seja encontrada.

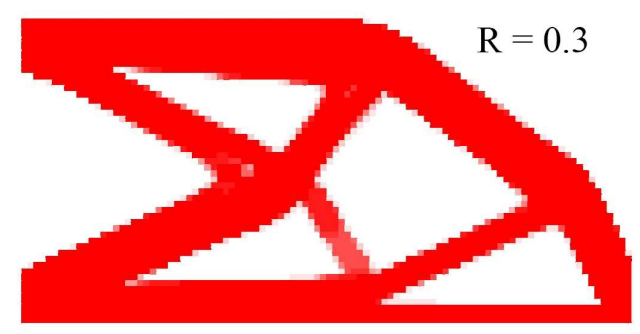

(a)

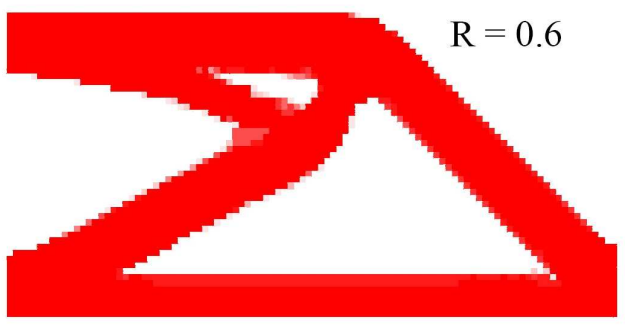

(b)

Figura 7.2: (a) Solução para o problema apresentado na figura 7.1 resolvido com raios diferentes de membro mínimo. (a) $R_{\min }=0,3$. (b) $R_{\min }=0,6$.

Da mesma maneira que em duas dimensões, o membro mínimo pode ser aplicado a problemas tridimensionais. Pode ser visto na figura 7.3, a relação 
existente o campo de variáveis de projeto, mostrado em (a) e o campo de pseudodensidades, mostrado em (b). A relação é a mesma da restrição em duas dimensões, ou seja, a quantidade de membros não é alterada, apenas as suas espessuras são controladas, de forma a não violarem a restrição de membro mínimo.

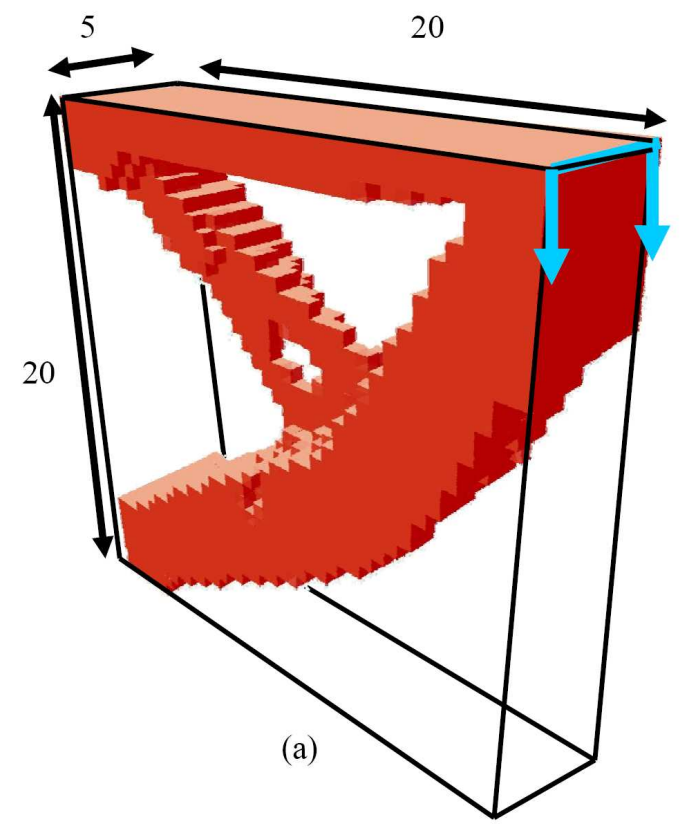

\section{Número de elementos: 16000 \\ Restrição de volume: $50 \%$}

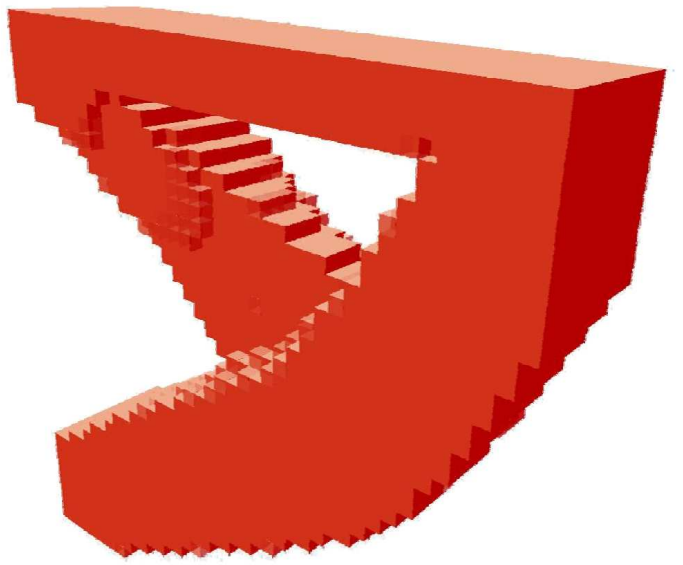

(b)

Figura 7.3: Resultados obtidos com volume restrito a 50\% do domínio. (a) Variáveis de projeto $d$. (b) Pseudo-densidades $\rho$.

No caso tridimensional, a restrição de membro mínimo é aplicada com um mapeamento em forma de esferas em torno dos elementos, porém, podemos fazer um mapeamento similar ao do problema bidimensional, considerando áreas em forma de discos, contidas em planos com normais nos eixos principais. Na figura 7.4 podemos ver em (a) uma solução sem nenhuma restrição, que possui uma grande região com instabilidade de tabuleiro. Em (b) temos a solução encontrada pelo membro mínimo esférico tradicional. Já nas figuras (c), (d) e (e), o problema foi resolvido com o membro mínimo em forma de discos aplicado, para cada um dos planos com a normal indicada na figura.

Esta restrição em forma de discos, permite um controle maior sobre a solução, de maneira a forçar que o material seja distribuído prioritariamente num sentido desejado. Por exemplo, quando se deseja fabricar uma solução através da soldagem de chapas, pode-se controlar a solução como feito em 7.4-d, onde os membros estão prioritariamente na horizontal. 


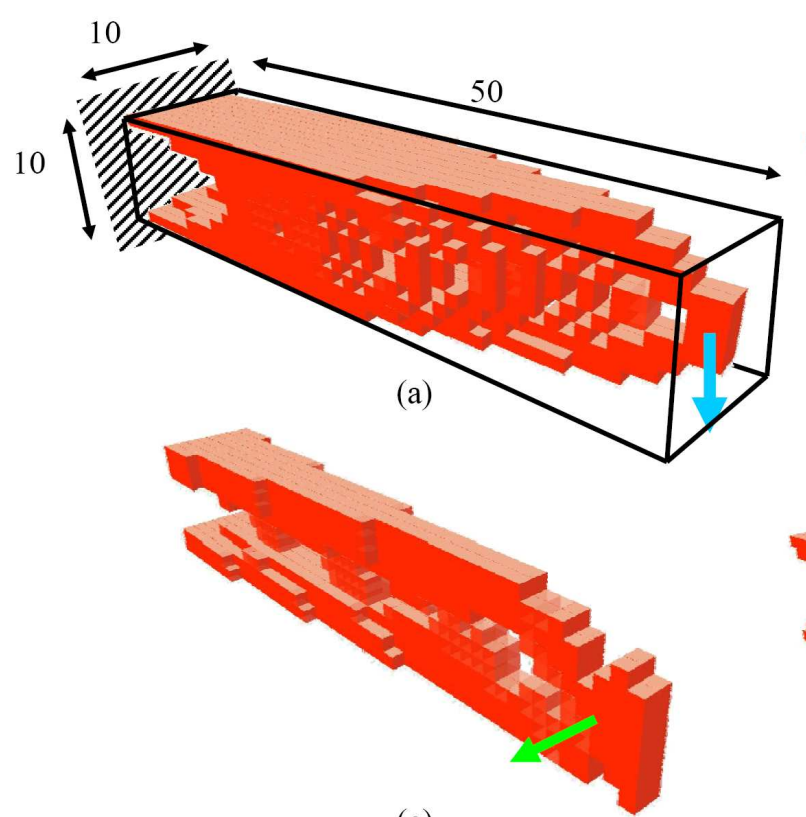

(c)

Número de elementos: 5000

Restrição de volume: $30 \%$
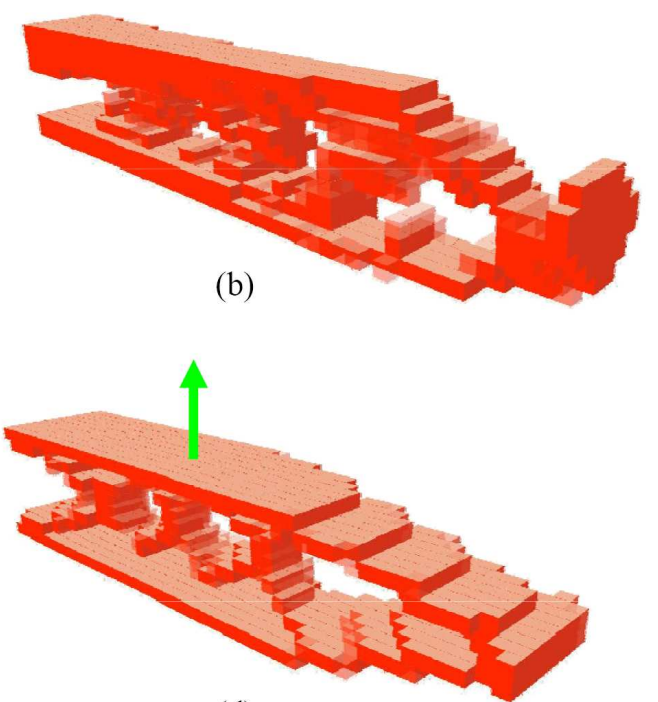

(d)

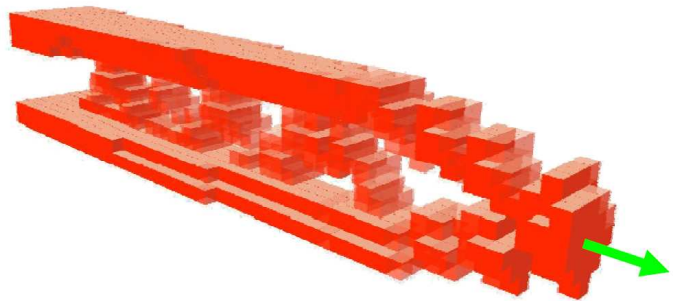

(e)

Figura 7.4: Resultados para o problema posto com: (a) sem restrições; (b) com membro mínimo esférico; (c), (d) e (e) membro mínimo aplicado como discos normais ao vetor indicado.

\subsection{Restrição de Buraco mínimo}

A restrição de buraco mínimo, controla o tamanho mínimo de furos que existem na solução final. Com isto porém acaba controlando de forma indireta a quantidade de membros existentes, podendo inclusive chegar a existência de um único membro. Como podemos ver na figura 7.5, a relação entre as variáveis (a) e (c) e as pseudo-densidades (b) e (d), é a inversa com relação ao membro mínimo, o domínio das variáveis de projeto, possuem membros mais grossos do que a solução propriamente dita. Porém como no caso do membro mínimo, o número de membros se mantém constante. Nas soluções encontradas na figura 7.5 (b) e (d), fica claro como uma pequena alteração no raio mínimo de buraco, pode causar uma mudança drástica na solução.

Como o algoritmo, não consegue colocar os buracos nos espaços existentes, sem ter que remover massa de elementos necessários, ele acaba colocando todos os buracos juntos, chegando a formar um único buraco externo. 
Número de elementos: 5000

Restrição de volume: $40 \%$

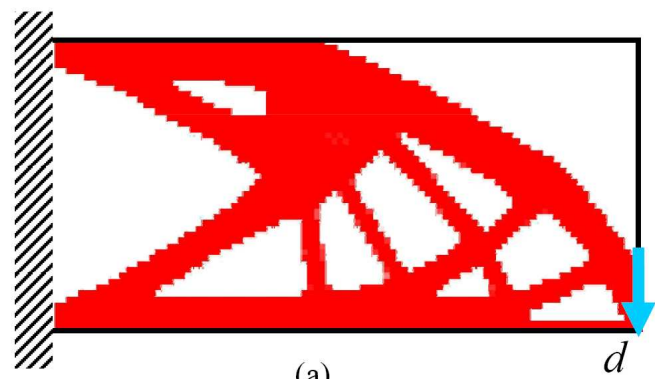

(a)

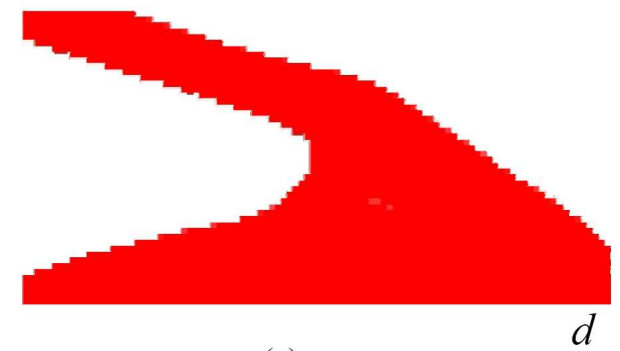

(c)

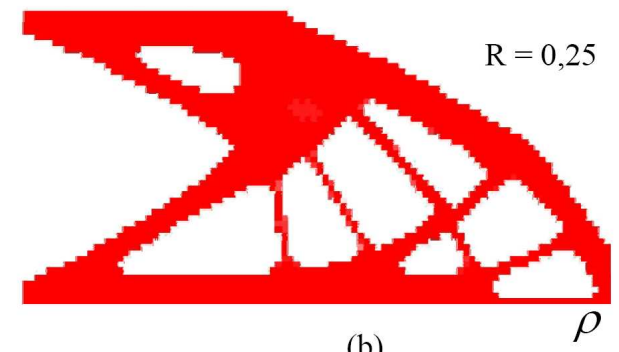

(b)

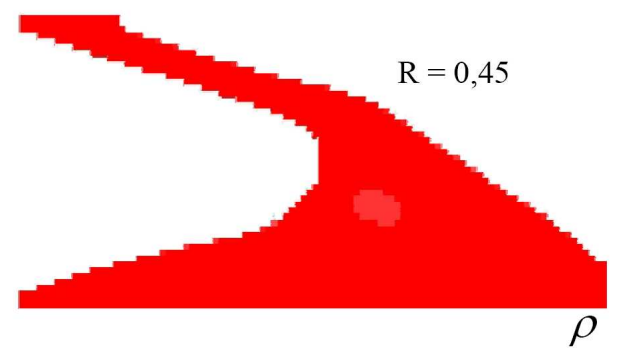

(d)

Figura 7.5: Resultados obtidos com volume restrito a 50\% do domínio. (a) Variáveis de projeto $d$. (b) Pseudo-densidades $\rho$.

Assim como no caso em duas dimensões, em problemas tridimensionais podemos perceber que quanto maior o tamanho do raio do furo mínimo, menor a quantidade de membros, como podemos ver na figura 7.6. Porém pode ser visto na figura 7.6 também, que quando o furo mínimo é grande o bastante, todo o espaço do domínio inicial que não é ocupado por massa, acaba por se acumular na parte de fora da peça, não criando furos internos. E uma vez que esta situação aconteça, um aumento no raio mínimo do furo, não altera de forma significativa a solução.

Devemos tomar cuidado porém ao aumentar o raio do buraco mínimo, o qual se for muito grande pode causar problemas de convergência, chegando a soluções com grandes quantidade de cinza, ou até mesmo, provocar a instabilidade no processo iterativo de busca da solução, violando a restrição de massa.

\subsection{Restrição de Simetria}

A restrição de simetria, espelha a solução com relação a um ou mais de seus planos centrais. O domínio das variáveis de projeto é apenas um pedaço do domínio total, como podemos ver na figura 7.7, onde em (a) temos as variáveis 


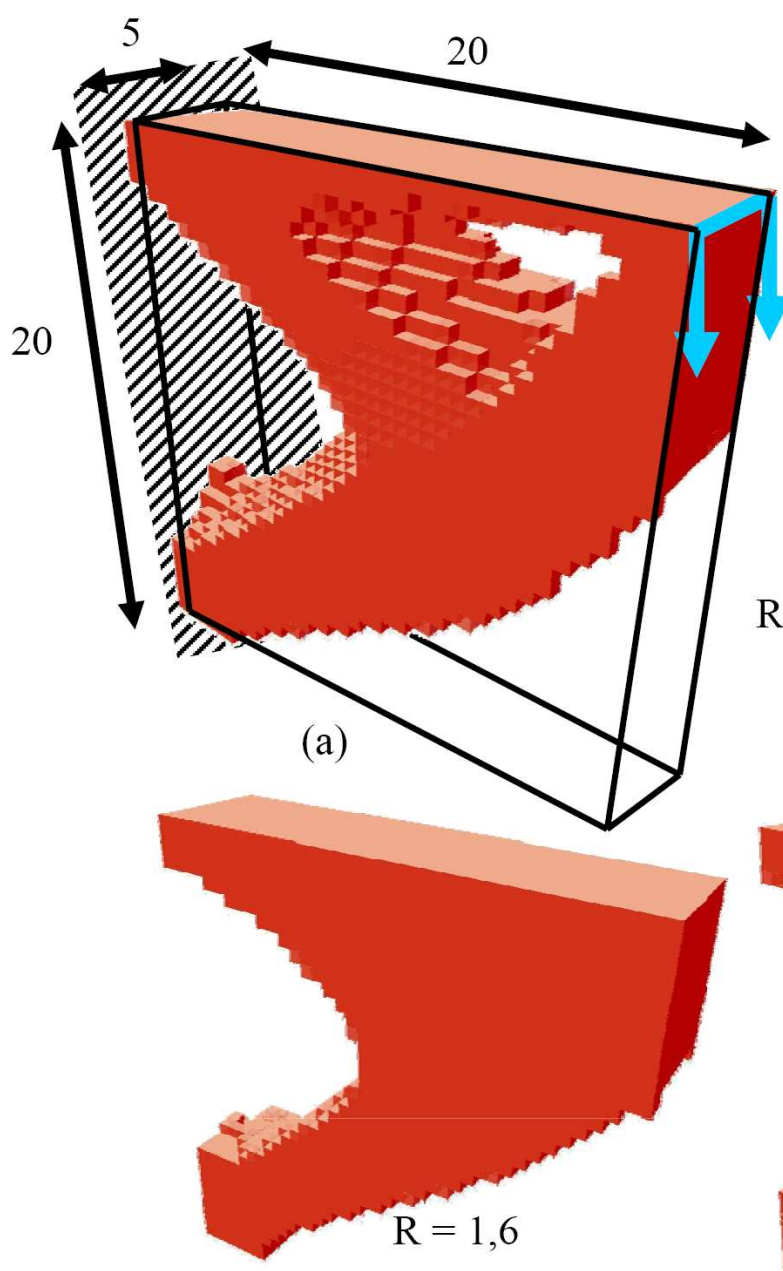

(b)
Número de

elementos: 16000

Restrição de volume: $50 \%$

Figura 7.6: Resultados obtidos com a restrição de buraco mínimo, com os seguintes raios mínimos de furo. (a) $R_{\min }=0,6$. (b) $R_{\min }=1,6$. (c)

$$
R_{\text {min }}=2,6
$$

de projeto, em (b) a projeção destas variáveis com a projeção de membro mínimo, e em (c) e (d) temos as pseudo-densidades encontradas para o caso das projeções pelos dois eixos de simetria. Com este tipo de abordagem encontramos uma solução que atende aos requisitos da restrição de simetria, mesmo em casos onde a carga não é simétrica.

Na figura 7.8 podemos ver como as soluções encontradas mudam quando são aplicadas as restrições de simetria. Diferentemente das restrições de membro e buraco mínimo, que levam a uma redução de membros na solução, mas mantinham uma forma aproximadamente igual para as soluções encontradas com diversos raios, as restrições de simetria alteram totalmente uma solução.

Em alguns casos, como nas soluções apresentadas na figura 7.9 podemos 
Número de elementos: 5000

Restrição de volume: $50 \%$

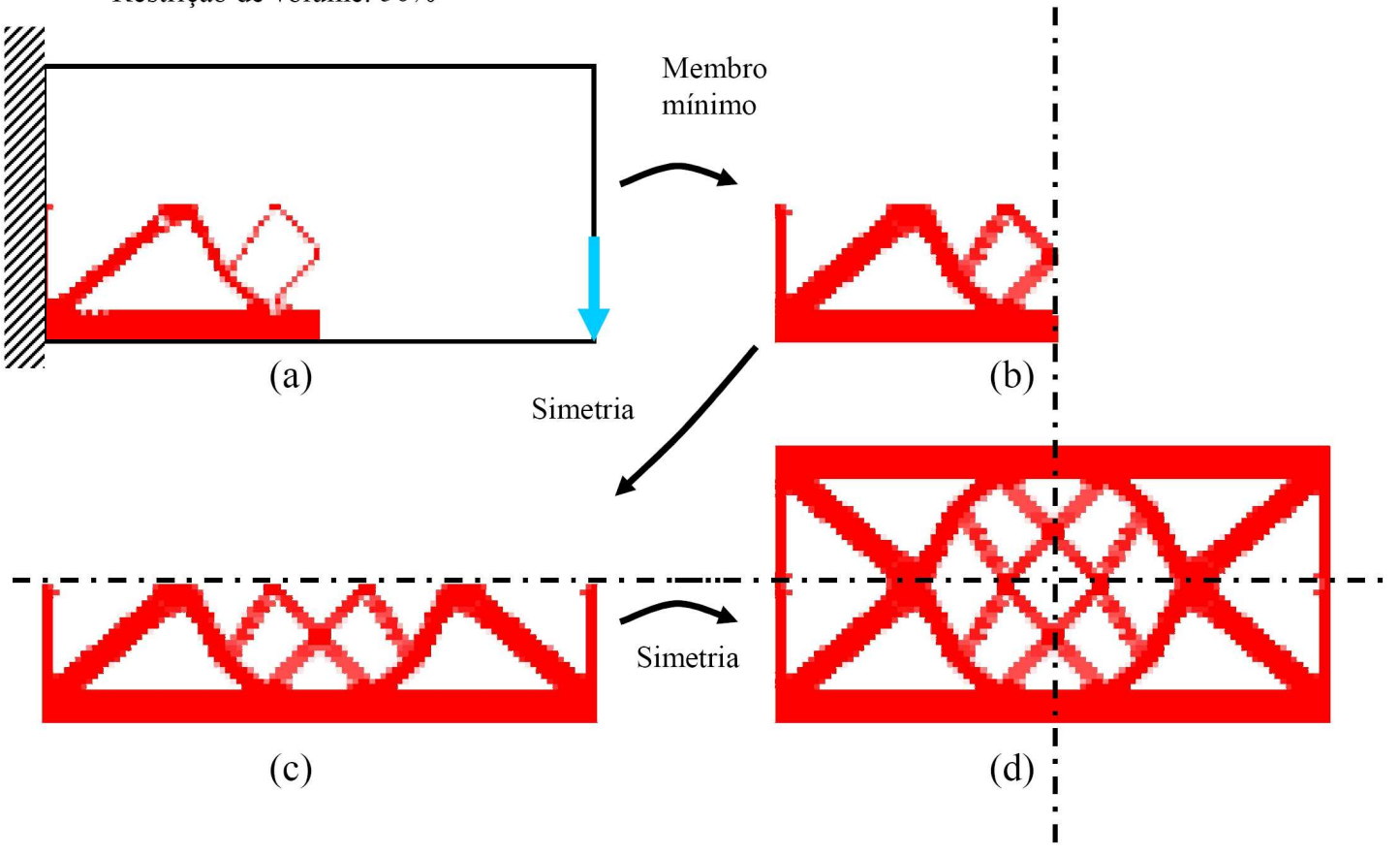

Figura 7.7: Solução encontrada com a restrição de simetria. (a) Campo de variáveis $d$. (b) Projeção da restrição de membro mínimo. (c) Projeção da simetria horizontal. (d) Projeção da simetria vertical.

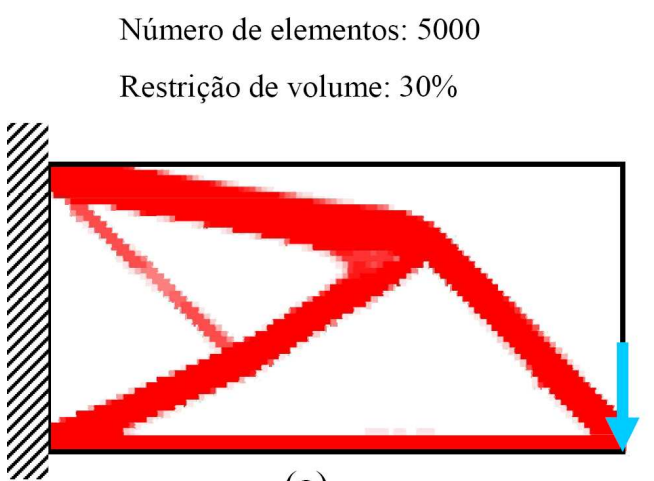

(a)

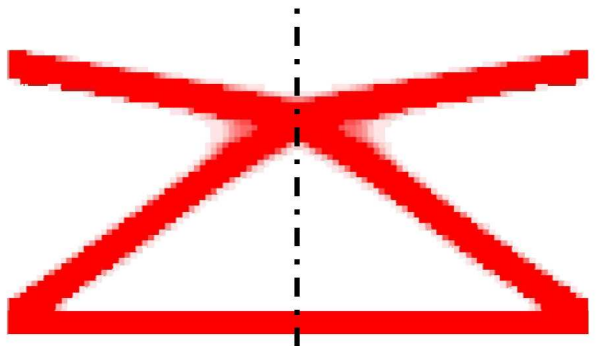

(b)

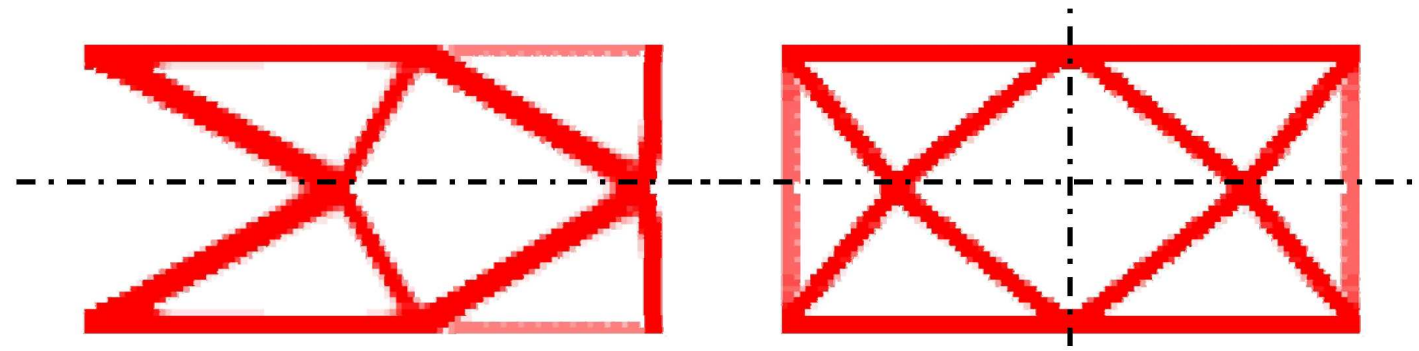

(c)

Figura 7.8: (a) Resultados sem restrição de simetria para uma viga em balanço. (b) e (c) Solução com restrição de simetria aplicada apenas a um plano. (d) Restrição de simetria aplicada aos dois planos simultaneamente. 
perceber que a solução com a restrição de simetria, pode ficar muito semelhante a soluções de outros problemas, até mesmo onde a situação de carga é diferente, porém devido as restrições de simetria impostas suas soluções são muito próximas visualmente. Esta semelhança pode ser percebida entre as soluções apresentadas nas figuras 7.8-c e 7.9-c, e 7.8-d e 7.9-d.

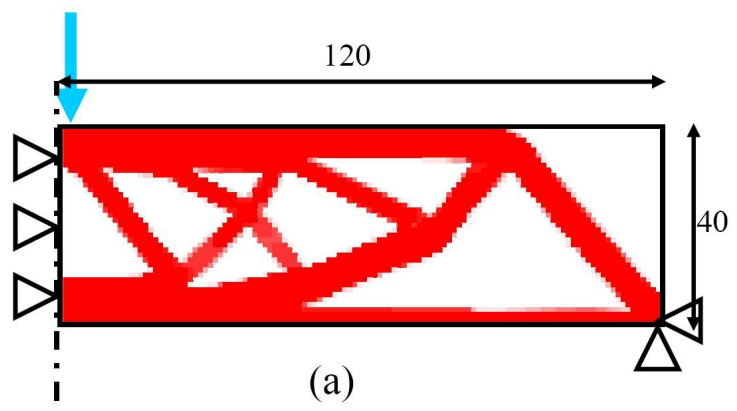

(a)
Número de elementos: 4800

Restrição de volume: $50 \%$

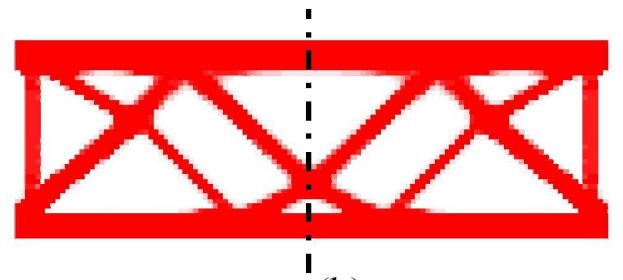

(b)

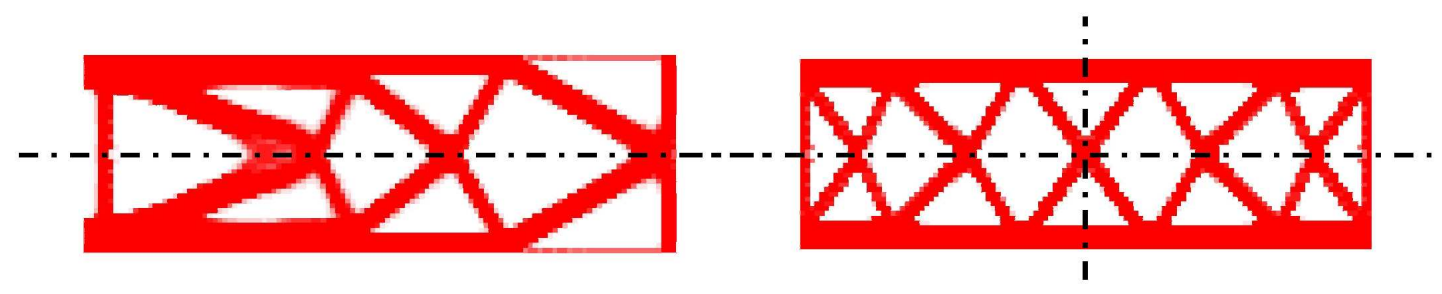

(c)

(d)

Figura 7.9: Resultados aplicados ao caso de carga da viga MBB, considerando sua simetria de carregamento com as condições de contorno indicadas na figura (a). (a) Resultados sem restrição de simetria. (b) e (c) Solução com restrição de simetria aplicada apenas a um plano. (d) Restrição de simetria aplicada aos dois planos simultaneamente.

As restrições de simetria e membro mínimo, podem impor uma restrição ao problema, de forma que o mesmo não consiga eliminar toda a região cinza. Este problema aparece em todas as restrições de manufatura implementadas neste trabalho com graus de severidade diferentes. Podemos percebê-lo na restrição de simetria através da figura 7.10-b. Quando o problema é resolvido sem a restrição de simetria, sua solução converge para uma solução sem cinza como pode ser visto na figura 7.10-a.

È possível também aplicar a restrição de simetria deslocada de seu centro, fazendo assim com que o mapeamento do domínio não inclua todos os elementos. Na figura 7.11, podemos ver duas soluções para um mesmo problema. Na figura 7.11-a o raio utilizado para o membro mínimo é 1 , e na figura 7.11-b o raio é 2 . A parte da solução que não se encontra na área da restrição de simetria, converge para uma solução muito próxima da solução encontrada sem a restrição, figura 7.8-a, porém garantindo que a parte incluída na restrição de simetria se encaixe 

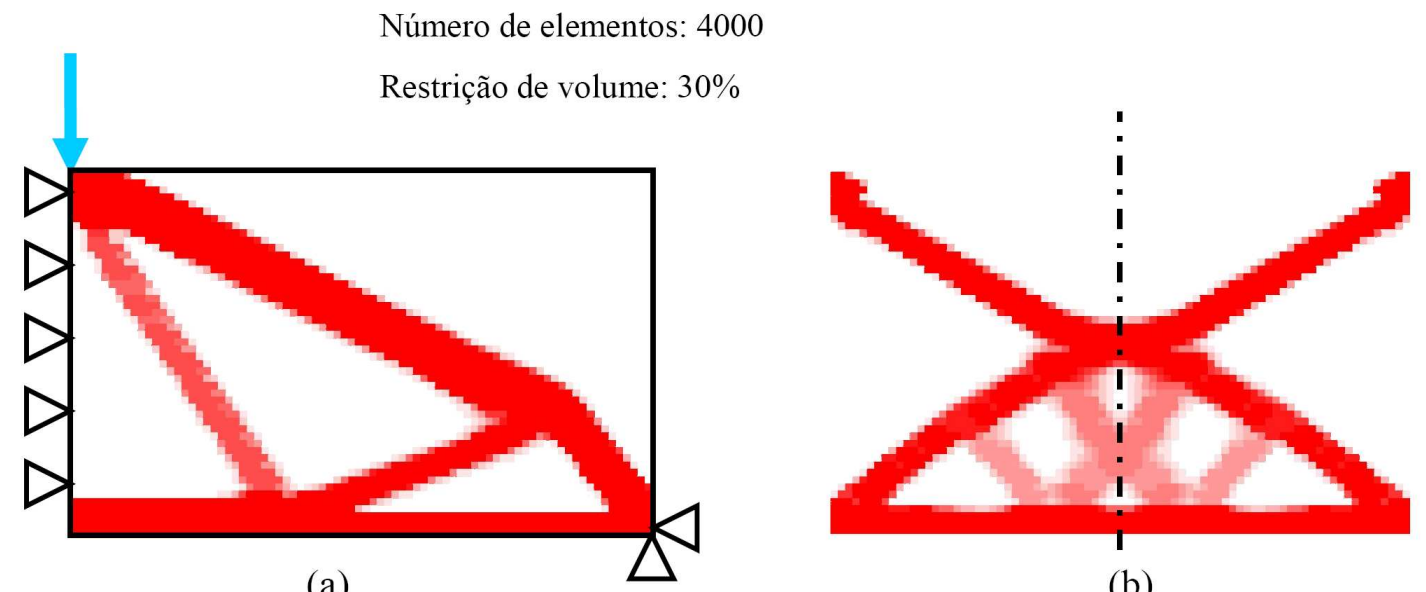

(b)

Figura 7.10: Exemplo da existência de regiões cinza devido as restrições aplicadas.

de forma coerente na solução como um todo.

Número de elementos: 20000

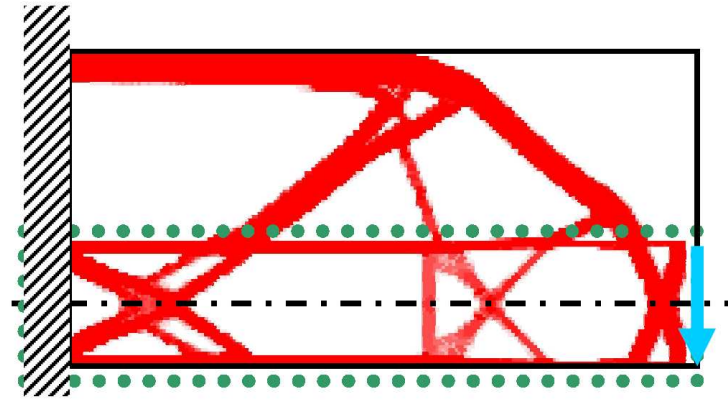

(a)
Restrição de volume: $40 \%$

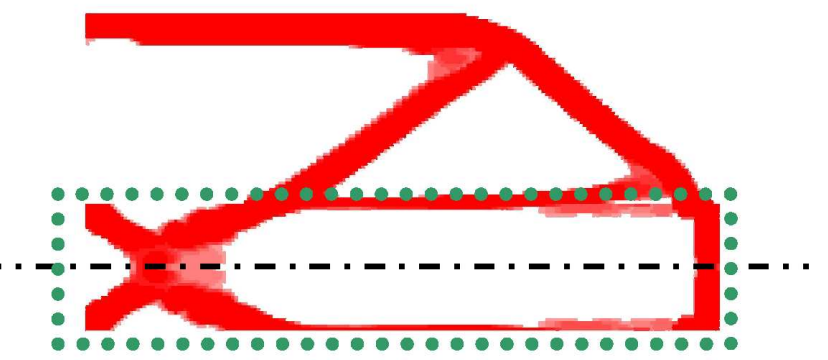

(b)

Figura 7.11: Soluções encontradas com simetria parcial. (a) Com membro mínimo com $R_{M i n}=1$. (b) Com membro mínimo com $R_{M i n}=2$.

Assim como nos problemas em duas dimensões, os problemas em três dimensões podem ser restringidos de forma que possuam soluções simétricas, em relação a cada um dos seus planos centrais. Como podemos ver na figura 7.12, as soluções tem um comportamento próximo do apresentado nos problemas em duas dimensões. Porém uma característica que somente é possível perceber nos problemas tridimensionais é o fato de que quando a carga é simétrica em relação a algum plano, a solução encontrada deveria ser simétrica em relação a este plano mesmo sem que a restrição seja aplicada. Isto de forma geral não é esperado devido a erros de arredondamento encontrados nos algoritmos utilizados, mas a restrição de simetria aplicada aos problemas ajuda a reduzir estes erros de arredondamento, levando a solução a esta simetria natural do problema. 


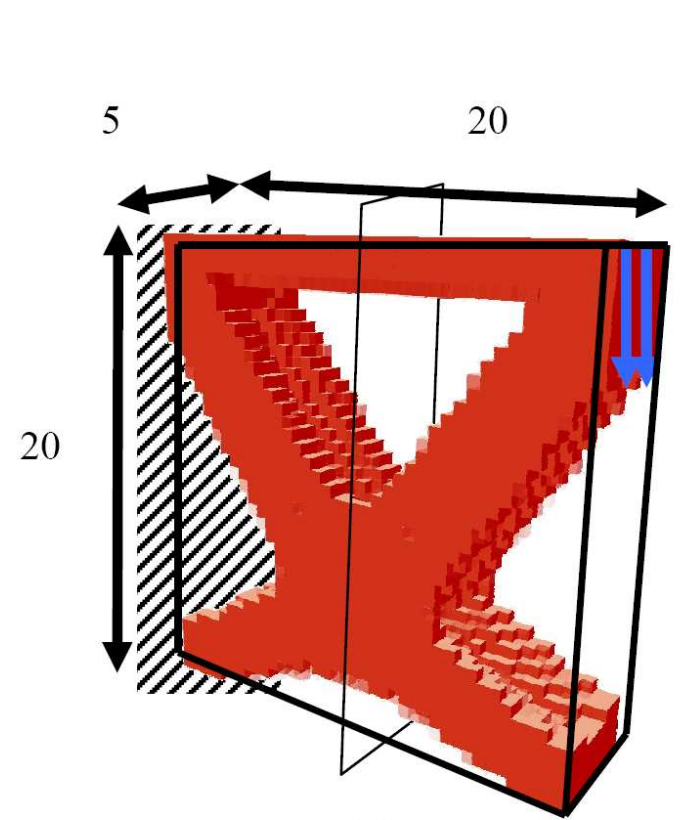

(a)
Número de

elementos: 16000

Restrição de volume: $50 \%$

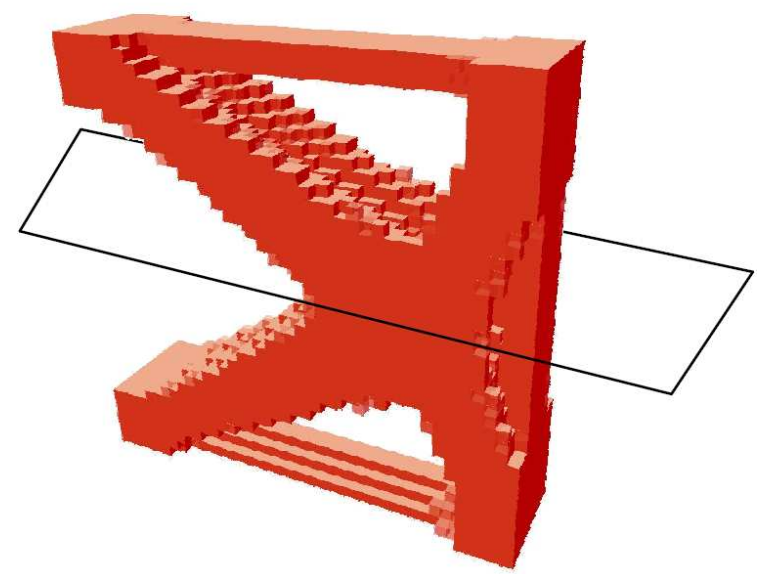

(b)

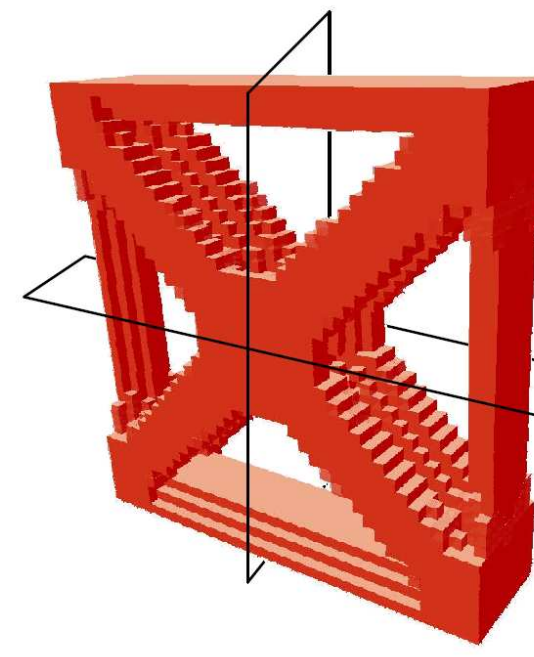

(c)

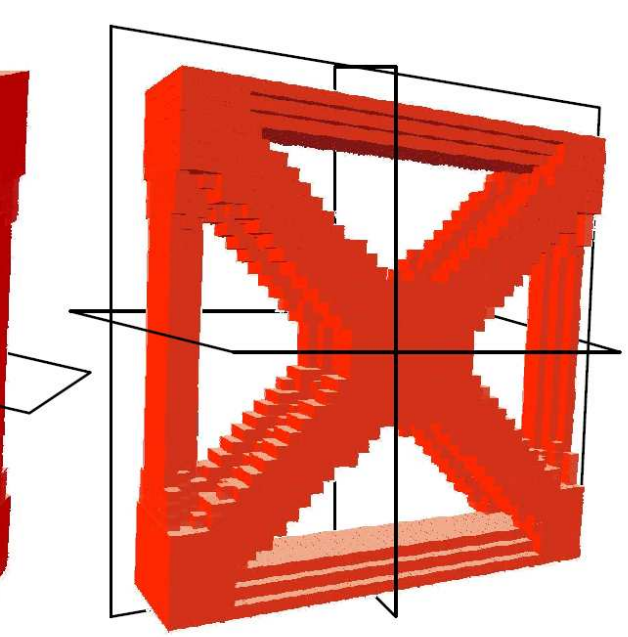

(d)

Figura 7.12: Solução com restrições de simetria aplicadas nos planos indicados demonstrando a ocorrência da simetria natural do problema.

\subsection{Restrição de Extrusão}

A restrição de extrusão, encontra soluções como as apresentadas na figura 7.13. Na figura 7.13-a temos um problema, que ao ser resolvido com a restrição de extrusão, remete a solução de um problema plano, já que em todas as seções longitudinais da problema a condição de carga é idêntica, e graças a restrição de extrusão, a solução encontrada repete a mesma solução ao longo da direção de extrusão.

Já na solução da figura 7.13-b, temos um problema que não pode ser consi- 
Elementos: 16000

Restrição de volume: $20 \%$

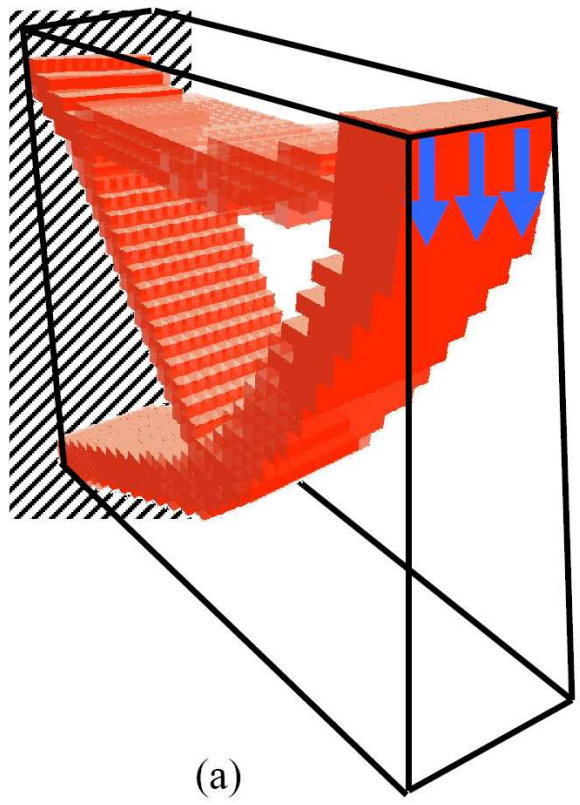

Elementos: 16000

Restrição de volume: 50\%

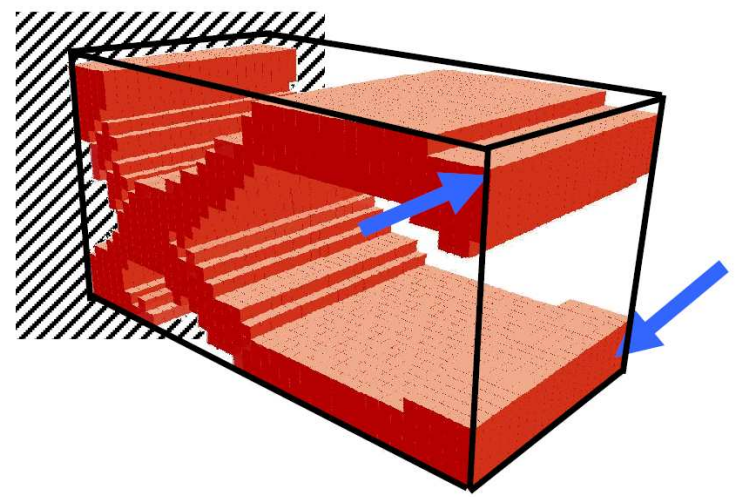

(b)

Figura 7.13: (a) Solução para o problema de uma viga com carga, com restrição de extrusão, sua resposta é similar a de um caso bidimensional. (a) Solução para um problema de torção com restrição de extrusão.

derado plano, já que as cargas estão perpendiculares ao plano longitudinal. Com isto podemos perceber, que a restrição de extrusão não atua simplesmente como uma projeção de problemas bidimensionais, ela atua criando soluções que possuem a mesma seção, com cargas aplicadas em qualquer sentido e direção. Nesta solução encontrada para um problema de torção, temos uma solução que dificilmente seria encontrada através da interpretação de dados de uma otimização sem restrições.

Com esta restrição, podemos verificar a validade da utilização do perfil "I" para vigas. Como podemos ver na figura 7.14, com diferentes razões de aspecto, em um problema de viga engastada com uma carga aplicada em seu centro, encontramos sempre uma mesma solução, que pode possuir proporções diferentes, e espessuras de alma e abas diferentes. Porém todas as soluções são formadas por perfis na forma de uma letra "I". Outro aspecto interessante destas soluções, que possuem a carga no seu centro, e podem portanto serem divididas em problemas simétricos, é o fato de as soluções apresentarem simetria, sem que seja aplicada uma restrição para isso.

Da mesma forma como foi encontrado na restrição de simetria, este efeito 


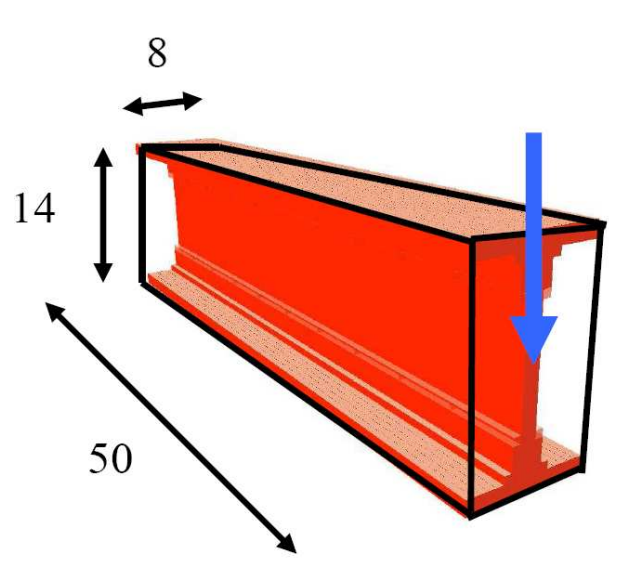

Elementos: 4480

Restrição de volume: $30 \%$

14

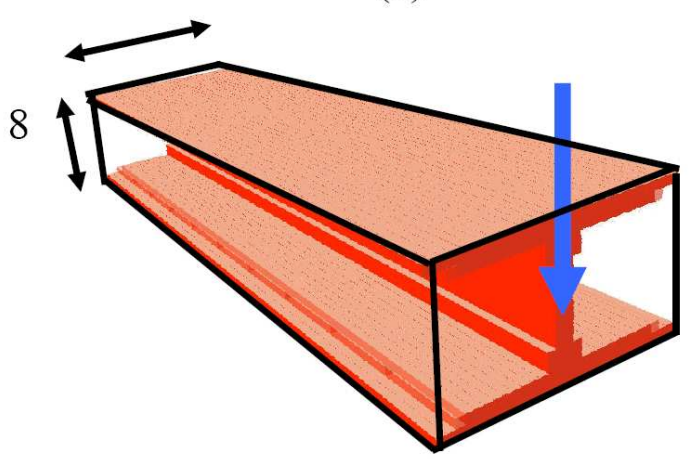

Elementos: 4480

Restrição de volume: $30 \%$

(c)
10

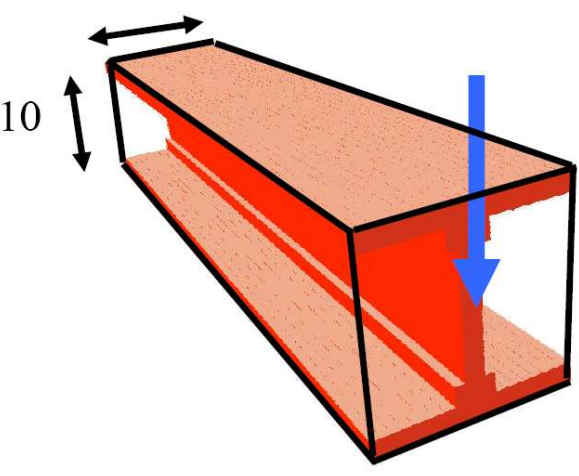

Elementos: 4000

Restrição de volume: $30 \%$

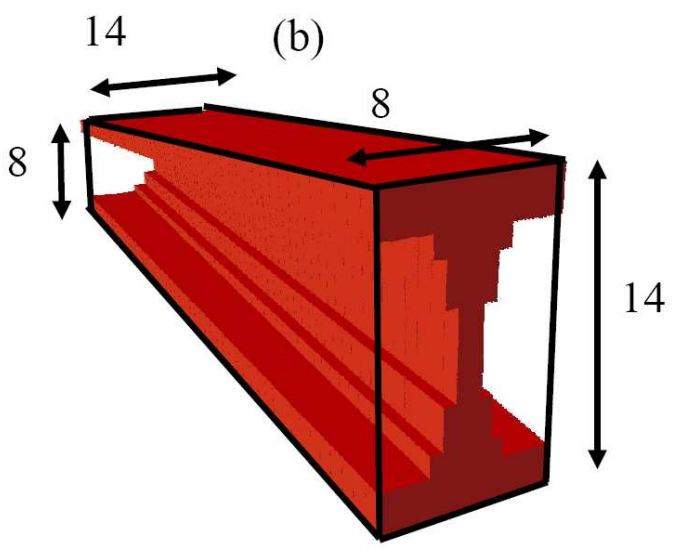

Elementos: 9996

Restrição de volume: $30 \%$

(d)

Figura 7.14: Soluções para o problema de barra engastada com carga de flexão resolvido com a restrição de extrusão, com as seguintes razões de aspecto.

(a) $1 \times 2$. (b) $1 \times 1$. (c) 2x1. (d) Extremidade engastada com razão 2x1 e extremidade com carga com razão 1x2.

de estabilização da solução surge devido a técnica de projeção aqui utilizada para impor a restrição de extrusão, que facilita o aparecimento das simetrias que deveriam existir no problema dadas as condições de carga, e que muitas vezes não surgem devido a problemas de arredondamento numérico.

Como a restrição de extrusão realiza seu mapeamento baseada na malha estruturada e não sobre a geometria diretamente, podemos utilizar a restrição de extrusão sobre domínios com fatores de escala diferentes sobre suas extremidades, como podemos ver na figura 7.15. O problema apresentado, se resolvido sem a restrição de extrusão possui a solução (7.15-a), que lembra duas vigas parale- 
las, uma sob cada uma das cargas aplicadas em suas extremidades. Já quando resolvido com a restrição de extrusão, possui uma única seção transversal, que podemos ver na figura (7.15-b) antes da aplicação do membro mínimo, e em (7.15-c) já com a aplicação do membro mínimo.

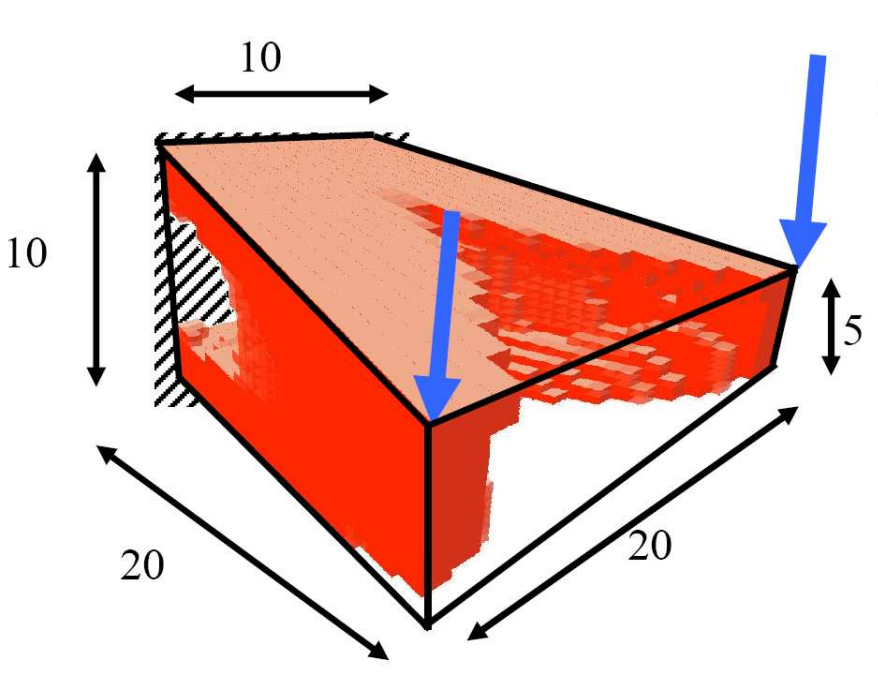

(a)

\section{Elementos}

Restrição de volume: 50\%

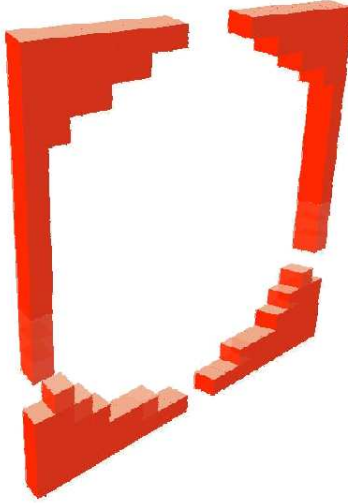

(b)

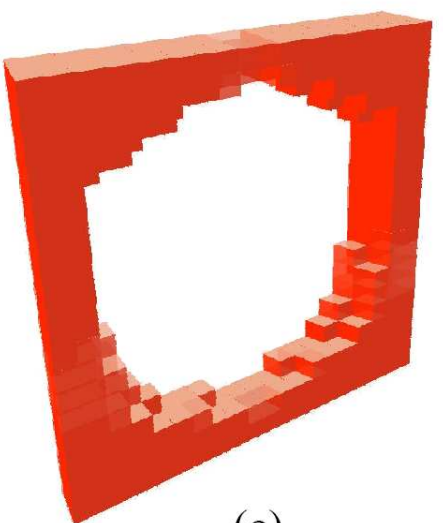

(c)

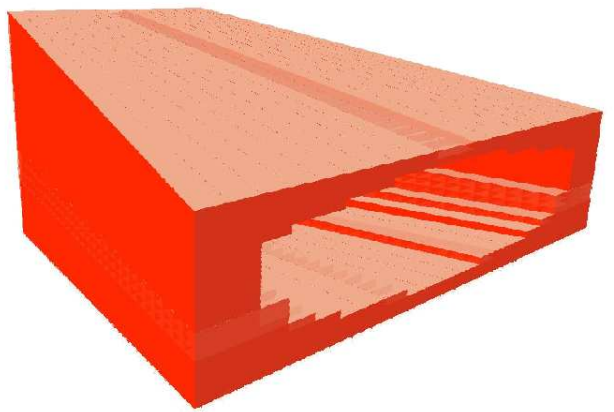

(d)

Figura 7.15: (a) Solução sem a restrição de extrusão. (b) variáveis de projeto $d$ da restrição de extrusão. (c) Solução após a projeção do membro mínimo. (d) Solução após a projeção da extrusão.

Como a solução encontrada não é projetada com relação a sua geometria, a solução final encontrada pelo problema é apresentada na figura (7.15-d), e apesar da relação de aspecto diferente entre suas diversas seções transversais, a solução é um perfil "extrudado" que atende as condições impostas.

Se levarmos em consideração que perfis, podem ser dobrados, ou até mesmo recortados e soldados de forma a parecerem uma única estrutura contínua, temos uma grande utilidade para a restrição de extrusão implementada de forma a acompanhar a malha estruturada. Como podemos ver na figura 7.16, ao resolvermos 
o problema apresentado, sem nenhuma restrição, encontramos a solução apresentada em (a). Já quando utilizamos a restrição de extrusão, encontramos um perfil fechado, que pode vir a ser dobrado como um tubo, como mostrado em (b).

6500 Elementos

Restrição de volume: $50 \%$

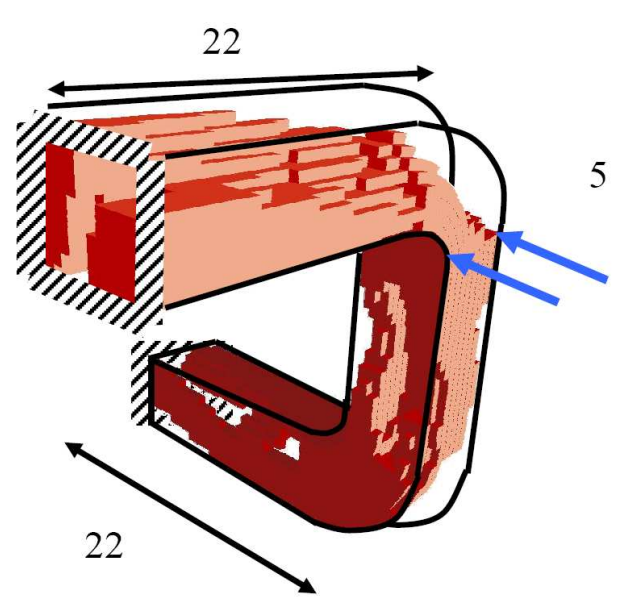

(a)

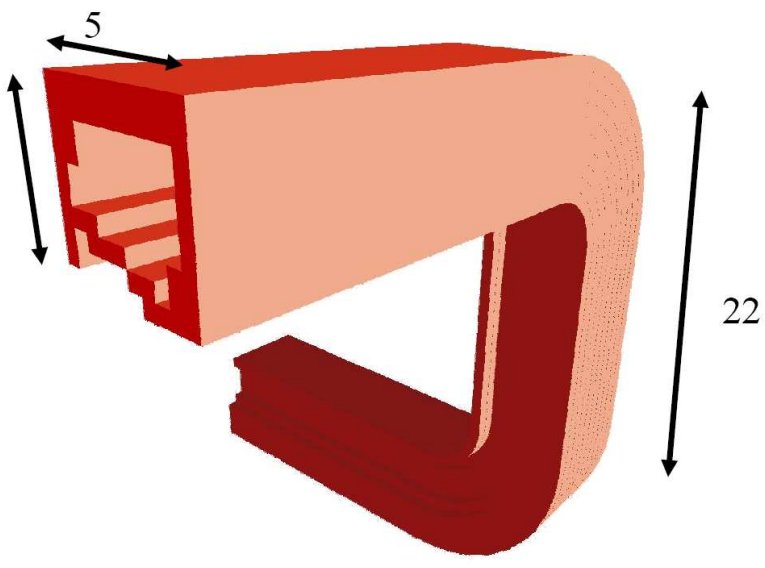

(b)

Figura 7.16: Resultado sem a restrição de extrusão. (b) Resultado com a restrição de extrusão.

Estas soluções mostram a grande diversidade de problemas que podem ser resolvidos e ter seu processo de manufatura simplificado com a restrição de extrusão. O mapeamento da restrição de extrusão lhe confere uma grande possibilidade de utilizações, e não a deixa restrita apenas para seções geometricamente idênticas.

\subsection{Restrição de Revolução}

Para representar uma peça torneada, podemos utilizar a restrição de revolução, como podemos ver na figura 7.17, a restrição de revolução rotaciona o domínio de variáveis de projeto $d$, para formar a solução projetada de pseudo-variáveis.

A restrição de revolução, assim como a restrição de extrusão, projeta uma seção ao longo de toda a peça, porém ao invés de projetar ao longo de um caminho, ela rotaciona em torno de um eixo definido. Como podemos ver na figura 7.18(a), uma solução encontrada com a restrição de revolução tem como solução para as variáveis de projeto, apenas um elemento para cada coroa circular existente 

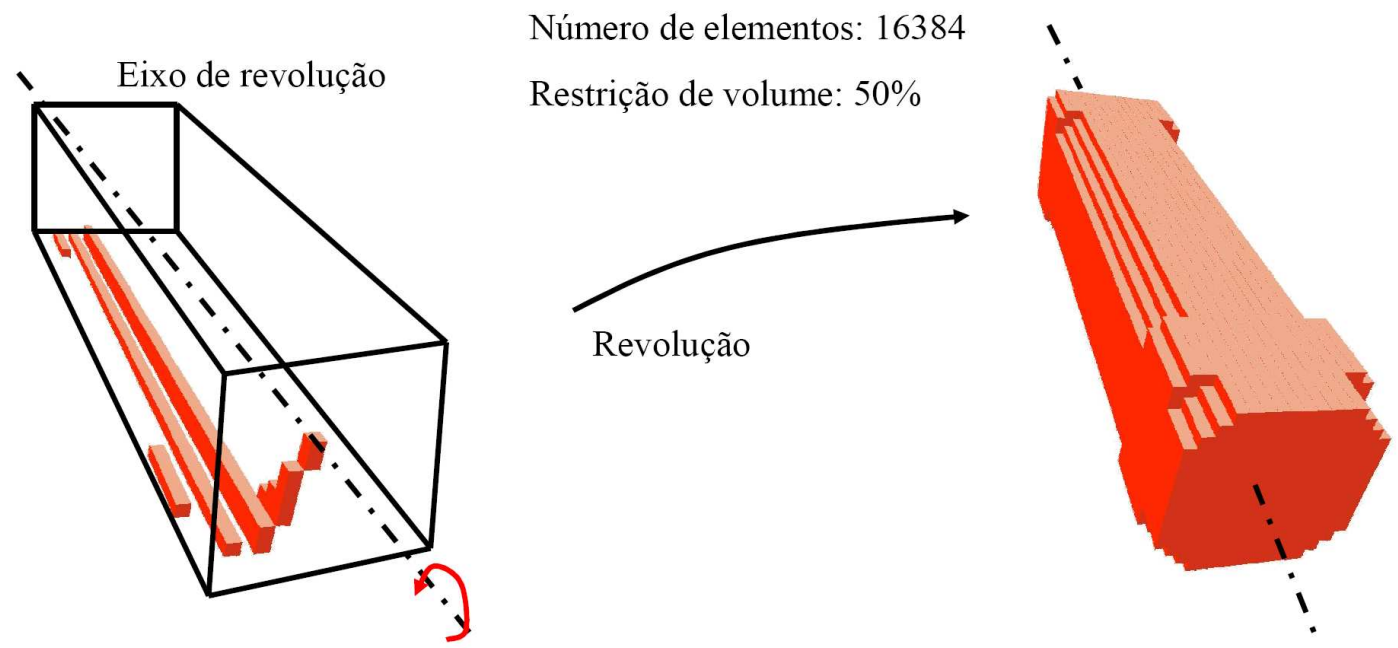

Figura 7.17: Rotação do domínio de variáveis de projeto de forma a gerar a solução para as pseudo-densidades.

no seu domínio. Esta solução é então projetada ao longo do eixo de rotação e depois tem seu membro mínimo projetado, respectivamente, nas figuras (b) e (c). Na solução encontrada após o membro mínimo, existe uma grande região oca, e com uma camada de elementos cinza. Se desconsiderarmos estes elementos, encontramos a solução apresentada na figura 7.18-(d). Este problema de regiões tomadas por áreas cinzas ocorre pelo mesmo motivo já apresentado na restrição de simetria, ou seja, devido a uma restrição muito grande do problema, que possui como solução regiões cinza, uma maneira de resolver este problema seria a utilização de membros mínimos ou buracos mínimos com tamanhos diferentes.

Quando resolvemos um problema de torção com a restrição de revolução, encontramos um tubo com sua borda fechada, como pode ser visto na figura 7.19(a) e (b), a solução forma uma caixa fechada, que é uma estrutura usualmente conhecida para resistir a torção.

Já na figura 7.19-(c), temos uma solução que apresenta revolução e extrusão, as duas considerando o eixo principal do domínio como direção de referência. Desta forma se obtém uma solução facilmente executável do ponto de vista de manufatura, um simples tubo. Esta solução seria improvável se obter através da interpretação simples da solução sem restrições de OT.

Podemos perceber que apesar do problema estar sendo restringido pela revolução, algumas seções lembram mais seções quadradas tanto no problema da figura 7.18, quanto na figura 7.19, isto se deve ao formato do domínio, como 
Número de elementos: 16000

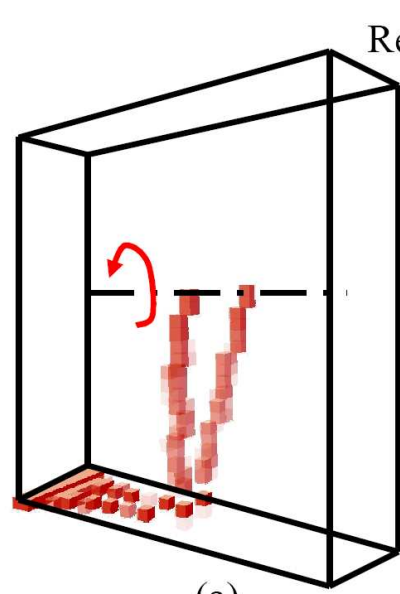

(a)

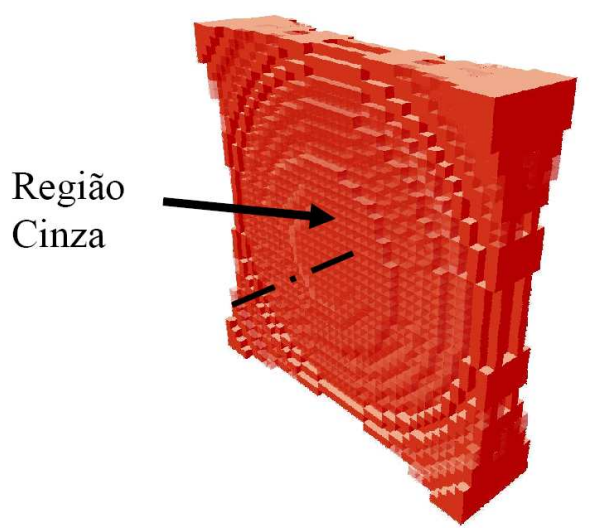

(c)
Restrição de volume: $40 \%$

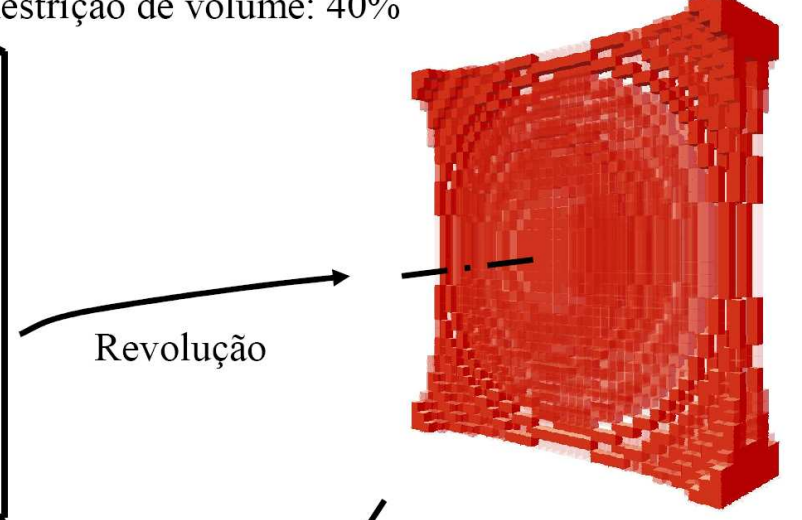

(b)

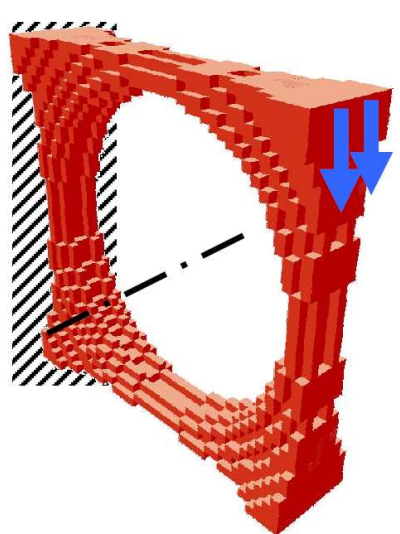

(d)

Figura 7.18: Resultado com a restrição de revolução. (a) variáveis de projeto. (b) Projeção da restrição de revolução. (c) Projeção do membro mínimo. (d) Solução ignorando elementos de pseudo-densidades intermediárias.

discutido em 6.5.

Este problema pode ser resolvido se for utilizado um domínio circular, onde todas as camadas obrigatoriamente terão um formato de coroa circular. Podemos ver um domínio deste tipo na figura 7.20. Em (a) temos o problema resolvido sem a restrição de revolução, o que nos leva a uma figura que nos lembra a solução apresentada na figura 7.4. Já quando aplicamos a restrição de revolução obtemos o resultado mostrado em 7.20-(b), que é uma solução que além de atender a restrição nela imposta, possui seus contornos realmente circulares. 


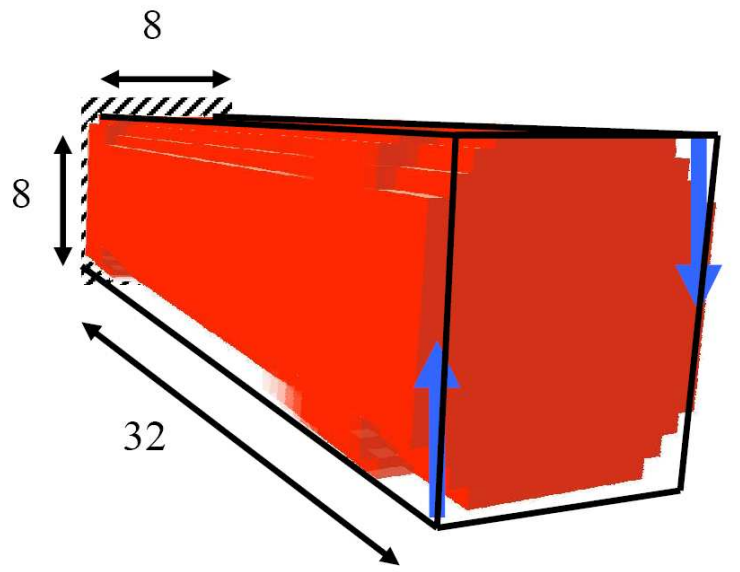

(a)

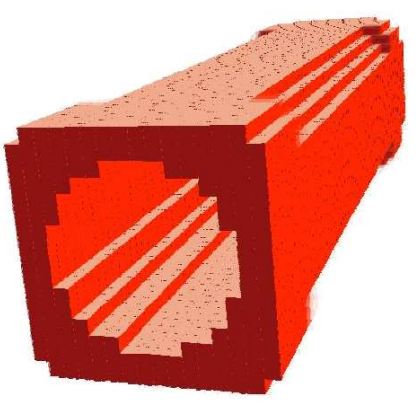

(b)

16384 Elementos

Restrição de volume: $50 \%$

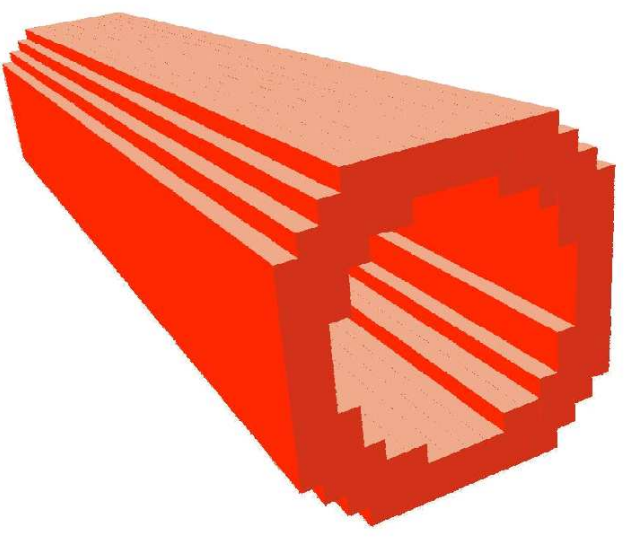

(c)

Figura 7.19: Resultado para a restrição de revolução (a) vista frontal (b) vista traseira. (c) Resultado com restrição de revolução e extrusão.

\subsection{Restrição de Repetição de Padrões}

A restrição de repetição de padrões, pode ser dividida em dois tipos de restrição, as que tem sua repetição realizadas sem manter uma única direção para as regiões repetidas, e aquelas que consideram o mapeamento sempre alinhado e contido dentro de um domínio único e conexo.

Na figura 7.21 temos um exemplo de uma solução onde a restrição de repetição garante três blocos idênticos, porém com direções e posições independentes. Como podemos perceber a solução encontrada tem uma configuração totalmente diferente da solução encontrada quando não se utiliza a restrição de repetição de padrões, tendo muitas regiões onde não se espera ter massa ocupada, devido a contrapartida desta região nos outros padrões, que acabam levando ao apareci- 


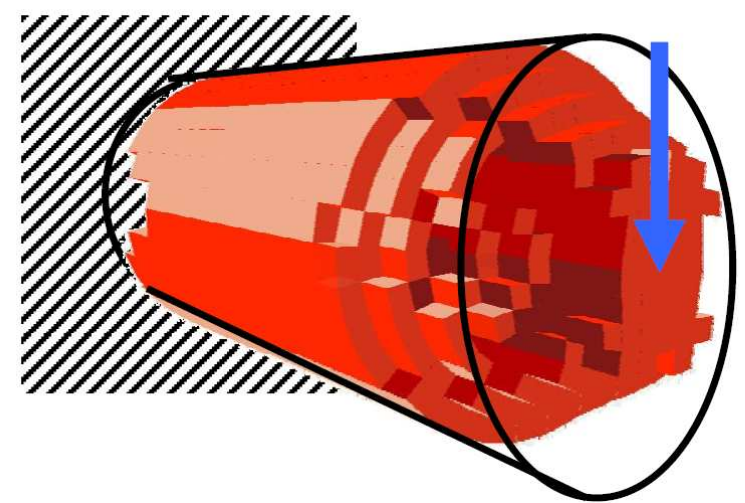

(a)

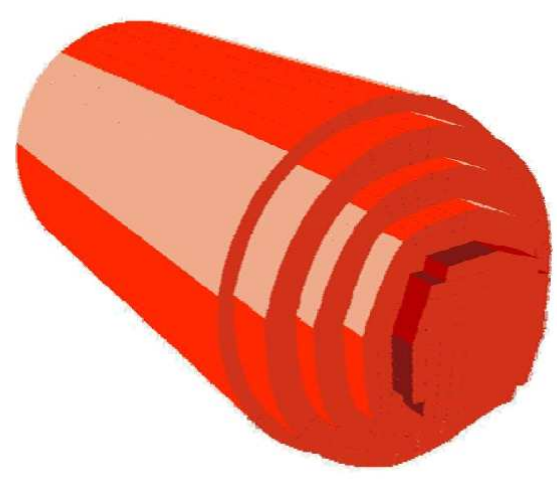

(b)

Figura 7.20: (a) Viga em balanço com domínio cilíndrico sem restrição de revolução. (a) Viga em balanço com domínio cilíndrico com restrição de revolução.

mento desta massa.

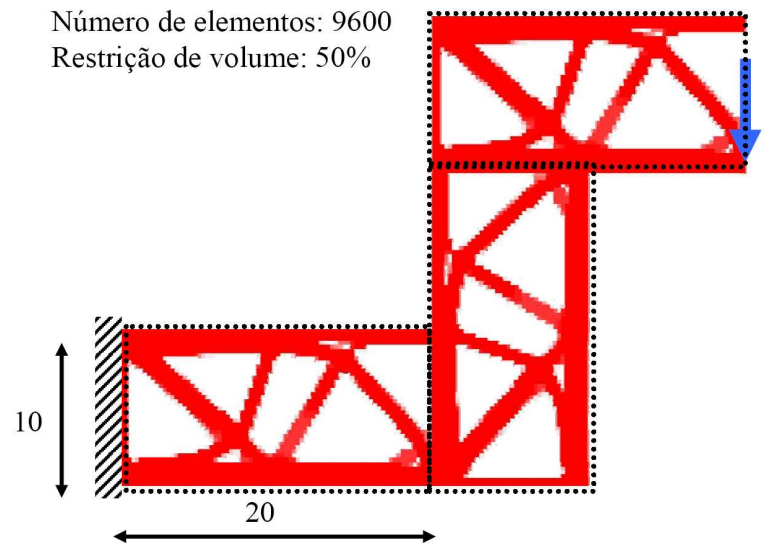

(a)

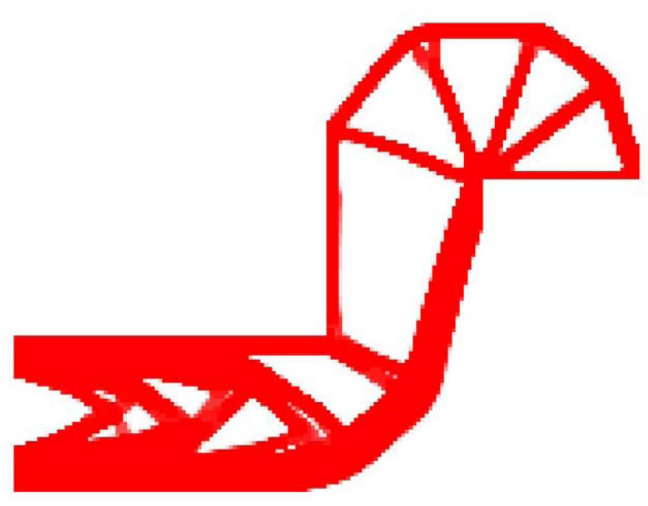

(b)

Figura 7.21: (a) Resultado com repetição de padrões. (b) Resultado sem repetição de padrões.

Aplicando a restrição de repetição de padrões a problemas tridimensionais podemos encontrar soluções como as apresentadas na figura 7.22. Neste caso ela atua para encontrar uma solução que seja equivalente aos dois casos de carga aplicados a uma viga engastada. Porém os casos são resolvidos como duas estruturas independentes relacionadas apenas pela restrição de repetição de padrões. Apesar de no caso apresentado os domínios não estarem conectados, se eles estivessem, a restrição continuaria a garantir a semelhança das estruturas. Isso não ocorreria ser feito com dois casos de carga distintos atuando numa única estrutura de viga.

Este tipo de restrição de repetição de padrões, onde temos domínios que po- 
Número de elementos: 32000

Restrição de volume: $50 \%$

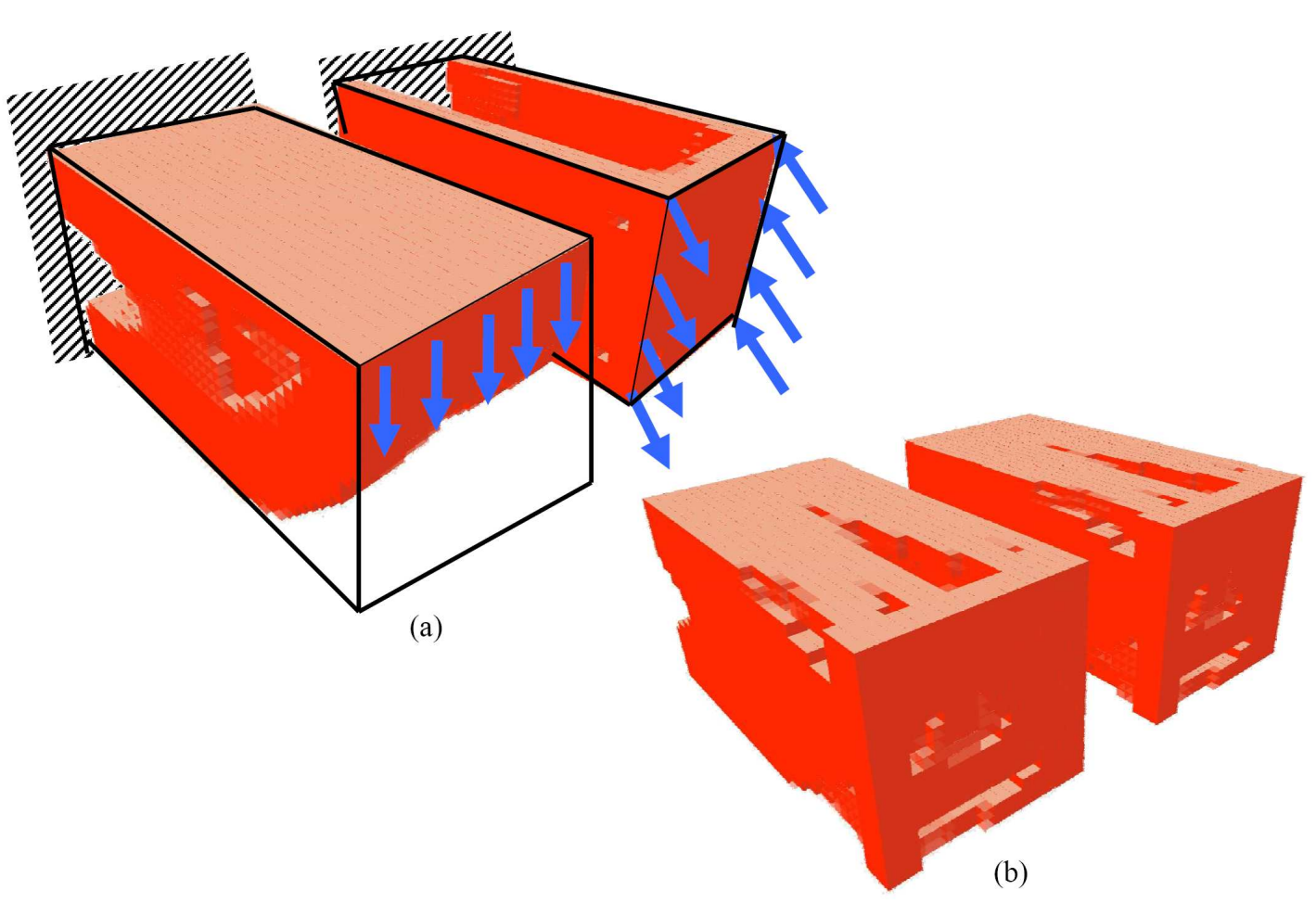

Figura 7.22: (a) Resultado sem repetição de padrões. (b) Resultado com repetição de padrões.

dem ter sua referência posicionada de forma aleatória no espaço, é uma restrição extremamente poderosa. Podendo emular outras restrições, como a de simetria, fazendo dois domínios espelhados, ou até mesmo de extrusão, fazendo com que cada faixa de elementos seja um domínio.

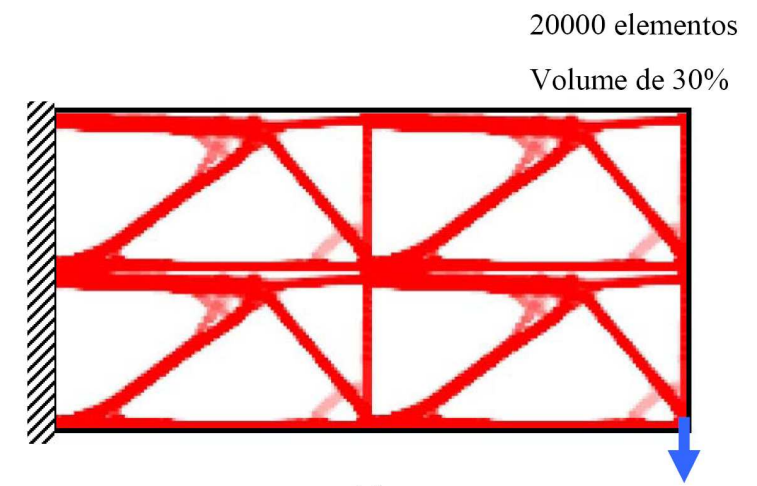

(a)

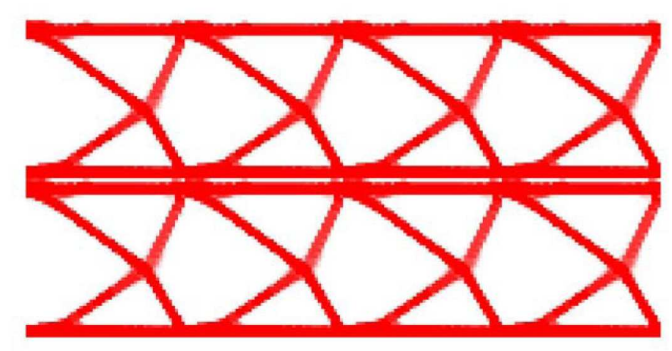

(b)

Figura 7.23: Viga em balanço. (a) 2x2 padrões. (b) 4x2 padrões.

Já a restrição de repetição de padrões, que repete um padrão sempre na mesma posição e disposto dentro de uma mesmo domínio, pode formar uma 
espécie de peça básica, formadora do domínio, como as soluções mostradas na figura 7.23. Podem ser utilizadas de forma a gerar estruturas padronizadas para fins estéticos, e uma outra importante aplicação que pode ser imaginada é para o projeto de materiais compósitos. Chegando a padrões pequenos o bastante para representar as micro-estruturas dos materiais compósitos, como é mostrado na figura 7.24 .

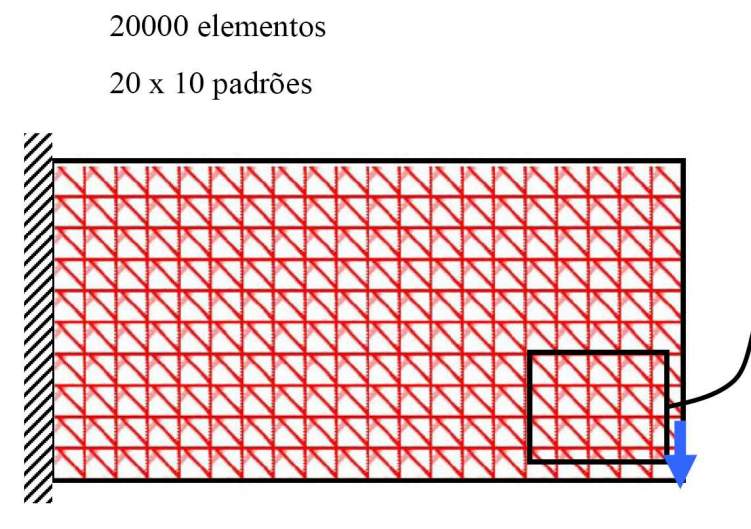

(a)

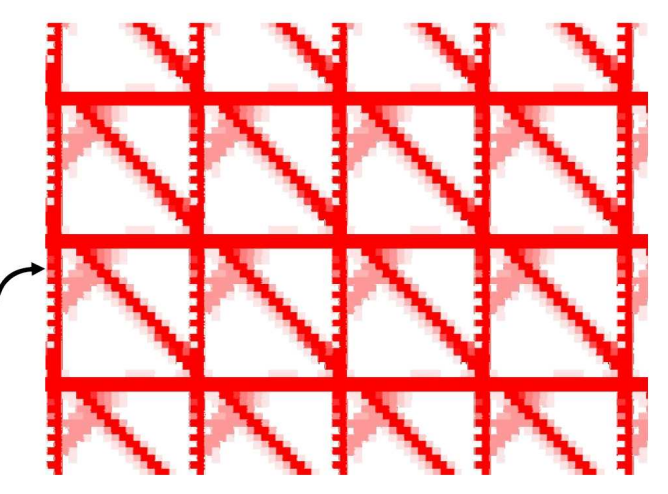

(b)

Figura 7.24: Viga em balanço. (a) 20x10 padrões. (b) Região ampliada para mostrar os detalhe do padrão.

Apesar de não ter sido implementada uma restrição específica para a chamada simetria radial, que nada mais é do que seções repetidas ao longo de um eixo de rotação, podemos realizar este tipo de restrição com a restrição de repetição de padrões, como podemos ver na figura 7.25.

Facilmente podemos trocar a quantidade de padrões que aparecem no caso apresentado na figura 7.25. Porém, um pequeno detalhe deve ser ressaltado, os domínios por mais refinados que sejam, possuem um número definido de elementos, e estes nem sempre são divisíveis pelo número de padrões solicitado. Quando isto ocorre, alguns elementos na extremidade do modelo acabam ficando fora do mapeamento, e são otimizados normalmente, sem a restrição de repetição de padrões agir sobre ele. Como podemos ver na figura 7.26-(a), uma pequena quantidade de elementos aparece no extremo do domínio, estes elementos são projetados com o membro mínimo, já que esta restrição engloba todos os elementos, porém não são modificados quando se dá a projeção da repetição de padrões, de (b) para (c).

Apesar de estarem fora do mapeamento da repetição de padrões, estes elementos não atrapalham a solução do problema,pois acabam se adequando ao formato do padrão. 


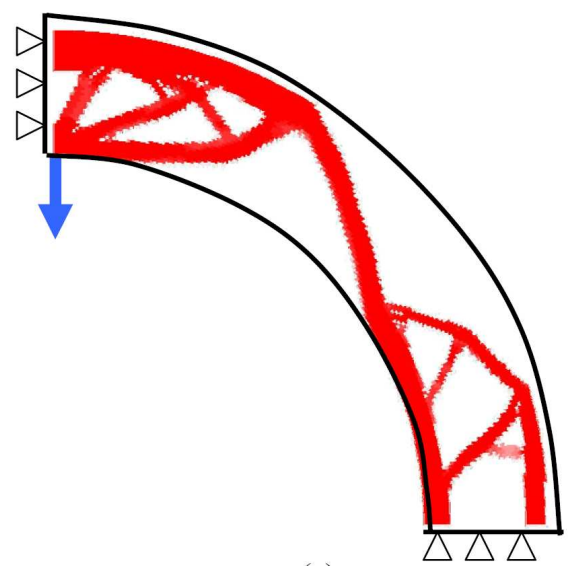

(a)

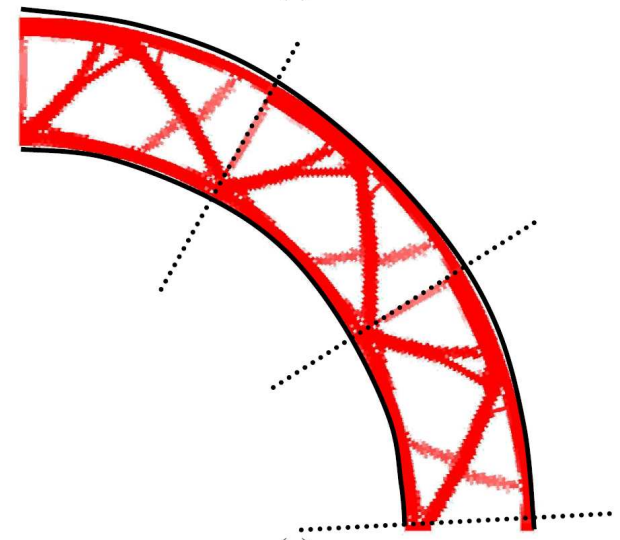

(c)

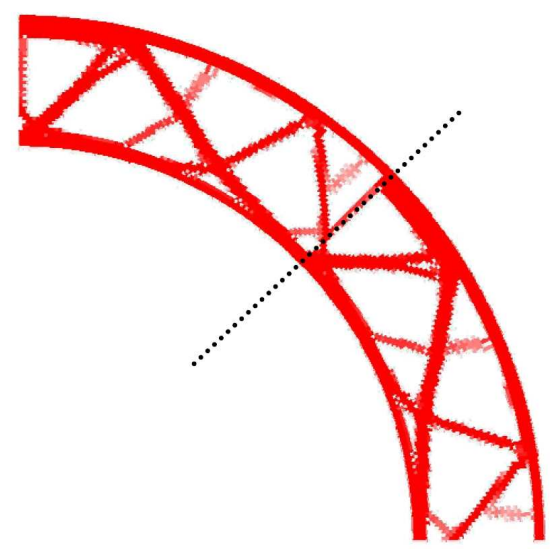

(b)

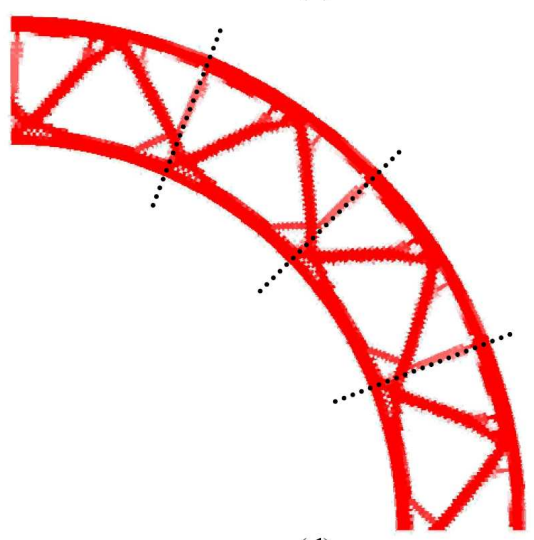

(d)

Figura 7.25: (a) Sem repetição de padrão. (b) Repetição com 2 padrões. (c) Repetição com 3 padrões. (d) Repetição com 4 padrões.

Podemos aplicar a restrição de padrões com outras restrições em conjunto, como no caso da figura 7.27, onde podemos ver a restrição de padrões agindo em conjunto com a extrusão e membro mínimo. A única ressalva para a utilização da repetição de padrões em três dimensões e com membro mínimo, é o fato de precisar de uma malha muito refinada, para que se possa representar de forma adequada o bloco padrão obtido.

Na figura 7.28 temos uma roda, que é resolvida com a utilização da repetição de padrões em conjunto em (a) com o membro mínimo, que resulta em sulcos muito estreitos e que seriam difíceis de serem manufaturados. Em (b) é utilizada a restrição de buraco mínimo, que leva a uma solução sem pequenos furos, porém, com hastes mais finas, lembrando muito os aros de uma bicicleta.

\subsection{Restrição de Fundição}

A restrição de fundição, implica uma restrição muito grande sobre os problemas, permitindo a existência de furos em apenas um sentido, obrigando que o elemento 


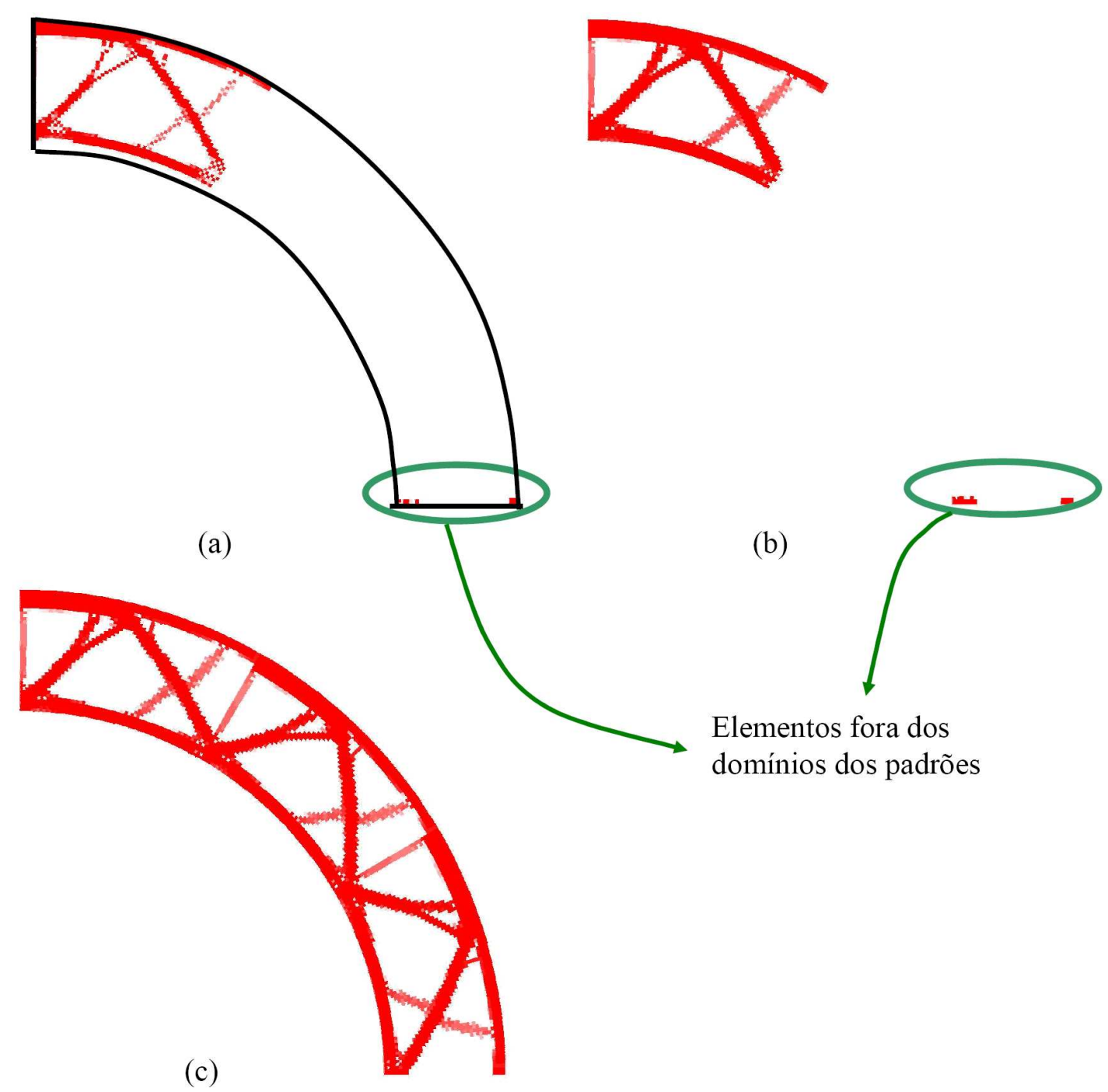

Figura 7.26: (a) variáveis de projeto. (b) projeção do membro mínimo (c) projeção da repetição de padrões

que esteja sobre um outro elemento na direção de referência da fundição, sempre possua a pseudo-densidade igual ou menor a do elemento interno, como podemos ver na figura 7.29, onde uma simples condição de carga gera uma forma sólida.

Porém nos casos onde se gostaria de permitir que a restrição de fundição possua dois moldes, devemos ter duas soluções que sejam executadas simultaneamente por direções opostas e obtenham através de sua interseção a solução para o problema, como podemos ver o exemplo na figura 7.30. Apesar de trabalhar com o dobro de variáveis de projeto do que outros casos, a sua execução se dá de forma igual, já que a resolução do MEF e o cálculo das sensibilidades das pseudo-densidades é sempre feita com a mesma quantidade de variáveis.

Em problemas tridimensionais, podemos perceber o quanto a restrição de fundição pode ser útil. Na figura 7.31, podemos ver uma solução para o problema 


\section{0 elementos}

\section{Volume de $40 \%$}

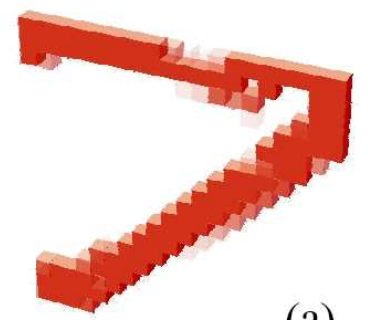

(a)

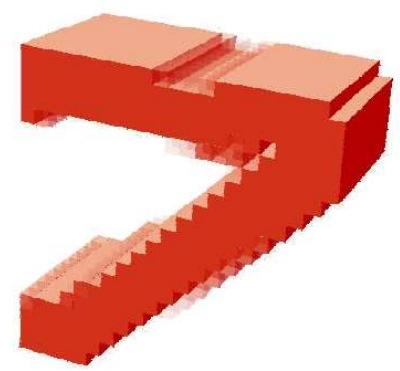

(c)

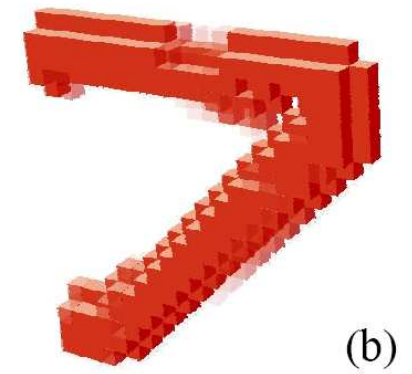

(b)

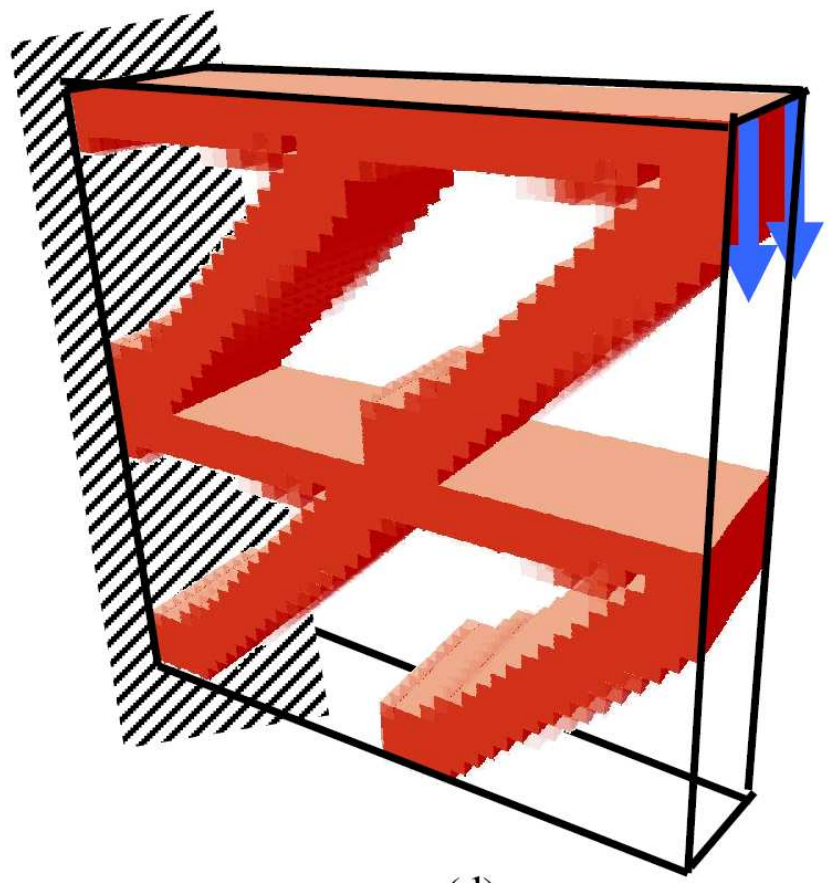

(d)

Figura 7.27: Restrição de extrusão em conjunto com a repetição de padrões. (a) Variáveis de projeto. (b) projeção da restrição de membro mínimo. (c) Projeção da restrição de extrusão. (d) Projeção da restrição de repetição de padrões.

de torção de uma barra engastada, e encontramos um padrão em forma de "X", que não é intuitivo de se imaginar, e que garante a possibilidade de se produzir a peça através do processo de fundição.

Como em outras restrições implementadas, vemos aqui neste caso o aparecimento de uma simetria na peça. A utilização da técnica de projeção para a restrição de fundição acaba por aumentar a estabilidade do método dos gradientes conjugados utilizado para resolver o problema, diminuindo diferenças devidos aos arredondamentos. 


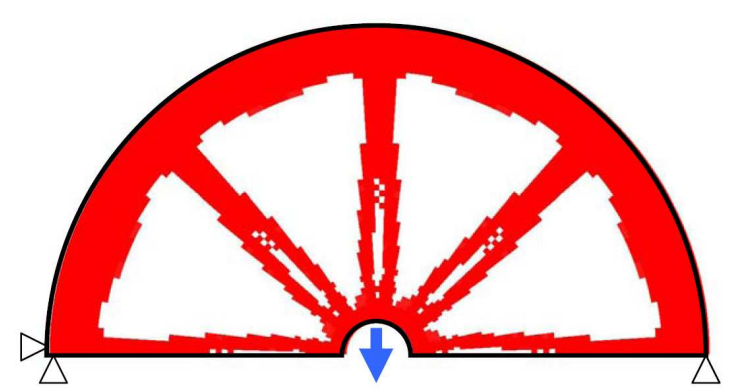

(a)

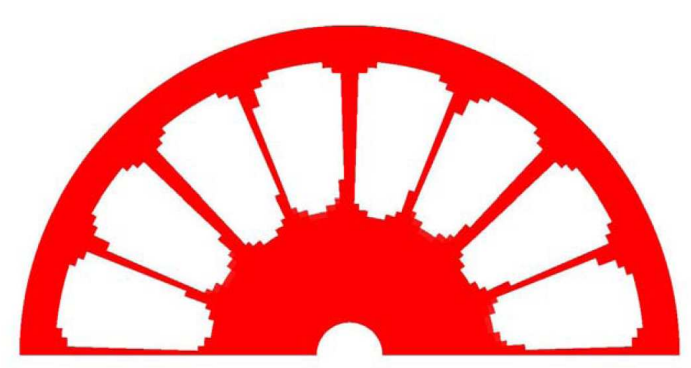

(b)

Figura 7.28: Solução do problema da roda com repetição de padrões com 5 repetições. (a) Com membro mínimo. (b) Com buraco mínimo.

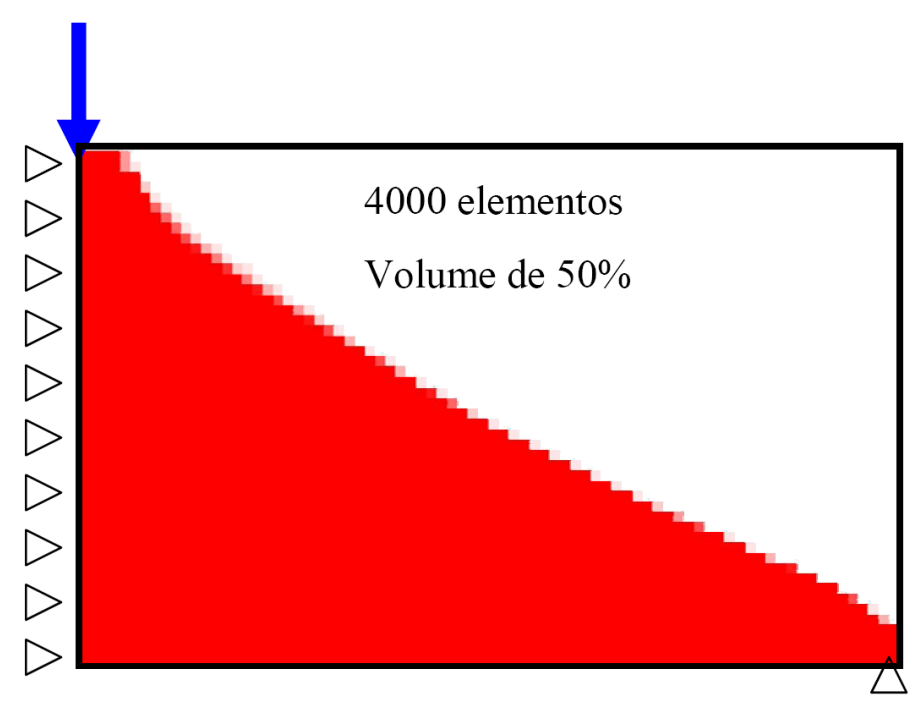

Figura 7.29: Solução para um problema com a restrição de fundição com o molde em apenas uma direção.

\subsection{Restrição de Forjamento}

A restrição de forjamento aplica uma restrição muito severa sobre o problema, de forma que não exista nenhum furo interno na solução. Como podemos ver na figura 7.32 uma solução para um problema de torção, que sem restrições, resulta no resultado da figura 1.2, que com a restrição de extrusão resulta no resultado apresentado na figura 7.13 e com a restrição de fundição resulta no resultado da figura 7.31. Quando resolvida com a restrição de forjamento, nada mais é do que uma barra, com curvas suaves, e espessamentos apenas onde estes são necessários, e que pode ser manufaturado através de forjamento.

Devido ao fato da restrição de forjamento não deixar que apareçam furos na peça em nenhum sentido, ela leva muitas vezes a soluções que podem servir 


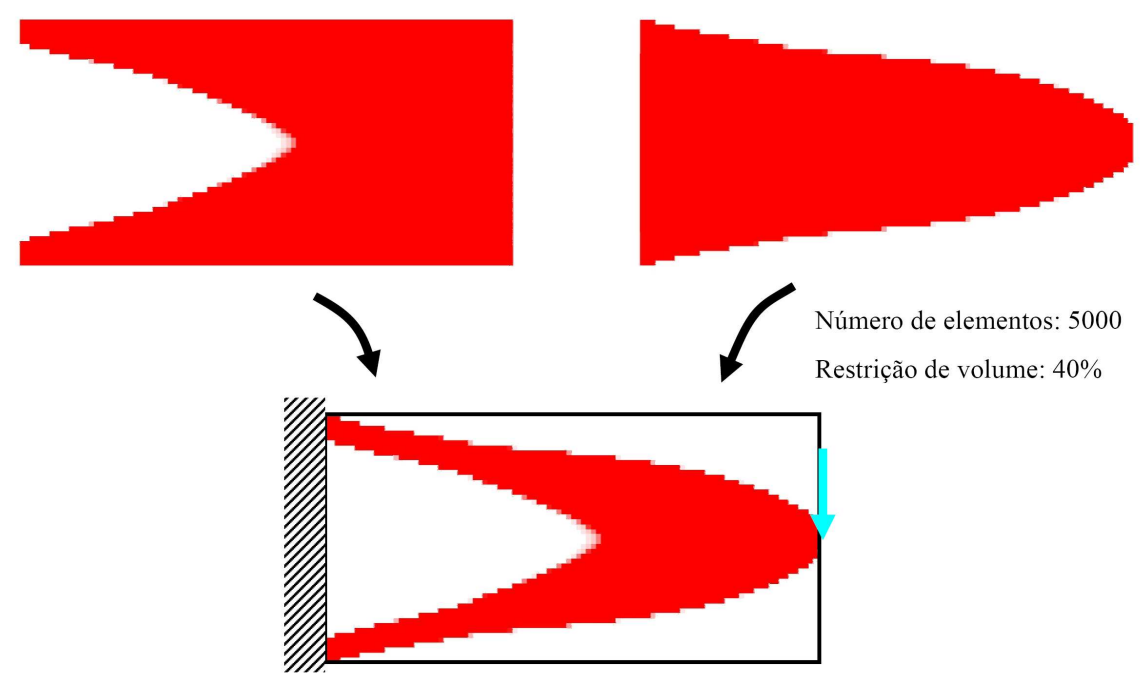

Figura 7.30: Exemplo de fundição feita com dois moldes, sem um plano definido de encontro entre os dois moldes.

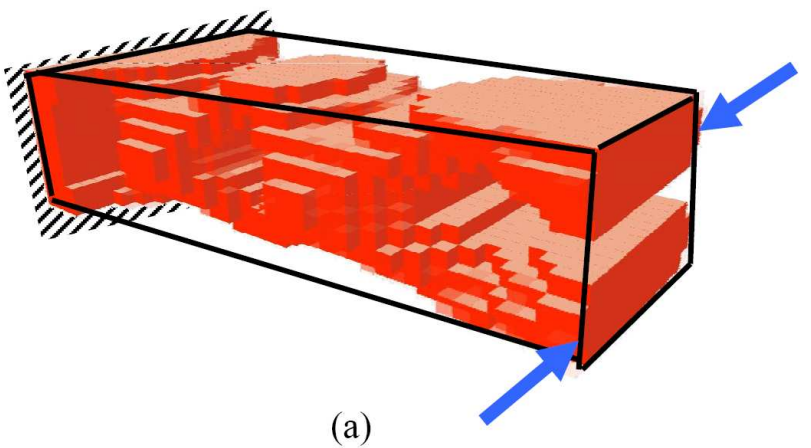

8000 elementos

Volume de $50 \%$

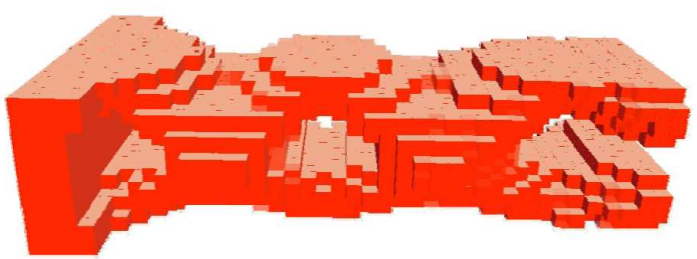

(b)

Figura 7.31: Exemplo da restrição de fundição aplicada a uma peça sob torção. (a) Vista em perspectiva. (b) Vista lateral.

como base para um futuro processo de otimização. Assim como o processo de fabrição de mesmo nome, a restrição de forjamento pode apenas fazer o esboço para depois essa peça ser usinada e trabalhada. Como por exemplo a solução encontrada na figura 7.33, que nada mais é do que uma barra, que tem sua seção reduzida conforme se aproxima da extremidade e da carga.

Esta solução pode por exemplo ser interpretada e otimizada novamente com o auxílio de outras restrições, como a de fundição, de forma a garantir furos em apenas um sentido. 


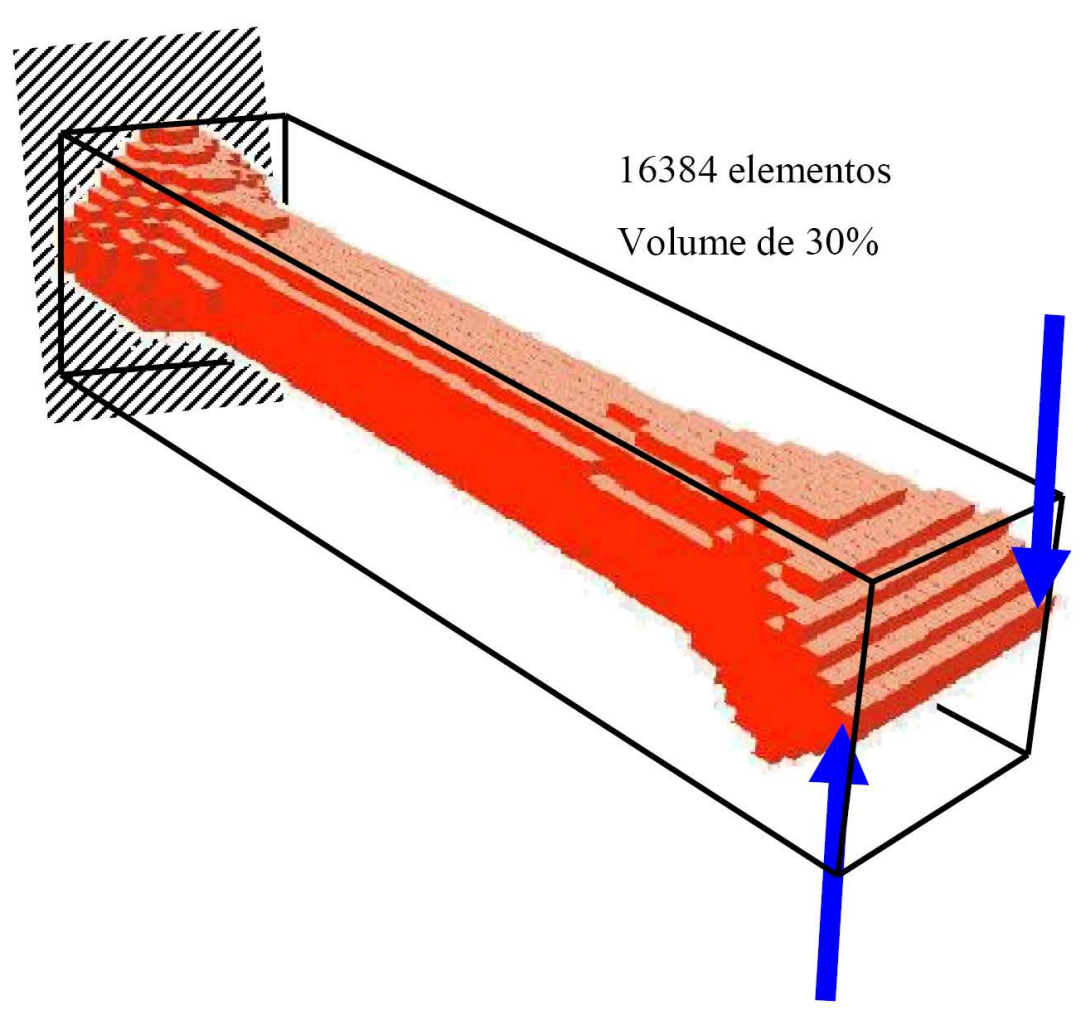

Figura 7.32: Resultado para a restrição de forjamento em um exemplo em três dimensões de uma viga engastada com carga de torção.

\subsection{Restrição de Laminação}

A restrição de laminação nada mais é do que a imposição de três restrições implementadas neste trabalho simultaneamente. A restrição de membro mínimo, a restrição de simetria, de fundição e de extrusão. A restrição de membro mínimo é necessária para garantir uma suavidade nos contornos encontrados na solução, e não para garantir tamanho mínimo de membro propriamente dito, já que a solução encontrará um único membro devido as outras restrições. Quando se considera um problema for bidimensional, a fundição junto com a simetria e membro mínimo resolvem o problema, já que existe apenas uma seção transversal. Em ambos os casos, a restrição de membro mínimo pode ser substituída pela restrição de buraco mínimo, sendo a escolha dependente do usuário e do tipo de problema posto.

Na figura 7.34, temos um problema em duas dimensões, que quando resolvido com uma restrição de $50 \%$ do volume, tem o resultado mostrado na figura 7.34(a). A grande região cinza ocorre devido ao fato da restrição de fundição com um plano central obrigar o algoritmo a espalhar a massa de forma a encontrar uma 


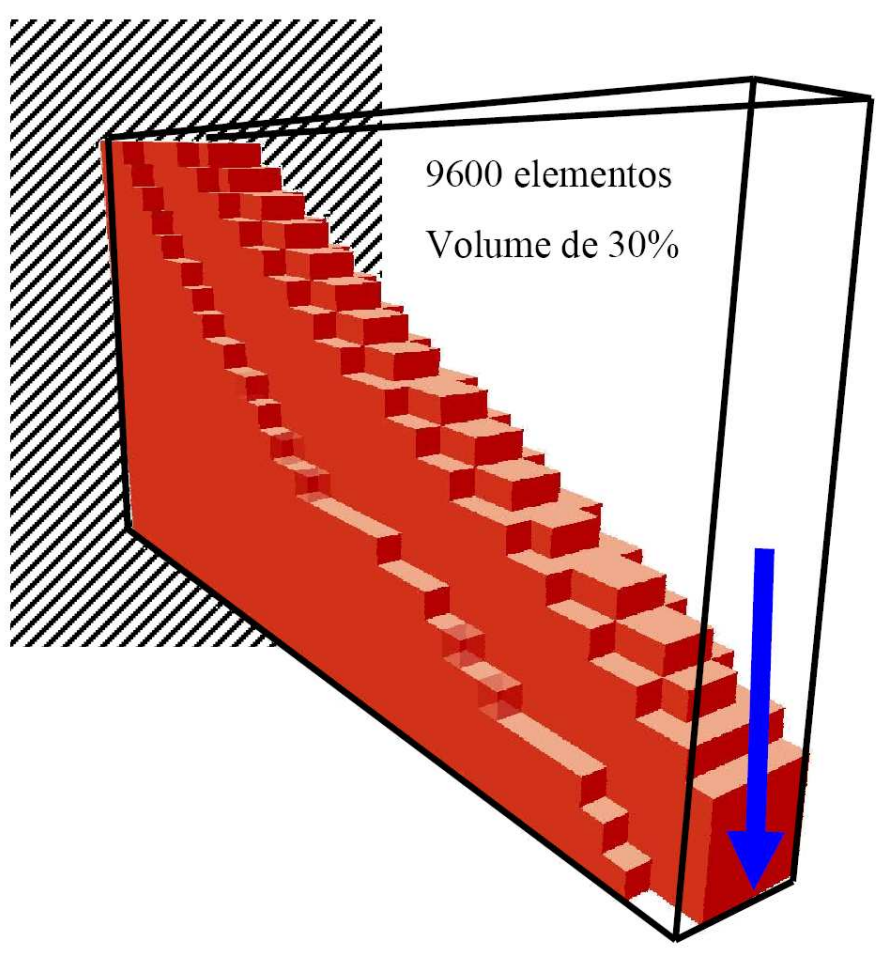

Figura 7.33: Resultado para a restrição de forjamento em um exemplo em três dimensões de uma viga em balanço.

solução para o problema. Com isto os elementos com pseudo-densidades mais baixas são mais relevantes do que membros mais finos em algumas regiões, e por isto, mesmo se aumentando a penalização sobre as pseudo-densidades, o cinza não deixa de aparecer. Para resolver este problema, devemos aumentar o limite de volume, e com isso vamos perceber que a região cinza se tornará preenchida, como podemos ver na figura 7.34-(b) que possui uma restrição de $70 \%$ de volume.

Já quando aumentamos a restrição para 80\% do volume, temos apenas uma leve modificação nos perfis encontrados.

Já em três dimensões, é necessário utilizar a restrição de extrusão também. Com isto temos uma solução como a mostrada na figura 7.35. Assim como no caso em duas dimensões, se o problema não possuir uma restrição de volume alta o suficiente para preencher a solução, haverá regiões cinza. 


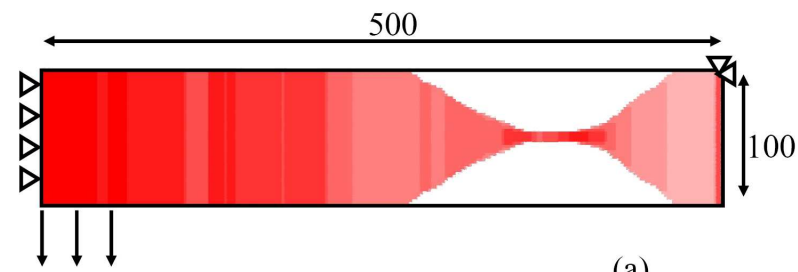

(a)

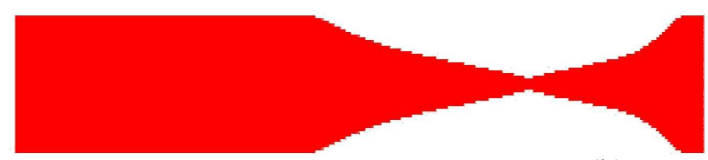

(b)

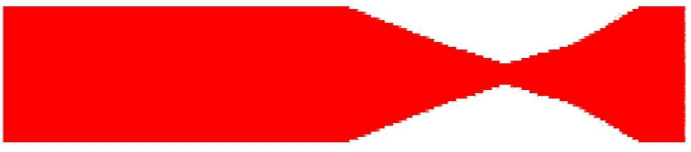

(c)
Restrição de volume $50 \%$

\section{Número de}

elementos: 12500

Restrição de volume $70 \%$

Restrição de volume $80 \%$

Figura 7.34: Muitas restrições forçam o surgimento de áreas cinza quando não existe massa o suficiente para a solução. (a) Restrição de volume a $50 \%$ com região cinza. (b) Restrição de volume a $70 \%$ sem cinza. (c) Restrição de volume a $70 \%$ sem cinza.

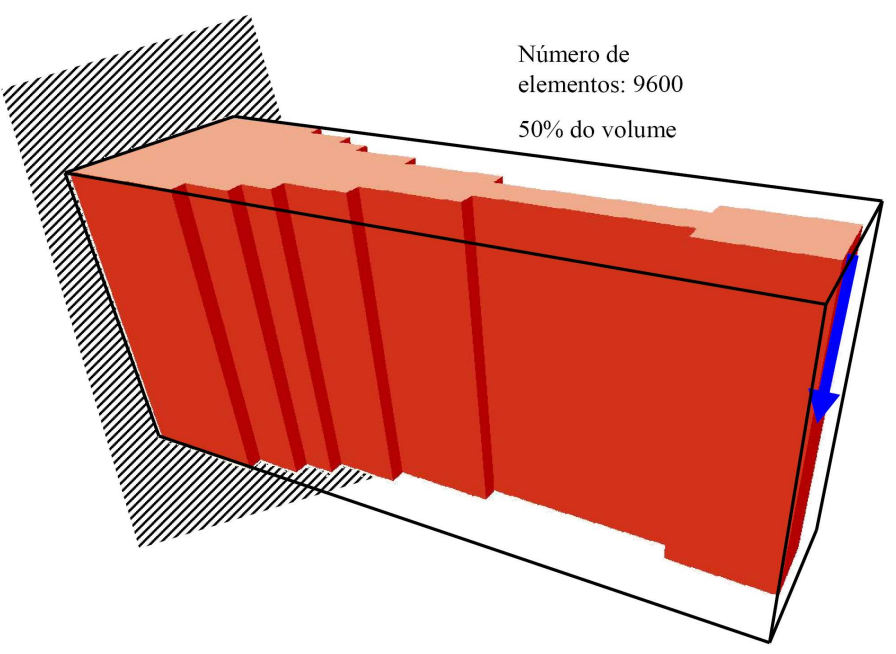

Figura 7.35: Resultado para a restrição de laminação em um exemplo em três dimensões. 


\section{Conclusões e Sugestões para Desenvolvimentos Futuros}

Os diversos resultados encontrados neste trabalho mostram a grande abrangência e importância das restrições de manufatura para a OT. O controle da geometria das soluções encontradas demonstram aplicações que vão desde a maior utilização da técnica de OT na indústria metal-mecânica até a uma abordagem estética.

A capacidade de obtenção de soluções sem furos internos ou com furos em apenas uma direção, como os obtidos pelas restrições de forjamento e fundição, demonstram que mesmo restrições complexas podem ser aplicadas de uma forma simples ao problema de otimização, com a utilização da abordagem aqui proposta.

Ao tratar o problema de otimização com a mudança de domínio, podemos trabalhar com mais variáveis que o problema original de forma simples, sendo necessário apenas resolver um problema simples de OT para os diversos conjuntos de variáveis. Assim, esse problema é resolvido de forma mais simples e genérica que a resolução de um problema com restrições extras.

Portanto podemos concluir que a técnica de projeção se mostrou muito satisfatória para ser utilizada na restrição de soluções para problemas de OT. Os resultados encontrados mostram o quão poderosa pode ser a técnica de projeção quando utilizada com mapeamentos e uma função projeção adequada.

Acreditamos que as restrições de manufatura iniciam um novo ramo do MOT que poderá mudar a forma como este método é visto dentro das empresas, trazendo-o para mais próximo do dia à dia dos projetistas mecânicos.

Problemas como excesso de área cinza, foram encontrados nas restrições de manufatura, pois estas acabam restringindo demais as possibilidades de solução do problema, levando a soluções com estas áreas de cinza. Isto pode ser modificado adequando-se o mapeamento para problemas específicos, aumentando a restrição de massa ou aumentando a resolução da malha de elementos finitos, permitindo assim maiores possibilidades para a alocação da massa. 
A implementação de um método de resolução para o MEF mais eficiente poderia em muito auxiliar no refinamento das soluções, através de modelos mais refinados ficaria mais fácil de se encontrar novos mapeamentos, que sejam mais adequados.

Existem diversas outras restrições que podem ser implementadas de forma quase direta, entre elas podemos citar: repetição de padrões simétricos, ou até mesmo repetição de padrões em um mesmo domínio em domínios desconexos. Assim como técnicas mais complexas, como por exemplo a utilização de um membro mínimo com o raio variável ao longo do domínio, ou ao longo das iterações, de forma a encaminhar a solução para uma solução mais próxima do esperado.

Grandes desafios que ficam em aberto são: a utilização das restrições de membro mínimo e buraco mínimo em conjunto, de forma eficiente, o que até o momento não foi realizado na literatura, e a utilização de restrições de manufatura para elementos de casca e placa, que abrangem processos de fabricação não incluídos no escopo deste trabalho, como a estampagem, e até mesmo a soldagem de placas planas, para a formação de conjuntos.

Enfim, este trabalho visa contribuir para o desbravamento das restrições de manufatura, um tema ainda muito pouco explorado na OT 


\section{Referências}

ALLAIRE, G. Shape optimization by the homogenization method. New York: Springer-Verlag, 2002. 456 p. (Applied Mathematical Sciences 146).

ALLAIRE, G.; BONNERTIER, E.; FRANCFORT, G.; JOUVE, F. Shape optimization by the homogenization method. Numerische Mathematik, v. 28, n. 2-3, p. 87-98, 2004.

ALLAIRE, G.; JOUVE, F.; TOADER, A. Structural optimization using sensivity analysis and a level -set method. Journal of Computational Physics, v. 194, p. 363-393, 2004.

AMBROSIO, L.; BUTTAZZO, G. An optimal-design problem with perimeter penalization. Calculus of Variations and Partial Differentiation Equations, v. 1, n. 1, p. 55-69, 1993.

BATHE, K.-J. Finite Elements Procedures. New York, USA: Prentice Hall, 1995.

BENDSØE, M. P. Optimal shape design as a material distribution problem. Structural Optimization, v. 1, p. 192-202, 1989.

BENDSØE, M. P. Optimization of Structural Topology, Shape, and Material. Berlin, Germany: Springer-Verlag, 1995.

BENDSØE, M. P.; KIKUCHI, N. Generating optimal topologies in structural design using a homogenization method. Computer Methods in Applied Mechanics and Engineering, Elsevier, v. 71, n. 2, p. 197-224, November 1988.

BENDSØE, M. P.; SIGMUND, O. Material interpolation schemes in topology optimization. Archive of Applied Mechanics, v. 69, n. 9-10, p. 635-654, 1999.

BENDSØE, M. P.; SIGMUND, O. Topology optimization: theory, methods and applications. In: . Berlin, Germany: Springer, 2002. p. 71-152.

BENSOUSSAN, A.; LIONS, J.; PAPANICOLAOU, G. Assymptotic analysis for periodic structures. North-Holland, 1978.

BOURDIN, B. Filters in topology optimization. International Journal for Numerical Methods in Engineering, v. 50, n. 9, p. 2143-2158, 2001.

BURGER, M.; HACKL, B.; RING, W. Incorporating topological derivatives into level set methods. Journal of Computational Physics, v. 194, n. 1, p. 344-362, 2004 .

BURGER, M.; OSHER, S. J. A survey on level set methods for inverse problems and optimal design. European Journal of Applied Mathematics, v. 16, p. 263-301, abr. 2005. 
CARDOSO, E. L. Controle de Complexidade na Otimização Topológica de Estruturas Contínuas. Dissertação (Mestrado) - Escola de Engenharia Universidade Federal do Rio Grande do Sul, Fevereiro 2000.

CARDOSO, E. L.; FONSECA, J. S. O. Spatial gradient control in the structural topology optimization. In: First ASMO UK/ISSMO Conference on Engineering Design Optimization. Ilkley,West Yorkshire, UK: [s.n.], 1999. p. 97-102.

CHENG, K. T.; OLHOFF, N. An investigation concerning optimal-design of solid elastic plates. International Journal of Solids And Structures, v. 17, n. 3, p. 305-323, 1981.

CHENG, K. T.; OLHOFF, N. Regularized formulation for optimal-design of axisymmetric plates. International Journal of Solids and Structures, v. 18, n. 2, p. 153-169, 1982.

CHERKAEV, A. Variational Methods for Structural Optimization. New York: Springer-Verlag, 2000. (Applied Mathematical Sciences 140).

CHU, D. N.; XIE, Y. M.; HIRA, A.; STEVEN, G. P. Evolutionary structural optimization for problems with stiffness constraints. Finite Elements in Analysis and Design, v. 21, n. 4, p. 239-251, 1996.

CHU, D. N.; XIE, Y. M.; HIRA, A.; STEVEN, G. P. On various aspects of evolutionary structural optimization for problems with stiffness constraints. Finite Elements in Analysis and Design, v. 24, n. 4, p. 197-212, 1997.

COOK, R. D.; MALKUS, D. S.; PLESHA, M. E.; WITT, R. J. Concepts and Applications of Finite Element Method. [S.1.]: John Wiley \& Sons Inc., 1995.

DUBBEL, H. Manual da Construção de Máquinas. primeira edição. São Paulo: Hemus, 1979.

ESCHENAUER, H. A.; OLHOF, N. Topology optimization of continuum structures. Applied Mechanic Review, v. 54, n. 4, p. 331-390, 2001.

FONSECA, J. S. .; KIKUCHI, N. Digital imaging filtering in topology optimization. In: Computational Mechanics New Trends and Applications. CIMNE, Spain: [s.n.], 1998.

GUEST, J. K.; PREVOST, J. H.; BELYTSCHKO, T. Achieving minimum length scale in topology optimization using nodal design variables and projection functions. Int. j. numer. methods eng., v. 61, n. 2, p. 238-254, 2004.

HABER, R. B.; BENDSØE, M. P.; JOG, C. S. A new approach to variable-topology shape design using a constraint on the perimeter. Structural Optimization, v. 11, p. 1-12, 1996.

HARZHEIM, L.; GRAF, G. A review of optimization of cast parts using topology optimization. i - topology optimization without manufacturing constraints. Structural and Multidisciplinary Optimization, v. 30, n. 6, p. 491-497, December 2005.

HARZHEIM, L.; GRAF, G. A review of optimization of cast parts using topology optimization. ii-topology optimization with manufacturing constraints. Structural and Multidisciplinary Optimization, v. 31, n. 5, p. 388-399, May 2006. 
ISHII, K.; AOMRA, S. Topology optimization for the extruded three dimensional structure with constant cross section. JSME International Journal Series A, v. 47, n. 2, p. 198-206, 2004.

JOG, C. S.; HABER, R. B. Stability of finite element models for distributedparameter optimization and topology design. Computer Methods in Applied, v. 130, n. 3-4, p. 203-226, 1996.

KOHN, R. V.; STRANG, G. Optimal-design and relaxation of variational problems .1. Communications on Pure and Applied Mathematics, v. 39, n. 1, p. 113-137, 1986.

KOHN, R. V.; STRANG, G. Optimal-design and relaxation of variational problems .2. Communications on Pure and Applied Mathematics, v. 39, n. 2, p. 139-182, 1986.

KOHN, R. V.; STRANG, G. Optimal-design and relaxation of variational problems .3. Communications on Pure and Applied Mathematics, v. 39, n. 3, p. 353-377, 1986.

LE, C. H. Achieving Minimun Scale and Design Constraints in Topology Optimization: a New Approach. Dissertação (Mestrado) - University of Illinois as Urbana-Champaign, 2006.

LIU, J.-S.; PARKS, G.; CLARKSON, P. Topology/shape optimisation of axisymmetric continuum structures - a metamorphic development approach. Structural and Multidisciplinary Optimization, v. 29, p. 73-83, 2005.

LIU, Z.; KORVINK, J.; HUANG, R. Structure topology optimization: fully coupled level set method via femlab. Structural and Multidisciplinary Optimization, v. 29, p. 407-417, 2005.

MATSUI, K.; TERADA, K. Continuous approximation of material distribution for topology optimization. International Journal for Numerical Methods In Engineering, v. 59, n. 14, p. 1925-1944, 2004.

MICHELL, A. The limits of economy of material in frame-structures. Phil. Mag., v. 8, n. 47, p. 589-597, November 1904.

NIORDSON, F. I. Optimal design of plates with a constraint on the slope of the thickness function. International Journal of Solids Structures, v. 19, p. 141-151, 1983.

OLHOFF, N.; BENDSØE, M. P.; RASMUSSEN, J. On cad-integrated structural topology and design optimization. Computer Methods in Applied Mechanics and Engineering, v. 89, n. 1-3, p. 259-279, 1991.

PETERSSON, J.; SIGMUND, O. Slope constrained topology optimization. International Journal for Numerical Methods in Engineering, v. 41, n. 8, p. 1417-1434, 1998.

POULSEN, T. A. A simple scheme to prevent checkerboard patterns and one node connected hinges in topology optimization. Structural and Multidisciplinary Optimization, v. 24, n. 5, p. 296-399, 2002. 
POULSEN, T. A. A new scheme for imposing a minimum length scale in topology optimization. International Journal for Numerical Methods in Engineering, v. 57, p. 741-760, 2003.

PRAGER, W. A note on discretized michell structures. Computer Methods in Applied Mechanics and Engineering, Elsevier, v. 3, n. 3, p. 349-355, May 1974.

RAHMATALLA, S.; SWAN, C. C. Form finding of sparse structures with continuum topology optimization. Journal of Structural Engineering-ASCE, v. 129, n. 12, p. 1707-1716, 2003.

RAHMATALLA, S. F.; SWAN, C. C. A q4/q4 continuum structural topology optimization implementation. Structural and Multidisciplinary Optimization, v. 27, n. 1-2, p. 130-135, 2004.

ROZVANY, G. I. N.; BENDSOE, M. P.; KIRSCH, U. Layout optimization of structures. Applied Mechanics Reviews, v. 48, p. 41-119, 1995.

ROZVANY, G. I. N.; ZHOU, M.; BIRKER, T. Generalized shape optimization without homogenization. Structural Optimization, v. 4, n. 3-4, p. 250-252, 1992.

SANCHES-PALENCIA, E. Non-homogeneous media and vibration theory. Lecture Notes in Physics, 127, v. 127, 1980.

SANCHEZ-PALENCIA, E.; ZAOUI, A. Homogenization techniques for composite media. In: Lecture Notes in Physics. [S.l.]: Springer-Verlag, 1985.

SIGMUND, O. On the design of compliant mechanisms using topology optimization. Mechanics of Structures and Machines, v. 25, p. 495-526, 1997.

SIGMUND, O. Morphology-based black and white filters for topology optimization. Struct Multidisc Optim, v. 33, p. 401-424, 2007.

SIGMUND, O.; PETERSSON, J. Numerical instabilities in topology optimization: A survey on procedures dealing with checkerboards, meshdependencies and local minima. Structural and Multidisciplinary Optimization, v. 16, n. 1, p. 68-75, July 1998.

SILVA, E. C. N. Topology optimization applied to the design of linear piezoelectric motors. Journal of Intelligent Material Systems and Structures, v. 14, n. 4-5, p. 309-322, 2003.

SILVA, E. C. N.; NISHIWAKI, S.; KIKUCHI, N. Topology optimization design of flextensional actuators. IEEE Transactions on Ultrasonics, Ferroelectrics, and Frequency Control, v. 47, n. 3, p. 657-671, 2000.

STOLPE, M.; SVANBERG, K. On the trajectories of penalization methods for topology optimization. Structural and Multidisciplinary Optimization, v. 21, n. 2, p. 128-139, 2001.

STUMP, F. V. Otimização Topológica Aplicada ao Projeto de Estruturas Tradicionais e Estruturas com Gradação Funcional sujeitas a Restrição de Tensão. Dissertação (Mestrado) — Escola Politécnica da Universidade de São Paulo, 2006. 
SUZUKI, K.; KIKUCHI, N. A homogenization method for shape and topology optimization. Computer Methods in Applied Mechanics and Engineering, v. 93, n. 3, p. 291-318, 1991.

SVANBERG, K. The method of moving asymptotes - a new method for structural optimization. International Journal of Numerical Methods in Engineering, v. 24, p. 359-373, 1987.

SWAN C., C.; KOSAKA, I. Homogenization-based analysis and design of composites. Computers and Strucutres, v. 64, n. 1-4, p. 603-621, 1997.

SWAN, C. C.; KOSAKA, I. Voigt-reuss topology optimization for structures with linear elastic material behaviours. International Journal for Numerical Methods in Engineering, v. 40, n. 16, p. 3033-3057, 1997.

TAYLOR, J. E.; BENDSØE, M. P. An interpretation for min-max structural design-problems including a method for relaxing constraints. International Journal of Solids and Structures, v. 20, n. 4, p. 301-314, 1984.

ZHANG, W. H.; DUYSINX, P. Dual approach using a variant perimeter constraint and efficient sub-iteration scheme for topology optimization. Computers \& Structures, v. 81, n. 22-23, p. 2173-2181, 2003.

ZHOU, M.; SHYY, Y.; THOMAS, H. Checkerboard and minimum member size control in topology optimization. Structural and Multidisciplinary Optimization, v. 21, n. 2, p. 152-158, April 2001.

ZUO, K.-T.; CHEN, L.-P.; ZHANG, Y.-Q.; YANG, J. Manufacturing- and machining-based topology optimization. Int J Adv Manuf Technol, v. 27, n. 5-6, p. 531-536, January 2006. 